\title{
Systematische Einleitung
}

in die

allgemeine Entwickelungsgeschichte.

Genealogische Uebersicht

des natürlichen Systems der Organismen.
„Alle Gestalten sind ähnlich und keine gleichet der andern;
Und so deutet der Chor auf ein geheimes Gesetz,
Auf ein heiliges Räthsel !‘
Goethe.

\section{Die Entwickelungsgeschichte und die Systematik.}

Das natürliche System der Organismen ist ihr Stammbaum oder Genealogema. Mit diesen wenigen Worten haben wir in unserer Einleitung in die generelle Morphologie der Organismen (Bd. I, S. 37, 196) das äusserst wichtige Verhältniss bezeichnet, welches die sogenannte „organische Systematik“ zur Entwickelungsgeschichte, und überhaupt zur gesammten Morphologie der Organismen einnimmt. Wir haben daselbst zu zeigen gesucht, dass die Systematik keineswegs, wie gewöhnlich angenommen wird, eine besondere Wissenschaft ist, sondern vielmehr nur eine besondere Darstellungsform der organischen Morphologie, ein concentrirter übersichtlicher Extract ihres wichtigsten Inhalts, ein übersichtlich nach der Blutsverwandtschaft geordnetes, durch compacte morphologische Charakteristi- . ken motivirtes Sach - und Namen-Register der Organismen (vergl. das dritte Capitel des ersten Bandes S. $31-42$ ).

Diese Erkenntniss der genealogischen Bedeutung des natürlichen Systems, welche durch die von Charles Darwin reformirte Descendenz-Theorie zu einer unerschütterlich festen Induction 
XVIII Systematische Finleitung in die Fntwickelungsgeschichte.

geworden ist, halten wir für die erste und unerlässlichste Bedingung eines klaren und naturgemässen Verständnisses der organischen Formen, welche uns in ihrer unendlichen Mannichfaltigkeit und dennoch ïberall sich verrathenden Aehnlichkeit ohne jene Frkenntniss als eben so viele unlösbare Räthsel gegenüber stehen. "St a mmverwandtschaft"! ist das "glücklich lösende Wort des heiligen Räthsels, des geheimen Gesetzes", welches Goethe in dem allgemeinen Widerstreit zwischen der unendlichen Verschiedenheit und der unleugbaren Aehnlichkeit der organischen Formen entdeckte.

Die fundamentale Bedeutung, welche die Entwickelungsgeschichte für die Systematik hat, ist im Laufe unseres Jahrhunderts, und namentlich der letzten drei Decennien desselben, unter den organischen Morphologen zu immer allgemeinerer und maassgebender Anerkennung gelangt. Mehr und mehr hat sich die Ueberzeugung Bahn gebrochen, dass nur dasjenige zoologische und botanische System ein wirklich ,natürliches" ist, welches der comparativen individuellen Entwickelungsgeschichte genügend Rechnung trägt. Dennoch war diese Ueberzeugung nur der erste Schritt zu dem vollen und klaren Verständniss des natürlichen Systems. Der zweite und bedeutendste Schritt, welcher dieses Verständniss erst vollendet, ist die Erkenntniss, dass das natürliche System der Stammbaum der ()rganismen ist; die hohe Bedeutung der individuellen Entwickelungsgeschichte für die Systematik erklärt sich dann einfach aus dem Umstande, dass die individuelle Entwickelungsgeschichte oder die Ontogenie nur eine kurze und gedrungene Wiederholung, gleichsam eine Recapitulation der paläontologischen Entwickelungsgeschichte oder der Phylogenie ist.

Die äusserst innigen und wichtigen Wechselbezichungen, welche zwischen diesen beiden Zweigen der Morphogenic oder der organischen Fntwickelungsgeschichte, zwischen der Ontogenie und der Phylogenie bestehen, haben wir bereits im dritten Capitel des ersten Buches hervorgehoben, als wir den beiden Hauptästen der organischen Morphologie, der Anatomie und der Entwickelungsgeschichte, ihre Aufgabe bestimmten und sie in untergeordnete Wissenschaften eintheilten (Bd. I, S. $24,50-60)$. Wir haben daselbst auch bereits mehrfach auf eine der wichtigsten allgemeinen organischen Erscheinungsreihen hingewiesen, auf die dreifache genealogische Parallele nämlich, welche zwischen den drei aufsteigenden Stufenleitern dér paläontologischen (phyletischen), der individuellen (biontischen) und der systematischen (specifischen) Entwickelung besteht. Da wir diesen Gegenstand, der bisher eben so allgemein vernachlässigt, als von der allergrössten monistischen Bedeutung für die gesammte Morphologie der Organismen ist, im dreiundzwanzigsten Capitel noch besonders erörtern werden, so beschränken wir uns hier auf die Bemerkung, dass ohne die richtige Werth- 
schätzung jenes dreifachen genealogischen Parallelismus sowohl das volle Verständniss der Entwickelungsgeschichte selbst, als auch der Systematik nothwendig verschlossen bleibt. Dieses gewinnen wir erst durch die Erkenntniss, dass die Stufenleiter des natürlichen Systems mit den parallelen Stufenleitern der individuellen und der paläontologischen Entwickelung in dem engsten mechanischen Causalnexus steht.

Da die genealogische Darstellung und Motivirung des natürlichen Systems Gegenstand der speciellen Morphologie und insbesondere der speciellen Entwickelungsgeschichte der Organismen ist, so können wir in diesem Werke, welches nur die Grundzüge der generellen Morphologie sich zur Aufgabe gestellt hat, nicht näher auf die Systematik eingehen. Da jedoch die genealogische Begründung des natürlichen Systems ihrerseits wiederum den grössten Werth für das Verständniss der allgemeinen Entwickelungsgeschichte besitzt, da ferner auf diesem höchst interessanten, bisher aber fast ganz uncultivirten Gebiete noch Alles $\mathrm{zu}$ thun übrig ist, so haben wir es nicht für überflüssig erachtet, hier als Einleitung zu unserer allgemeinen Entwickelungsgeschichte eine kurze Uebersicht des natürlichen Systems der Organismen zu geben, wie dasselbe nach unserer Ansicht ungefähr genealogisch zu begründen sein würde.

Unsere Eintheilung der gesammten Organismenwelt in drei oberste Hauptgruppen oder Reiche: Thierreich, Protistenreich und Pflanzenreich, haben wir bereits im siebenten Capitel des ersten Bandes ausführlich gerechtfertigt (S. 203 fi.). Ebendaselbst haben wir auch vorläufig die Bedeutung der Systemgruppen als subordinirter genealogischer Kategorieen des Stammbaums erörtert ( $S .115$ ff.), welche im vierundzwanzigsten Capitel ausführlicher motivirt werden wird. Auch haben wir dort bereits die verschiedenen Stämme oder Phylen in den drei organischen Reichen namhaft gemacht, welche mit einiger Wahrscheinlichkeit bei dem gegenwärtigen unvollkommenen Zustande unserer biologischen Kenntnisse unterschieden werden können (S. 203-206). Unter Stamm oder Phylum verstehen wir, wie dort festgestellt wurde, ein für allemal „die Gesammtheit aller jetzt noch existirenden oder bereits ausgestorbenen Organismen, welche von einer und derselben gemeinsamen Stammform ihre Herkunft ableiten". Diese Stammform selbst mussten wir uns stets als ein autogones Moner denken.

Es kann sich hier für uns natürlich nur um eine ganz allgemeine und skizzenhafte Feststellung der ersten Grundlinien für die Stammbäume oder Genealogeme handeln, in welchen die Morphologie der Zukunft allen natürlichen Gruppen der Organismen ihren Platz anzuweisen haben wird. Wir geben diese Skizze zugleich als Frläuterung zu dem ersten Versuche genealogisch-systematischer Tafeln, welche wir 
XX Systematische Einleitung in die Entwickelungsgeschichte.

diesem Bande angehängt haben. Wir heben ausdrücklich hervor, dass wir in diesen genealogischen Tafeln, wie in der nachfolgenden genealogischen Uebersicht des natürlichen Systems der Organismen nur den ersten provisorischen Versuch zur Begründung der organischen Genealogeme geben wollen! Die ungeheure Schwierigkeit, welche diesen ersten derartigen Versuchen entgegensteht, und der wirkliche, obwohl nur annähernde, Werth, welchen dieselben besitzen, wird nur denjenigen, von der Descendenz-Theorie vollständig überzeugten, denkenden Morphologen klar sein, welche vielleicht selbst einmal im Entwurfe solcher Stammbäume sich versucht haben. Von den zahlreichen Gegnern derselben aber verlangen wir, dass sie dieselben nicht bloss tadeln, sondern etwas Besseres an ihre Stelle setzen!

Wir beginnen mit einer kurzen genealogischen Uebersicht über die problematischen Stämme des Protistenreichs, lassen auf diese die Phylen des Pflanzenreichs, und zuletzt diejenigen des Thierreichs folgen. Die letzteren liefern uns bei weitem die reichste und sicherste Ausbeute, wogegen wir von den ersteren bei dem gegenwärtigen, höchst unvollkommenen Zustande unserer Kenntnisse nur sehr wenig Befriedigendes zu gebeu vermögen. Wegen der näheren Begründung der nachfolgenden genealogischen Skizze verweisen wir auf das fünfte und sechste Buch, und ganz besonders auf das XXIV. und XXV. Capitel. Die neuen Namen, welche wir zur Bezeichnung der neu von uns aufgestellten natürlichen Gruppen einzuführen gezwungen worden sind, haben wir durch ein angehängtes $\mathrm{H}$. bezeichnet.

\section{Das natürliche System des Protistenreichs.}

Das Reich der Protisten oder Urwesen betrachten wir, wie bereits im sechsten Capitel des zweiten Buches ausgeführt wurde, als eine Collectivgruppe von mehreren selbstständigen organischen Stämmen oder Phylen, welche sich ohne Zwang weder dem Thierreiche noch dem Pflanzenreiche einordnen lassen. Es zeigt sich diese zweifelhafte Zwitterstellung am deutlichsten darin, dass alle diejenigen Organismen, welche wir als Protisten zusammenfassen, von den verschiedenen Naturforschern bald als Pflanzen, bald als Thiere ausgegeben worden sind, und dass der Streit über ihre zweifelhafte Stellung auch heutzutage noch keineswegs entschieden ist. Manche Protisten sind sowohl von den Botanikern als von den Zoologen verschmäht, andere wiederum sowohl von diesen als von jenen für sich in Anspruch genommen worden. Viele Protisten verhalten sich in ihrer ganzen Anatomie, Morphogenie und Physiologie so indifferent, dass sie in der That weder für Thiere, noch für Pflanzen gelten können; andere zeigen eine so. eigenthümliche Mischung von beiderlei Charakteren, dass man sie jedem 
der beiden Reiche mit gleichem Rechte zustellen könnte. Aus diesen und anderen bereits oben erörterten Gründen haben wir uns für berechtigt gehalten, neben dem Pflanzenreiche und dem Thierreiche noch das Protistenreich als eine selbstständige Hauptabtheilung der Organismenwelt aufzustellen, und haben diese Neuerung bereits oben gerechtfertigt (Bd. I, S. 203, 215; vergl. auch die übrigen Abschnitte des sechsten Capitels).

Da die allermeisten Organismen des Protistenreiches wegen ihrer sehr geringen Grösse dem unbewaffneten Auge verborgen bleiben und aus diesen und vielen anderen Gründen erst in den letzten Decennien genauer untersucht worden sind, da aber auch jetzt immer nur sehr wenige Naturforscher sich mit diesen höchst interessanten und wichtigen Organismen abgegeben haben, so ist unsere Kenntniss derselben leider noch höchst unvollständig, und gar nicht mit derjenigen der 'Thiere und Pflanzen zu vergleichen. Es ist aus diesem Grunde eigentlich auch gar nicht möglich, jetzt schon ein natürliches System des Protistenreiches aufzustellen. Wem wir dennoch hier den provisorischen Versuch dazu unternehmen, so geschieht es bloss, weil doch einmal damit ein Anfang gemacht werden muss, weil wir hoffen, dadurch Anregung zu baldiger Verbesserung dieses höchst unvollkommenen Wagnisses zu geben, und weil wir mit Goethe der Ansicht sind, dass „eine schlechte Hypothese besser ist, als gar keine".

Wir haben im siebenten Capitel acht verschiedene selbstständige Stämme von Protisten unterschieden, nämlich: 1. Spongince, 2. Nortilucae, 3. Rllizopoda, 4. Protoplasla, 5. Moneres, 6. Flagellata, 7. Diatomene, 8. Myrumyrefes. Von diesen werden die letzten zwei oder drei Gruppen gegenwärtig meistens für Pflanzen, die ersten drei oder vier meistens für Thiere gehalten, während die Moneren durchaus zweifelhafter Natur sind. Wahrscheinlich ist jedoch die Zahl der selbstständigen Stämme des Protistenreichs sehr viel grösser, und vielleicht entstehen noch gegenwärtig durch Archigonie stets neue Protisten, während dies von Thieren und Pflanzen nicht wahrscheinlich ist. Sowohl die Bestimmung der Anzahl als des Lmfangs der angeführten ProtistenStämme betrachten wir natürlich nur als eine ganz provisorische, und geben sie nur, um überhaupt etwas Positives und eine erste Grundlage für die Genealogie des Protistenreiches, einen festen Boden zur Discussion und zur Verständigung über diese äusserst wichtige und interessante Frage zu liefern.

Eine gemeinsame Abstammung, ein genealogischer Zusammenhang der verschiedenen Phylen, wie er für die thierischen und pflanzlichen Stämme (und namentlich für die letzteren) sehr wahrscheinlich ist, erscheint dagegen für die Protisten-Phylen durchaus unwahrscheinlich. Vielmehr spricht Alles dafür, dass nicht nur die angeführten acht, son- 
XXII Systematische Einleitung in die Entwickelungsgeschichte.

dern auch noch sehr zahlreiche andere Protisten-Stämme sich vollkommen unabhängig von einander aus selbstständigen autogonen Stammformen entwickelt haben, und vielleicht noch heutzutage durch Archigonie entstehen. Andererseits ist es sehr wohl möglich, dass einige der hier zu den Protisten gerechneten Formen niedere Fntwickelungsstufen theils von Thieren, theils von Pflanzen sind. Da wir diese Frage noch im fünfundzwanzigsten Capitel näher zu erörtern haben, so wollen wir hier nicht weiter darauf eingehen. Wenn man unser Protistenreich verwirft und bloss die beiden Reiche der 'Thiere und Pflanzen anerkennen will, so würde man die Diatomeen und Myxomyceten wohl am passendsten dem Pflanzenreiche, die Rhizopoden, Noctiluken und Spongien dem Thierreiche anschliessen müssen, wogegen die systematische Stellung der Flagellaten, Protoplasten und Moneren unter allen Umständen höchst zweifelhaft bleiben muss. .

\section{Erster Stamm des Protisten-Reiches: \\ Moneres, H. Moneren.}

Moneren ${ }^{1}$ ) nennen wir alle vollkommen structurlosen und homogenen Organismen, welche lediglich aus einem Stückchen Plasma (einer schleimartigen Eiweiss-Verbindung) bestehen, das sich einfach durch Endosmose ernährt, und durch Schizogonie oder Sporogonie fortpflanzt. Die meisten Moneren führen trotz alles Mangels differenzirter BewegungsOrgane ausgezeichnete Bewegungen aus, die bald mehr denen der Amoeben ('rolamoeba), bald mehr denen der Rhizopoden gleichen ('rologenes). Rinige von ihnen scheiden im Ruhezustand eine äussere Hülle (Cyste) aus. Stets sind sie einfachste Cytoden. Diese äusserst merkwürdigen und höchst wichtigen Organismen, welche sich von allen andern bekannten Organismen durch den vollständigen Mangel jeglicher Structur unterscheiden, und in der That nur ein Stückchen lebendiges Eiweiss oder Schleim darstellen, sind erst in neuester Zeit Gegenstand der verdienten Aufmerksamkeit geworden.

Das grösste bis jetzt bekannte Protist, welches in den Stamm der Moneren gehört, ist von uns im Mittelmeere entdeckt und als Prolngenes primordialıs beschrieben und abgebildet worden ${ }^{2}$ ). Es stellt einen kolossalen homogenen Plasmaklumpen dar, welcher nach Art der echten Rhizopoden (Acyttarien und Radiolarien) nach allen Seiten verästelte und verschmelzelnde Pseudopodiencomplexe ausstrahlt, und sich durch Theilung vermehrt. Unserem Prologenes primordialis nächstrerwandt ist der kleinere, von Max Schultze im adriatischen Meere beobachtete Protogenes porreclus (. Imocba porrecla). Die Gattung Protogenes stellt zeitlebens denselben einfachsten biologischen Zustand dar, den die Plasmodien einiger Myxomyceten in ihrer Jugend durchlaufen.

Im Süsswasser haben wir ein amoebenartiges, aber kernloses homogencs $W^{\top}$ csen entdeckt, welches wir oben als Profamoeba primiriva beschrieben haben (Bd. I, S. 133). Seitdem sind die höchst interessanten neuen

1) poyrons, einfach Vergl. Bd. I, S. 135.

2) E. Haeckel. über den Sarcodekörper der Rhizopoden, Zeitselır für wissenschuftl. Zoslogie, XV, 1865, S. 342,360 , Taf. XXVI, Fig 1, 2. 
„Beiträge zur Kenntniss der Monaden" von L. Cienkowski.1) erschienen, worin dieser ausgezeichnete Protistikcr die vollständige und höchst wichtige Naturgeschichte einer Anzahl neuer, der Prolamweha nächst verwandter Moneren gegeben hat. Wir verweisen hier vorzüglich auf diese letztere Arbeit, welche um so mehr zu beachten ist, als sie von einem Naturforscher herrührt, der nicht allein als objectiver und vorurtheilsfreier Beobachter mit Recht anerkannt ist, sondern auch logisch zu denken, richtig zu vergleichen und aus der Synthese der einzelnen analytischen Beobachtungen allgemeine Schlïsse zu ziehen versteht, eine unter den organischen Morphologen wirklich seltene Eigenschaft! Unter den von Cienkowski als Monaden beschriebenen Wesen gehören zwei kernlose, lediglich aus einem lebenden Plasmaklumpchen bestehende Formen zu unserem Moneren-Stamm, nämlich die Zoosporen bildende .Monas amyli, welche wir als Protomonas amyli von den übrigen Monaden sondern, und die äusserst merkwürdigen Vampyrellen, rothe Moneren, welche sich nicht durch Schwärmsporen, sondern durch actinophrys - ähnliche Keime fortpllanzen. Von Vampyrella hat Cien k owski drei verschiedene Arten: $V$. vorax, $r$. pendula und $\boldsymbol{I}^{r}$ spirogyrae beschrieben. Endlich müssen wir zu den Moneren auch die seltsame Organismen-Gruppe der Vibrioniden rechnen, welche zuerst Ehrenberg in seinem grossen Infusorienwerke näher beschrieben und in die Gattungen Vibrio, Bacterium, Spirnchamta, Spirillum, Spirodiscus geschieden hat.

Alle echten Moneren, so verschieden sie auch sonst sein mögen, stimmen darin überein, dass sie zeitlebens structurlose und homogene Plasmakörper bleiben und keinerlei Organisation erhalten. Es sind "Organismen ohne Organe" (vergl. Bd. I, S. 135). Der einzige Differenzirungs-Process, den sie erleiden können, besteht darin, dass sie beim Uebergange in den Ruhezustand eine Hülle (Cyste) abscheiden (Prolomonas, Vampyrella). Die Gymnocytode wird dadurch zur Lepocytode. Niemals aber differenzirt sich im Plasma der echten Moneren ein Kern; niemals wird also aus der Cytode eine Zelle. Die Bewegungen, welche das structurlose Eiweissstuckchen des Moneres ausführt, sind sehr verschiedenartig, bald wie bei den Amoeben (Profomoeba, bald wie bei den echten Rhizopoden (Profogrenes), bald zu verschiedenen Lebenszeiten verschieden (Prolomonas, Vampyre/li), bald charakteristisch lebhaft schlängelnd (die Vibrionen).

Will man unter den Moneren verschiedene Gruppen unterscheiden, so können wir als solche die Gymnomoneren und Lepomoneren bezeichnen. Die Gymnomoneren (Protogenes, Prolamoeba, Bacterium, Vibrio etc.) bleiben zeitlebens nackt, während die Lepomoneren (Protomonas, F'ampyrella) beim Uebergange in den Ruhezustand eine Hülle ausschwitzen.

Was die Phylogenie der Moneren anbelangt, so ist uns dieselbe noch ganz unbeliannt. Nach unserer persönlichen Ueberzeugung entstehen dieselben, wenigstens zum Theil, noch fortwährend durch Archigonie, sei es nun durch Autogonie oder durch Plasmogonie (S. 33). Ob dieselben noch gegenwärtig sich zu höheren Organismen weiter entwickeln, wissen wir nicht. Doch kann es uns nicht zweifelhaft sein, dass die autogonen Stammformen sämmtlicher organischer Stämme, sowohl der protistischen als der vegetabilischen und animalischen Phylen, den morphologischen Charakter der Moneren besessen haben müssen. Aus einem Prologentes können sich vielleicht zunächst der Rhizopoden -Stamm, aus einer Amoeba der ProtoplastenStamm etc. entwickelt haben, wic die Jugendzustände dieser Phylen beweisen.

1) Max Schultze, Archiv für mikr. Anatomie. I, 1865, S. 203, Taf. XII - XIV. 
XXIV Systematische Einleitung in die Entwickelungsgeschichte.

\section{Zweiter Stamm des Protisten-Reiches: Protoplasta, H. Protoplasten.}

In dem Phylum der Protoplasten ${ }^{1}$ ) vereinigen wir mehrere sehr niedrig stehende Organismen-Gruppen, welche bisher gewöhnlich als Glieder des sogenannten Protozoen-Kreises aufgefiihrt wurden, nämlich die entozoischen Gregarinen und die freien Sphygmiken, welche bald als Infusoriu rhizopoda oder als Atricha mit den echten Infusorien (Ciliaten), bald als Lobosa oder Amoebina mit den echten Rhizopoden vereinigt wurden. Den Ausgangspunkt des Stammes bilden die echten Amoeben, von denen wahrscheinlich ein Theil durch Uebergang zur entoparasitischen Lebensweise zu Gregarinen geworden ist, während ein anderer Theil durch Ausscheidung ciner Schaale die Arcelliden-Gruppe gebildet hat. Wir können diese drei Gruppen als Ordnungen der Protoplasten-Classe, der einzigen ihres Stammes, unterscheiden. Alle echten Protoplasten enthalten zu irgend einer Zeit ihres Lebens einen oder mehrere Kerne, sind also nicht mehr blosse Cytoden, sondern echte Zellen. Viele besitzen ausserdem eine Haut oder Schaale.

Von den Protoplasten sind viele früheste Entwickelungszustände anderer Organismen nicht zu unterscheiden; sowohl Thiere als Pflanzen durchlaufen sehr allgemein einen Entwickelungszustand, der von gewissen Protoplasten (Amoeben, Gregarinen) nicht anatomisch verschieden erscheint. Die Eier der meisten Thiere und Pflanzen haben den morphologischen Werth von einzelligen Amoeben oder einzelligen Gregarinen (Monocystideen). Vielleicht ist daher das Phylum der Protoplasten ebenso wie das der Moueren Ausgangspunkt und gemeinsame Wurzel für andere Stämme. Vielleicht ist dasselbe aber andererseits selbst aus mehreren ursprünglich selbstständigen Phylen zusammengesetzt.

\section{Erste Ordnung der Protoplasten-Classe: \\ Gymnamoebae, H. Nackt-Amoeben.}

Diese Ordnung wird durch die Autamoeba oder die echte kernhaltige Anoeba als die ursprüngliche Grundform des ganzen Stammes, und durch die verwandten Gattungen Petalopus, Polostoma etc. gebildet. Auch einige von den Monaden Cienk owski's gehören hierher, nämlich die Zoosporen bildende Pseudospora und die durch actinophrys-ähnliche Keime sich fortpflanzende Nuclearia. Die meisten Gymnamoeben enthalten in ihrem nackten homogenen Plasmakörper einen einzigen Kern, sind also einfache NacktZellen (Gymnocyta). Einige (Nuclearia delicatula) sind in erwachsenen $\mathrm{Zu}$ stande mehrzellig, da der Plasmakörper mehrere Kerne enthält. Die meisten Gymnamoeben enthalten ausserdem eine oder mehrere contractile Blasen.

\section{Zweite Ordnung der Protoplasten-Classe: \\ Lopamoebae, H. Schaal-Amoeben.}

Diese Ordnung hat sich aus den Gymnamoeben durch Secretion einer mehr oder weniger differenzirten Schale entwickelt, die bald eine weiche Haut, bald ein fester Panzer ist. Es gehört hierher der grösste Theil der Arcelliden (Arcella, Difflugua, Euglypha, Echinopyxis etc.), welche gewöhnlich zu den echten einkammerigen Khizopoden oder Monothalamien, (Gromia, Lngymis etc.) gestellt werden.

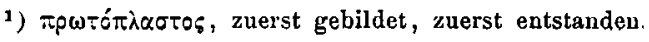


Dritte Ordnung der Protoplasten-Classe:

Gregarinae. Gregarinen.

Wie die Lepamoeben durch progressive, so sind die Gregarinen durch regressive Metamorphose aus den Gymnamooben hervorgegangen. Wir betrachten diese ausschliesslich parasitische Protisten-Gruppe als Gymnamoeben, welche sich an entoparasitische Lebensweise gewöhnt und sich mit einer schützenden Hülle umgeben, vielleicht auch ihre contractile Blase, falls sie eine solche besassen, verloren haben. Die Ordnung zerfällt in zwei Familien: Monocystidea (Monocystis) und Polycystidea (Stylorhynchus), jenachdem der reife Körper aus einer einzigen oder aus mehreren (meist zwei oder drei) verbundenen Zellen besteht.

\section{Dritter Stamm des Protisten-Reiches: \\ Diatomea. Kieselzellen.}

Die formenreiche Gruppe der Diatomeen wurde früher wegen ihrer eigenthümlichen Bewegungen gewöhnlich zu den Thieren (Infusorien), neuerdings meist zu den Pflanzen (Algen) gerechnet. Am passendsten erscheint es, dieselbe als ein selbstständiges Protisten-Phylum aufzufassen, welches durch seine eigenthümliche Kieselschalenbildung und Bewegung hinlänglich charakterisirt ist. Diese Ansicht hat auch schon Max Schultze in seinen neuesten „Mittheilungen über die Bewegungen der Diatomeen“ begründet, worin er zeigt, dass dieselben weder Thiere noch Pflanzen, sondern „Urorganismen " sind ${ }^{1}$ ). Verbindende Uebergangsformen zu anderen OrganismenGruppen sind nicht vorhanden. Am nächsten scheinen ihnen sonst die Desmidiaceen unter den Algen zu stehen. Von diesen unterscheiden sie sich aber wesentlich durch die spaltförmige Oeffinung (Raphe) in der kieseligen Zellenwand, durch welche ihr Protoplasma-Körper frei zu Tage tritt.

Die Paläontologie zeigt uns, dass dieses Phylum schon seit sehr langer Zeit in wenig verändertem Zustande existirt hat. Schon in der Steinkohle finden sich Diatomeen. Häufig sind sie in den Feuersteinen der Kreide. In der älteren Tertiärzeit bilden sie mïchtige Lager. Ein Stammbaum der Gruppe lässt sich aber aus ihren fossilen Resten bis jetzt nicht construiren, so wenig als bei den Rhizopoden.

Die Diatomeen sind entweder einfache kieselschalige Zellen, oder mehr oder weniger innig verbundene kieselschalige Zellencomplexe. Theils schwimmen sie frei umher, theils sitzen sie fest. Nach der Structur der Kieselschaale unterscheidet man drei Gruppen: 1) Gestreifte, Striatae (Surirella, Navicula); 2) Striemige, Vittatae (Licmophora, Tabellaria); 3) Gefelderte, Areolatae (Coscinodiscus, Tripodiseus).

\section{Vierter Stamm des Protisten-Reiches: Flagellata. Geisselschwärmer.}

Die systematische Stellung der Flagellaten ist noch heutzutage völlig unentschieden, da eben so viel Stimmen sie zu den Pflanzen, wie zu den Thieren zählen. Viele hierher gehörige Organismen sind nicht zu unterscheiden von den Jugendzuständen (Schwärmsporen) echter Pflanzen (Algen) und gewisser Protisten anderer Stämme (Myxomyceten); andere schliessen

1) Max Schultze, Archiv f. mikr. Anat. 1, 1865, S. 400 


\section{Systematische Einleitung in die Entwickelungsgeschichte.}

sich mehr an die echten Infusorien (Ciliaten), also an unzweifelhafte Thiere an. Es erscheint daher am passendsten, die unzweifelhaft selbstständigen Formen, welche hierher gehören und welche alle unter sich sehr nahe verwandt sind, als $Z_{w}$ eige eines selbstständigen Protisten-Stammes zu betrachten. Mit Ausnahme der Cilioflagellaten (Peridinien), deren charakteristisch gebildete Kieselschalen sich bisweilen im Jura und in der Kreide finden, sind keine fossilen Reste dieses Stammes bekannt.

Der Flagellaten-Stamm kann in zwei Ordnungen gespalten werden. Die niedere Ordnung der $\mathrm{Nud}$ oflage llaten oder der unbewimperten Geisselschwärmer umfasst die Familien der Astasiaeen (Euglrna, As/asia), Dinobryinen (Dinobryon), Volvocinen (Volvox, Gonium), Hydromorinen (Spondylomorum) und einige verwandte Fannilien. Die höhere Ordnung der Cilioflagellaten, welche vielleicht aus ersterer sich entwickelt hat, enthält bloss die eine Familie der Peridiniden (Peridinium, Ceratium etc.).

Fünfter Stamm des Protisten-Reiches:

Myxomycetes. Schleimpilze.

(Synonym: Mycetozoa. Mysogastres.)

Die merkwürdige Gruppe der Myxomyceten stand wegen der Aehnlichkeit ihrer reifen Zustände mit unzweifelhaften Pilzen, den echten Gastromyceten, unangefochten in der Classe der Pilze und wurde gleich diesen als echte Pflanzen angesehen, bis vor sieben Jahren A. de Bary durch seine ausgezeichneten Untersuchungen nachwies, dass dieselben durch ihre höchst eigenthümliche Entwickelung sich gänzlich von allen Pilzen nicht nur, sondern von allen Pflanzen überhaupt entfernen. Der gastromyceten-ähnliche Fruchtkörper oder das Sporangium der Myxomyceten entwickelt sich unmittelbar durch einen sehr merkwürdigen Differenzirungs-Process aus einem grossen Plasmodium, einem homogenen und structurlosen Plasmakörper, welcher durch Verwachsung (Concrescenz) vieler ursprünglich selbstständiger amoebenförmiger Keime entsteht, deren jeder nach seinem Ausschlüpfen aus der Spore sich frei umherbewegt hat.

Dieser höchst eigenthümliche Entwickelungsmodus veranlasste de B ary, die Myxomyceten als Mycetozoen zu dem Thierreich zu stellen, wo sie den Rhizopoden unter den Protozoen am nächsten stehen würden. Gleich den echten Rhizopoden selbst betrachten wir auch die Myxomyceten als Glieder eines selbstständigen Protisten - Stammes, der seine eigene phyletische Entwickelung ganz unabhängig von anderen Organismen durchlaufen hat. Doch können wir auf seine Phylogenie nur aus seiner biontischen Fntwickelung schliessen, da die empirische Paläontologie uns über die erstere gar keine Aufschlüsse liefert. A. de Bary hat vier verschiedene Ordnungen aufgestellt, in welche der Myxomyceten -Stamm sich differenzurt hat; diese sind: 1) Physareae (Physarum, Aethalium); 2) Stemoniteae (Stemonitis, Enerthenema); 3) Trichiaceae (Licea, Arcyria); 4) Lycogaleae (Lyeogala, Reticularia).

Sechster Stamm des Protisten-Reiches:

\section{Noctilucae. Meerleuchten.}

Als einen eigenthümlichen Stamm des Protisten-Rcichss müssen wir die merkwürdige Gruppe der Meerleuchten oder Noctiluken (IIyxocystodea) auffassen, welche bloss aus dem einzigen Genus loctilluca besteht. Von dieser 
Gattung ist nur eine Art (N. miliaris) mit Sicherheit bekannt. Es sind kleine pfirsichförmige Bläschen, welche gegen $1^{\mathrm{mm}}$ Durchmesser erreichen und das Meer oft in so ungeheuren Massen bedecken, dass sie eine mehr als zolldicke Schleimschicht auf dessen Oberfläche bilden. Sie sind eine der wesentlichsten Ursachen des Meeresleuchtens.

Eine Verwandtschaft der Noctiluken zu anderen Organismen ist durchaus nicht mit Sicherheit zu ermitteln. Finige stellen sie zu den Rhizopoden, andere zu den Infusorien; doch könnte man sie fast mit demselben Rechte auch in die Reihe der grossen Diatoween stellen. Da sie keine harten, der Fossilisation fähigen Theile besitzen und da auch ihre Ontogenese zur Zeit noch ganz unbekannt ist, so sind wir über ihre Phylogenie gänzlich im Dunkeln. Unter diesen Umständen erscheint es am sichersten, sie als einen eigenen, besonderen Stamm des Protisten-Reiches aufzufassen.

\section{Siebenter Stamm des Protisten-Reiches: Rhizopoda. Wurzelfüsser.}

Eine der formenreichsten und merkwürdigsten Organismen-Gruppen bildet die grosse Abtheilung der Rhizopoden, welche wir als einen vollkommen selbstständigen Stamm des Protistenreiches betrachten Zwar werden dieselben gewöhnlich als Thiere aufgeführt; indessen ist irgend ein Uebergang oder überhaupt nur irgend eine unzweifelhafte Beziehung zu echten Thieren nicht vorhanden. Die einzigen Organismen, mit denen man die echten Rhizopoden allenfalls in Verbindung bringen könnte, sind einerseits die Spongien, andererseits die Protoplasten, von welchen letzteren bisher ein Theil (Amoebiden und Arcelliden) gewöhnlich mit den echten Rhizopoden vereint gewesen ist. Doch sind auch die Beziehungen zu diesen Gruppen so allgemeiner und indifferenter Natur, dass es uns vorläufig bei weitem am sichersten scheint, die echten Rhizopoden als ein eigenes selbstständiges Phylum zu sondern.

Fossile Reste von Rhizopoden sind in Masse bekannt, und zwar sind die kieselschaligen Radiolarien bisher nur tertiär, die kalkschaligen Acyttarien dagegen schon von den ältesten Formationen an gefunden worden. Doch hat es bis jetzt nicht gelingen wollen, in der Masse der paläontologischen Thatsachen das Gesetz der phyletischen Entwickelung des Rhizopoden-Stammes zu erkennen.

Der Rhizopoden-Stamm, wie wir ihn nach Ausschluss der Protoplasten begrenzen, umfasst ausschliesslich hautlose Protisten, deren nackter Protoplasmakörper allenthalben verästelte und confluirende Pseudopodien ausstrahlt und ausserdem meistens ein kieseliges oder kalkiges Skelet ausscheidet. Eine contractile Blase, wie sie die Infusorien und Protoplasten meistens besitzen, fehlt stets. Es gehören hierher die beiden umfangreichen Gruppen der Acyttarien und Radiolarien und die kleine Gruppe der Heliozoen (Aclmosphaerium und die verwandten Rhizopoden), von denen die letzteren vielleicht alte Süsswasser-Formen repräsentiren, die sich von dem gemeinsamen Urstamm der Rhizopoden schon frühzeitig abgezweigt haben.

Erste Classe des Rhizopoden-Stammes:

Acyttaria, H. Spiralrhizopoden.

(S ynonym: Polythalamia. Foraminfera. Reticularia.)

Die Acyttarien-Classe, welche im Ganzen den Gruppen der Polythalamicn, Foraminiferen oder Reticularien, im Sinne der neueren Autoren, je- 
XXVIII Systematische Einleitung in die Entwickelungsgeschichte.

doch nach Ausschluss gewisser Gruppen entspricht, ist die niedere und unvollkommnere Abtheilung des Rhizopoden-Stammes. Der Weichkörper des Thieres besteht hier lediglich aus nicht differenzirter Sarcode, in welcher sich jédoch häufig (vielleicht immer?) Kerne entwickelt haben. Es fehlt aber die Centralkapsel, welche den Radiolarien eigenthümlich ist. Meist ist eine kalkige, seltener eine häutige oder kieselige Schale vorhanden, welche in den vollkommneren Acyttarien einen hohen Grad von Complication in Form und Structur erhält. Ueber die Classification dieser formenreichen Classe ist die neueste Bearbeitung derselben von Carpenter $\mathrm{zu}$ vergleichen ${ }^{1}$ ). M ax Schultze hatte dieselben nach Zahl und Anordnung der Schalenkammern in Einkammerige oder Monothalamia (Groma, Lagynis) und Vielkammerige oder Poly thala mia eingetheilt, und unter letzteren die Gruppen der Acervuliniden, Nodosariden, Milioliden, Nautiloiden, Turbinoiden, Alveoliniden und Soritiden unterschieden ${ }^{2}$ ). Carpenter dagegen unterscheidet nach der $\mathrm{Be}-$ schaffenheit der Schalenwand-Structur die beiden Ordnungen der Imperforata mit undurchbohrter und der Perforata mit durchbohrter Schale. Zu ersteren gehören die Gromiden, Milioliden und Lituoliden, zu letzteren die Lageniden, Globigeriniden und Nummuliniden. Wir halten uns hier nicht mit deren Anordnung auf, da die Ergebnisse aller bisherigen ClassificationsVersuche noch nicht in Einklang mit den paläontologischen Resultaten haben gebracht werden können und für die Phylogenie werthlos sind.

Die Acyttarien sind dadurch merkwürdig, dass zu ihnen der alteste bekannte fossile Rest eines Organismus gehört, die Kalkschale von Eozoon canalense, welche vor wenigen Jahren in der unteren laurentischen Formation Canadas (Ottawa) gefunden worden ist, und plötzlich die ungeheuer lange Zeit der organischen Erdgeschichte noch um colossale Zeitrüume verlängert hat. Sehr zahlreich finden sich Polythalamien-Schalen auch schon im Silur und Devon, namentlich kieselige Steinkerne derselben. Ihre eigentliche Acme erreicht die Classe jedoch erst in der Kreide- und besonders in der älteren Tertiär-Zeit (Nummuliten-Formation!), wo sowohl die Anzahl ihrer verschiedenen Arten und die bedeutende Grösse cines Theiles derselben (Nummulites), als auch besonders die ungeheure Masse der Individuen erstaunlich ist, die oft ganze Berge fast allein zusammensetzen.

\section{Zweite Classe des Rhizopoden-Stammes:}

Heliozoa, H. Sonneuthierchen.

Die Classe der Heliozoen oder Actinosphäriden wird bis jetzt mit Sicherheit nur durch ein einziges Protist repräsentirt, durch Actunosphaerium Eichhornii (Actinophrys Eichhornii), den bedeutendsten unter den wenigen Vertretern der echten Rhizopoden im süssen Wasser. Wahrscheinlich ist derselbe als ein sehr alter und wenig veränderter directcr Alkömmling der älteren Rhizopoden-Vorfahren zu betrachten (wie auch Gromia unter den Acyttarien), welcher sich, gleich anderen alten Sïssw: sour - Formen (Hydra, Ganoida) in dem einfacheren Kampfe um das Dasein gui conservirt hat. Seiner Structur nach scheint Actinosphaerium zwischen dis Acjttarien und Radiol-rien in der Mitte zu stehen, kann jedoch keiner von beiden Abtheilungen zugerechnet werden. Insbesondere fehlt ihm die charakteristische Centralkapsel der Radiolarien.

1) Carpenter, Introduction to the study of the Foraminifera. London 1862.

a) Max Schultze, über den Organismus der Polythalamien, Leipzig 1854. 


\section{Dritte Classe des Rhizopoden -Stammes:}

Radiolaria. Strahlrhizopoden.

(Synonym: Cytophora. Polycystina. Echinocystida.) .

Die Radiolarien-Classe ist noch ungleich formenreicher als die Acyttarien -Classe, von der sie sich wesentlich durch den Besitz einer Centralkapsel unterscheidet, welche der letzteren stets fehlt. Gewöhnlich sind ausserdem noch gelbe Zellen in der die Kapsel umhüllenden Sarcode-Masse vorhanden. Meistens ist ein Kieselskelet ausgebildet, welches die zierlichsten und mannichfaltigsten Formen darbietet, die überhaupt in der organischen Natur vorkommen. Wir haben in unserer Monographie der Radiolarien versucht, die reiche Fülle dieser höchst verschiedenartigen Formen auf Grund ihrer vergleichenden Anatomie derartig in eine genealogische Verwandtschaftstabelle systematisch zu ordnen, dass daraus die Möglichkeit einer gemeinsamen $\mathrm{Ab}$ stammung derselben von einer einzigen Grundform (Heliosphaera) ersichtlich wird ${ }^{1}$ ).

Die fossilen Reste der Radiolarien bieten für ihre Phylogenie eben so wenig Anhaltspunkte, als es bei den Acyttarien der Fall ist. Uebrigens sind sie ungleich seltener, als die der letzteren: In grossen Massen, und ganz vorwiegend das Gestein bildend, sind die Kieselschalen der Radiolarien bisher nur an zwei Orten, auf der Insel Barbados und den Nikobaren - Inseln, gefunden worden (l. c. S. 191). Diese sowohl, als alle anderen Gesteine, welche fossile Radiolarien enthalten, sind in der Tertiärzeit abgelagert worden.

\section{Achter Stamm des Protisten-Reiches: Spongiae. Schwämme.}

(Sgnonym: Porifera. Amorphozoa. Spongida. Spongiaria.)

Die schwierige und viel verhandelte Frage von der systematischen Stellung der Schwämme oder Spongien scheint uns ebenso wie diejenige von der Stellung der Rhizopoden am besten dadurch gelöst zu werden, dass wir sie als einen besonderen und unabhängigen Stamm des Protisten-Reiches hinstellen. Unter allen Organismen stehen die Rhizopoden den Schwämmen am nächsten, doch nicht in solcher Beziehung, dass wir sie mit diesen in einem einzigen Phylum vereinigen können. Früherhin wurden die Spongien meistens von den Zoologen für Pflanzen, von den Botanikern für Thiere angesehen, und deshalb von Beiden vernachlässigt. Erst als vor zehn Jahren ihre Biologie durch die vortrefflichen Untersuchungen von Lieberkühn näher bekannt wurde, beschloss man allgemein sie für Thiere zu erklären, obwohl in den wichtigen Resultaten jener Untersuchungen selbst durchaus kein genügender Grund für diese Bestimmung lag. Sie wurden nun als eine besondere Classe bald in den Protozoen-Kreis, bald in den Coelenteraten-Kreis eingereiht. Die Aehnlichkeit mit den letzteren ist aber offenbar bloss Analogie, keine Homologie.

1) Ernst Haeckel, die Radiolarien. Eine Monographie. Berlin, G. Reimer 1862 , S. 234. Wie wir dort ausdrücklich bemerkt haben, wollten wir durch jenen provisorischen Versuch nur zeigen, dass die unendlich mannichfaltige Radiolarien-Classe als eine einzige blutsverwandte Gruppe nachgewiesen werden kann. Als eigentliche Ausgangsform oder gemeinsame Stammform würde nicht Heliosphaera, sondern ein einfachstes Radiolar der Colliden-Familie, etwa eine der Thalassosphaera nahe stehende Form anzusehen sein. 


\section{Systematische Einleitung in die Entwickelungsgeschichte.}

Alle jetzt lebenden Schwämme besitzen kein zusammenhängendes Skelet. Die einzelnen Skeletstücke (Spicula etc.), welche das Fasergerüst der meisten stützen, sind zwar vielfach in fossilem Zustande erhalten, vermögen uns aber keinerlei Aufschluss über ihre Phylogenie zu ertheilen. Dagegen giebt es eine grosse Anzahl von sehr charakteristisch geformten fosslen Körpern, welche man gewöhnlich als ,,Petrospangine“ der Schwammclasse-einverleibt. Wir gestehen, dass wir diese Vereinigung nur mit dem grössten Misstrauen betrachten können, und aus vielen, an einem anderen Orte ausführlich zu erörternden Gründen, vielmehr geneigt sind, die Petrospongien für einen eigenthümlichen, schon am Beginn der Tertiärzeit völlig ausgestorbenen Protisten-Stamm zu halten. Da wir jedoch, bei unserer höchst unvollständigen Kenntniss desselben, keine genügende Charakteristik davon geben können, und er immerhin unter allen anderen Organismen den echten Spongien am nächsten zu stehen scheint, so wollen wir denselben hier als eine besondere Classe des Spongien-Stammes den echten Spongien oder Autospongien gegenüber stellen:

\section{Erste Classe des Spongien-Stammes:}

\section{Autospongiae, H. Echte Schwämme}

Diese Classe umfasst alle jetzt lebenden Schwämme, von denen keiner ein derartiges verwickelt organisirtes Skelet und eine so ausgezeichnete und regelmässige Form besitzt, wie die fossilen Petrospongien. Wenn die Autospongien ein Skelet besitzen, so besteht es bloss aus einzelnen kieseligen oder kalkigen Stücken: Nadeln (Spicula), Kreuzen, Stachelsternen, Amphidisken, Siebkugeln etc. Diese sind auch sehr zahlreich in fossilem Zustande, besonders in den Tertiär-Gebilden, erhalten gefunden worden, ohne dass sie über die Phylogenie der Autospongien irgend etwas Bestimmtes aussagten. Die lebenden Autospongien zerfallen nach der chemischen Beschaffenheit ihres Skelets in vier Ordnungen: I. M y x o sp on gi a e oder Schleimschwämme (Halısarca) ohne jedes Skelet, bloss aus weichen Plastiden zusammengesetzt. II. Ceratospongiae oder Hornschwämme (Euspongia, Fillfera, Darwiuella) mit organischem Skelet vou hornähulicher oder chitinähnlicher Consistenz. III. Silicispongiae oder Kieselschwämme (Clione, Halichondria, Spongilla etc.) mit kieseligem Skelet. IV. Calcispongiae (Grantia, Sycon) mit kalkigem Skelet. Offenbar bilden die Myxospongien die älteste Stammform, aus der sich erst später die Ceratospongien entwickelt haben. Aus den letzteren sind dann als zwei unabhängige divergirende $Z_{w e i g e}$ die Silicispongien und Calcispongien hervorgegangen, wie es Fritz Müller so klar erläutert hat ${ }^{1}$ ).

\section{Zweite Classe des Spongien-Stammes: \\ Petrospongiae. Becherschwämme.}

Diese sehr merkwürdige Organismengruppe, welche aller Wahrscheinlichkeit nach einen ganz besonderen und selbstständigen, schon im Beginn der Tertiärzeit völlig erloschenen Stamm des Protistenreiches darstellt und sich durch seine charakteristische Form und Structur sehr wesentlich von den Autospongien unterscheidet, umfasst folgende fünf Ordnungen: I. Turonida (Turonia, Stromatopora, Ainorphospongia); II. B oth roconida (Spar-

1) Fritz Müller, über Damezella aurea, einen Schwarnm mit sternförmigen Horunadeln. Archiv f. mikr. Anat 1865 , S 344 
sispongia, Bothroconis, Pleurostoma); III. Ly muorida (Lymnorea, Liospongiu, Actinospongia); IV. Siphonida (Siphomin, Euden, Cnemidium); V. Ocellarida (Coeloptychium, Ocellariu, Guettardia). Die formenreiche Petrospongien-Classe beginnt bereits nit Stromalopora und Palaeospongia im unteren Silur, bleibt aber iu der Primärzeit im Ganzen noch spärlich. Massenhaft entwickelt sic sich von Beginn der Secundürzeit an, für welche sie sehr charakteristisch ist, und erreicht die Acme ihre Entwickelung am Ende der Mesolithzeit, in der Weisskreide. Dann stirbt sie fast völlig aus, und nur ein einziger, merkwürdiger Repräsentant, Guettardia Thiolati, findet sich noch als letzter Ausläufer im Beginn der Tertiärzeit, im Nummulitenkalk.

\section{Das natürliche System des Pflanzenreichs.}

Von den drei organischen Reichen oder obersten Hauptgruppen, denen sich sämmtliche Organismen einordnen lassen, repräsentirt das Pflanzenreich am meisten eine geschlossene Einheit, so dass, falls man jedes der drei Reiche als einen einzigen natürlichen Stamm (Phylum) auffassen und für jedes derselben eine selbstständige autogone Stammform annehmen wollte, diese Annahme sich noch am ersten für das Pflanzenreich rechtfertigen liesse. Der Unterschied, den das Pflanzenreich in dieser Beziehung gegenüber dem Protistenreiche und dem Thierreiche darbietet, ist sehr augenfällig, und äussert sich unter Anderem auch darin, dass die Botaniker keine solchen grossen natürlichen Hauptabtheilungen des Pflanzenreichs aufzustellen vermocht haben, wie sie im Thierreiche gegenwärtig von allen Zoologen als unabhängige „Typen“ oder "Kreise" (Orbes, Branches, Embranchements, Subkingdoms) anerkannt sind. Die charakteristische Eigenthümlichkeit dieser thierischen "Kreise" oder "Unterreiche" besteht darin, dass jeder derselben seinen eigenen „Organisationsplan oder Organisationstypus" besitzt, welcher ihm eigenthümlich und ausschliesslich zukommt, und welcher innerhalb des Kreises sich zu einem hohen Grade der Vollkommenheit entwickeln kaun, unabhängig von allen anderen Kreisen. Die anatomischen, embryologischen und paläontologischen Verhältnisse dieser Kreise führten uns zu der Vorstellung, dass jeder derselben einem natürlichen Stamme oder Phylum entspricht. Wir konnten daher das Thierreich als ein Aggregat von fünf verschiedenen Stämmen 'auffassen, welche den fünf allgemein anerkannten Typen oder Subkingdoms entsprechen: Vertebraten, Articulaten, Mollusken, Echinodermen und Coelenteraten. Keine von diesen Abtheilungen kann einfach als eine niedere Entwickelungsstufe der anderen angesehen werden. Einc analoge Eintheilung ist nun im Pflanzenreiche keineswegs durchführbar. Jenen fünf thierischen Abtheilungen entsprechen nicht die wenigen grossen Hauptabtheilungen, welche man im Pflanzenreiche schon seit langer Zeit als Cryptogamen und Phanerogamen, oder als Thallophyten und Cormo- 
XXXII Systematische Einleitung in die Entwickelungsgeschichte.

phyten, oder als Plantac cellulares und Plantae vasculares unterschieden hat. Vielmehr erscheint es hier ungleich natürlicher, die ersteren nur als persistente Nachkommen von niederen Entwickelungsstufen der letzteren anzusehen.

Wenn wir die ganze Anatomie und Morphogenie des Pflanzenreichs vergleichend ins Auge fassen, so erscheint es uns wohl am natürlichsten, dasselbe als einen einzigen Stamm oder Phylum aufzufassen, jedoch nach Ausschluss derjenigen, bald zum Thierreich, bald zum Pflanzenreich gerechneten Stämme, welche wir bereits im Vorhergehenden als zu den Protisten gehörig bezeichnet haben: Myxomyceten, Diatomeen, Flagellaten etc. Wir haben auf Taf. II den Versuch gemacht, diese Anschauung durch die Darstellung eines Stammbaums, welcher sämmtliche echte Pflanzen urnfasst, zu erläutern.

Neigt man andrerseits mehr zu der Ansicht, dass auch das Pflanzenreich, gleich dem Thierreich und dem Protistenreich, aus mehreren verschiedenen, selbstständigen Stämmen zusammengesetzt ist, so würden als solche isolirte Phylen sich vielleicht zunächst diejenigen vier Hauptgruppen darbieten, die wir bereits oben (Bd. I, S. 220) unterschieden haben, nämlich die Phycophyten, Characeen, Nematophyten und Cormophyten. Jedoch ist der genealogische Zusammenhang auch dieser vier Gruppen uns aus mehreren Gründen sehr wahrscheinlich, und es ist sehr leicht möglich, dass nicht allein die Characeen und Nematophyten, sondern auch die Cormophyten aus dem Phycophyten-Stamme ihren Ursprung genommen haben. Dagegen ist das Phylum der Phycophyten selbst vielleicht ein Aggregat von mehreren ganz selbstständigen Stämmen, und es ist z. B. selhr leicht möglich, dass die Florideen ein eigenes Phylum bilden, ebenso die Fucoideen und andere Gruppen der sogenannten Algenclasse. Da wir diese schwierige Frage im fünfundzwanzigsten Capitel nochmals berühren werden, so halten wir uns hier nicht länger bei derselben auf, und wenden uns zu einer kurzen Uebersicht des natürlichen Systems des Pflanzenreichs, wobei wir zugleich auf Cap. XXV, sowie Taf. II und deren Erklärung verweisen. Den vier Stämmen, welche wir bereits im siebenten Capitel geschieden haben, fügen wir hier noch als zwei selbstständige Phylen die eben genannten eigenthümlichen Algengruppen hinzu, indem wir die Algenclasse in drei Stämme auflüsen, in die Archephyten, Florideen und Fucoideen. Wir erhalten demnach sechs verschiedene Stämme des Pflanzenreichs, welche jedoch höchst wahrscheinlich sämmtlich an ihrer Wurzel zusammenhängen und gemeinsamen Ursprungs sind, wie es Taf. I andeutet. Die Paläontologie vermag über diese wichtige Frage wieder keine Auskunft zu geben, da fast alle fossilen Pflanzenreste, welche deutlich erkennbar und von phylogenetischer Bedeutung sind, dem Cormophyten-Stamme angehören. 
Das natürliche System des Pflanzenreichs.

\section{Erster Stamm des Pflanzenreichs: Archephyta, H. Urpflanzen.}

Als Archephyten oder Urpflanzen fassen wir den grössten Theil der niederen Algen zusammen, welche von der Algengruppe nach Abzug der Fucoideen und Florideen und derjenigen einfachsten Pfianzen iubrig bleiben, welche die Stammformen der übrigen vegetabilischen Phylen sind. Wenn das ganze Pflanzenreich einem einzigen Phylon entsprechen sollte, wie es auf Taf. II dargestellt ist, so würden die Archephyten wahrscheinlich zugleich die ältesten Stammformen und die am wenigsten veränderten Nachkommen derselben enthalten. Wir würden dann die Archephyten als Wurzel des ganzen Pflanzenreichs zu betrachten haben. Leider wissen wir von ihrer Phylogenie so gut wie nichts, da die meisten Archephyten äusserst weich und zart, und gar nicht der Erhaltung in fossilem Zustande fähig sind. Einzelne unsichere Reste finden sich in verschiedenen Schichten, die ältesten bisher bekannten im Perm (Ulvaceen) und in der Kreide (Confervaceen). Jedoch lässt sich aus diesen unbedeutenden Resten kein Schluss auf die paläontologische Entwickelung der Gruppe ziehen. Von allen echten Pflanzen stehen die Archephyten den Protisten, und namentlich den Flagellaten und Protoplasten am nächsten. Vielleicht ist dieser Stamm auch, gleich mehreren Protisten-Stämmen, ein Aggregat von mehreren selbstständigen Phylen. Wir theilen den Archephyten-Stamm in fünf Ordnungen, die jedoch schwer zu trennen sind und vielfach zusammenhängen.

Erste Ordnung der Archephyten:

Codiolaceae, H. Einsiedler-Algen.

Codiolaceen nennen wir die einfachsten und unvollkommensten monoplastiden Archephyten (Codiolum, Hydrocytium, Protococcus, Ophiocytium etc.). Die Phylogenie dieser Ausgangsgruppe ist ganz unbekannt. Es gehören hierher ausschliesslich monocytode und cinzellige Algen.

\section{Zweite Ordnung der Archephyten:}

Desmidiacoae. Fellen-Algeu.

Die Ordnung der Desmidiaceen umfasst die in ausgezeichneter Form entwickelten monoplastiden oder zu charakteristischen polyplastiplen Synusieen (Ketten) verbundenen Algen, welche sich gleich den Zygnemaceen durch Conjugation fortpflanzen. Es gehören hierher die bekannten Genera Closterium, Micrasterias, Euastrum, Staurastrum etc. Ihre Phylogenie ist ganz unbekannt. Wahrscheinlich stammen sie von Codiolaceen ab.

\section{Dritte Ordnung der Archephyten: Nostochaceae. Gallert-Algen.}

In dieser Ordnung finden sich, wie in der der Codiolaceen, viele äusserst einfache und unvollkommene Algen, welche vielleicht zum Theil Ausgangspunkte für höhere Gruppen abgeben. Sie kann in die drei Familien der Palmellaceen (Palmella, Cuccochloris), Spermosireen (Nostoc, Spermosira) und Hydrureen (Hydrurus, Hydrococcus) gespalten werden. Auch von diesen Ordnungen ist die Phylogenie ganz unbelkannt. Sie sind vielleicht theilweis auch Voreltern höherer Pflanzengruppen.

Hackel, Generelle Morphologie, II. 
XXXIV Systematische Einleitung in die Entwickelungsgeschichte.

Vierte Ordnung der Archephyten:

Confervaceae. Faden-Algen.

Die Ordnung der Confervaceen ist aus den Unter-Ordnumgen der Oscillatorieen (Oscillaria, Lingbya, Rivuluria), der Ectocarpeen (Myxunema, Conferua, Ectocarpus) und der Zy gnemaceen (Zygnema, Spyrogyra etc.) zusammengesetzt. Die Algen dieser Ordnung sind zum Theil schon höher entwickelt, als die rorigen; doch ist auch ihre Phylogenie uns ganz unbekannt. Einige Arten Conferviles sind in der Kreide fossil gefunden, einige andere tertiär.

\section{Fïnfte Ordnung der Archephyten:}

Ulvaceae. Schlauch-Algen.

Auch von dieser Algengruppe ist leider die Phylogenie fast ganz unbekannt. Caulerpiles Bronni findet sich fossil in der Steiukohle; viele andere Arten derselben Gattung im Perm. Diese Ordnung ist die am höchsten entwickelte und vollkommenste Gruppe unter den echten Archephyten. Es gehören hierher die drei Unterordnungen der Siphoneen (Faucheriu, Bryopsis, Caulerpa, Codium), der Corallineen (Corallina, Acelahularia) und der echten Ulven oder Porphyraceen (Ulva, Porphyra). Sowohl die Corallineęn als die Siphoneen gehörer vielleicht selbstständigen Phylen an.

\section{Zweiter Stamm des Pflanzenreichs: \\ Florideac. Roth-Algen.}

Die schöne und interessante Algengruppe der Florideen oder Pyrrhophyten, meistens roth gefärhter Meerpflanzen, ist durch so vicle Figenthümlichkeiten im Bau, in der embryologischen Entwickelung und in den physiologischen Ernährungs - und Fortpflanzung's-Verhältnissen ausgezeichnet, dass man dieselbe wohl als einen besonderen selbstständigen Stamm des Pflanzenreichs betrachten kann, der sich aus einer eigenen autogonen $\mathbf{1}$ [oneren-Form entwickelt hat; doch hängrt derselbe vielleicht an seiner Wurzel mit anderen Algenstämmen zusammen und würde daun wahrscheinlich von der Archephyten-Gruppe sich abgezweigt haben. Leider ist auch ron dieser Algengruppe die Phylogenie sehr unbekaunt. Die weichen, zarten und sehr leicht zerstörbareu Körper dieser Seepflanzen sind nur selten der fossilen Erhaltung fähig. Doch finden sich Abdrücke von ziemlich vielen Arten in verschiedenen Schichten vom Deron an aufwärts, vorzüglich im unteren Jụra, seltener in der Kohle.

Erste Ordnung der Florideen:

Ceramiaceae. Horn-Tonge.

Von den beiden Ordnungeu, welehe wir in der Florideen-Classe unterscheiden, umfasst die artenreiche Gruppe der Ceramiaceen die kleineren und unvollkommnereu Formen: Nemastoma, Ceramium, Callithamnion, Chondrus etc. Ihre Phylogenie ist sehr unbekannt. Viele Arten Chondrites finden sich im Devon, Carbon und Jura; viele Arten Halymenites im Jura. Unter ihnen finden sich wahrscheinlich die Voreltern der Sphaerococcaceen. 


\author{
Zweite Ordnung der Florideen: \\ Sphaerococcacea. Purpur-Tange.
}

Diese Ordnung umfasst die ausgebildeteren und vollkommneren Formen der Florideen-Classe, die Polysiphonia, Sphaerococcus, Rhodomela, Delesseria, Plocamium etc. Auch ihre Phylogenie ist wieder sehr unbekannt. Viele Arten von Sphaervcocciles finden sich im Devon, Jura und Tertiär; mehrere Arten Rhodomeliles in der Kohle und Kreide, und Delesseriles im Eocen.

\title{
Dritter Stamm des Pflanzenreichs: Fucoideac. Braun-Algen.
}

(Synonym: Hucaceae. Phyceae. Phycoda.)

Von dieser umfangreichen und vielgestaltigen Algengruppe, welche die grössten und vollkommensten aller marinen Cryptogamen umfasst, gilt dasselbe, was wir im Allgemeinen von der Florideen-Gruppe gesagt haben. Auch diese Gruppe zeichnet sich durch ihre anatomischen und physiologischen Verhältnisse so sehr vor den übrigen Algen, und namentlich einerseits vor den Florideen, andererseits vor den Archephyten aus, dass man sie wohl als ein besonderes Phylum auffassen kann. Andererseits ist es leicht möglich, dass auch sie sich aus den Archephyten hervorgebildet hat, wie es auf Taf. II angedeutet ist. Leider ist uns auch von dieser wichtigen Pflanzengruppe die Phylogenie höchst unbekannt. Die weichen, schleimigen und leicht zerstörbaren Körper dieser Seepflanzen sind trotz ihrer sehr bedeutenden Grösse nur sehr selten der fossilen Erhaltung fähig. Einzelne Abdrücke finden sich in verschiedenen Schichten, von der Kohle an, besonders im Jura, sind jedoch ohne Bedeutung.

\section{Erste Ordnung der Fucoideen:}

Chordariaceae. Strick-Tange.

Diese Ordnung umfasst die niedersten Fucoideen, Chordaria, Haliseris, Asperococcus, Eucoelium etc. Ihre Phylogenie ist sehr unbekannt. Einzelno Arten von Haliseriles und Eucoelites finden sich im unteren Jura.

\section{Zweite Ordnung der Fucoiden: \\ Laminariaceae. Blatt-Tunge.}

Auch von dieser Ordnung, zu welcher die colossalen Blatt-Tange Laminaria, Haligenia, Alaria etc. gehören, ist die Phylogenie fast ganz unbekannt. Einzelne Arten von Laminarites enthält das Carbon und Tertiär.

Dritte Ordnung der Fucoiden:

Sargassaceae. Baum-Tange.

Die Ordnung der Sargassaceen, welche die grössten und vollkommensten von allen Algen enthält (Fucus, Halidrys, Cystoseira, Sargassum etc.), giebt uns leider durch ihre wenigen und unvollständigen fossilen Reste eben so wenig befriedigende Aufschlüsse iber ihre phyletische Entwickelung, als alle yorhergehenden Gruppen. Einzelne Arien von Laminariles sind fossil in der Steinkohle und im Tertiär gefunden worden. 
XXXVI Systematische Einleitung in die Entwickelungsgeschichte.

Vierter Stamm des Pflanzenreichs:

Characeae. Armleuchter-Pflanzen.

(Synonym: Gyrophyceae. Charaphyta. Spral-Tange.)

Diese merkwürdige Pflanzengruppe besteht nur aus den beiden Gattungen Nitella und Chara. Ihre Phylogenie ist ganz unbekannt. Die weichen und leicht zerstörbaren Körper dieser Wasserpflanzen sind nur selten der fossilen Erhaltung fähig. Abdrücke einzelner Arten finden sich im TertiärGebirge, vom Eocen an. Die Früchte finden sich öfter in eocenen und miocenen Süsswasser - Schichten und sind als Gyrogoniten beschrieben worden. Doch kann man aus diesen unbedeutenden Resten keinerlei Schlüsse auf ihre paläontologische Entwickelung zichen. Die ganz eigenthümlichen anatomischen, ontogenetischen und physiologischen Verhältnisse der Characeen berechtigen zu der Annahme, dass sie einem selbstständigen Phylum angehören, welches sich ans einem eigenen autogonen Moner entwickelt hat. Doch ist es andererseits auch leicht möglich, dass sich die Characeen von den Archephyten, sei es von den Codiolaceen, oder von den Confervaceen oder von einer andern, vielleicht ausgestorbenen und uns nicht bekannten Gruppe abgezweigt haben, wie es auf Taf. II angedeutet ist.

\section{Fünfter Stamm des Pflanzenreichs: Inophyta. Faser-P/lanzen.}

Als Inophyta (Faser-Pflanzen) oder Nematophyta (Faden-Pflanzen) fassen wir hier die beiden nächstverwandten Classen der Pilze (Fungi) und Flechten (Lichenes) zusammen, welche höchst wahrscheinlich gemeinsamen Ursprungs sind. Auch von ihnen ist leider die Phylogenie ganz unbekannt: Die weichen und leicht zerstörbaren Körper dieser Pflanzen, vorzüglich der Pilze, sind nur selten der Erhaltung fähig, sondern sehr rasch vergänglich. Viele leben als Parasiten, viele andere als Baumbewohner etc. und gelangen deshalb selten in Verhältnisse, welche der fossilen Cónservation günstig sind. Einzelne, sehr unbedentende und zum Theil unsichere Reste sind in verschiedenen Formationen gefunden worden, die ältesten in der Steinkohle. Die Inophyten müssen entweder aus den Archephyten sich entwickelt haben, oder aus einem oder mehreren autogonen Moneren. Im letzteren Falle müssten sie eine oder mehrere besondere Phylen bilden.

\section{Erste Classe der Nematophyten:}

\section{Fungi. Pilze.}

Die paläontologische Entwickelung der Pilze ist ganz unbekannt. Wenige unbedeutende Reste von Hyphomyceten (Rhizomorphites, Nyctomyces) finden sich im Tertiär, von Gasteromyceten (Excipulites in der Steinkohle, Xylomiles im Jura, Hysleristes im Tertiär), sowie von Pyrenomyceten (Sphaeria) im Tertiär. Auch ein Hymenomycet (Polyporites) wird aus der Steinkohle angegeben. Aus allen diesen unbedeutenden Resten lässt sich kein Ergebniss für die Phylogenie der Pilz̧e gewinnen.

\section{7weite Classe der Nematophyten:}

Lichenes. Flechten.

Auch die paläontologische Entwickelung der Flechten ist uns ebenso wie diejenige der Pilze gänzlich unbekannt. In kenntlichem fossilen Zustande 
finden sich nur sehr wenige, ganz unbedeutende und zum Theil auch noch zweifelhafte Reste: Ramallinites im Jura und Verrucariles im Tertiär. Wahrscheinlich haben sich die Flechten, vereinigt mit den Pilzen, aus Archephyten entwickelt.

\section{Sechster Stamm des Pflanzenreichs: Cormophyta. Stockpflunzen.}

Den sechsten und letzten Stamm des Pflanzenreichs bildet die umfangreiche Abtheilung der Cormophyta. Wir fassen hier die Gruppe in demselben Umfange auf', wie sic Unger und Endlicher aufgestellt haben und stellen darin also die sämmtlichen Phanerogamen oder Anthophyten mit den höheren Cryptogamen zusammen, und zwar mit den sämmtlichen moosartigen (Bryophyten) und farrnartigen (Pteridophyten). Es gehören mithin zu den Cormophyten sämmtliche Pflanzen mit Ausnahme der Thallophyten, wenn man unter diesem Ausdruck die fünf vorhergehenden Stämme zusammenfasst.

Dass alle Pflanzen, welche wir in dem Phylum der Cormophyten zusammenfassen, durch das Band wirklicher Blutsverwandtschaft zusammenhängen, scheint uns durch die vergleichende Anatomie, Ontogenie und Phylogenie dieser Gruppe auf das Bündigste bewiesen zu werden. Zunächst ist es klar, dass sämmtliche Phanerogamen (trotz aller Mannichfaltigkeit im Einzelnen) dennoch durch die wesentlichsten Grundzüge ihres Baues und ihrer Entwickelung so innig verbunden sind, dass ihre gemeinsame Abstammung nicht geleugnet werden kann. Ebenso klar ist dies andererseits für die Pteridophyten und Bryophyten, von denen ein Theil der letzteren permanente Prothallium-Formen der ersteren repräsentirt. Die unmittelbare Verbindung der angiospermen Phanerogamen mit den Pteridophyten wird durch die Gymnospermen hergestellt, von denen die Coniferen den Lepidophyten nächst verwandt sind.

Während die Paläontologie uns für die Phylogenie aller vorhergehenden Stämme so gut wie gar keine empirischen Grundlagen lieferte, so bietet sie uns dagegen für die Construction des Cormophyten-Stammbaums die werthvollsten Materialien. Wenn man dieselben unbefangen und reiflich in Erwägung zieht und mit den Daten der vergleichenden Anatomie und Embryologie der Cormophyten zusammenstellt, so wird man, glauben wir, nicht leicht zu einem wesentlich anderen Resultate hinsichtlich ihrer Genealogie kommen können, als ey von uns auf Tafel II entworfen worden ist.

Hiernach haben sich also zunächst aus den Moosen die Pteridophyten entwickelt, deren Lepidophyton-Zweig den gymnospermen Anthophyten den Ursprung gegeben hat. Aus diesen haben sich weiterhin die Angiospermen entwickelt, welche sich wahrscheinlich schon frühe in die beiden Gruppen der Monocotylen und Dicotylen differenzirt haben. Von letzteren sind offenbar zuerst die Monochlamydeen entstanden, aus denen sich erst später die Polypetalen, und aus diesen zuletzt die Gamopetalen hervorgebildet haben.

Sowcit lässt sich der Cormophyten-Stammbaum mit befriedigender Sicherheit herstellen. Es entsteht nun aber weiter die Frage, welche Pflanzenformen zwischen den Moosen, als den niedersten unzweifelhaften Gliedern des Stammes, und zwischen ihren autogonen Stammformen liegen. Am nächstliegenden erscheint es es hier, auf die Thallophyten, und zwar entweder zunächst auf die Flechten, oder unmittelbar auf die Archephyten zurückzugehen, auf welche das Prothallium der Moose uns hinfuhrt. Wir gelangen also auch auf diesem Wege zu der Annahme, welche wir aus vielen 
XXXVIII Systematische Einleitung in die Entwickelungsgeschichte.

Gründen für die Genealogie des Pflanzenreichs als die wahrscheinlichste ansehen: dass die sechs von uns provisorisch aufgestellten Phylen des Pflanzenreichs an ihrer Wurzel zusammenhängen und dass das ganze Pflanzenreich ein einziges zusammenhängendes Phylum darstellt, wie Taf. II es andeutet.

\author{
Erster Unterstamm der Cormophyten: \\ Prothallophyta, H. Vorkeim-P/lanzen. \\ (Synonym: Cryptogamae phyllogonicae. Blatt-Cryptogamen.)
}

Die Abtheilung der Prothallophyten umfasst die moosartigen (Muscinae) und farrnartigen Cryptogamen (Filicinae) im weiteren Sinne, also sämmtliche zur Differenzirung von Stengel und Blatt gelangte Cryptogamen. Sie können daher auch Blatt-Cryptogamen (Phyllogonicac) heissen, im Gegensatz zu den die fünf vorhergehenden Phylen bildenden Thallus-Cryptogamen (T'/hallogomicae). Die Ontogenie sämmtlicher hierher gehörigen Pflanzen, soweit sie bekannt ist, verläuft mit echtem Generationswechsel (Metagenesis productiva). Die erste Generation (Prothallium) zeigt noch den einfachen Zustand der alten Voreltern der Classe, ein algen- oder flechtenähnliches Prothallium, ohne Differenzirung von Stengel und Blättern. Letżtere tritt erst in der zweiten höher entwickelten Generation auf. Die Entwickelung des Prothalliums beweist theils die gemeinsame Abstammung aller von uns hier vereinigten Pflanzen, theils ihren Ursprung aus niederen Thallophyten, welche vielleicht den vorigen Stämmen (Archephyten, Nematophyten) angehören, in welchem Falle diese Stämme zu verschmelzen sind (vgl. Cap. XXV). Das Prothallium der Moose weist auf Archephyten, das Prothallium der Farrne auf Lebermoose und weiterhin auf Flechten zurück. Leider kann uns die Paläontologie für diese wichtige Frage keine Anhaltspunkte liefern, während sie dagegen die weitere Phylogenie der Pteridophyten in sehr bofriedigender Weise erläutert.

\title{
Erster Cladus der Prothallophyten:
}

Bryophyta. Moose.

(Synonym: Muscinae. Musci (sensu ampliori). Bryomorpha).

Die Phylogenie der Moose ist ganz unbekannt, soweit sie sich auf fossile Reste stützt. Dagegen lassen Anatomie und Ontogenie derselben kei-

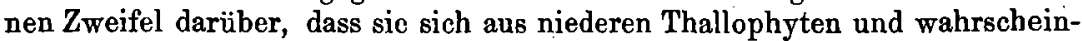
lich aus confervenartigen Archephyten entwickelt haben. Der deutlichen Erhaltung in fossilem Zustande sind die sehr zarten und zerstörbaren, auch meist sehr kleinen Pflanzenkörper nur sehr selten fähig. Auch ihr Wohnort begünstigt dieselbe nicht. Einzelne unbedeutende Reste sind in verschiedenen Tertiär-Gebilden gefunden worden.

\section{Erste Classe der Bryophyten:}

\section{Thallobrya. Leberinoose.}

(Synonym: Hepatobrya. Hepaticae. Musci hepatici. Thallusmoose.)

Die Lebermoose vermitteln in ausgezeichneter Weise den Uebergang von den Thallophyten zu den Cormophyten, da die Differenzirung von Stengel und Blatt aus einem nicht differenzirten Thallus innerhalb dieser Classe vor sich geht. Wir können daraus auf die phyletische Abstammung der Cormo- 
phyten von einfachen Thallophyten schliessen. Die fossilen Reste dieser Classe sind nur sehr unbedeutend; die ältesten finden sich tertiär: mehrere Arten von Jungermannites (transversus, contortus, Neesianus) in eocenem Bernstein; Marchantiles sczamensis ebenfalls im Eocen.

Zweite Classe der Bryophyten:

Phyllobrya. Laubmoose.

(Synonym: Musci (sensu strictiori). Musci frondosi: Blattmoose.)

Die Laubmoose haben bereits sämmtlich wohl differenzirte Stengel- und Blatt-Orgañe, und sind demnach rollkommene Uebergangsformen von don Thallobryen zu den Pteridophyten, und insbesondere zu den Lepidophyten. Die fossilen Reste der Laubmoose sind ebenso wie die der Lebermoose nur von sehr geringer Bedeutung. Ihre Phylogenie ist fast ganz unbekannt. Die ältesten bekaunten Reste finden sich im unteren Tortiär: mehrere Arten von Musciles (apiculatus, confertus, hirsutissimus) in eocenen Bernstein; ferner Muscites Tournalii im Miocen ron Armissan und Muscites Schimperi in Pliocen von Parschlug.

\section{Zweiter Cladus der Prothallophyten: Pteridophyta, H. Farrn-Pflanzeu. \\ (Synonym: Filicinae. Cryptogamae vasculares.)}

Die paläontologische Entwickelung dieser Gruppe ist ziemlich vollständig bekannt und von der grössten Bedeutung. Diese Pflanzengruppe bildete in dem ganzen palïolithischen Zeitalter den bei weitem überwiegenden Bestandtheil der gesammten Landregetation, so dass man dieses Zeitalter eben so gut, wie das Zeitalter der Fische, auch das Zeitalter der Farrn-Pflanzen (Filicinen oder Pteridophyten) nennen könnte. Die Angiospermen (Monocotylen und Dicotylen), welche gegenwärtig ungefähr $1 / 5$ der Artensumme des Pflanzenreichs ausmachen, fehiten damals noch völlig und neben den Pteridophyten kamen von höheren und grösseren Landpflanzen nur noch Gymnospermen vor. Nach einer Angabe von Bronn betrug die bekannte Arten-Zahl sämmtlicher paläolithischen Pflanzen im Jahre 1855 im Ganzen ungefähr Eintausend. Darunter befanden sich 872 Arten von Pteridophyten, 77 Arten von Gymnospermen, 40 Arten von Thallophyten (grösstentheils Florideen, Fucoiden und Ulvaceen) und gegen 20 unsichere Cormophyten (wohl irrthümlich für Monocotylen gehalten). Die gesammten Pteridophyten, welche gegenwärtig noch leben, erscheinen nur als die letzten unbedeutenden Ausläufer jener ausserordentlich manuichfaltig und vollkommen entwickelten paläolithischen Filicinen-Flora. Letztere verhält sich zu ersteren ungefăhr ebenso, wie die Ganoiden-Fauna der Primärzeit zur jetzigen. Die echten Farrne sowohl (Filices), als die Schafthalme (Equisetaceen) und Bärlappe (T/ycopodiaceen) enthielten damals weit zahlreichere, mannichfaltigere und grossartigere Repräsentanten, als gegenwärtig, und ausserdem hatte sich aus jenen Gruppen noch eine Anzahl von eigenthümlichen Pflanzen-Ordnungen abgezweigt, welche entweder schon gegen Ende der Primärzeit oder wenig später völlig zu Grunde gingen, so namentlich die Calamiten, Asterophylliten, Lepidodendren und Sigillarien. Sehr viele von diesen Pteridophyten waren in Gestalt mächtiger Bäume entwickelt, welche, grossentheils blattlos oder uur mit ganz kleinen und rudimentären Blättern bedeckt, der paläozoischen Flora ein höchst eigenthümliches Aussehen müssen verliehen haben. 


\section{Systematische Einlöitung in die Entwickelungsgeschichte.}

Die Stämme dieser baumartigen Filicinen sind es vorzüglich, welche díe mächtigen Kohlenflötze der Steinkohlen-Formation zusammensetzen. Neben diesen oft sehr schön erhaltenen Stämmen finden sich noch die Blätter (Wedel) der Farrne, sowie die Friichte anderer Filicinen sehr zahlreich und schön erhalten vor. Zweifelsohne entwickelten sich sämmtliche Pteridophyten aus niederen Cryptogamen, zunächst wahrscheinlich aus Bryophyten, vielleicht auch direct aus niederen Thallophyten. Die erste Generation derselben, welche ein thallusförmiges Prothallium darstellt, beweist dies deutlich ${ }^{1}$ ). Diese Entwickelung fand höchst wahrscheinlich in der langen Antedevon-Zeit statt, da in den silurischen Schichten die Pteridophyten, wie alle Landpflanzen, noch völlig fehlen, während in den devonischen Schichten sämmtliche Gruppen der Filicinen bereits vertreten sind; doch sind dieselben im Devon noch spärlich gegenüber den colossalen Massen, welche sie in der Steinkohlenzeit bilden. Diejenigen Ordnungen der Filicinen, welche am meisten von den jetzt lebenden abweichen, die Asterophylliten, Lepidodendren und Sigillarien, scheinen unmittelbar nach der Steinkohlenzeit (in der Anteperm-Zeit) ausgestorben zu sein, da sie sich in späteren Schichten nicht mehr finden. Die Calamiten reichen noch bis zum Keuper. Sämmtliche Pteridophyten erreichen in der Steinkohlen-Zeit den Gipfel ihrer Entwickelung. Nur die Classe der Rhizocarpeen ist hiervon ausgeschlossen; doch ist deren Phylogenie überhaupt nur höchst unvollständig bekannt.

Erste Classe der Pteridophyten:

Calamophyta, H. Hohlschaft-Pflanzen.

Die Phylogenie dieser Classe, in welcher wir die Equisetaceen, Calamiteen und Asterophylliteen vereinigen, ist durch zahlreiche und sehr merkwürdige paläolithische Reste bekannt. Sie entwickelte sich wahrscheinlich in der Antedevon-Zeit entweder aus moosartigen Pflanzen oder aus niederen Cryptogamen (Thallophyten), und erreichte in der Steinkohlen-Zeit die Höhe ihrer Bildung. Die Asterophylliten starben bald nachher aus, während sich die Calamiten bis zum Keuper, und die Equisetaceen in verkümmerten Zwergformen bis heute fortsetzen. Alle drei Ordnungen scheinen nach dem Bau des hohlen gegliederten und gerippten Stengels, und der quirlförmig die Internodien umstehenden Aeste und Blätter nächstverwandt zu sein. Doch werden die Asterophylliten von Anderen zu den Gymnospermen gezählt.

\section{Erste Ordnung der Calamophyten: \\ Equisetaceae. Schaflhalme.}

Die heutigen Equisetaceen erscheinen nur als die dürftigen, kümmerlich erhaltenen Reste der reichen Calamophyten-Flora, welche in der paläolithischen Zeit sich entwickelt hatte. Am nächsten verwandt diesen degenerirten Epigonen sind die mächtigen, baumartig entwickelten Equisetiles, von denen sich zahlreiche Arten in fossilem Zustande erhalten haben. Die ältèsten Arten finden sich im Devon ( $E$. radiatus, Brongniarti), zahlreichere in der Steinkohle, die meisten im Keuper der Trias, einzelne auch noch im Jura bis zum Wealden hinauf. Einige Arten des echten Equisetum, welches nur einen schwachen Ausläufer der Equisetites darstellt, finden sich tertiär.

1) Specielle Schlüsse aus dem Generations-Wechsel der Pteridophyten auf ihre Phylogenie sind übrigens sehr schwierig, und nur mit grösster Vorsicht anzustellen, wie dies z. B. auch von der Metamorphose der Insectev gilt (vergl. unten). 


\section{Zweite Ordnung der Calamophyten:}

Calamiteae. Riesenhalme.

An die Equisetaceen schliessen sich als ihre nächsten Verwandten die Calamites an, meist mächtige starke Stämme, den Equisetites nahe stehend, gegen 50 Fuss hoch. Die ältesten Calamites-Arten finden sich im Devon, die bei weitem grösste Zahl in der Steinkohle, aber auch noch viele Arten im Perm und in der Trias, woselbst sie mit dem Keuper ganz oder grösstentheils aufhören. Einige setzen sich vielleicht auch bis in den unteren Jura hinein fort.

\section{Dritte Ordnung der Calamophyten: \\ Asterophyllitea. Sternblatthalme.}

Diese ganz eigenthümliche Pflanzen-Ordnung ist von den Botanikern an sehr verschiedene Stellen des Systems versetzt worden. Vielleicht gehört sie schon zu den Gymnospermen (in die Nähe der Phyllocladus unter den Coniferen), vielleicht auch bildet sie eine $Z_{\text {wischenform zwischen Equisetaceen }}$ und Coniferen; höchst wahrscheinlich sind sie jedoch den Calamiten und Equisetaceèn nächst verwandt, und stellen einen eigenthümlichen Zweig der Calamophyten-Classe dar. Die Asterophylliten sind ausschliesslich auf die Primär-Zeit beschränkt; sie treten zuerst mit wenigen Arten im Devon auf (Asterophyllites pygmaeus und Römeri) und erreichen eine sehr hohe Entwickelung in der Steinkohle, mit welcher sie erlöschen (Asterophyllites, Volkmannia, Sphenophyllum, Annularia, Vertebraria und mehrere andere Gattungen mit sehr zahlreichen Arten).

\section{Zweite Classe der Pteridophyten:}

Filices. Farrne.

\section{(Synonym: Geopterides. Filicinae verae.)}

Die echten Farrne oder Farrnkräuter beginnen mit wenigen Arten im Devon und erreichen eine ausserordentlich massenhafte und hohe Entwickelung in der Steinkohlen-Periode, in welcher sie vielleicht den überwiegend grösseren Bestandtheil vieler Wälder bildeten. Die Form der baumartigen Farrnkräuter erreichte hier ihre höchste Entwickelung, um nachher abżuehmen, so dass die jetzt lebenden Baumfarrne nur als einzelne dürftige Reste jener reichen und vielgestaltigen paläolithischen Farrnwälder gelten können. Sowohl Stämme als Blätter (Wedel) sind massenhaft erhalten, aber meist nur unsicher auf einander zu beziehen. Die arteureichsten Gattungen waren Sphenopteris, Hymenophyllites, Neuropteris, Odontopteris, Cyclopteris, Cyatheiles, Alelhopteris, Pecopteris etc. Zu den ältesten devonischen gehören viele Arten Cyclopleris. Im Perm sowohl als in der Trias (im bunten Sandstein und Keuper) sind die Baumfarrne noch stark entwickelt, nehmen aber dann sehr rasch ab.

Dritte Classe der Pteridophyten:

Rhizocarpeae. Wasser-Farrne.

(Synonym: Hydropterides. Marsiteaceae. Wurzelfriichter.)

Die Phylogenie dieser Classe, welche gegenwärtig die Gattungen Marsilea, Piluluria, lsoetes etc. umfasst, ist sehr wenig bekannt, viel weniger als diejeuige der anderen Filicinen. Als meistens zarte und kleine Süsswas- 


\section{Systematische Einleitung in die Entwickelungsgeschichte.}

ser-Pflanzen sind sie zur fossilen Erhaltung schlecht geeignet. In verschiedenen Schichten des Jura, vom Lias an, werden mehrere Arten von Buiera, Isoctiles und Pilulurites angegebeu. Wahrscheinlich haben sie sich aus gemeinsamer Wurzel mit der folgenden Ordnung entwickelt, und sind als Lepidophyten zu betrachten, welche sich an das Wasserleben angepasst haben.

Vierte Classe der Pteridophyten:

Lepidophyta, H. Schuppen-Pflanzen.

Die Phylogenie dieser Classe, in welcher wir die Lycopodiaceen, Lepidodendren und Sigillarien (nebst Stigmarien) vereinigen, ist durch zahlreiche, sehr wichtige und merkw ürdige fossile Reste bekannt. Sie entwickelte sich wahrscheinlich gleich der vorigen (und mit ihr vereinigt) in der AntedevonZeit aus niederen Cryptogamen, vielleicht zunächst aus Moosen, und erreichte ihre höchste Entwickelung in der Steinkohlen-Zeit, nach welcher ihre hervorragendsten Vertreter, die mächtigen Lepidodendren und Sigillarien, ausstarben. Die heutigen Lycopodiaceen sind nur schwache Reste dieser wichtigen und eigenthümlichen Pflanzenform, welche in der Steinkohlen-Zeit nebst den Farrnen vorzugsweise die sumpfigen Wälder bildete. Die Lepidophyten, und zwar vermuthlich die Lycopodiaceen, sind aller Wahrscheinlichkeit nach diejenigen Pteridophyten, aus denen sich die Gymnospermen und somit alle Anthophyten oder Phanerogamen hervorgebildet haben.

Erste Orduung der Lepidophyten:

Lycopodiaceae. pürlappe.

Die Lycopodiaceen begimen im Devon mit zahlreichen Arten von Knorria und mit einzelnen Arten von Lycopodites, welche Gattung durch zahlreiche Arten in der Steinkohle, durch einzelne auch noch im Keuper und im unteren Jura vertreten ist. Im Lias kommen mehrere Arten von Psilofites vor. In mehreren Beziehunger scheinen diese und andere fossile Lycopodiaceen näher den Lepidodendren und zum Theil selbst den Coniferen, als deu heutigen Lycopodiaceen gestanden zu haben, und stellen die wahrscheinlichen Stammelteru der Gymnospermen dar.

\section{Zweite Ordnung der Lepidophyten: \\ Lepidodendraceae. Schuppenbüume.}

Diese wichtige Ordnung, welche in der Steinkohle mit Stämmen von mehr als funfzig Fuss Höhe mächtige und sehr eigenthümliche Wälder bildete, beginnt mit mehreren Arten von Sagenaria und Aspidiaria in Devon, und erreicht ihre höchste Ausbildung in der Steinkohle, mit welcher sie aufhört. Die Gattungen Lepidodendron, Ulodendron, Sagenaria, Bergeria etc. vertreten sie durch zahlreiche Arten, welche zum Theil sich den Coniferen eng anzuschliessen scheinen. Vielleicht gehören hierher die alten Stanmeltern der Coniferen.

Dritte Ordnung der Lepidophyten:

Sigillariaceae. Siegelbäume.

Auch diese wichtige Orduung beginnt gleich der vorigen mit einzelnen Arten im Devon, erreicht dann in der Steinkohle eine äusserst mächtige Entwickelung, und hört mit dieser auf. Die zahlreichsten Arten enthält die 
Gattung Sigillaria, von welcher wahrscheinlich die als besondere Gattung betrachtete Stigmarin nur die Wurzeln bildete. Die Sigillarien bildeten in der Steinkohlen-Zeit an vielen Orten der Erde fast allein ungeheure Wälder, und ihre Stämme setzen oft fast allein ganze Kohlenflötze zusammen. Von Anderen werden die Sigillarien bereits zu den Gymnospermen gerechuet, mit denen sie jedenfalls, gleich den Lepidodendren, sehr nah verwandt sind. $\mathrm{Ob}$ aber die Gymnospermen sich unmittelbar aus den Sigillarien, oder aus den Lepidodendren, oder aus den Lycopodiaceen, oder aus einer gemeinsamen, vielleicht nicht einmal unmittelbar zu den Lepidophyten gehörigen Wurzelform entwickelten, muss dahingestellt bleiben.

\section{Zweiter Unterstamm der Cormophyten: Phanerogamae. Blüthen-Pflunzen. \\ (S y nonym: Anthophyta. Cotyledoneae.)'}

Die Phylogenie der Phanerogamen oder cotyledonen Cormophyten lässt sich aus paläontologischen, embryologischen und anatomischen Daten mit Sicherheit dahin feststellen, dass offenbar alle Phanerogamen sich aus den Gefäss - Cryptogamen oder Pteridophyten hervorgebildet haben. Doch gilt dies zunächst wohl nur ron der Abtheilung der Gymnospermen (Cycadeen und Coniferen), welche sich in der paläolithischen Zeit, wie es scheint, unmittelbar aus Lepidophyten entwickelt haben. Ob dieser Uebergang gewisser Lepidophyten in die niedersten Gymnospermen schon in der antedevonischen oder in der devonischen, oder erst in der antecarbonischen Zeit stattfand, ist noch unsicher. In der Kohlenzeit waren jedenfalls Gymnospermen schon reichlich entwickelt. Dagegen haben sich die Angiospermen wahrscheinlich erst sehr viel später, nämlich in der Antecreta-Zeit, entwickelt, da sichere Reste von ihnen erst in den Kreide-Schichten auftreten. Zwar werden einzelne Monocotyledonen-Reste schon in der Kohlen-Zeit und von da an aufwärts bis zur Kreide angegeben. Indessen sind diese so $z$ weifelhafter Natur, dass bedeutende Paläontologen sie nicht als solche anerkannt haben. Vielmehr scheinen die ersten Angiospermen, die gemeinsamen Stammformen der Monocotyledonen und Dicotyledonen, erst nach der Jura-Zeit sich von den Gymnospermen, und zwar wahrscheinlich von den Cycadeen, abgezweigt zu haben. Jedenfalls bekräftigt die Phylogenie der Anthophyten den wichtigen Schluss, zu dem auch die Ontogenie und Anatomie führt, dass die Dicotyledonen viel näher mit den Monocotyledonen, als mit den Gymnospermen verwandt sind, und dass es. nicht richtig ist, die letzteren, wie noch vielfach jetzt geschieht, mit den Dicotyledonen zu vereinigen und den Monocotyledonen gegenüberzustellen.

Erster Cladus der Phanerogamen:

G ymnospermae. Nachtsamen-Pflinzen.

Die paläontologische Entwickelung des Gymnospermen-Cladus, welcher die beiden Classen der Cycadeen und Coniferen umfasst, ist durch zahlreiche fossile Reste bis zur.Steinkohlen-Zeit hinauf festgestellt. In den SteinkohlenSchichten treten bereits die beiden durch ihre Holzstructur und ihren Fruchtbau leicht kenntlichen Classen in deutlich erkenntbaren Resten auf, und es würde demnach zu schliessen sein, dass dieselben in der Antecarbon-Zeit sich von den Pteridophyten abgezweigt habeu. Neuerdings scheinen indessen auch im Devon bereits Spuren derselben erkennbar geworden zu sein, und 


\section{Systemattsehe Einleitung in die Entwickelungsgeschichte.}

dann würde man den Zeitpunkt ihrer Entwickelung in der Deron - oder Antedevon-Zeit suchen müssen. Diejenige Filicinen-Gruppe, welche wahrscheinlich als die nächste Stammform der Gymnospermen betrachtet werden muss, sind die Lepidophyten, unter denen sowohl die Lepidodendren und die Lycopodiaceen, als auch die Sigillarien bereits vielfache Anklänge an die Gymnospermen und namentlich an die Coniferen zeigen. Andererseits finden wir auch bei den Asterophylliten mehrfache Hinweise auf die Coniferen, und bei den echten Farrnen (Geopterides) auf die Cycadeen. Selbst die Rhizocarpeen (Hydropterides) zeigen sich den Gymnospermen nahe verwandt. Alles zusammen genommen, ist kein Zweifel daran, dass der Gymnospermen-Ast von dem Pteridophyten-Ast sich abgezweigt hat, während die Frage, welche Ordnung der letzteren hierbei am nächsten betheiligt ist, vorläufig noch offen bleibt.

\section{Erste Classe der Gymnospermen: \\ Coniferae. Nadelhölzer.}

Unzweifelhafte Nadelbäume finden sich nicht selten bereits in der Steinkohle, besonders viele Arten der den Araucarien nahe stehenden Gattung Araucariles und des diesem nahe verwandten Missadendron, sowie auch einige Arten von Piniles. Noch ältere Reste scheinen neuerlich im Devon nachgewiesen zu sein. Eine sehr bedeutende Entwickelung erreicht die Classe in dem bunten Sandstein oder dem Vogesen-Sandstein der Trias, welcher sogar als das Reich der Coniferen $x \alpha \tau^{\prime} \dot{\xi} \xi o \chi \eta^{\prime} \nu$ bezeichnet werden kann, insofern dieselben hier als der ganz überwiegende Bestandtheil der Wälder auftreten. Besonders sind es mehrere Arten der Gattungen Voltzia $(\boldsymbol{V}$. heterophylla, $\boldsymbol{V}$. acutifolia) und Haidingera oder Albertia (A. latifolia, elliptica, Braunii, speciosa), welche hier in grossen Individuen-Massen dichte Nadelwälder bildeten. In der Jura-Zeit treten die Coniferen ganz gegen die Cycadeen zurück, noch mehr in der Kreide. Doch beginnt hier bereits die Entwickelung einer zweiten mächtigen Coniferen-Flora, welche in der Tertiärzeit, besonders im Eocen und Miocen, ihre eigentliche Ausbildung erlangt. Die zahlreichen Coniferen-Arten, welche die Wialder in dieser zweiten Blüthen-Periode der Classe zusammensetzten, sind aber wesentlich verschieden von denen der ersten Blüthen-Periode. In der Steinkohle und Trias waren es vorzüglich Verwandte der Araucarien, welche jetzt vorzuggweise an das Tropenklima gebunden sind. In der Tertiärzeit dagegen überwiegen Verwandte der Abietineen (Pinites, Abietiles), Cupressineen (Cupressiniles, Juniperites, Thuites) und Taxineen (Taxiles). Vorzüglich sind die Gattungen Piniles und Cupressinites hier durch sehr zahlreiche Arten vertreten.

\section{Zweite Classe der Gymnospermen: \\ Cycadeae. Palmenfarrne.}

Die nahe anatomische und embryologische Verwandtschaft der Cycadeen und Coniferen macht es höchst wahrscheinlich, dass sie beide divergente Zweige einer gemeinsamen Gymnospermen-Form sind, welche sich vermuthlich in der devonischen oder antecarbonischen Zeit aus den Lepidophyten oder einer anderen Pteridophyten-Form entwickelt hat. Doch ist die paläontologische Entwickelung des Cycadeen-Zweiges langsamer vor sich gegangen, als die des Coniferen-Zweiges, und er erreicht auch dem entsprechend später, erst im Jura, die Höhe seiner Entwickelung. Die ältesten Cycadeen-Reste finden sich in der Steinkohle, doch nur wenige Arten von Cycaliles, Zumi- 
les und Pterophyllum. Auch in der Trias (Buntsand und Keuper) sind sie nur spärlich. Dagegen erscheinen die Cycadeen in ausserordentlichen Massen in der Jura-Zeit, in welcher sie eben so überwiegend die Wälder zusammensetzen, wie die Coniferen in der Trias, die Pteridophyten in der Steinkohle. Durch sehr zahlreiche Arten sind hier pamentlich die Genera Nilssonia, Pterophyllum und Zamites vertretell. Nach dem Jura sinken die Cycadeen rasch von dieser Höhe herab. In der Kreide finden sich nur noch wenige Arten von Plerophyllum und Zamiostrobus, im Tertiär einige Arten von Raumeria, Cycadiles und Zamiles. Die jetzt noch lebenden Cycadeen erscheinen nur als schwache und cataplastische Reste der reichen Cycadeen-Flora, welche in der Jura-Zeit dominirte. Als wenig veränderte Nachkommen der mächtigen Gymnospermen, aus denen sich zunächst die Angiospermen hervorbildeten, sind sie jedoch ron hohem Interesse.

\section{Zweiter Cladus der Phanerogamen: \\ Angiospermae. Declisamen-Pflanzen.}

Die Phylogenie der Angiospermen beweist uns in Uebereinstimmung mit ihrer Ontogenie und Anatomie, dass diese höchstentwickelte Pflanzengruppe, welche die Hauptmasse der gegenwärtigen Erdflora bildet, erst verhältnissmässig spät aus der Gymnospermen-Gruppe sich entwickelt hat. Wie schon vorher bemerkt, ist es das Wahrscheinlichste, dass die ersten Angiospermen gemeinsame Stammformen der Monocotyledonen und Dicotyledonen waren, und dass dieselben erst in der Antecreta-Zeit von dem Gymnospermen - Aste, und zwar wahrscheinlich von der Cycadeen-Gruppe, sich abzweigten. Allerdings werden in den Petrefacten-Verzeichnissen schon seit langer Zeit eine Anzahl von angeblichen Mónocoiyledonen-Resten angefïhrt, die bedeutend älter als die Kreide sein sollen, namentlich Palmenreste aus der Steinkohle. Bronn führt 1855 aus letzterer 20 Arten von Monocotyledonen an, ferner 8 Arten aus der Trias und 25 Arten aus dem Jura. Indessen ist es nach dem Zeugnisse eines der bedeutendsten Paläophytologen (A. Brongniart), welchem auch Bronn später zugestimmt hat, sehr wahrscheinlich, dass diese zweifelhaften und spärlichen Reste nicht von Monocotyledonen herrühren. Ganz sichere und unzweifelhafte, wenn auch spärliche Reste derselben finden sich erst in der Kreide, woselbst auch gleichzeitig die ersten sicheren Dicotyledonen-Reste auftreten. Wir können daraus den wichtigen Schluss ziehen, dass erst in der Antecreta-Zeit, zwischen Jura und Kreide, die Umbildung eines Gymnospermen-Zweigs in die ersten Angiospermen stattgefunden hat. Höchst wahrscheinlich waren es nicht Coniferen, sondern Cycadeen, oder diesen verwandte ausgestorbene Gymnospermen, aus deren Umbildung jene ersten Angiospermen-Formen hervorgingen, die sich dann in Monocotyledonen und Dicotyledonen differenzirten. Ebenso wie uns die Phylogenie der ganzen Angiospermen-Gruppe so einen ausgezeichneten Beweis für das Fortschritts-Gesetz liefert, so thun dies gleicherweise auch die einzelnen Hauptzweige der Gruppe und vorzüglich die verschiedenen Unterclassen der Dicotyledonen-Classe, wie wir sogleich bei dieser zeigen werden. Die Angiospermen-Flora tritt übrigens in der Kreide noch sehr zurück gegen die Gymnospermen und Pteridophyten, und erlangt erst in der Tertiär-Periode die ganz überwiegende Bedeutung, welche sie noch gegenwärtig besitzt. Ganz besonders wichtig ist es, dass die formenreichste und höchstentwickelte Pflanzengruppe der Gegenwart, diejenige der Gamopetalen, erst in der Tertiär-Zeit auftritt. Alle Dicotyledonen der Kreide-Zeit gehören entweder der Polypetalen- oder der Apetalen-Gruppe an. 
XLVI Systematische Einleitung in die Entwickelungsgeschichte.

\author{
Erste Classe der Angiospermen: \\ Monocotyledones. Einkeimblätterige.
}

(Synonym: Endogenae. Dictyogenae. Amplibrya. Monocotyleae.)

Die Phylogenie der Monocotyledonen ist weit unvollständiger bekannt, als diejenige der Dicotyledonen. Die Mehrzahl der ersteren ist ihrer Structur nach weit weniger zur Erhaltung in fossilem Zustande befähigt, als die Mehrzahl der letzteren. Ausserdem sind die Laubblätter, welche in weit höherem Maasse als die Blüthenblätter erhaltungsfähig sind, bei den Monocotyledonen höchst einförmig und weit weniger differenzirt, als bei den Dicotyledonen, so dass Abdrücke der Laubblätter von letzteren weit wichtiger und instructiver als von ersteren sind. Endlich ist auch die Differenzirung aller Theile bei den Dicotylen viel weiter als bei den Monocotylen gegangen. Unter den letzteren giebt es keine solchen natürlichen und stark divergenten Unterclassen, wie es die Gruppen der Apetalen, Polypetalen und Gamopetalen sind.

Wenn wir von den oben erwähnten, ganz zweifelhaften, angeblichen Monocotyledonen-Resten in Steinkohle, Trias und Jura absehen, so finden wir die ersten sicheren Spuren derselben in der Kreide, aber auch nur spärlich: mehrere Arten von Palmen (Flabellaria, Cocites) und von Seegras oder Zosterites (Najadeen); jm Ganzen nur etwa ein Dutzend Arten. In der Tertiär-Zeit nehmen die Monocotyledonen allmählich zu und differenziren sich, besonders in den älteren Tertiär-Schichten. Immerhin bleiben auch hier ihre Reste sehr unbedeutend gegenüber denen der Dicotyledonen. Die meisten tertiären Monocotyledonen - Reste gehören Palmen, Pandaneen und Najadeen an. Unter den Palmen ist besonders die Gattung Flabellaria sehr artenreich, unter deu Pandaneen Nipudites. Als andere Palmen werden im Eocen Pulmacites, im Miocen Phoeniciles genannt. Unter den tertiären Najadeen sind die, Genera Zosteriles, Caulinites, Ruppia, Potamogeton und andere durch mehrere Arten vertreten. Ausserdem finden sich noch spärliche Reste von Liliaceen, Typhaceen, Gräsern und einigen anderen Familien. Im Ganzen sind jedoch alle diese Spuren nur sehr unbedeutend.

\title{
Zweite Classe der Angiospermen: \\ Dicotyledones. Zweikeimblällerige. \\ (Synonym: Exogenae. Acramphibrya. Dicotylene.)
}

Die Phylogenie der Dicotyledonen ist, wie bemerkt, ungleich besser bekannt, als diejenige der Monocotyledonen, und liefert zugleich ausgezeichnete Argumente fïr das Fortschritts-Gesetz. Aus anatomischen und ontogenetischen Gründen zerfällt diese äusserst formenreiche Pflanzengruppe, welche gegenwärtig die Hauptmasse der Vegetation bildet, zunächst in zwei Hauptgruppen: Monochlamydeen und Dichlamydeen. Bei den tiefer stehenden Monochlamydeen ist, gleichwie bei den Monocotyledonen, noch nicht die Differenzirung der Blüthenhülle in Kelch und Krone eingetreten, durch welche sich die Gruppe der Dichlanydeen als die vollkommenste aller Pflanzengruppen auszeichnet. Diese letztere zerfällt selbst wieder in zwei Untergruppen, die Dialypetalen (Polypetalen) und Gamopetalen (Monopetalen). Bei ersteren bleiben die tinzelnen Blätter der Blumenkrone getrennt, während sie bei den letzteren zu einem einzigen Organ verwachsen. Nun entwickeln sich zwar im Gauzen die Polypetalen und Gamopetalen jede in ihrer Art selbstständig. Aber dennoch muss aus vielen ontogenetischen und ana- 
tomischen, besonders aus promorphologischen Gründen, die gamopetale Form als die vollkommnere gelten. Dieser Schluss wird durch die Phylogenie vollkommen bestätigt, indern die fossilen Gamopetalen ausschliesslich der TertiärZeit angehören, während die Polypetalen und ebenso die Mouochlamydeen bereits in der Kreide erscheinen. Wir können hieraus schliessen, dass die Gamopetalen, als die vollkommensten Pfianzen, sich zu allerletzt, erst in dem Zeitraume zwischen Kreide - und Tertiär-Zeit, durch Verwachsung der bis dahin getrennten Blumenblätter aus den Polypetalen entwickelt haben.

\section{Erste Unterclasse der Dicotyledonen: \\ Monochlamydeae. Kelchblüthige. \\ (Synonym: Apetala. Dicotyledonen mit homogener- Blüthenhülle.)}

Die Phylogenie dieser Unterclasse bestätigt, was übereinstimmend durch die allgemeinen Gesetze der Ontogenie und Anatomie dargethan wird, dass sie die unvollkommenste, weil am wenigsten differenzirte unter allen drei Abtheilungen der Dicotyledonen ist. Durch die mangelnde Differenzirung der Blüthenhülle, deren Blattkreise sich nicht in Kelch und Krone scheiden, stimmt sie noch vollständig mit den Monocotyledonen überein, und zweifelsohne ist es diese Abtheilung der Dicotyledonen, welche sich zuerst und unmittelbar entweder aus den Monocotyledonen selbst, oder aus einer gemeinsamen Stammform der Monocotylen und Dicotylen, während der AntecretaZeit entwickelt hat. Zwar erscheinen neben den Monochlamydeen in der Kreide-Zeit auch bereits einzelne Polypetalen, indessen nur sehr spärliche und aus verhältnissmässig tief stehenden Familien. Nur vier Arten Polypetalen sind mit einiger Sicherheit aus der Kreide bekannt, während die Anzahl der sicheren Monochlamydeen-Arten hier mehr als dreissig beträgt. Dieselben gehören grösstentheils zur Gruppe der Cupuliferen oder kätzchentragenden Laubbäume und der Salicineen oder Weiden. Die merkwürdigen Crednerien, welche in dor Kroido durch vorhältnissmässig viele Arten vertreten werden, sind von, zwcifelhafter Stellung, vielleicht Ausläufer der gemeiusamen Stammform von Monocotyledonen und Dicotyledonen.' Ebenso sind auch andere derartige zweifelhafte Dicotyledonen vielleicht Uebergangsformen. Im Tertiär-Gebirge sind die Monochlamydeen durch sehr zahlreiche (mehr als 600) Arten vertreten, welche grösstentheils unseren gewöhnlichen Waldbäumen aus den Gruppen der Cupuliferen, Salicineen, Vlmaceen, Betulaceen etc. angehören. Auch Myriceen, Plataneen, Laurineen etc. sind durch viele Arten vertreten.

\section{Zweite Unterclasse der Dicotyledonen: \\ D i c h l a m y d a e. Kronenblüthige. \\ (Synonym: Coralliflorae. Dicotyledonen mit differenzirter Blüthenhille.)}

Die Phylogenie dieser Gruppe ist, wie bemerkt, dadurch sehr interessant, dass sie vollkommen das Fortschritts-Gesetz bestätigt. Von den beiden grossen Reihen derselben, Polypetalen und Gamopetalen, tritt die unvollkommnere und niedere Stufe, die Reihe der Polypetalen, zuerst, schon in der Kreide auf, während die vollkommnere und höhere Stufe, die Reihe der Gamopetalen, erst in dem Eocen der Tertiär-Zeit erscheint. Offenbar ist die letztere aus der ersteren in der Anteocen-Zeit oder Zwischenzeit zwischen Kreide - und Tertiär-Zeit durch Verwachsung der ursprünglich getrennten Blumenblätter entstanden. 
XIVIII Systematische Einleitung in die Entwickelungsgeschichte.

\author{
Erste Legion der Dichlamydeen: \\ Polypetala e. Sternblïthige. \\ (Synonym: Dralypetalae. Choristopetalae. Diapetalae.)
}

Die Phylogenie dieser Legion beginnt entweder in der Kreide-Zeit oder in der Antecreta-Zeit, in welcher dieselbe sich aus den Monochlamydeen durch Differenzirung der einfachen Blüthenhülle in Kelch und Krone entwickelte. Die ältesten Reste, welche sich in der Kreide finden, sind nur sehr spärlich, darunter eine Wallnuss (Juglandiles minor); einige davon auch zweifelhaft, wie z. B. Acerites cretaceas, Sedites Rabenhorsti. Eine bedeutendere Entwickelung erreicht auch diese Reihe, wie die folgende, erst in der Tertiär-Zeit. Hier sind im Eocen vorzüglich Leguminosen, Oenothereen (Trapa) und Malvaceen (Highlea) bemerkenswerth. Im Miocen finden wir viele Leguminosen, Umbelliferen, Acerineen, Juglandeen, Rhamneen, Anacardiaceen etc. Endlich kommen dazu im Pliocen noch zahlreiche Rosaceen, Pomaceen, Amygdaleen, Celastrineen und viele andere Polypetalen. Die meisten derselben gehören, ebenso wie die meisten Monochlamydeen - und Gamopetalen-Reste, strauchartigen und baumartigen Pflanzen an, deren Theile besser als diejenigen krantartiger Gewächse sich fossil erhalten können.

\title{
Zweite Legion der Dichlamydeen: \\ G a m o p e t a la e. Glockenbliithige. \\ (Synonym: Monopetalae. Sympetalae.)
}

Mit der Phylogenie der Gamopetalen schliesst die paläontologische Entwickelungsgeschichte des Pflanzenreichs in ihren Hauptzügen ab. Wie die Phylogenie den aus ontogenetischen und anatomischen Verhältnissen erschlossenen Satz bestätigt, dass die Gamopetalen vollkommener als die Polypetalen sind, ist schon vorher bewiesen worden. Nach Allem, was wir bis jetzt wissen, ist die grosse Pflanzengruppe der Gamopetalen, zu welcher die vollkommensten aller Pflanzen-Familien, die Synanthereen (Compositen), Labiaten, Primulaceen, Rubiaceen, Gentianeen etc. gehören, die höchst differenzirte und zugleich diejenige, welche zuletzt in der Erdgeschichte auftritt. Sie erscheint erst in der Tertiär-Zeit, und zwar zuerst im Eocen mit einigen Ericaceen (Dermatophyllites). Diesen schliessen sich im Miocen einige Rubiaceen (Sieinhauera) und im Pliocen eine grössere Anzahl von anderen Gamopetalen an. Das Fortschrittsgesetz wird dadurch lediglich bestätigt.

\section{Das natürliche System des Thierreichs.}

Weit umfassendere, festere und wichtigere Resultate, als die systematische Genealogie des Protistenreiches und des Pflanzenreiches, liefert uns diejenige des Thierreiches. Wenn wir unter den gesammten Protisten nur mit der grössten Unsicherheit eine Anzahl selbstständiger Phylen erkennen und umschreiben, eine paläontologische Begründung ihres Stammbaumes aber nirgends gehörig durchführen konnten, wenn wir ferner unter den Pflanzen dies nur für den einen Stamm der Cormophyten vermochten, für die übrigen drei bis fünf Stämme aber ganz darauf verzichten mussten, so gelangen wir dagegen im Thier- 
reiche mit sehr befriedigender Sicherheit zu der Aufstellung eines genealogischen Systems von fünf deutlich geschiedenen Phylen und vermögen mit Hülfe der Paläontologie, sowie der vergleichenden Anatomie und Embryologie, ihre Phylogenie wenigstens den Grundzügen nach festzustellen.

Wir haben bereits im siebenten Capitel des ersten Bandes die Zahl der thierischen Stämme, die wir gegenwärtig zu unterscheiden vermögen, auf fünf fixirt. Es entsprechen dieselben sechs von den sieben thierischen Typen oder Kreisen, in welche gegenwärtig das Thierreich fast allgemein eingetheilt wird. Unsere fünf Stämme sind: I. Die Wirbelthiere (Vertebrata); II. Die Weichthiere (Mollusca); III. Die Gliederthiere (Articulata); IV. Die Fünfstrahlthiere (Echinodermata) und V. Die Nesselthiere (Coelenterata). In dem Stamme der Gliederthiere oder Articulaten fassen wir die beiden gewöhnlich getrennten Typen der Gliederfüsser (Arthropoda) und der Würmer (Vermes) zusammen, welche wir nicht zu trennen vermögen, und gesellen ihnen ausserdem die Infusorien hinzu, welche wir für die Ausgangsform des ganzen Phylon halten. Die letzteren werden jetzt ziemlich allgemein mit den Rhizopoden, Spongien, Noctiluken und Flagellaten in einem siebenten und letzten „Kreise“, dem der Urthiere oder Protozoen, zusammengefasst. Wir halten diese Abtheilung für keinen natürlichen Stamm, und haben sie daher aufgelöst, indem wir die meisten hierher als „Protozoen - Classen" gestellten Gruppen in der That für selbstständige „Protisten-Phylen" halten. Wenn wir dann noch die Infusorien, als unzweifelhafte Thiere, mit den Würmern und dadurch mit den Articulaten vereinigen, so beschränken wir das eigentliche Thierreich auf die fünf genannten Stämme.

Dass die drei Phylen der Vertebraten, Articulaten und Mollusken drei vollkommen selbstständige, natürliche Gruppen sind, deren jede ihren eigenen sogenannten "Organisations - Plan" besitzt, ist allgemein anerkannt, seitdem inh Anfange unseres Jahrhunderts zwei der grössten Zoologen, Bär und Cuvier, gleichzeitig und unabhängig von einander, der erstere durch gedankenvolle vergleichend-embryologische, der letztere durch umfassende vergleichend -anatomische Untersuchungen geleitet, die vier "Typen" oder "Grundpläne" oder "Kreise“ des Thierreichs aufstellten. Von dem vierten Typus, den Bär und Cuvier unterschieden, den Radiaten, hat dann zuerst Leuckart 1848 nachgewiesen, dass derselbe in zwei ganz verschiedene Typen, die Echinodermen und Coelenteraten, gespalten werden müsse. Dass nun diese "Typen, Kreise oder Unterreiche" des Thierreichs (Orbes, Branches, Embranchements) in der That "Phylen oder Stämme" in unserem Sinne sind, d. h. Einheiten von blutsverwandten Organismen, glauben wir durch ihre ganze paläontologische, embryologische und systematische Entwik- 
L Systematische Einleitung in die Entwickelungsgeschichte.

kelungsgeschichte und die äusserst wichtige dreifache Parallele derselben auf das Bestimmteste nachweisen zu können. Wir halten den einheitlichen Organisations-Typus jedes Kreises, den mystischen ,Grundplan" ihres Baues, einfach für die nothwendige Folge der gemeinsamen Abstammung voń einer und derselben Stammform; für eine Folge der Vererbungs - Gesetze.

Wir glauben, dass diese unsere Auffassung der fünf echten thierischen "Typen" als besonderer „Phylen" zunächst unter den Anbängern der Descendenz-Theorie am meisten ansprechen und Beifall finden wird. Die Stammbäume, welche wir auf Tafel III-VIII entworfen haben, sprechen für sich selbst. Wir können aber hier nicht verschweigen, dass wir selbst noch einen Schritt weiter über die hier durchgeführte Annahme hinausgehen, und dass wir, je länger und inniger wir die Verwandtschafts-Verhältnisse des Thierreichs durchdacht haben, desto entschiedener zu diesem wichtigen Schritt hingedrängt worden sind - zu der Annahme nämlich, dass auch die fünf thierischen Phylen an ihrer Wurzel zusammenhängen, und dass nicht allein die Vertebraten, Arthropoden und Mollusken, sondern auch die Echinodermen und Coelenteraten, aus dem Würmer-Stamme hervorgegangen sind. Wir würden dann also ebenso für das Thierreich, wie für das PflanzenReich einen einzigen Stamm annehmen, während wir das ProtistenReich unter allen Umständen für einen Complex von mehreren selbstständigen Stämmen halten. Da wir diese wichtige Frage im XXV. Capitel noch näher erörtern werden, so gehen wir hier ohne Weiteres zur genealogischen Uebersicht der fünf einzelıeì thierischen Phylen über.

Frster Stamm des Thierreichs:

Coclenterata. Nesselthiere.

(Synonym: Acalephae. Cnidae. Zoophyta. Nematozoa. Onidoroa.)

Die Thiergruppe der Coelenteraten, welche den Acalephen des $\Lambda \mathbf{r i}$ stoteles, den Zoophyten in dem beschränlsten Sinne der neueren Autoren entspricht ${ }^{1}$ ), ist gegenwärtig als ein vollkommen ,natiirlicher" und einheitlicher Kreis oder Typus des Thierreichs, als eine selbstständige, eigenthümlich organisirte Hauptgruppe oder ein Unterreich, allgemein anerkannt. In der That stimmen sämmtliche Glieder dieses umfangreichen Thierkreises so vollkommen in den charakteristischen Grundzügen ihrer Orgànisation überein, dass über ihre wirkliche und nahe Blutsverwandtschaft kein Zweifel herrschen kann und dass wir mit voller Sicherheit ihre gemeinsame Abstammung von einer einzigen Stammform annehmen können. Jie sehr eigenthümliche

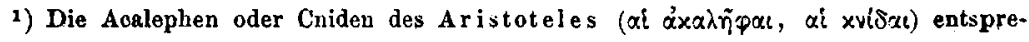
chen rollkommen dem Coelenteraten-Stamme, wie Leuckart dessen Umfang und Inbalt festgestellt hat. Aristoteles fasste bereits mit richtigem Instinkte die beiden wesentlich verschiedenen Haupttypen, welche wir unterscheiden, unter jenen Begriff zusammen, nämlich die an Felsen festsitzenden Petracalephen oder Polypen (Actinien) und die frei schwimmenden Nectacalephen (Medusen). 
Einrichtung des Gastrovascular - Apparats oder des coelenterischen Gefäss-Systems, die allgemeine Bewaffnung der Haut mit Nesselorganen, der pflanzenähnliche Wachsthums - Modus, das Vorherrschen der homostauren und autopolen Grundform ete. zeichnen die Coelenteraten so bestimnt als einen besonderen Stamm aus, dass sie mit keiner anderen Thiergruppe Berührungen zu haben scheinen. Wir betrachten demgemäss, gestützt vor allen auf die enge anatomische Verwandtschaft aller Coelenteraten, auf die gemeinsamen Charaktere ihrer Ontogenese und auf die Andeutungen ihrer Phylogenese, die ganze Gruppe als einen einzigen natiirlichen Stamm, als das niederste Phylon des eigentlichen 'l'hierreichs.

Das Phylon der Coelenteraten ist entweder aus einer einzigen autogonen Moneren-Form als gan\% selbstständiger Stiunm hervorgegangen, oder es hängt an seinem unteren Stammende mit den tieferen Stufen anderer Gruppen, und zwar höchstwahrscheinlich der Würmer zusammen. Sowohl unter den Infusorien, als unter den niedersten Platyelminthen lassen sich Anknüpfungspunkte für diese Verbindung finden, wie wir im XXV. Capitel zeigen werden.

Ein einziges Coelenterat existirt, welches uns noch von der ungefähren Beschaffenheit der gemeinsamen Stammform aller Coelenteraten eine annähernde Vorstellung zu geben vermag. Dieser uralte, wenig veränderte $\mathrm{Ty}$ pus ist die Hydra, nebst Cordy/ophora der einzige Süsswassor-Repräsentant des ganzen Stammes, welcher gleich vielen anderen Süsswasser-Bewohnern, (wegen der eiufacheren Verhältnisse des Kampfs ums Dasein im süssen Wasser) seine ursprüngliche einfache Structur nur wenig verändert zu haben scheint. Die $/ / y d / n$ spiclt in dieser Beziehung unter den Coelenteraten eine ähnliche Rolle, wie Actinophrys und Gromia unter den Rhizopoden, die Ganoiden unter den Fischen. Sämmtliche anatomische und ontogenetische Verhältnisse der Hydra deuten darauf hin, dass sie sich am wenigsten unter allen noch lebenden Coelenteraten von ihrem ursprínglichen gemeinsamen Stammvater entfernt hat, und dass sic als ein nur sehr wenig veränderter, conservativer Nachkomme jener uralten gemeinsamen Stammformen aller Coelenteraten $\mathrm{zu}$ betrachten ist, aus denen sich schon in friiher archolithischer Zeit alle übrigen hervorgebildet haben, und welche wir als A rchydrae zusammenfassen wollen.

Alle uns bekannten Coelenteraten zerfallen in zwei Gruppen, von denen wir glauben, das sie sich schon sehr frühzeitig als zwei selbstständige Hauptäste oder Unterstämme von dem gemeinsamen Archydra-Stamme losgelöst und nach zwei divergenten Richtungen hin entwickelt haben. Das eine Subphylum umfasst die alte gemeinsame Stammgruppe der Archydren selbst, und den mächtigen, zunächst von ihm abgelösten Unterstamm, welcher durch die Polypen in engeren Sinne des Worts oder die Corallen (Anthozoa) gebildet wird. Da diese sämmtlich ebenso wie die alten Archydren während des grössten Theiles ihres Lebens (meisteus an Felsen) festsitzen, nennen wir das ganze Subphylum „Petracalephen“ oder „Haftnesseln". Das andere, frühzeitig von diescm divergirend abgegangene Subphylum umfasst die Gruppe der Medusen odor Quallen in dem weitesten und ältesten Sinne des Wortes, nämlich die Classe der Hydromedusen (mit den Subclassen der Leptomedusen, Trachymedusen und Discomedusen) und die Classe der Ctenophoren, welche offenbar erst später von der Hydromedusen-Classe sich abgezweigt hat. Wir nennen dieses Subphylum "N ectacal ephen" oder Schwimmnesseln, weil die meisten Thiere dieser Gruppe sich während der längsten Zeit ihres Lebens frei schwimmend umher bewegen. (Vergl. Taf. III.) 
LII Systematische Einleitung in die Entwickelungsgeschichte.

\author{
Erstes Subphylum der Coelenteraten: \\ Petracalephae, H. Haftnesseln oder Polypen.
}

Dieser Unterstamm zerfält in zwei sehr ungleichwerthige Gruppen, in die Classe der Archydren, von der uns nur noch die Hydra und vielleicht auch noch einige nahverwandte marine Hydroidpolypen übrig sind, und in die umfangreiche und vielgestaltige Classe der Corallen oder Anthozoen, welche sich, ebenso wie das Subphylum der Nectacalephen, selbstständig von der Archydren- Wurzel abgezweigt hat. Strenggenommen müssten wir die Nectacalephen und die Anthozoen als dic beiden coordinirten Hauptäste des Archydren-Stammes, als Stammäste oder Unterstämmc des gemeinsamen ältesten Phylum ansehen, dessen Schattenbild noch gegenwärtig in der Hydra lebt. Da wir jedoch von dem ganzen Urstamm. so wenig kennen, und die Anpassung an die festsitzende Lebensweise der Archydren sich bei den Corallen constanter erhalten hat, als bei den Nectacalephen, dürfen wir die Corallen mit den Archydren als Petracalephen vereinigt lassen. Sie entsprechen den „an Felsen haftenden" Acalephen des Aristoteles, während die Nectalephen den ,weichen und abgelösten, frei schwimmenden Acalephen“ desselben correspondiren.

\title{
Erste Classe der Petracalephen: Archylrae, H. Urpolypen.
}

Diese Classe würde die älteste Stammform des Coelenteraten-Stammes und deren Abkömmlinge umfassen, soweit dieselben nicht schon entweder der Anthozoen - oder der Nectalephen-Gruppe angehören. Es würden dahin also alle Coelenteraten der ältesten Primordialzeit, von der Entstehung des Phylum bis zu seiner Spaltung in die Anthozoen - und Nectacalephen-Gruppe, zu rechnen sein. Da uns fossile Reste dieser Urpolypen nicht mit Sicherheit bekannt sind, so können wir auf die Beschaffenheit derselben nur aus den frühesten Fntwiclelungsstadien ihrer Nachkommen, insbesondere aus den infusorienähnlichen Larven der Anthozoen und Nectacalephen schliessen, und aus den hydraförmigen einfachen Polypen, welche aus diesen zunächst hervorgehen. Als einen sehr wenig veränderten, directen Nachkommen des Archydrenstammes, der für die Coelenteraten eine ähnliche Bedeutung hat, wie Amphioxus für die Wirbelthiere, dürfen wir den Süsswasser-Polypen, die echte Hydra auffassen. Ausserdem könnten vielleicht noch eine Anzahl von niedrigsten Nectaphalephen hierher gezogen werden, jene unvollkommneren marinen Hydroid - Polypen nämlich, welche sich zunächst an Hydra anschliessen und gleich dieser keine Medusen, sondern ganz einfache Geschlechtskapseln in ihrer Leibeswand erzeugen. Daher könnte ein Theil derjenigen „Hydroid-Polypen“, welche gewöhnlich mit den niedersten Hydromedusen (Leptomedusen) vereinigt werden, insbesondere eine Anzahl von Sertulariden und Tubulariden unter die Archydren gestellt werden. Ebenso könnte wohl noch andererseits von den Anthozoen die Tubulosen-Gruppe hierher gerechnet werden, bei welcher die charakteristischen Radial-Septa der. übrigen Anthozoen nicht entwickelt sind. Innere Scheidewände, welche die Leibeshöhle in getrennte Fächer theilen, wie jene Radial-Septa der Anthozoen, finden sich auch bereits bei mehreren Hydroid-Polypen vor (Tubularia, Parypha, Corymorpha etc.). Doch sind diese Verhältnisse im Ganzen noch zu unbekannt, um sie hier näher zu erörtern. 
Zweite Classe der Petracalephen:

Anthozoa. Corallen.

(S ynonym: Corallo. Corallia. Corallaria. Polypi sensu strictiori.)

Die umfangreiche und vielgestaltige Corallen - Classe ist die einzige Coelenteraten-Gruppe, über deren. Phylogenese uns die Paläontologie directe Aufschlüsse giebt. Die sehr ausgedehnte und starke $V_{\text {erkalkung, welche }}$ bei einem grossen Theile dieser Thiere statt fand und welche ihre Form und Structur auch am todten Thiere fast vollständig erhielt, hat zur Conservation sehr zahlreicher und werthvoller fossiler Reste derselben geführt, welche uns über die Aufeinanderfolge einzelner Gruppen derselben (jedoch nicht aller!) in der Erdgeschichte sehr bedeutende Aufschlïsse geben. Zweifelsohne haben sich die Corallen aus den Archydren als ein selbstständiger Zweig entwickelt, welcher von dem anderen Hauptzweige der Nectacalephen sich schon in sehr früher Primordialzeit abgelöst hat. Auf die nahe Verwandtschaft beider deuten auch die rudimentären Radialsepta hin, wclche bereits bei grösseren Hydroidpolypen (Tubularia, Corymorpha etc.) sich finden und als Anfänge der bei den Anthozoen ausgebildeten radialen Scheidewände zwischen Magenund Leibeswand gelten können. Andrerseits sind diese bei den Tubulosen so unentwickelt, dass wir diese vielleicht noch zu den Archydren rechnen dürfen. Als Eintheilungs - Moment für die verschiedenen Anthozoen -Gruppen benutzen wir in erster Linie die Antimeren-Zahl, welche hier (im Gegensatz zu den Nectacalephen) eine sehr bemerkenswerthe Constanz zeigt. Wahrscheinlich haben sich die Anthozoen nach ihrer Trennung von den Nectacalephen alsbald in zwei Aeste gespalten, bei deren einem sich die Sechszahl, bei dem anderen die Vierzahl der Antimeren frühzeitig fixirt hat, und von dem letzteren haben sich dann diejenigen abgezweigt, bei denen durch constante Verdoppelung der Antimeren die Achtzahl derselben sich befestigt hat. So erhalten wir drei natürliche Gruppen, welche auch in anderer Hinsicht als nächstverwandte erscheinen, und welche wir, nach ihrer bestimmenden homotypischen Grundzahl, die Tetracorallien, Octocorallien und Hexacorallien nennen wollen.

Erste Subclasse der Anthozoen:

Tetracorallia, H. Vierzählige Corallen.

Diese Gruppe umfasst diejenigen Corallen, welche sich durch Befestigung der homotypischen Vierzahl am nächsten an die Nectacalephen anschliessen und wahrscheinlich schon sehr frühzeitig von dem gemeinsamen AnthozoenStamme abgezweigt haben. Wir vereinigen darin die umfangreiche und sehr alte Abtheilung der stark verkalkten Rugosen mit der eigenthümlichen Gruppe der noch lebenden Cereanthiden, welche wir als einen nicht verkalkten Ausläufer derselben Unterklasse betrachten.

\section{Erste Ordnung der Tetracorallien:}

Rugosa. Furchencorallen.

Die Rugosen stellen eine sehr eigenthümliche, auf die archolithische und paläolithische Zeit beschränkte Ordnung dar, welche sich aus den Familien der Cystiphylliden, Cyathophylliden, Cyathaxoniden und Stauriden zusammensetzt. Gewöhnlich werden sie mit der Mehrzahl der Hexacorallen in 


\section{Systematische Einleitung in die Entwickelungsgeschichte.}

der Abtheilung der sogenannten Sclerodermata, von Anderen dagegen mit den Hydroidpolypen vereinigt. Indessen sind sie durch die constante Vierzahl der Antimeren, den vollständigen Mangel des Coepenchyms etc. ebenso von den ersteren, wie durch die entwickelte Ausbildung zahlreicher Systeme von starken, radialen Septen ron den letzteren entfernt. Schon im Silur zahlreich vertreten, erreichten sie ihre Acme im Devon und haben ihren jüngsten Repräsentanten im Perm, so dass sie ausschliesslich auf die primordiale und primäre Zeit beschränkt bleiben.

\section{Zweite Ordnung der Tetracorallien: \\ Paranemata. Cereanthiden.}

Diese kleine Ordnung besteht bloss aus dor Familie der Cereanthiden (Cereanthus und Saccanthus) und wird gewöhnlich mit den sechszähligen Malacodermen vereinigt. Sie unterscheidet sich aber von diesen und von den anderen Hexacorallen sehr wesentlich nicht allein durch die constante Vierzahl der Antimeren, sondern auch durch die ganz eigenthümliche doppelte Tentakelkrone, einen labialen und einen marginalen Kreis von Tentakeln, die in denselben Meridianebenen (nicht alternirend!) stehen. Ebenso sind sie sehr ausgezeichnet durch ihren eigenthümlichen Hermaphroditismus. Wir erblicken daher in den Cereanthiden einen isolirten, sehr alten Ueberrest einer vormals bedeutenden Gruppe, den letzten Ausläufer des sehr früh entwickel. ten skeletlosen Hauptzweiges der Tetracorallen, von dem die Rugosen sich erst später abgezweigt haben. Da sie keine harten Theile besitzen, sind fossile Reste nicht vorhanden.

Zweite Subclasse der Corallen:

$$
\text { Octocorallia, H. Achtzïhlige Corallen. }
$$

Diese Gruppe, welche sehr wahrscheinlich schon in früher Zeit aus den Tetracorallen durch Verdoppelung der vier Antiweren entstanden ist, und durch Befestigung der homotypischen Achtzahl sich von denselben abgezweigt und selbstständig entwickelt hat, umfasst die Alcyonarien oder Octactinoten und die bloss der Primordią-Zeit angehörigen Graptolithen, welche wir als besondere Ordnung neben jene stellen.

\section{Erste Ordnung der Octocorallien: \\ Graptolithi. Graptocorallen.}

Die Graptolithen bilden eine sehr eigenthümliche Coelenteraten - Gruppe, welche wir nur aus der Silurzeit kennen. Gewöhnlich werden sie als die nächsten Verwandten der Alcyonarien und namentlich der Pennatuliden betrachtet. Doch ist ihre Stellung noch sehr zweifelhaft. Andere betrachten sie als Hydroidpolypen, welche den Sertulariden am nächsten stehen.

\section{Zweite Ordnung der Octocorallien:}

\section{Alcyonaria. Federcorallen.}

$$
\text { (Synonym: Octactinia. Monocyclia octarithma.) }
$$

Diese umfangreiche Gruppe umfasst die Familien der Tubiporiden, Alcyoniden, Gorgoniden und Pennatuliden, welche sämmtlich in der coustanten Achtzahl der Antimeren, und in der Structur des einfachen Cyclus ron acht 
platten gefiederten Tentakelu übereinstimmen. Die Phylogenie der Gruppe ist nur sehr unvollständig bekannt, da sie sich wenig zur fossilen Erhaltung in deutlich erkennbarer Form eignet. Man kennt einige Reste schon aus der Primärzeit, welche das hohe Alter der Urdnung beweisen. In allen Formationen bleiben sie aber selten, und fehlen in vielen ganz.

Dritte Subclasse der Anthozoen:

Hexacorallia, H. Sechsählige Corullen.

Alle Corallen, welche wir in dieser Ordnung zusammenstellen, stimmen überein in der constanten Sechszahl der Antimeren, welche neben anderen Indicien auf eine nähere Blutsverwandtschaft zwischen denselben, als zwischen ihnen und den Octocorallien und Tetracorallien hinweist. Wir glauben daher, dass die verschiedenen $Z$ weige der Hexacorallien-Gruppe erst nach ihrer Trennung von den vereinigten vierzähligen und achtzähligen Anthozoen sich von einander entfernt haben.

\section{Erste Ordnung der Hexacorallien:}

Tubulosa: Röhrencorallen.

Diese kleine Gruppe sechszähliger Polypen, welche nur die Familie der Auloporiden, (Aulopora, Pyrgia) umfasst, scheint uns einen der ältesten Scitenzweige der Anthozoenclasse darzustellen, welcher eigentlich (wegen der nicht entwickelten Septa) kaum dazu gerechnet werden kann, und wahrscheinlich eine Uebergangsform ron den Archydren zu den Anthozoen repräsentirt. Sie finden sich nur fossil, und nur in wenigen silurischen und paläolithischen Formen, und scheinen mit der Kohle bereits aufzuhören.

\section{Zweite Ordnung der Hexacorallien: \\ Tabulata. Bödencorallen.}

Zu dieser Gruppe gehöron dio Familien der Favositiden, Milleporiden, Seriatoporiden und Theciden, welche alle die constante Sechszahl der Antimeren und lie horizontalen Kelch - Böden gemein haben, sonst aber sich so vielfach unterscheiden, dass sie, falls sie Aeste eines gemeinsamen Zweiges sind, jedenfalls weit divergiren. Ueberhaupt ist ihre Stellung unter den Corallen noch unsicher. Neuerdings sind sie auch zu den Hydroidpolypen unter die Nectacalephen gestellt worden, denen namentlich die Milleporiden sehr nahe zu stehen scheinen. Die Seriatoporiden schliessen sich zunächst an die Syringoporen an, aus denen sie wahrscheinlich hervorgegangen sind. Die ganze Ordnung ist sehr alt und hatte bereits in der Silur-Zeit ihre Acme erreicht. Während der Primärzeit nimmt sie stark ab, und setzt sich nach derselben nur durch einige wenige Repräsentanten fort, von denen einige Pocilloporen, Milleporen und Seriatoporen noch heute leben.

\section{Dritte Ordnung der Hexacorallien : \\ Cauliculata. Staudencorallen.}

(Synonym: Antipatharia. Zoantharia sclerobasica. Monocyclia hsxarithma.)

Diese Ordnung umfasst nur die eine Familie der Antipathiden (Antipathes, Hyalopathes ete.) und ist, mit Ausnahme des zweifelhaften miocenen Liopathes, in fossilem Zustande nicht bekannt. Wegen ihres einfachen Kranzes von sechs Tentakeln und ihrer sonstigen anatomischen Eigenthümlichlseiten 


\section{Systematische Einleitung in die Entwickelungsgeschichte.}

ist die Ordnung an die verschiedensten Stellen des Corallen-Systems versetzt worden. Sie scheint uns ein einzelner sehr alter Zweig des HexacorallenAstes zu sein, welcher sich von demselben schon ablöste, ehe die Multiplication der Septa und Tentakeln begonnen hatte, durch welche die meisten übrigen Hexacorallen ausgezeichnet sind.

\section{Vierte Ordnung der Hexacorallien: \\ Halirhoda, H. Seerosen.}

Diese Ordnung umfasst die skeletlosen sechszähligen Corallen, welche man gewöhnlich als „Zoantharia mąlacodermata“ bezeichnet, jedoch nach Ausschluss der Paranemen oder Cereanthiden, welche wir für eine ganz verschiedene und weit entfernte Corallenform halten. Dagegen scheinen uns die Halirhoden mit den Eporosen und Perforaten so nahe verwandt zu sein, dass wir am liebsten diese drei Gruppen als Unterordnungen in einer einzigen Ordnung zusammenstellen möchten, die man „Anthocorallien" nennen könnte. Wahrscheinlich hat sich diese Ordnung aus Tabulaten hervorgebildet. Von den skeletlosen, sehr weichen Seerosen, welche die Familien der Autactiniden (Actiniden), Phyllactiniden, Thalassanthiden und Zoanthiden umfassen, sind natürlich keine fossilen Reste bekannt.

\section{Fünfte Ordnung der Hexacorallien: \\ Perforata. Porencorallen.}

Diese Ordnung, welche in mehrfacher Beziehung, besonders aber durch ihre unvollkommene Skelet-Entwickelung, den Uebergang zwischen den Halirhoden und Eporosen bildet, hat sich wahrscheinlich entweder aus den ersteren oder aus dem einen Zweige der Tabulaten, oder aus einem gemeinsamen Aste mit letzteren hervorgebildet. Gleich der folgenden Ordnung hat sie sich erst spät reichlicher entwickelt. Doch finden sich bereits Vertreter im Silur. Von den beiden hierher gehörigen Familien ist diejenige der Poritiden (die niedere und unvollkommnere, die sich zunächst an die Halirhoden anschliesst) bereits im Silur (durch Protaruea) und im Devon (durch Pleurodic/yum) vertreten. Die andere (höhere und vollkommnere) Familie, die der Madreporiden, beginnt erst (mit Discopsammia) in der Weisskreide. Beide werden erst im Tertiär hänfiger und sind noch jetzt in Epacme begriffen.

\section{Sechste Ordnung der Hexacorallien: \\ Eporosa. Riffcorallen.}

Diese ausserordentlich umfangreiche Gruppe umfasst die höchsten und vollkommensten, und zugleich vorzïglich diejenigen Corallen, welche durch ihre colossalen Stöcke die Corallenriffe bilden. Es gehören hierher die wichtigen und formreichen Familien der Turbinoliden, Oculiniden, Astraeiden und Fungiden. Gleich den vorigen hat sich diese Ordnung erst spät entwickelt. Mit einziger Ausnahme des silurischen Paläocyclus, welcher zu den Fungiden gehört, sind sämmtliche Eporosen und Perforaten der secundären, tertiären und quartären Zeit angehörig. In der Trias noch spärlich vertreten, nehmen dieselben im Jura und von da bis zur Jetztzeit mächtig zu, sind also noch in der Epacme begriffen. Wahrscheinlich haben sie sich aus den Perforaten hervorgebildet. 


\section{Zweites Subphylum der Coelenteraten: Nectacalephae, H. Schwimmnesseln. Medusen.}

In dem zweiten Unterstamm der Acalephen oder Coelenteraten vereinigen wir die Classe der Hydromedusen mit derjenigen der Ctenophoren, welche offenbar nur einen einzelnen, einseitig entwickelten Zweig der letzteren darstellt. Die meisten Repräsentanten dieser Gruppe sind, wenigstens zu gewissen Zeiten, pelagische Schwimmer. Wir sind der Ansicht, dass dieser ganze Unterstamm, ebenso wie die Classe der Corallen oder Anthozoen, sich selbstständig, (also unabhängig von der letzteren,) aus dem Urstamm der Archydren entwickelt hat. Im Gegensatz zu den Corallen sind die meisten Nectacalephen ohne Skelet und haben daher nur seltene und im Ganzen werthlose Spuren ihrer Phylogenie in der Erdrinde hinterlassen. Wir können daher auf ihre phyletische Entwickelung nur aus ihrer Anatomie und Ontogenie schliessen. Doch sind die sich hieraus ergebenden Verwandtschafts - Verhältnisse so äusserst verwickelter Natur, dass wir nur mit sehr grosser Ungewissheit den folgenden Stammbaum aufstellen können.

\section{Erste Classe der Nectacalephen: \\ Hydromedusae: Polypenquallen.}

Die äusserst vielgestaltige Hydromedusen - Classe, welche sich zweifelsohne unmittelbar aus den Archydren entwickelt hat, wird gewöhnlich in zwei Subclassen oder Ordnungen eingethcilt: die niederen Hydromedusen oder Crasped ota (Synonym: Cryptocarpae, Gymnophthalmata, Hydroida), und die höheren Hydromedusen oder Acraspeda (Synonym: Phanerocarpae, Steganophthalmala, Discophora). Jedoch erscheint es natirlicher, wie es bereits Fritz Müllèr vorgeschlagen hat, diese sehr verwickelte Gruppe in drei coordinirte Ordnungen oder besser Subclassen zu spalten, deren jede sich relativ unabhängig von der anderen entwickelt hat, obwohl sie an der Wurzel sicher zusammenhängen. Wir benennen diese drei Unterclassen nach der charakteristischen Beschaffenheit ihres Schirms als Leptomedusen, Trachymedusen und Discomedusen.

\section{Erste Subclasse der Hydromedusen: \\ Lep tomedusae, H. Zartquallen.}

Zu dieser Gruppe würden zunächst die uns unbekannten Coelenteraten zu rechnen sein, welche, unmittelbar aus den Archydren sich hervorbildend, die gemeinsamen Stammformen der ganzen Hydromedusen-Classe wurden und deren nächste Verwandte wir wohl in einem grossen Theile der HydroidPolypen zu suchen haben. Ferner rechnen wir hierher die Siphonophoren, und sodann den grössten Theil der sogenannten craspedoten oder cryptocarpen Medusen, jedoch nach Ausschluss der Trachymedusen. Wahrscheinlich hat sich der älteste Leptomedusen - Stamm zunächst in drei Zweige gespalten, nämlich die Siphonophoren, Ocellaten und Vesiculaten, von denen jedoch die beiden letzteren unter sich wieder näher zusammenzuhängen scheinen. 
LVIII Systematische Einleitung in die Entwickelungsgeschichte.

Erste Ordnung der Leptomedusen:
Vesiculata, H. Randbläschen-Medusen.

Diese Ordnung umfasst den grössten Theil der sertularienartigen $\mathrm{Hy}$ droidpolypen und derjenigen craspedoten oder cryptocarpen Medusen, welche Randbläschen besitzen und welche die Unterordnung der Sertulariae im Sinne von Agassiz bilden, jedoch nach Ausschluss der Trachymedusen. Die Genitalien liegen meistens längs der Radiärcanäle. Als charakteristische Typen der Ordnung können die Eucopiden (niederste Form) und Aequoriden (höchste Form) gelten. Ausserdem gehören hierher die Geryonopsiden, Plumulariden, die meisten Campanularien und ein grosser Theil der übrigen Sertulariden und der Thaumantiaden: Es befinden sich in dieser Ordnung die einfachsten und unvollkommensten aller Medusen, welche wir vielleicht als Ausgangspunkte nicht allein für die höheren Vesiculaten, sondern auch für die 'Trachymedusen und Discomedusen betrachten können. Doch sind die Verwandtschafts-Verhältnisse dieser Gruppe so äusserst verwickelt, dass sich zur Zeit noch nichts Näheres darüber angeben lässt.

\section{Zweite Ordnung der Leptomedusen: Ocellata, H. Augenfleck-Medusen.}

Diese Ordnung entspricht im Ganzen (jedoch mit Ausschluss mehrerer Gruppen) der Unterordnung der Tubulariae im Sinne von Agassiz, oder der Oceaniden-Familie von Gegenbaur, und umfasst den grössten Theil der tubularienartigen Hydroidpolypen und derjenigen craspedoten oder cryptocarpen Medusen, welche keine Randbläschen, dafür aber Augenflecke als Sinnesorgane besitzen. Die Genitalien liegen meistens in der Magenwand. Es gehören dahin die Familien der Tiariden (Oceaniden oder $\mathrm{Nu}$ cleiferen), Sarsiaden, Hippôcreniden, Clàdonnemiden und ein grosser Theil der Tubulariden und Thaumantiaden. Wahrscheinlich hat sich diese Ordnung unabhängig von der vorigen aus den Archydren hervorgebildet und hat wahrscheinlich auch den Ausgangspunkt für die Siphonophoren ubgegeben.

\section{Dritte Ordnung der Leptomedusen:}

\section{Siphonophora. Schiwimmpolypen (Medusenstöcke).}

Diese Ordnung wird gewöhnlich als eine besondere Hauptabtheilung (etwa äquivalent den Leptomedusen oder Discomedusen) hingestellt. Doch ist der Polymorphismus, welcher diese schwimmenden Mcduscnstöcke in so hohem Grade auszeichnet, gleicherweise auch schon bri anderen, festsitzenden Hydroidenstöcken, besonders bei den Hydractinien, zu finden, mit denen sie auch sonst eng zusammenhängen. Es scheint dahcr am passendsten, die Siphonophoren nur als eine Ordnung der Leptomedusen zu betrachten, welche in die Familien der Velelliden, Physaliden, Physophoriden und Calycophoriden zerfällt. Indessen sind diese Familien nicht gleichwerthig und es entfernt sich namentlich diejenige der Velelliden (I'elella, Porpita) weiter von den übrigen, und ist vielleicht besonderen Ursprungs. Die Siphonophoren müssen sich entweder aus den Ocellaten oder direct uus den Archydren hervorgebildet haben. 
Zweite Subclasse der Medusen:

Trach y medusae, H. Starrquallen.

Diese Gruppe setzt sich aus verschiedenen, offenbar einem gemeinsamen $Z$ weige angehörigen Medusen zusammen, welche bisher theils mit den Craspedoten, theils mit den Acraspeden vereinigt waren. Der gemeinsame Charakter derselben liegt zunächst in einer eigenthümlichen Starrheit und oft fast knorpelartigen Hürte des Gallertschirms, welcher auch ihren Bewegungen einen eigenthümlichen Charakter verleiht; diesem entspricht auch eine besondere Entwickelung des Velum, welches meist sehr breit, dick und herabhängend ist. Wie hierdurch mit den Craspedoten, so stimmen sie durch den gelappten Schirmrand mit den Acraspeden überein. Als Ausgangsform der Subclasse betrachten wir die uralten Aeginiden, von denen aus sich die drei Ordnungen der Phyllorchiden, Marsiporchiden und Elasmorchiden abgezweigt haben.

\section{Erste Ordnung der Trachymedusen:}

\section{Phyllorchida, H. Phyllorchiden.}

In dieser Ordnung haben wir bereits früher die beiden Familien der Aeginiden und Geryoniden vereinigt, welche durch die seltsame, von uns entdeckte und als Alloeogenesis beschriebene Form des Generationswechsels so innig zusammenhängen, dass wir sie nicht $\mathrm{zu}$ trennen vermögen. Die Aeginiden (Cunina Aegineta) betrachten wir als eine ganz alte, sehr wenig veränderte Medusenform, wofür schon die schwankende und nicht befestigte Antimeren-Zahl (ebenso wie bei den Asteriden unter den Echinodermen) den Beweis liefert. Die Geryoniden haben sich zweifelsohne erst aus den Aeginiden entwickelt, ebenso wie wir als einen zweiten Ast, dieses Zweiges die Marsiporchiden, und als einen dritten die Elasmorchiden betrachten (vergl. unten S. 93, Anm.).

\section{Zweite Ordnung der Trachymedusen:}

Marsiporchida, H. Marsiporchiden.

In dieser Ordnung vereinigen wir die eigenthümliche Familie der Trachynemiden (Trachynema, Rhopalonema) mit derjenigen der Aglauriden (Aglaura, Lessonia), mit welcher sie uns durch den starren Charakter des fast knorpelartigen Schirms, sowie des eigenthümlichen Velum, die Structur der Tentakeln, der beutelförmig herabhängenden Genitalien und der Randbläschen nächstverwandt zu sein scheint. Wahrscheinlich gehören hierher auch noch andere, bisher in verschiedene Craspedoten-Familien vertheilte Medusen, z. B. Sminthea, Circe etc.

Dritte Ordnung der Trachymedusen :

Elasmorchida, H. Elasmorchiden.

Diese Gruppe umfasst die beiden merkwürdigen Familien der Charybdeiden (Charybdea periphylla), und Marsupialiden (Marsupialis, Tamoya, Chiropsalnus, Bursarius), welche in mancher Beziehung als die höchstorganisirten Medusen gelten können, aber von den Discomedusen, mit denen sie bisher vereinigt waren, ganz getrennt werden müssen. Am richtigsten hat sie Fritz Mïller aufgefasst, welcher sie als einseitig ent- 
LX Systematische Einleitung in die Entwickelungsgeschichte.

wickelte und höchst vervollkommnete Ausläufer der Aeginiden-Familie betrachtet. $\mathrm{Ob}$ sie unmittelbar von diesen oder von den Marsiporchiden abstammen, erscheint $z$ weifelhaft.

\section{Vierte Ordnung der Trachymedusen: \\ Calycozon, Haftmedusen. \\ (S ynonym: Podactinaria. Lucernarida.)}

Diese scheinbar sehr isolirte Coelenteraten-Gruppe, welche gewöhnlich mit den Corallen vereinigt, oder als eine besondere Classe zwischen diese und die Hydromedusen gestellt wird, scheint sehr eng mit der vorhergehenden Subclasse der Trachymedusen und namentlich mit der Ordnung der Elasmorchiden zusammenzuhängen, aus welcher sie sich wahrscheinlich unmittelbar entwickelt hat. Die Lucernarien sind Medusen und zwar wahrscheinlich Trachymedusen, welche ihre schwimmende Lebensweise aufgegeben und sich festgesetzt haben. Neuerlich sind sie in die beiden Familien der Cleistocarpiden (Halimocyathus) und Eleutherocarpiden (Haliclystus) gespalten worden. Will man sie als besondere Subclasse aufstellen, so müssen sie ihren Platz zwischen Trachymedusen und Discomedusen erhalten.

Dritte Subclasse der Medusen:

Discomedusae, H. Scheibenquallen.

(Sy uonym: Discophorae, Acraspeda, Phanerocarpae; pro parte!)

Diese Gruppe entspricht im Ganzen den Acraspeden oder Phanerocarpen, jedoch nach Ausschluss der Charybdeiden. Sie zerfällt in die beiden Ordnungen der Semäostomeen und Rhizostomeen, von denen sich die letzteren aus den ersteren entwickelt haben. $O b$ die ersteren von den 'Trachymedusen oder Leptomedusen, oder direct von Archydren abstammen, erscheint zweifelhaft. Doch ist das Letztere das Wahrscheinlichste. Fossile Abdrücke von hierher gehörigen Medusen sind im lithographischen Schiefer des Jura aufgefunden worden, sowohl von Semäostomeen, als von Rhizostomeen.

\section{Erste Ordnung der Discomedusen: \\ Semaeostomeae. Seeflaggen.}

Diese Ordnung umfasst die typischen Discomedusen, welche sich in die drei Familien der Pelagiden (Nausithoe, Pelagia), Cyaneiden (Cyanea, Patera), Sthenoniden (Sthenonia, Phacellophora) und Aureliden (Aurelia) spalten. Ihrer Ontogenese nach zu urtheilen, haben sie sich unmittelbar aus Archydren entwickelt, vielleicht jedoch auch (theilweis!) aus Leptomedusen oder Trachymedusen (Aeginiden?).

\section{Zweite Ordnung der Discomedusen: \\ Rhizostomeae. Wurzelquallen.}

Diese Ordnung hat sich erst secundär, durch Verwachsung der Falten des Mundrandes zu Röhren, aus den Semäostomeen hervorgebildet, und zwar sicher lange vor der Jura-Zeit. Denn im lithographischen Schiefer von Solenhofen finden sich ausgezeichnet erhaltene Abdrücke von bereits 
völlig enttwickelten Rhizostomen vor (Rhizostomites admirandus etc.) Die Ordnung spltet sich in die sechs Familien der Favoniden, Polycloniden, Cepheidem, Cassiopeiden, I Jeptobrachiden und Rhizostomiden. Sie können als in eimsetiger Richtung höchst entwickelte und als die vollkommensten aller Hydlronedusen gelten, wie sie auch die absolut grössten Formen der Classe enthilten.

Zweite Classe der Nectacalephen.

Ctenophora. Kammquallen.

(Synonym: Vibrantes. Ciliograda. Jriptera. Beroida.)

Die Ctmophoren fassen wir, wie bemerkt, als einen einseitigen und in einer eizzigen Richtung sehr hoch entwickelten Ausläufer der Hydromedusen-Classe auf, der sich zu dieser ähnlich verhält, wie die Vögel zu den Rertilien. Obwohl die Entwickelungsgeschichte der Ctenophoren noch sehr venig bekannt ist, so geht doch aus Allem, was wir davon wissen, sowie aus ihrer gesammten Anatomie, mit Sicherheit hervor, dass sie nur einen späten und verhältnismässig kleinen Zweig der HydromedusenClasse bilden. Ob sie sich aber aus den Leptomedusen oder aus den Trachymedusen oder aus den Discomedusen herangebildet haben, ist rorläufig noch nicht zu sagen. Doch ist das letztere vielleicht das Wahrscheinlichste und spricht dafür namentlich die auffallende Aehnlichkeit, welche die Larven gewisser Rhizostomiden mit Beroiden haben. Die Classe zerfällt in zwei Subclassen, Eurystomen und Stenostomen, von denen sich die letzteren ebenso aus den ersteren, wie diese aus den Hydromedusen entwickelt haben.

Erste Subclasse der Ctenophoren:

Eurystoma. Weitmündige Ctenophoren.

Diese Subclasse umfasst nur dio einzige Ordnung der Beroiden oder Eurystomen, welche in die drei Familen der Rangiden, Neisiden und Pandoriden zerfällt. Vor diesen stehen in mancher Beziehung die Rangiden, in anderer die Pandoriden den Discomedusen am nächsten und haben sich wohl unmittelbar von diesen abgezweigt. Jedenfalls sind die Eurystomen die älteren Ctenophoren, welche sich unmittelbar aus den $\mathrm{Hy}$ .dromedusen entwickelt, und aus denen sich erst später die Stenostomen differenzirt haben.

Zweite Subclasse der Ctenophoren:

Stenostoma. Engmündige Ctenophoren.

Diese Subclasse umfasst die drei Ordnungen der Saccalae, Lobatae und Taenialae. Von diesen haben sich zunächst wohl als zwei divergirende Aeste einerseits die Saccaten (Cydippiden, Mertensiden; Callianiriden), andererseits die Lobaten (Euchariden, Calymmiden, Boliniden) aus den Beroiden entwickelt. Entweder aus diesen oder aus jenen hat sich zuletzt die höchst differenzirte Ordnung der Täniaten (Cestum) hervorgebildet. Doch sind die Verwandtschafts-Verhältnisse und namentlich die ontogenetischen Beziehungen der verschiedenen Ctenophoren-Gruppen zu verwickelt und noch $\mathrm{zu}$ wenig bekannt, als dass wir jetzt schon den Stammbaum derselben näher feststellen könnten. Fossile Restè derselben sind nicht bekannt. 
LXII Systematische Einleitung in die Entwickelungsgeschichte.

\section{Zweiter Stamm des Thierreichs: Echinodermata. Fünstrahlthiere.}

Alle Echinodermen, welche wir kennen, stimmen in ihrer gesammten Organisation und Entwickelung durch so zahlreiche besondere und auszeichnende Charaktere überein, dass über ihre natürliche Blutsverwandtschaft kein Zweifel bestehen kann. Das ganz eigenthümliche locomotorische Wassergefässsystem oder Ambulacral-System und die ausgezeichnete Form der Verkalkung des Perisoms sind so hervorragende Charaktere, dass man kein Echinoderm mit Thieren eines anderen Stammes verwechseln kann. Dazu kommt noch der eigenthümliche Generationswechsel, die successive Metagenesis, welche nur noch einige Würmer mit ihnen theilen (vergl. unten S. 95, 97). Während die erste Generation aus sehr kleinen und zarten wurmartigen Ammen besteht, die mittelst einer Wimperschnur frei im Meere umherschwimmen, und gleich den Würmern bald eudipleure, bald eutetrapleure Grundform besitzen, erscheint dagegen die zweite Generation sehr viel grösser, stärker und robuster, sitzt fest oder kriecht auf dem Grunde des Meeres umher, und ist fast constant aus fünf Antimeren zusammengesetzt, so dass die Körpergrundform entweder pentactinot oder pentamphipleurisch ist. Die nahe und innige Verwandtschaft, welche alle Echinodermen hierdurch verbindet, ist demgemäss auch so allgemein anerkannt, dass dieser "Typus" des Thierreichs als ebenso „natürlich“, d. h. völlig abgeschlossen, wie der der Vetebraten, betrachtet wird, und dass wir bei den Anhängern der Descendenz-Theorie gewiss keinen Widerspruch finden werden, wenn wir alle Echinodermen als blutsverwandte Descendenten einer und derselben Stammform betrachten. Dieser, auf die Anatomic und Ontogenie der Echinodermen gegründete Schluss wird in ausgezeichneter Weise durch die paläontologische Entwickelungsgeschichte bestätigt, dereji Verlauf durch so zahlreiche und wohlerhaltene Reste fest bezeichnet ist, dass wir wenigstens bis zur Silurzeit hinauf mit seltener Sicherheit ihren natürlichen Stammbaum reconstruiren können (Taf. IV).

Während so über den genealogischen Zusammenhang aller Echinodermen unter sich kein Zweifel sein kann, ist dagegen die Frage über die successive Entwickelung der rerschiedenen Echinodermen-Gruppen aus einer gewissen Stammform, und die Frage nach der Natur dieser hypothetischen Stammform, sowie über ihren erentuellen Zusammenhang mit anderen thierischen Stämmen sehr viel schwieriger. Was die Verwandtschaft mit anderen Phylen betrifft, so gelten noch fast allgemein als die nächsten Verwandten der Echinodermen die Coelenteraten, und selbst Agassiz hat noch neuerdings diese beiden gänzlich verschiedenen Thierstämme in der veralteten und durchaus künstlichen Abtheilung der Radiaten oder Strahlthiere vereinigt erhalten, obschon Leuckart und Johannes Müller längst die völlige Unhaltbarkeit dieser Gruppe dargethan hatten. Mit demselben Rechte, mit dem man Coelenteraten und Echinodermen als Radiaten viereinigt, könnte man auch Vertebraten, Würmer und Mollusken als Dipleure vereinigen. Dagegen zeigen die Echinoderwen sehr wichtige und innige, bisher aber meistens gänzlich übersehene VerwandtschaftsBeziehungen zu den Würmern, von denen einige (Nemertiden, Sipunculiden) denselben eigenthümlichen successiven Generationswechsel (S. 97) und 
die meisten ein ähnliches "Wassergefässsystem" besitzen. Zwar fungirt dies bei den Würmern nicht als ambulacraler, sondern als excretorischer Apparat, ist aber doch höchstwahrscheinlich dem der Echinodermen'wirklich homolog. Die Echinodermen-Larren stehen ausserdem gewissen Würmerlarven so nahe, dass sie früher allgemein für solche gehalten wurden. Der erste Zoologe, der diese sehr wichtigen Verwandtschaftsbeziehungen gehörig gewürdigt hat, ist $\mathrm{Huxley}$, welcher 1864 (l. c. p. 76, 79) auf Grund derselben die Echinodermen mit den Scoleciden (Würmer nach Ausschluss der Anneliden) in dem besondern Typus der Annuloida vereinigt hat, wie er andererseits die Auneliden mit den Arthropoden in dem Unterreiche der Anmulosa zusammenstellt. Doch hat er keine Andeutungen weiter über den etwaigen Ursprung der Echinodermen aus den Scoleciden gegeben.

Nach unserer Ansicht sind die Echinodermen als echte Stöcke.oder Cormen von gegliederten Würmernzubetrachten, welchedurch innere Knospung oder vielmehr durch fortschreitende Keimknospenbildung (Polysporogonia jrugressiva, S. 53) im Inneren echter Würmer entstanden sind. Wir denken uns diesen Vorgang in ähnlicher Weise, wie die innere Keimbildung in Ascaris nigrovenosa oder in den viviparen Larven der Cecidomyien. Wir denken uns, dass eine Anzahl solcher gegliederter Würmer im Inneren ihres Mutterleibes mit ihrem einen Ende durch eine Art Conjugations-Process (Concrescenz) rerwachsen sind, und sich an der Verwachsungsstelle in ähnlicher Weise eine gemeinschaftliche Ingestions-Oeffnung gebildet haben, wie die Botrylliden unter deu zusammengesetzten Ascidien sich eine gemeinsame Egestionsöffnung geschaffen haben. Diese Hypothese scheint uns sowohl durch die Anatomie der Echinodermen als durch ihre Ontogenie und Phylogenie lediglich bestätigt zu werden. Die zusammengesetzten Augen, welche wir selbst an den Asteriden nachgewiesen haben, kommen ausserdem nur noch bei Descendenten des Articulaten-Stammes vor. Die ausgezeichnete Metameren-Bildung der Echinodermen mit ihrem hoch differenzirten Bewegungs-Apparat (Musculatur und Hautskelet) erinnern gleichfalls an die Articulaten, und vorzugsweise an die Crustaceen.

Jedes Echinodermen-Bion würde nach dieser Vorstellung nicht als eine Person, sondern als ein echter Stock (also als ein morphologisches Individuum sechster, nicht fünfter Ordnung) zu betrachten sein. Jedes Antimer des fünfstrahligen Echinoderms dagegen würde ursprünglich eine Metameren- (nicht Epimeren-!) Kettc, eine gegliederte Wurmperson (also ein Form-Individunm fünfter Ordnung) darstellen. Auch die getrennte Entstehung der fünf Antimeren in vielen Echinodermen-Larven, wo sie sich als fünf ganz selbstständige Stiicke um den Magen herum anlegen, scheint uns diese Ansicht lediglich zu bestätigen. Der Nervenstrang, welcher in der Mitte jeder Ambulacralfurche verläuft, muss dann dem Bauchmark der Articulaten homolog sein, und der Nervenring, welcher den Mund umgiebt, würde erst eine secundär entstandene Commissur zwischen den ursprünglich getrennten Wurmleibern darstellen.

Wir sind darauf gefasst, unsere Hypothese als einen paradoxen Einfall verspottet zu sehen, und er ist uns selbst anfangs als solcher erschienen. Je mehr wir aber darüber nachgedacht, je intensiver wir die innigen Verwandtschafts-Beziehungen der Echinodermen und der scheinbar so weit davon entfernten Articulaten erwogen haben, desto bestimmter hat sich 


\section{Systematische Einleitung in die Entwickelungsgeschichte.}

in uns die Ueberzeugung von der Richtigkeit jener Vorstellung befestigt. Der paradoxe Generationswechsel der Echinodermen scheint uns in keiner anderen Weise erklärbar. Wenn man aber unsere Hypothese verwirft, so bleibt nichts übrig, als eine gänzlich unbekannte Reihe von älteren, archolithischen Stammformen für die Echinodermen anzunehmen, die sich aus einer eigenen autogonen Moneren-Form völlig selbstständig entwickelt haben.

Vielleicht kann auch die Verwandtschaft der Holothurien mit den Gephyreen (Sipunculiden, Echiuriden), welche schon früher zu einer Vereinigung dieser Würmer mit den Echinodermen geleitet hat, zu Gunsten unserer Hypothese angefüht werden. Wenn diese $\mathrm{Hypoth}_{\mathrm{p}} \mathrm{se}$ on der Abstammung der Echinodermen von echten Würmern richtig ist, so können wir als die ursprüngliche gemeinsame Stammform der Echinodermen nur Asteriden denken, welche offenbar die ursprüngliche Stockform des Echinoderms am deutlichsten zeigen. Das grösste Gewicht legen wir hierbei auf die wechselnde Antimeren-Zahl der Asteriden, welche dagegen bei allen andern Echinodermen sich bereits auf fünf fixirt hat. Bekanntlich kommen nicht allein unter denjenigen Seestern-Arten, welche gewöhnlich fünf Antimeren besitzen, sehr häufig auch Exemplare mit mehr oder weniger als fünf Antimeren vor; sondern es giebt auch zahlreiche Seestern-Arten, welche ganz constant eine verschiedene, meist grössere und wechselnde Anzahl von Antimeren besitzen (Solaster papposus z. B. 11-13, Asteracantliun tenuispinus 5-10 (meist 6-8), A. helianthus $20-40$, Luidia senegalensis constant 9, L Savignyi constant 7, Brisinga endecacnemos constant 11). Alle andercn Echinodermen dagegen besitzen constant fünf Antimeren. Offenbar hatte sich also die Fünfzahl der Antimeren bereits fixirt, ehe die übrigen Echinodermen sich von dem Urstamme der Seesterne abzweigten. Auch ist bei allen anderen Echinodermen in viel höherem Grade eine mehr oder weniger vollstïndige Centralisation des Cormus eingetrcten, als bei den Asteriden, deren einzelne Antimeren noch sehr vollständig sind, und den ursprünglichen gegliederten Wurmleib noch am deutlichsten erhalten zeigen. Unter den Asteriden selbst sind es die Colastren oder die echten Asteriden im engeren Sinne (Asteracanthion oder Uraster, Soluster, Archaster etc.), welche in dieser Beziehung am wenigsten verändert sind, und den ursprünglichen Typus, obwohl in seiner Art sehr hoch vervollkommnet, doch am getreuesten erhalten zeigen.

Die glänzendsten Bestätigungen unserer Hypothese haben die äusserst wichtigen paläontologischen Entdeckungen der jüngsten Zeit geliefert. Während man früher die Asteriden für jüngere, die Crinoiden für die ältesten Vertreter des Echinodermen-Kreises hielt, sind jetzt so zahlreiche und mannichfaltige Asteriden-Reste, (vorzüglich durch Salter) im silurischen Systeme Englands und Nord-Amerikas aufgefunden worden, dass mit Sicherheit daraus hervorgeht, dass die Asteriden-Classe von keiner andern Echinodermen-Classe an Alter übertroffen wird. Und was das Wichtigste ist, diese ältesten silurischen Seesterne sind theils von den heutigen Colastren (insbesondere Asteracanthion oder Uraster), kaum oder nicht generisch zu unterscheiden, theils entschiedene $Z$ wischenformen sowohl zwischen Colastren und Ophiastren (Tocastra) als auch zwischen Colastren und Crinoiden (Crinastra). Wir halten demnach die Crinoiden nicht, wie es allgemein geschieht, für die älteste und ursprünglichste Echinodermen-Form, sondern sind vielmehr der Ansicht, dass sich die Crinoiden aus den 
Asteríden durch Anpassung an festsitzende Lebensweise (also durch phyletische Rückbildung) en twi ckelt habon. Die Echiniden scheinen aus dem Cinoiden, mit denen sie durch die Palechiniden und Cystideen unmittelbar zusammenhängen, hervorgegangen zu sein, während die Holothurien sich sehr wahrscheinlich aus den Echiniden entwickelt haben. Da wir an einem anderen Orte diese Ansicht ausführlicher begründen werden, so begnügen wir uns hier mit einer kurzen Skizze derselben und einem Hinweis auf den Stammbaum der Tafel IV.

Erste Classe der Echinodermen:

Asterida. Seesterne.

Synonym: Haliastra, H. Asteriae. Asteractinòta. Stellerida.)

Die Phylogenie der Asteriden eröffuet nach unserer Ansicht diejenige des gesammten Echinodermen-Stammes, da wir diese Gruppe für den Ausgangspunkt des ganzen Phylums halten. Wenn unsere Annahme richtig ist, dass die Ehinodermen von den Würmern abstammen, so ist die AsteridenClasse die einzige, deren Entwickelung in dieser Weise leicht zu denken ist. Die ältesten Seesterne stellten demgemäss echte Würmerstöcke dar, die sich allmählich immer mehr centralisirten. Die Asteriden galten bis vor Kurzem allgemein tür eine spätere Echinodermen-Gruppe, die erst mit den Autechiniden gleichzeitig in der Trias zuerst auftreten sollte. Dagegen haben neuere Entdeckungen von der grössten Wichtigkeit nachgewiesen, dass zahlreiche echte Seesterne sich bereits in den ältesten Erdschichten finden, welche überhaupt fossile Echinodermen enthalten, nämlich im unteren Silur, und zwar befinden sich unter diesen Asteriden sowohl echte Colastren, welche von der heute noch lebenden Gattung Uraster (Asteracanthion) kaum zu unterscheiden sind, als auch sehr eigenthümliche, weder mit den Colastren, noch mit den Ophiastren vereinbare Seesterne, welche gemeiusame Stammformen theils der beiden letaten Ordnungen, theils der Colastren und der Crinoiden darstellez. Wir nennen die letzteren Crinastra, die ersteren Tocastra, und stellen diese beiden ausgestorbenen Ordnungen den rior jetzt noch lebenden SeesternGruppen an die Seite.

\section{Erste Ordnung der Asteriden: \\ Tocastra, H. Stammsterne.}

In dieser Ordnung fassen wir diejenigen Seesterne zusammen, welche bestimmende Charaktere der Colastren und der Ophiastren in der Weise vereinigt zeigen, dass man sie weder den ersteren noch den letzteren unmittelbar einreihen kann. Vielleicht stellen dieselben die gemeinsamen Stanmformen beider Ordnungen dar, und höchst wahrscheinlich die unmittelbaren und wenig veränderten Nachkommen jener archolithischen. Seesterne, welche wir als die gemeinsamen Stamınväter des gesammten Echinodermen-Stammes ansehen. Der grösste Theil der hierher gehörigen Seesterne (vielleicht alle) findet sich in den Silurschichten, und zwar meistens in den unteren Silurschichten. Die wichtigsten Gattungen sind: Palueodiscus, Palaeas/er, Lepillaster, Archusterias, Aspidosnma, Pulueocoma, Rhopalocoma etc. Auch einige Arten von Prolaster gehören hierher, z. B. Protuster Miltoni, welcher gleich Palaeodise"s eine ausgezeichnete Zwischenform zwischen den Colastrer und Ophiastren ist. Der obersilurische Lepidaster Grayi (mit dreizehn Antimeren!) zeigt auch schon Crinoiden-Charaktere. Als ein noch lebender Aus- 
LXVI Systematische Einleitung in die Entwickelungsgeschichte.

läufer dieser wichtigen Asteriden-Ordnung ist vielleicht die merkwürdige Brisinga hendecacnemos zu betrachten, welche ebenfalls eine Mischung ron Colastren - und Ophiastren-Charakteren darbietet.

Zweite Orduung der Asteriden:

Colastra, H. Glieders/crne.

(Sgnопуm: Asteriac. Asteriadae. Asterida sensu strictiori. Colasțeriae.)

Als Colastra oder Gliedersterne bezeichnen wir die sogenannten ,echten Seesterne" oder Asterien, welcher Name aber oft auch auf die ganze Classe ausgedehnt wird. Es gehören also zu den Colastren die Familien der Urasteriden (Uraster, Asterucanthion, mit 4 Fussreihen und mit After), Solasteriden (mit 2 Fussreihen und mit After, Solas/er, Archaster) und Astropectiniden, mit 2 Fussreihen, ohne After (Astropecten, Luidia). Die Phylogenie dieser Ordnung ist besonders dadurch höchst interessant, dass von ihr (ebenso wie von Lingula unter den Brachiopoden) schon in den ältesten silurischen Schichten Repräsentanten gefunden werden, welche von den jetzt noch lebenden nicht generisch, zum Theil selbst kaum specifisch verschieden $\mathrm{zu}$ sein scheinen. Diese haben sich also am wenigsten von allen Echinodermen seit jenen ältesten Zeiten verändert. Am merkwïrdigsten in dieser Beziehung ist das Genus Asteracamlhion (oder Uraster), zu welchem der gemeinste lebende Seestern der deutschen Küsten gehört: $A$. rubens. Aus dem unteren Silur sind schon fünf Arten desselben bekannt: $A$. oblusus, hirudo, primaemus, Ruthveni und matutimus. Ihnen sehr nahe steht Tropidaster aus dem Jura. Im Jura finden sich auch bereits Reste von Asirogonium, Solasler, in der Kreide von Oreasler und Gouiodiscus. Aber auch die afterlosen Gattungen Astropectel und Luillia kommen bereits im Jura und der Kreide vor. Wenn nicht zu den Tocastren, wïrden wir wahrscheinlich zu den Colastren jene ältesten unbekannten Seesterne stellen müssen, welche unmittelbar aus den Würmern entstanden sind (vergl. \$. LXIII).

Dritte Ordnung der Asteriden:

Brisingastra, H. Brisingas/erne.

Diese, in fossilem Zustande nicht bekannte Ordnung wird nur durch die merkwürdige Brisinga hondecacnemos gebildet, den seltsamen norwegischen Seestern mit elf Antimeren, welcher in auffallender Weise Charaktere der Colastren und Ophiastren verbindet. Falls derselbe vicht ein Ausläufer der Tocestren-Gruppe ist, müssen wir ihn als eine sehr alte Fortsetzung der verbindenden Uebergangs-Formen von den Colastren zu den Ophiastren ansehen. Da reine Ophiuren-Formen erst in der Trias auftreten, werden sich die Brisingasterne schon vor dieser Zeit von jenen $Z$ wischenformen zwischen vorigen und folgenden abgezweigt haben.

Vierte Ordnung der Asteriden:

Ophiastra, H. Schlangensterne.

(Synonym: Ophiurae. Ophiurida. Ophiasteriae.)

Die Phylogenie dieser Asteriden-Ordnung ist weniger sicher bekannt, als diejenige der meisten anderen Echinodermen, was wohl mit der geringen Grösse und der ausserordentlichen Zerbrechlichkeit dieser zierlichen Seesterne zusammenhängt. Mit voller Sicherheit kennt man fossile Ophiuren-Reste nur 
aus dem Mesolith - und Caenolith-Zeitalter, und es würde daraus zu schliessen sein, dass dieselben erst in der Antetrias-Zeit von ihren Stammeltern, den Tocastren, sich abzweigten. Doch ist es auch möglich, dass diese Differenzirung schon früher erfolgtc, da einige silurische Tocastren den echten Ophiastren schon sehr nahe zu stehen scheinen Die ältesten Ophiastren, zu den Gattungen Acroura, Aspidura, Aplocoma gehörig, finden sich im Muschelkalk der Trias. In dem lithographischen Schiefer des Jura finden sich die Genera Ophiurella, Geocoma und das noch lebende Ophioderma. Von da an scheinen sie zugenommen zu haben, obwohl ihre Abdrücke immer noch selten bleiben.

\section{Fünfte Ordnung der Asteriden:}

\section{Phytastra, H. Baums/erne.}

(Synonym: Euryalae. Euryalida. Astrophyta. Costata. Phytasteriae.)

Die Phylogenie dieser Seestern-Abtheilung ist am wenigsten von allen bekannt. Von den jetzt lebenden Phytastren (As/erophyton, Euryale, Trichaster, Asteronyx) sind keine fossilen Reste bekannt. Dagegen ist die ausgezeichnete fossile Gattung Saccocoma, welche gewöhnlich als eine besondere Abtheilung der Crinoiden unter dem Namen Coslata aufgestellt wird, sehr wahrscheinlich eine fossile Euryale, oder doch wenigstens ein $Z_{w}$ eig ihrer unmittelbaren Vorfahren. Die Gattung Saccocoma (mit 3 Arten) ist bis jetzt nur im lithographischen Schiefer des Jura gefunden worden, woraus zu schliessen wäre, dass die Phytastren sich vor dieser Zeit von den übrigen Asteriden abgezweigt haben. Als ihre unmittelbaren Vorfahren wïrden entweder Ophiastren oder Tocastren anzusehen sein (vielleicht auch Crinastren, z. B. einige Arten von Prolasler?).

\section{Sechste Ordnung der Asteriden: Crinastra, H. Liliensterne.}

In dieser Gruppe wïrden wir diejenigen, noch sehr wenig bekannten Seesterne zusammenfassen, welche den unmittelbaren Uebergang zu den Crinoiden und dedurch zugleich zu den iibrigen Echinodermen herstellen. Da wir im unteren Silur die Crinoiden bereits entwickelt antreffen, so müssen die eigentlichen Stammformen derselben schon vorher sich von dem gemeinsamen Tocastren-Stamme abgezweigt haben, und es köunen daher die paläolithischen Crinastren nur als wenig veränderte Ausläufer jener Uebergangsformen angesehen werden. Es gehören hierher einige Arten der Gattung Protaster (P. Sedgwichii Forbes u. a. aus dem Silur, I'. Aruoldi aus dem Devon der Eifel), welche von den zu den Tocastren gehörigen Arten derselben Gattung (Prolaster Miltoni etc.) so sehr verschieden sind, dass wir erstere hier als Encrinoster (E. Sedgwickii, E. Arnoldi etc.) absondern. Auch Lepidnster und einige andere Tocastren-Gattungen, welche bereits CrinoidenCharaktere zeigen, müssen vielleicht später hierher gezogen werden.

\section{Zweite Classe der Echinodermen: Crinoida. Seelilien.}

(S y о у у : Halicrina, H. Crinoidea. Actinoidea. Crinactinota.)

Die Phylogenie der Crinoiden lässt sich, wie diejenige der Asteriden und Echiniden, im Ganzen recht gut errathen, obwohl auch hier, wie überall, sich sehr empfindliche Lücken finden. Besonders ist zu bedauern, dass 


\section{Systematische Einleitung in die Entwickelungsgeschichte.}

uas die sämmtlichen archolithischen Crinoiden, welche vor der Silurzeit lekten (abgesehen von einigen unbedeutenden Cystideen-Resten im cambrischen System), so gut wie unbekannt sind. Ihre Kenntniss würde uns die gemeinsame Abstammung aller Crinoiden von den Asteriden enthüllen. In dem unteren Silur, welches die ältesten bekannten deutlichen Echinodermen - Reste enthält, sind bereits die rerschiedenen Abtheilungen der Crinoiden, Brachiaten, Cystideen und Blastoideen so reichlich neben einander entwickelt, dass offenbar schon sehr lange Zeit seit ihrer Abzweigung von den Asteriden verflossen sein musste. Dass diese letztere unzweifelhaft ist, glauben wir auf Grund ausgedehnter anatomischer und morphogenetischer Vergleichungen. Die Crinastren bilden bereits den Uebergang von den Asteriden zu den Brachiaten. Aus den letzteren sind wahrscheinlich erst die beiden anderen $\mathrm{Ab}$ theilungen: Cystideen und Blastoideen, hervorgegangen.

\section{Erste Subclasse der Crinoiden:}

\section{Brachiata. Armlilien.}

(Synonym: Autocrina, H. Brachiocrina. Crinoidea sensu strictiori.)

Die Phylogenie dieser Subclasse bildet den Ausgangspunkt für diejenige der ganzen Crinoiden-Classe, da sehr wahrscheinlich Brachiaten oder Autocrinen es waren, welche zuerst aus den Asteriden sich entwickelten, und von denen später erst einerseits die Blastoideen, andererseits die Cystideen sich abzweigten. Die fossilen Reste dieser Subclasse sind äusserst zahlreich und mannichfaltig, und gehen von den untersten Silursehichten durch alle Formationen bis zur Jetztzeit hindurch, in welcher sie durch die lebenden Pentacrinus und Comatuls vertreten sind. Die Autocrinen zerfallen in zwei grosse Ordnungen, von denen die eine aus der anderen hervorgegangen ist. Die erste Ordnung, die Phatnocrinen oder Tafel-Lilien, sind fast ausschliesslich paläolithisch (rom Silur bis zum Perm; nur ein einziger Ausläufer derselben (Mursupiles) reicht bis zur weissen Kreide. Die zweite Ordnung dagegen, die Colocrinen oder Glieder-Lilien, sind ausschliesslich mesolithisch oder caenolithisch, und reichen von der Trias bis jetzt, so dass sie vollständig die primären Phatnocrinen in der Secundär - und Tertiär-Zeit vertreten. Zweifelsohne haben sich daher die vollkommneren Colocrinen aus den unvollkommneren Phatnocriuen in der Antetrias-Zeit entwickelt.

\section{Erste Ordnung der Brachiaten: Phatnocrina, H. Tafellilien.}

(Synonym: Tessellata. Tessellocrina. Phatnocrinoidea.)

Diese Ordnung, die umfangreichste der ganzen Crinoiden-Classe, bildet mit sehr zahlreichen Familien, Gattungen und Arten den grössten Theil der mannichfaltigen paläolithischen Crinoiden-Fauna. Sie beginnt schon im unteren Silur, mit Formen, welche sich zum Theil sehr nahe den Crinastren, Phytastren und Tocastren anschliessen (Rhodocrinus, Glyptocrinus, Heterocrinus etc.). Im Obersilur sind Thysanocrinus, Eucalyptocrinus und Plalycrinus zu bemerken, im Devon Cyalhocrinus, Cupressocrinus, Hexucrinus, in der Kohle Poleriocrinus, Actinocrinus, Dichocrinus etc. Im Perm finden sich nur noch sehr wenige Arten (Cyathocrinus). Die ganze Ordnung erreicht in der Kohle ihre höchste Blüthe. Nur ein einzelner Ausläufer setzt sich in die Secundär-Zeit fort, der dem carbonischen Astylocrinus nächstverwandte Marsupites, welcher mit drei Arten in der weissen Kreide erscheint. 
Zweite Ordnung der Brachiaten:

Colocrina, H. Gliederlilien.

(S yоопуm: Articulata. Arthrocrina. Colocrinoidea.)

Diese Ordnung ist auf das secundäre und tertiäre, wie die vorige (Marsupiles ausgenommen) auf das primordiale und primäre Zeitalter beschränkt. Zwar werden auch einige ältere Arten in paläolithischen Schichten angegeben, doch sind diese ganz unsicher. Es ist demnach das Wahrscheinlichste, dass die Colocrinen sich in der Antetrias-Zeit aus den Phatnocrinen entwickelt haben, während die letzteren grösstentheils ausstarben. Die ältesten, mit Sicherheit bekannten Colocrinen bilden die Familie der Encriniden (Encrimus, Flubellocrints), welche der Trias ausschliesslich eigenthümlich ist. Daneben finden sich in der Trias auch mehrere Arten l'emlunrinus. Die höchste Entwickelung erreicht dje Ordnung in der Jura-Zeit, wo besonders Eugemincrinus, Apiocrinus, Millerocrimas und l'entucrimss durch sehr zahlreiche Arten vertreten sind. In der Kreide - und in der Tertiär-Zeit nehmen die Colocrinen schnell ab, und sind gegenwärtig nur noch durch Penlucrimus caput Medusue und durch die beiden Gattungen Comalula und Alec/o vertreten.

Zweite Subclasse der Crinoiden:

Blas to id ea. Knospen-Lilien.

(Synonym: Blastocrina. Blastactinota. Pentremitida. Pentatrematitida.)

Diese Crinoiden-Gruppe weicht so sehr von den Brachiaten und von den Cystideen ab, dass sie rielleicht am besten als eigene Classe aufgestellt würde. Immerhin steht sie den ersteren näher, als allen anderen lichinodermen-Gruppen. Durch die Bildung der fünf Genitalspalten-Paare nähert sie sich den Ophiuren und Echiniden. Höchstwahrscheinlich hat sich diese alte Subclasse in antesilurischer (also archolithischer) Zeit aus den Phatnocrinen oder aus gemeinsamer Wurzel mit diesen, vielleicht aber auch aus dem Crinastren-Zweige, oder noch tiefer aus der Asteriden-Wurzel heraus entwickelt. Sie erscheint zuerst im oberen Silur mit 3 Arten Pentremiles (oder Pentatremariles). Ihre Zahl nimmt zu im Devon, und besonders im Kohlengebirge, wo sie ihr Maximum (über 40 Arten) und zugleich ihren Schluss erreicht. Das sehr stark amphipleurisch differenzirte Genus Elentherocrinus (im Devon) verdient eine besondere Ordnung zu bilden. Eine Fortsetzung in späterer Zeit scheinen die Blastoideen nicht gehabt zu haben. Wir betrachten sie als einen einseitig entwickelten Seitenzweig der Crinoiden, welcher auf das primordiale und primäre Zeitalter beschränkt bleibt.

Erste Ordnung der Blastoideen:

Elaeacrina, H. Eläacriniden.

Diese Gruppe umfasst die eigentlichen Pentremitiden, die Gattungen Pentremiles, Codonaster und Elacacrimus, welche vom oberen Silur bis zur Kohle gehen. Abgesehen von dem excentrischen After, ist die Grundform fast ganz regelmässig pentactinot, nicht amphipleurisch.

Zweite Ordnung der Blastoideen:

Eleutherocrina, H. Eleutherocriniden.

Diese merkwürdige Gruppe besteht zwar bis jetzt nur aus einer einzigen devonischen Form, welche aber durch die sehr starke Differenzirung 


\title{
IJXX Systematische Einleitung in die Entwickelungsgeschichte.
}

ihrer Antimeren und die ausgezeichnete Pentamphipleuren-Form, sowie durch andere anatomische Verhältnisse von den Elaeacrinen mindestens eben so sehr abweicht, als die petalostichen von den desmostichen Echiniden. Wir müssen daher dieser weit vollkommneren Form den Rang einer besonderen Ordnung zugestehen.

Dritte Subclasse der Crinoiden:

Cystidea. Blasen-Lilien.

(Synonym: Cystocrina. Pseudocrinida. Sphaeronitida.)

Auch diese Crinoiden-Gruppe entfernt sich so sehr von den Brachiaten, dass sie als eine eigene Classe angesehen werden kann. Sie ist sehr wichtig als die wahrscheinliche Stammform der Echiniden, welche sie mit den Autocrinen verbindet. Gleich den Blastoideen sind auch die Cystideen auf die archolithische uud paläolithische Zeit beschränkt, haben sich aber wohl in noch früherer Zeit, als letztere, von den Brachiaten oder von den Crinastren abgezweigt. Sie zeigen sich nämlich vereinzelt schon in der cambrischen Formation, und haben im unteren Silur bereits das Maximum ihrer Entwickelung erreicht. Schon im oberen Silur werden sie seltener, und im Deron und der Kohle finden sich nur noch einzelne Arten. Schon im Perm fehlen sie ganz. Wir können zwei Ordnungen unterscheiden, die Agelacrinen und die Echinencrinen.

\author{
Erste Ordnung der Cystideen: \\ Agelacrina, H. Agelacriniden. \\ (Synongm: Thyroidea. Edrioasterida.)
}

Diese neuerlich erst mehr bekannt gewordene Ordnung scheint eine unmittelbare $Z$ wischenform $Z$ wischen den Asteriden (vielleicht den Crinastren) und den echten Cystideen herzustellen. Die meisten Arten finden sich im Unter-Silur (Edriaster, Hemirystites, Age/ncrinus etc.). Einzelne gehen bis zum Devon hinauf. Es fehlt ihnen der Stiel der echten Cystideen.

\section{Zweite Ordnung der Cystideen:}

Echinencrina, H. Echinencriniden.

Diese Orduung, welche die Cystideen im engeren Sinne enthält (Sphaeruniles, Caryocystites, Echinencrinus, Stephanocrinus etc.), ist ebenfalls im unteren Silur am häufigsten, und hört mit der Kohle. auf. Sie scheint Uebergangsformen zu den Palechiniden zu enthalten.

\section{Dritte Classe der Echinodermen:}

Echindia. Seeigel.

(Synonym: Halechini, H. Echini. Echinoidea. Echinactinota.)

Die Phylogenie der Seeigel ist am besten von allen Echinodermen bekannt, und liefert uns in ihrer Vollständigkeit viele treffliche Beweise für die Descendenz-Theorie, und besonders für das Fortschritts-Gesetz. Die Echiniden verdanken dieses besondere Interesse dem festen Bau und den deutlichen Formverhältnissen ihrer Kalkschale, welche besser als das Skelet der meisten anderen Echinodermen der vollständigen Erhaltuug fähig ist. Vielleicht ist keine andere Abtheilung der Wirbellosen rejcher an paläontologi- 
schen Beweismitteln für das Progressions-Gesetz, bis auf die einzelnen Familien hinab. Eine sorgfältige Vergleichung der fossilen und lebenden Formen erlaubt es, hier den Stammbaum an vielen einzelnen $Z$ weigen bis zu den Gattungen und Arten hinab festzustellen. Wir behalten die detaillirte Darstellung dieser interessanten Verhältnisse einer anderen Arbeit vor, und beschränken uns hier auf die allgemeinsten Züge. Die Echiniden stellen zweifelsohne die vollkommenste und höchstentwickelte Echinodermen-Classe dar (abgesehen vielleicht von den Holothurien, welche sie in einzelnen Beziehungen übertreffen). Sie erreichen daher ihre höhere Entwickelung erst in späterer Zeit als'die Crinoiden und Asteriden, aus denen sie sich hervorgebildet haben. Ihre nächsten Stammeltern sind höchstwahrscheinlich die Cystideen, und zwar die Echinencrinen, mit denen ihre niedersten Formen, die Palechiniden, nächstverwandt sind. Letztere finden sich schon im Silur und bleiben auf die paläolithische Zeit beschränkt. Aus ihnen habeu sich erst in der Antetrias-Zeit die höheren Formen entwickelt, die Autechiniden, welche. sämmtlich der secundären und tertiären Zeit angehören. Bei allen Autechiniden ist die Kalkschale aus 20 meridianalen Plattenreihen in der Art zusammengesetzt, dass 5 Paare ambulacraler Reihen mit 5 Paaren interambulacraler Reihen abwechseln. Bei den Palechiniden dagegen sind mindestens 3 , gewöhnlich 5-6 interambulacrale Plattenreihen zwischen je 2 Ambulacralfelder eingeschaltet.

Erste Subclasse der Echiniden:

\section{Palechinida, H. Vielreihige Seeigel.}

(Synonym: Tessellata. Perischoechinoidea. Palaechinoidea. Crinechini.)

Die Unterclasse der Palechiniden umfasst alle paläolithischen Seeigel, da alle Echiniden, welche wir aus dem primären Zeitalter kennen, mehr als 2, meistens $5-6$ interambulacrale Plattenreihen $z$ wischen je 2 ambulacralen besitzen. Diese Gruppe hat sich zweifelsohne aus den Crinoiden und zwar höchstwahrscheinlich aus der Echiueucriuen - Ordnung der Cystideen hervorgebildet. Sie bildet das vermittelnde $Z$ wischenglied zwischen diesen und den Autechiniden. Im Silur beginnend, hört sie nach dem Perm bereits wieder auf. Man kann sie in zwei Ordnungen theilen, die sich sehr wesentlich durch die Bildung der Ambulacralfelder unterscheiden, die Melonitiden und Eocidariden.

\section{Erste Ordnung der Palechiniden: Melonitida, H. Meloniliden.}

Diese Gruppe ist bis jetzt nur durch die Gattung Melonites vertreten, von der man nur eine Art kennt, $\boldsymbol{M}$. mullipora aus dem Kohlenkalk von S. Louis (Missouri). Doch ist dieselbe durch ihre Schalenstructur so sehr ausgezeichnet, dass wir nicht anstehen, auf dieselbe cine besondere Ordnung zu gründen. Während nämlich alle anderen Seeigel, sowohl die Autechiniden, als die Eocidariden, nur 2 Plattenreihen in jedem Ambulacralfelde besitzen, finden sich bei Melomites deren nicht weniger als 8 vor. Auch sind die einzelnen Platten meist vierseitig oder sechsseitig, während sie bei allen übrigen meist fünfseitig sind. Da ansserdem in jedem Interambulacralfeld nicht weniger als 7 Platteureihen vorhanden sind, so erreicht hier die Gesammtzahl der meridianalen Plattenreihen die ausserordentliche Höhe von 75, wovon 40 ambulacral, 35 interambulacral sind. Bei den anderen Palechiuiden 


\title{
LXXII Systematische Einleitung in die Entwickelungsgeschichte.
}

erreicht sie höchstens 40. Bei allen Autechiniden sind deren stets nur 20 vorhanden. Die Melonitiden stehen demnach den Cystideen, und nameutlich den Echinencrinen noch näher, als die Eocidariden und vermitteln den Uebergang vou jenen zu diesen.

\section{Zweite Ordnung der Palechiniden: \\ Eocidarida, H. Eucidariden.}

Diese Gruppe umfasst alle Palechiniden mit Ausuahme von Melonites. Es sind hier stets nur 2 Plattenreihen in jedem Ambulacrum vorhanden, wie bei den Autechiniden. Dagegen beträgt die Anzahl der Plattenreihen in jedem Interambulacrum mindestens 3 , gewöhnlich aber $5-6$. Sie bilden also den unmittelbaren Uebergang von den Melonitiden zu den Autechiniden. Die Gruppe beginnt im Silur mit Prolechimus P'hllupsine (Pulaerhinus Phillipsiale Autorum), ist durch mehrere Arten von Encilaris und Archacocidaris in Devon vertreten und erreicht die Höhe ihrer Entwickelung im Kohlenkalk (vicle Arten der Genera Pulaechimus, Aichaencilaris, Eocidu'is, Perischodomus, Lepulocenrmus etc.) Die I'tzten Vertreter finden sich im Perm (Eocidaris Kaiserlingii).

\author{
Zweite Subclasse der Echiniden: \\ Autechinida, H. Zwanzigreihige Seeigel. \\ (Synonym: Euechinoidea. Typica. Echinida sensu strictiori.)
}

Die Unterclasse der Autechiniden umfasst sämmtliche mesolithische und cänolinhische Seeigel, da alle Echiniden, welche wir aus der Secundär - und Tertiär-Zeit kennen, nur 2 interambulacrale Plattenreihen zwischen je 2 ambulacralen besitzen. Sie sind demnach für diese beiden Zeitalter ebenso ausschliesslioh charakteristisch, wie die Palechiniden für das primäre, und vertreten hier vollständig die Stelle der letzteren. Zweifelsohne haben sich demnach die Autechiniden während der Antetrias-Zeit aus den Palechiniden durch Transformation hervorgebildet. Wir zerfällen diese wichtige Subclasse, welche alle sogenannten ,echten oder typischen Seeigel" umfasst, in zwei Ordnungen, die sich wesentlich durch die Differenzirung der ambulacralen Plattenreihen unterscheiden. Bei den älteren und unvollkommneren Desmostichen sind die Ambulacra einfach bandartig, bei den jüngeren und vollkommneren Petalostichen dagegen petaloid differenzirt. Erstere beginnen schon in der Trias, letztere erst im Jura.

Erste Orduung der Autechiniden:

Desmosticha, H. Autechiniden mit Band-Ambulucren.

In dieser Ordnung vereinigen wir alle sogenannten „regulären Seeigel“ oder Endocyclica (die grosse Familie der Cidariden, sowie die Saleniden und Echinometriden) und einen Theil der sogenannten irregulären oder Exocyclica, nämlich die Familien der Galeritiden, Echinoniden und Dysasteriden. Alle diese Seeigel stimmen überein in dem Mangel der petaloiden Differenzirung der Ambulacra, welche die Petalostichen auszeichnet. Die Ambulacra laufen als einfache, nicht petaloide Bänder vom oralen zum aboralen Pol. Aus diesen und anderen Gründen ist die Gruppe der Desmostichen unvollkommener, als die der Petalostichen. Die ersteren bilden den Uebergang von den Palechiniden zu den Petalostichen. Hiermit stimmt ihre Phylogenie völlig überein. 
Die Demostichen treten bereits in der Trias auf, mit der Familie der angustistellen Cidariden, welche sich wahrscheinlich in der Antetrias-Zeit aus den Eocidariden entwickelt haben.

Erste Familie der Desmostichen:

Go $\mathrm{n}$ i o c id arida, H. Turban-Igel.

(Synonym: Angustistellae. Cidarida sensu strictiori. Cidarida anguste-stellata.)

Diese Familie enthält die ältesten und zugleich die regelmässigsten Formen ron allen Autechiniden, welche am wenigsten differenzirt sind. Die Pentactinoten-Form ist hier meistens eben so rein, wie bei den Palechiniden erhalten. Sie schliessen sich unmittelbar an letztere an und haben sich jedenfalls aus denselben durch Transformation entwickelt. Sie sind die einzigen Autechiniden der Trias, wenn man von einigen zweifelhaften Arten $\boldsymbol{H} y$ podiadema der folgenden Familie absicht, welche sich-in den obersten TriasSchichten (S. Cassian) finden sollen. Die älteste Gattung von allen Autechiniden ist Eucidaris (Ciduris selsu stric/issimn;, welche mit zahlreichen Arten (E. penfugona, venusfa, subsimilis etc.) in der Trias von S. Cassian (Keuper) erscheint. Ebenda findet sich auch eine Species von Hemiciduris. Die Familie der Angustistellen oder Goniocidariden erreicht die Blüthe ihrer Entwickelung im Jura, wo allein mehr als hundert Arten von Eucidaris rorkommen, und sinkt dann allmählich herab bis zur Gegenwart, wo sie nur durch wenige Arten vertreten ist.

Zweite Familie der Desmostichen:

E c h i n o c id a rida, H. Kronen-Igel.

(Synonym: Latistellae. Echinida sensu strictissimo. Cidarida late-stellata.)

Diese Familie schliesst sich zunächst an die rorige an, mit welcher sio gewöhnlich unter dem vieldeutigen Namen der Cidariden vereinigt wird. Sie hat sich höchst wahrscheiulich aus derselben entwickelt, und ist ihr gegenüber als spätere und vollkommnere Gruppe zu bezeichnen. Wenn man ron den oben erwähnten problematischen Arten von Hyporliadema aus der Trias absieht, so erscheint diese Familie zum ersten Male im Jura, und zwar in den untersten Schichten desselben. Sie hat sich also sehr wahrscheinlich erst in der Antejura-Zeit (vielleicht schon in der Keuper - Epoche der TriasZeit) aus einem Zweige der vorigen Familie hervorgebildet. Hemiciduris und die verwandten Formen vernitteln deu unmittelbaren Uebergang zwischen Beiden. Auch diese Familie erreicht, gleich der vorigen, ihre Blüthezeit im Jura, wo sehr zahlreiche Arten von Pseudodiudemu, Hemipedina, Stomechinus etc. vorkommen. Sie nimmt schon in der Kreide, und noch stärker späterhin bis zur Gegenwart ab.

Dritte Familie der Desmostichen:

Echinometrida. Quer-Igel.

Diese Familie (die "Latestellati polypori transversi“ Desor's), welche die Genera Echimometra, Porlophora und Acrocludiel umfasst, und welche sich durch die Verlängerung der lateralen Richtaxe so auffallend vor allen anderen Echiniden auszeichnet, ist in fossilem Zustande nicht bekannt. Sie scheint sich demnach erst in neuerer Zeit von den Echinocidariden, unter denen Heliocidaris ihr am nächsten steht, abgezweigt zu haben. 
LXXIV Systematische Einleitung in die Entwickelungsgeschichte.

Vierte Familie der Desmostichen:

S a l en ida. Höcker-lgel.

Diese Familie scheint ebenso einen seitlich entwickelten $Z_{w e i g}$ der Goniocidariden oder Angustistellen zu bilden, wie die vorige einen besonderen, divergenten Seitenzweig der Latistellen darstellt. Sie ist ausschliesslich auf die secundäre Jura - und Kreide-Zeit beschränkt, und umfasst zwei verschiedeue Unterfamilien, welche in parentalem Verhältniss zu einander stehen. Die Subfamilie der Acrosaleniden (Acrosaleniu) umfasst die artenreiche Gruppe der älteren Saleniden, welche ausschliesslich im Jura vorkommen, und sich durch perforirte Stachelhöcker auszeichnen. Die Subfamilie der H yposaleniden dagegen (Salenia, Hyposalemia, l'ellasler etc.) begreift die jüngeren Saleniden, welche undurchbohrte Stachelhöcker besitzen, und nur in der Kreide vorkommen. Offenbar sind also die Hyposaleniden ebenso durch Transformation aus den Acrosaleniden, wie diese aus den Goniocidariden hervorgegangen.

Fünfte Familie der Desmostichen:

Ga leritida. Pyramiden-Igel.

Diese Familie scheint sich ebenso, wie die Familie der Echinometriden, aus den Latistellen oder Echinocidariden entwickelt zu haben. Sie ist auf die beiden secundären Formationen Jura und Kreide beschränkt, in welcher letzteren sie ihre Blüthe erreicht.

\section{Sechste Familie der Desmostichen: Echinonida. Nuss-Igel.}

Diese Familie, welche man gewöhnlich mit der vorigen unter dem $\mathrm{Na}$ men der Galerideen vereinigt, scheint sich zwar, gleich den echten Galeritiden, ebenfalls von den Latistellen abgezweigt zu haben, aber selbstständig, und erst in späterer Zeit. Sie ist in fossilem Zustande nicht bekannt.

\section{Siebente Familie der Desmostichen:}

Dysasterida. Streck-Igel.

Diese merkwürdige Familie, welche sich durch die räumliche Trennung der beiden aboralen Convergenzpunkte des Bivium und Trivium so auffallend vor allen anderen Echiniden auszeichnet, steht dennoch den Galeritiden sehr nahe und hat sich entweder aus diesen selbst, oder mit ihnen zusammen aus gemeinsamer Wurzel, aus den Latistellen oder Echinocidariden herrorgebildet. Sie beginnt mit der artenreichen Gattung Collyriles schon im Lias, erreicht ihre Blüthe im mittleren und oberen Jura, und vimmt in der Kreide bereits wieder $a b$, mit welcher sie auch aufhört.

Zweite Ordnung der Autechiniden:

Petalosticha, H. Autechiniden mit Blatt-Ambulacren.

In dieser Ordnung fassen wir alle diejenigen ,irregulären“ Seeigel oder Exocyclica zusammen, welche sich durch petaloid differenzirte Ambulacra (blumenblattförmige Ambulacralkiemen) auszeichnen. Offenbar ist diese morphologische und physiologische Differenzirung ein Alt der Vervollkommnung, und dem entsprechend sehen wir diese höchst entwickelte Echiniden-Gruppe 
erst durch progressive Transformation eines Seitenzweiges der Desmostichen sich entwickeln, und erst in späterer Zeit, als die letzteren ihre Blüthezeit erreichen. Erst in der Jura-Zeit zweigen sie sich von den Desmostichen ab, aus welchen sie zweifelsohne durch Transmutation hervorgegangen sind.

\section{Erste Familie der Petalostichen: \\ Cassidulida. Helm-Igel.}

Die Cassiduliden sind von allen Petalostichen die ältesten, indem sie bereits im Jura erscheinen, während die anderen alle erst in der Kreide auftreten. Da sie zugleich in anatomischer Hinsicht den Desmostichen näher stehen, so dürfen wir wohl mit Sicherheit annehmen, dass sie zuerst von allen Petalostichen sich aus den Desmostichen hervorgebildet haben. Da unter den letzteren die Galeritiden ihnen am nächsten stehen, so haben sie sich vermuthlich aus diesen in der früheren Jura-Zeit oder in der Antejura-Zeit entwickelt. Die Cassiduliden-Familie zerfällt in drei Subfamilien, von denen diejenige der Echinanthiden, als die älteste, den Ausgangspunkt bildet. Sie tritt mit vielen Arten von Clypeus und Echinobrissus bereits im unteren Jura auf, erreicht in der Kreide eine sehr starke Entwickelung, und sinkt im Eocen schon wieder herab. Die beiden anderen Subfamilien sind nur unbedeutende Seitenzweige, welche in der Kreide-Zeit von den Echinanthiden sich abzweigen. Die seltsame und spärliche Subfamilie der Claviastriden, ein gleichsam monströs degenerirter Seitenzweig, bleibt auf die Kreide beschränkt, während die andere Subfamilie, die der Caratomiden, noch mit einigen Ausläufern in die Eocen-Zeit hineinreicht.

\section{Zweite Familie der Petalostichen: \\ Spatangida. Herz-Igel.}

Diese umfangreiche und vielgestaltige Echiniden-Gruppe wird gewöhnlich als die vollkommenste von allen angesehen, und in vielen Beziehungen ist sie zweifelsohne am höchsten differenzirt. In anderen Beziehungen dagegen scheinen uns die Clypeastriden vollkommener zu sein, und hiermit stimmt auch ihre Phylogenie uiberein. Die Spatangiden treten mit sehr zahlreichen Arten bereits in der Kreide auf und scheinen gegen Ende der Kreide-Zeit bereits die Höhe ihrer Entwickelung erreicht zu haben, während allerdings die am höchsten differenzirten Formen derselben erst in der Jetztzeit zu ihrer vollen Blüthe zu gelangen scheinen. 1Die Familie zerfällt in zwei Subfamilien, die Ananchytiden und Brissiden, von denen die erstere auf die KreideZeit beschränkt ist. Die Ananchytiden scheinen sich in der Antecreta-Zeit, wahrscheinlich durch Transformation eines Cassiduliden-Zweiges, vielleicht jedoch auch direct aus den Galeritiden (oder Dysasteriden?) entwickelt zu haben. Die Spatangiden im engeren Sinne, oder die Brissiden, dagegen sind erst aus den Ananchytiden, vielleicht auch aus gemeinsamer Wurzel mit ihnen, entsprungen.

\section{Dritte Familie der Petalostichen: Clypeastrida. Schild-Igel.}

In vielen Beziehungen steht diese Familie, wie bemerkt, an der Spitze der ganzen Echiniden-Classe, vorzüglich durch die ausserordeutliche: Entwickelung der petaloiden Ambulacren, welche hier allein die Interambulacra oft so bedeutend an Breite übertreffen, dass diese nur als schmale Bänder zwi- 


\section{Systematische Einleitung in die Fntwickelungsgeschichte.}

schen ihnen erscheinen. Auch durch sehr beträchtliche Körpergrösse, Differenzirung der inneren Organe und eigenthümliche Ausbildung der äusseren Körperform übertroffen viele Clypeastriden (am meisten die Mellitiden und Euclypeastriden) so sehr die übrigen Echiniden, dass wir sie als die höchst entwickelte Gruppe ansehen, wenngleich sie in anderer Beziehung hinter den Spatangiden zurücksteht. Dafür spricht auch ihre Phylogenie. Denn die Clypeastriden-Familie ist die jüngste von allen Echiniden, und fast ausschliesslich tertiär, mit Ausnahme von ein Paar Echinocyumms-Arten aus der oberen Kreide. Sie haben sich also erst in dieser Zeit von den übrigen Petalostichen abgezweigt, und zwar höchst wahrscheinlich von den Cassiduliden, so dass wir Clypeastriden und Spatangiden als zwei selbstständige divergente Seitenzweige der Cassiduliden zu betrachten haben. Die Clypeastriden-Familie zerfältt in drei Subfamilien. Von diesen ist diejenige der Laga niden die älteste und der eigentliche Stamm der Familie, welcher sich direct aus den Cassiduliden hervorgebildet hat. $\mathrm{Zu}$ ihr gehört die einzige Clypeastriden-Gattung der Secundär-Zeit (Echinocyamıs aus der oberen Kreide). Diese Stamm - Gruppe erreicht schon in der Eocen-Zeit ihre höchste Blüthe und sinkt dann herab. Dagegen erreichen die beiden auderen Subfamilien, Euclypeastriden und Scutelliden, welche aus den Laganiden erst in der Tertiär-Zeit hervorgegangen sind, erst in der Gegenwart ihre volle Entwickelung. Zuerst scheint sich ron den Laganiden die Subfamilie der Euclypeastriden (Clypenster) in der Eocen-Zeit abgezweigt zu haben, worauf aus dieser sich die Subfamilie der Scutelliden oder Mellitiden (Encope, Rolula) entwickelte, die erst im Miocen beginnt.

\section{Vierte Classe der Echinodermen:}

Ilolothuriac. Seewnlzen.

(Synonym: Haliposthae, H. Scytodermata. Scytactinota.)

Im Gegensatze zu allen übrigen Echinodermen, deren mehr oder minder vollständig verkalktes und zusammenhängendes Hautskelet meistens der Erlhaltung in fossilem Zustande ausgezeichnet fähig ist, besitzen die Holothurien nur einzelne zerstreute Kalkkörperchen in der Haut, welche zwar einzeln wohl der Erhaltung fähig, aber theils wegen ihrer sehr geringen (meist mikroskopischen) Grösse schwer zu entdecken, theils nicht im Stande sind, nähere Auskunft über die Beschaffenheit des ganzen Körpers zu geben; die ältesten derartigen Kalkkörperchen, den bekannten Kalk-Aukerchen der Synapten sehr ähnlich, sind in den Bayreuther Scyphien-Kalken des Jura gefunden worden (Synapla Siebo/dii). Die Paläontologie wird uns also niemals über die Phylogenie der Holothurien belehren.

Aber auch die sonstigen Verwandtschafts-Verhältnissc der Holothurien, soweit wir dieselben durch die vergleichende Anatomic und durch die Ontogenie ermitteln können, sind uns nur sehr unvollständig bolkannt, und wir können nicht wagen, einen Stammbaum derselben zu entwerfen. Gewöhnlich wird die Holothurien-Classe in die beiden Ordnungen der fusslosen (Apodia) und der wasserfüssigen (Eupodia) gespalten. $Z \mathbf{u}$ den $\mathrm{A}$ podia gehören zwei sehr verschiedene Familien: 1. Synaptida (Synap/a, Chirodola); 2. Liodermatida (Lioderma, Molpadia). Dic Ordnung der Eupodia umfasst ebenfalls zwei Familien: 1) Aspidochirota (Aspidochir, Mïlleria, Thelenola [Holuthuria], Bohudschia); 2) Dendrochirota (Penturta, Psolus, Cuvieria). Die beiden letzteren Familien sind wahrscheiulich divergirende 
Zweige eines gemeinsamen Eupodien-Astes; doch sind die VerwandtschaftsBeziehungen aller verschiedenen Holothurien-Gruppen zu einander so verwickelt und noch so wenig bekannt, dass wir dieselben hier nicht in der Weise wie die der übrigen Ëchinodermen systematisiren können.

Unter den übrigen Echinodermen scheinen uns die Echiniden den Holothurien am nächsten verwandt $z u$ sein, und wir vermuthen demnach, dass sich die letzteren aus einem Ziveige der ersteren hervorgebildet haben. Sobald das Hautskelet der Echiniden weich wird, sobald die Kalkablagerung bloss zur Bildung isolirter Stückchen zurückgeführt wird, kann man sich ohne Schwierigkeit den Uebergang eines Echiniden in eine Holothurie vorstellen. Wahrscheinlich erfolgte derselbe erst im Beginn der Secundär-Zeit, als die Autechiniden sich von den Palechiniden abzweigten.

\section{Dritter Stamm des Thierreichs: \\ Articulata. Gliederthiere.}

Den Stamm der Articulaten behalten wir, geringe Modificationen abgerechnet, in fast demselben Umfange bei, in welchem Bär und Cuvier denselben aufgestellt haben. Er umfasst die beiden mächtigen Subphylen der Würmer (Vermrs) und der Gliederfüsser (Arthropoda), welche gegenwärtig fast allgemein als zwei getrennte Typen oder Unterreiche aufgeführt werden und als solche zwei selbstständigen Phylen entsprechen würden. Indessen stellen nach unserer Ansicht die Arthropoden, welche sich nur durch die stärkere Differenzirung (Heteronomie) der Metameren (Rumpf-Segmente), und die Gliederung der an denselben befindlichen Extremitäten unterscheiden, nur einen höher entwickelten Zweig des $W$ ürmerstammes dar. Die gesammte Organisation beider Subphylen stimmt im Uebrigen so vollständig überein, dass wir dieselben nicht zu trennen vermögen.

Als ein drittes Subphylum des Articulaten-Stammes schliessen wir den vereinigten Würmern und Arthropoden die Classe der echten Infusorien an, welche wir allein von allen Gliedern des aufgelösten Protozoen-Kreises für echte Thiere halten können. Wir betrachten die Infusorien als überlebende Reste der alten gemeinsamen Stammform der Articulaten, und zwar scheinen sich aus denselben zunächst die Strudelwürmer oder Turbellarien entwickelt $z u$ haben, aus deren Differenzirung dann weiter die übrigen Würmer hervorgegangen sind.

Wie wir im fünfundzwanzigsten Capitel besonders erörtern werden, müssen wir für den Fall, dass wir eine gemeinsame Wurzel aller thierischen Stämme, d. h. ihre Abstammung von einer gemeinschaftlichen Stammform, annehmen, in der Würmer-Gruppe diese Stammform suchen. Auf Tafel I ist im Felde $\mathrm{g}$ h y $\mathrm{n}$ die eventuelle Form dieses Zusammenhanges dargestellt. Falls wir nicht für jeden der vier übrigen Stämme eine besondere autogone Moneren-Form als Ausgangspunkt annehmen, erscheint es am naturlichsteu, letzteren in den niederen Würmern, und zwar entweder unter den Strudelwürmern oder unter den Infusorien zu suchen.

Die Verwandtschafts-Verhältnisse des Articulaten-Stammes, und vorzüglich des Subphylum der Würmer, sind die complicirtesten von allen thierischen Stämmen, selbst von jenem möglichen genealogischen Zusammenhange mit den übrigen Thierstämmen abgesehen. Die meisten Aufschlüsse liefert uns noch die vergleichende Anatomie. Dagegen kennen wir die Ontogenie der meisten Articulaten erst sehr unvollständig; und die Paläontologie besitzt 
LXXVIII Systematische Einleitung in die Entwickelungsgeschichte.

nur von den hartschaligen und wasserbewohnenden Crustaceen zahlreichere Reste, von den übrigen, meistens landbewolhneuden Arthropoden nur verhältnissmässig sehr wenige und unbedeutende, von der ungeheuren Masse der Würmer und Infusorien wegen ihrer weichen und zerstörbaren Leibesbeschaffenheit fast gar keine nennenswerthen und kenntlichen Reste. Wir können aus diesen Gründen hier nur die allgemeinsten und flüchtigsten Umrisse des Stammbaums der Articulaten skizziren, und müssen den besten Theil dieser eben so interessanten als schwierigen Aufgabe der besser unterrichteten Zukunft überlassen. Den autogonen Moneren, welche den Infusorien den Ursprung gegeben haben müssen, nächstverwandte Formen sind vielleicht noch heute unter den Moneren des Protistenreichs zu finden, ebenso wie vielleicht weitere Entwickelungs - Stadien derselben unter den Protoplasten und Flagellaten, die bereits zu den Infusorien hinüber zu leiten scheinen.

\section{Erstes Subphylum des Articulaten-Stammes: Infusoria. Infusionsthierchen.}

Der Unterstamm der Infusorien, wie wir denselben hier als Ausgangsgruppe des Articulaten-Stammes betrachten, umfasst bloss die beiden Classen der Ciliaten (Wimper-Infusorien) und der Suctorien (Acineten). Diese beiden Classen, welche in ihrer Metaplase so weit auseinander gehen, scheinen doch durch ihre Ontogenese auf das Innigste zusammenzuhängen. Sowohl die Ciliaten als die Acineten scheinen sich nach den neueren Untersuchungen durch acinetenähnliche Tarven oder sogenannte "Schwärmsprösslinge“ fortzupflanzen, die in beiden Classen nicht zu unterscheiden sind. Sie tragen Saugröhren wie die festsitzenden Acineten, und schwimmen mittelst eines Wimperkleides umher wie die Ciliaten. Diese gemeinsamen Jugendformen scheinen uns unzweifelhaft (zwar keinen ontogenetischen! wohl aber) einen phylogenetischen Zusammenhang zu beweisen. Wir betrachten Infusorien, welche zeitlebens in der Form der bewimperten actinetenartigen Larven verharrten, als die uralten Stammeltern aller Infusorien (und somit aller Articulaten), und nehmen an, dass sich die beiden Classen der Acineten und $\mathrm{Ci}$ liaten als zwei divergente $Z$ weige aus denselben entwickelten; die Acineten verloren durch Anpassung an festsitzende Lebensweise die Wimpern der Larven und behielten die Saugröhren; die Ciliaten umgekehrt behielten die Wimpern und verloren die Saugröhren. Was den tieferen Ursprung der Gruppe anbelangt, so sind die alten Urahnen, welche die Brücke zwischen der autogonen Moneren-Form des Articulaten-Stammes (und somit vielleicht des ganzen Thierreichs) and den bewimperten Acineten-Larven herstellen, vielleicht noch heute in Protisten des Flagellaten - oder des Protoplasten -Stammes zu finden.

\section{Erste Classe der Infusorien: \\ Ciliata. Wimper-Infusorien.}

Von den vier Ordnungen, in welche diese Classe gegenwärtig gewöhnlich zerfällt wird, scheinen uns die Holotricha (Glaucoma, Opaliua, Paramecium, Nassula etc.) die älteste und am wenigsten differenzirte Gruppe zu bilden, aus denen sich die drei anderen Ordnungen erst durch Differenzirung des Wimperkleides hervorgebildet haben. Diese drei Ordnungen sind die Heter otricha (Bursuria, Slentor, Tintinnus etc.), die H ypotricha (Loxodes, Oxytricha, Euploles etc.) und die Peritricha (Vorlicella, Ophrydium, Trichodina etc.). 
$\mathrm{Z}_{\text {weite }}$ Classe der Infusorien:

Acinetue (Sucloria). Saug-Infusorien.

Die Classe der Acineten oder Sauginfusorien, welche ihren gemeinsamen phyletischen Ursprung mit den Ciliaten deutlich durch ihre gleichen Larven verrathen, umfasst die beiden Ordnungen oder Familien der Podophryida (Podophryu, Trichophrya, Aulacinela) und der Dendrocometida (Dendracomeles, Ophryodendron). Vielleicht hängt diese Classe mit den Rhizopoden oder den Protoplasten unmittelbar zusammen.

\section{Zweites Subphylum des Articulaten-Stammes: Vormes. Würmer.}

Der Unterstamm der Würmer, wie wir denselben hier umschreiben, umfasst drei Hauptäste oder Claden, nämlich: I. die Würmer im engeren Sinne (Scolecida oder Helminthes); II. die Ringelwürmer (Annelida) und IIL. die Räderthierchen (Rolatorii). Entweder bloss der letztere oder auch die beiden letzten Claden werden von Anderen bereits zu den Arthropoden gezogen. Sowohl die Rotatorien als die Anneliden stellen eigenthümlich entwickelte Zweige der Scoleciden dar, welche ihrerseits durch die Turbellarien mit den Infusorien zusammenhängen.

Erster Cladus der Würmer:

Scolecida (Helminthes). Uiwïmer.

Dieser umfangreiche Ast des Subphylum der Articulaten umfasst dio drei Classen der Platyelminthen, Rhynchelminthen und Nematelminthen, von denen die beiden letzteren divergirende Aeste der ersteren darstellen.

\section{Erste Classe der Scoleciden: \\ Platyolminthes. Plallwïrmer.}

Diese Classe bildet unzweifelhaft den Ausgangspunkt für den gesammten Unterstamm der Würmer, da derselbe durch die Turbellarien unmittelbar mit den Ciliaten zusammenhängt. Man pflegt gewöhnlich an den Anfang desselben die Cestoden als die unvollkommensten Würmer zu stellen. Indessen sind diese zweifelsohne ebenso wie die Trematoden erst aus den Turbellarien durch Anpassung an parasitische Lebensweise hervorgegangen.

\section{Erste Ordnung der Platyelminthen: \\ Turbellaria. Strudelwürmer.}

Von allen Würmern stehen diese ohne $Z_{w}$ eifel den Infusorien am nächsten, und sind selbst durch einige so zweifelhafte Uebergangs-Formen mit den Ciliaten verbunden, dass ihre Abstammung von diesen nicht geleugnet werden kann. Wir beschränken diese Ordnung auf die eigentlichen Turbellarien, die hermaphroditischen und afterlosen (Aproctu), indem wir die sehr viel höher entwickelten afterfuihrenden und gonochoristischen Nemertinen (Proctucha) als besondere Orduung abtrennen. Die Ordnung der Turbellarien spaltet sich in zwei Unterordnungen: Dendrocoela (Planuria, Stylochus) und Rhabdocoela (Monocelis, Vortex). Von diesen stehen die Dendrocoelen offenbar tiefer und den Ciliaten näher; aus ihnen wahrscheinlich haben sich die anderen Platyelminthen und vielleicht auch die Rhabdocoelen 
LXXX Systematische Einleitung in die Entwickelungsgeschichte.

hervorgebildet. Diese letzteren betrachten wir als Stammgruppe der Nemertinen, der übrigen Würmer, und der Rotatorien, und dadurch zugleich aller höheren Articulaten. Unter den Dendrocoelen befinden sich vielleicht Uebergangsformen von den Ciliaten zu den Rhabdocoelen.

\section{Zweite Ordnung der Platyelminthen:}

Trematoda. Suugwïrmer.

Diese parasitischen Würmer sind wohl jedenfalls durch Anpassung an parasitische Lebensweise aus den Turbellarien und zwar aus den Dendrocoelen hervorgegangen. Durch weiter gehenden Endoparasitismus und entsprechende phyletische Degeneration haben sich aus ihnen die Cestoden hervorgebildet, während andererseits vielleicht die Hirudineen als höher entwickelte ectoparasitische Trematoden zu betrachten sind.

\section{Dritte Ordnung der Platyelminthen: \\ Cestoda. Bandwürmer.}

Mit Unrecht, wie bemerkt, werden die Bandwürmer gewöhnlich als unvollkommenste Wurmgruppe an den Anfang der Würmergruppe gestellt. Offenbar können sie nicht Ausgangspunkt derselben sein, sondern haben sich erst secundär durch phyletische Degeneration aus den Turbellarien in ähnlicher Weise entwickelt, wie die Acanthocephalen aus den Gephyreen. Dass die Cestoden durch weiter gehende parasitische Rückbildung aus den Trematoden entstanden sind, zeigen deutlich die völlig zweifelhaften Uebergangsformen zwischen beiden Gruppen (Amphiplyches, Amphilina etc.).

\section{Vierte Ordnung der Platyelminthen: \\ Hirudinea (Discophorn), Escel.}

Die Hirudineen haben sich wahrscheinlich ebenso durch fortschreitende, wie die Cestoden durch rückschreitende phyletische Mretamorphose aus den Trematoden entwickelt. Zahlreiche, neuerdings entdeckte Uebergangsformen zwischen beiden Ordnungen scheinen diese, besonders von Le u ckart betonte nahe Verwandtschaft beider Gruppen zu bestätigen, obwohl die Möglichkeit nicht ausgeschlossen bleibt, dass sich die Hirudineen als ein Seitenast von den Anneliden abgezweigt haben.

Fünfte Ordnung der Platyelminthen:

Onychophora. Krallenuïrmer.

Diese ausgezeichnete kleine Gruppe, welche nur die Familie der Peripatiden mit der einzigen Gattung leripalus umfasst, wird gewöhnlich zu den Anneliden (Chaetopoda) gestellt. Sie schliesst sich aber durch viele und wichtige anatomische Charaktere viel näher an die Plattwürmer, und unter diesen zunächst an die Hirudineen an. Insbesondere ist sehr wichtig die völlige Uebereinstimmung im Bau der Leibes-Muskulatur, auf deren grosse systematische Bedeutung zuerst A. Schneider mit Recht hingewiesen hat. Falls nicht aus den Hirudineen selbst, mit denen sie auch noch die $Z_{w}$ itterbildung theilen, haben sich die Onychophoren wohl tiefer unten von dem Platyelminthen-Aste abgezweigt. 


\section{Sechste Ordnung der Platyelminthen:}

Nemertina. Schnuruiümer.

Die Ordnung der Nemertinen hängt mit der Ordnung der Turbellarien, und insbesondere mit den Rhabdocoelen, so eng zusammen, dass sie gewöhnlich nicht von dieser Ordnung getrennt wird. Zweifelsohne hat sie sich unmittelbar aus den letzteren entwickelt. Indessen entfernt sie sich doch weseatlich von ihnen schon durch die Differenzirung der Geschlechter, durch die Entwickelung einer Leibeshöhle und durch andere Eigenthümlichkeiten. Vielleicht haben sich die echten Anneliden (Chaetopoden) aus ihnen hervorgebildet.

\section{Zweite Classe der Scoleciden: \\ Hhynchelminthes. Rüsselwürmer.}

Als Rüsselwürmer fassen wir nach dem Vorgange von A. Schneider die beiden Ordnungen der Gephyreen und Acanthocephalen zusammen, welche in dem eigenthïmlichen Bau ihrer Leibes - Muskulatur und ihres Hakenrüssels auffallend übereinstimmen und sich dadurch zugleich von allen andern Würmern entfernen, so dass sie weder den Platyelminthen, noch den Nematelminthen, noch den Anneliden, ohne Zwang eingefügt werden können. Wir betrachten die Rhynchelminthen als einen Scoleciden-Zweig, welcher wahrscheinlich unmittelbar aus den Rhabdocoelen, und unabhängig von den beiden Aesten der Anneliden und Nernatelminthen, vielleicht jedoch auch im Zusammenhang mit einem der beiden letzteren Zweige hervorgegangen ist. Die Acanthocephalen sehen wir als Gephyreen an, welche durch Anpassung an Entoparasitismus riickgebildet worden sind.

\section{Erste Ordnung der Rhynchelminthen: \\ Gephyrea. Sternuiurmer.}

Die Gruppe der Gephyreen, welche die Familien der Priapuliden, Sipunculiden, Echiuriden und Sternaspiden umfasst, hat an den verschiedensten Stellen des Systems ihren Platz gefunden. Gewöhnlich wird sie entweder als eine besondere Würmer-Classe oder als eine Ordnung der AnnelidenClasse angesehen, bisweilen auch mit den Nematoden vereinigt. Früher galten die Gephyreen lange für Echinodermen, von denen insbesondere die Holothurien Manches mit ihnen gemein haben. Wahrscheinlich haben sie sich als selbstständiger Ast von den Rhabdocoelen abgezweigt, vieleicht in Zusammenhang mit denjenigen unbekannten Würmern, welche Stammväter der Echinodermen wurden.

\section{Zweite Ordnung der Rhynchelminthen: \\ Acanthocephala. Kratzüirmer.}

Von den Nematoden, mit welchen die Acanthocephalen gewöhnlich vereinigt werden, entfernen sie sich durch den Bau ihrer Muskulätur eben so sehr, als sie dadurch andrerseits mit den Gephyreen übereinstimmen, mit denen sie auch den retractilen, mit rückwärts gerichteten Haken besetzten Rüssel theilen. Wir vermuthen, dass die Acanthocephalen ebenso durch phyletische Rückbildung aus den Gephyreen, wie die Cestoden und Trematoden aus den Turbellarien entstanden sind. Beide Gruppen zeigen uns in ausgezeichneter Weise den hohen Grad, welchen die paläontologische Dege- 


\section{Systematische Einleitung in die Entwiokelungsgeschichte.}

neration in Folge langer Anpassung an entoparasitische Lebensweise erreichen kann, und der sich namentlich im Verlust des Darmcanals ausspricht.

\section{Dritte Classe der Scoleciden: Nematelminthes. Rundwiirmer.}

Die Rundwürmerclasse beschränken wir auf die beiden Abtheilungen der Chaetognathen (Sagittae) und der echten Nematoden (Strongy/oidea). Beide sind, wie A. Schneider gezeigt hat, besonders durch den eigenthümlichen Bau ihrer Leibesmuskulatur auf das nächste verwandt. Der eylindirische Körper aller Nematoden ist stets deutlich aus vier Antimeren zusammengesetzt, welche durch die vier longitudinalen Muskelfelder, 2 dorsale und 2 ventrale, bezeichnet werden. Diese sind getrennt in der Medianebene durch die dorsale und ventrale Medianlinie (area mediana), in der Lateralebene durch die rechte und linke Seitenlinie (area lateralis) ${ }^{1}$ )

\section{Erste Ordnung der Nematelminthen: \\ Chaotognathi. Pfeilwürmer.}

Die merkwürdige Ordnung der Chaetognathen oder Oestelminthen wird gegenwärtig nur durch die einzige Gattung $S_{\text {ugilta gebildet. Diese erscheint }}$ nach unserer vorhergehenden Auseinandersetzung als ein ausserordentlich alter Wurm-Typus, welcher sich von scinen alten Stammeltern seit dem archolithischen Zeitalter, in welchem sich vermuthlich die Wirbelthiere von letzteren abzweigten, nur wenig entfernt hat. Wie auch ihre durch Gegen b a u r bekannt gewordene Ontogenie beweist, bilden die Sagitten einen sehr conservativen Typus, der uns die ursprüngliche gemeinsame Stammform der Nematoden und Vertebraten vielleicht nur wenig modificirt zeigt.

\section{Zweite Ordnung der Nematelminthen: \\ Nomatoda. Fadenwürmer.}

(Synonym: Nematoidea. Strongyloidea. Filariae. Filarina.)

Die Fadenwürmer müssen, nach dem Bau ihrer Muskulatur zu schliessen, Sagittinen sein, welche durch Anpassung an entoparasitische Lebensart in ähnlicher Weise, obwohl nicht so weit gehend, zurückgebildet sind, wie die Acanthocephalen und Cestoden. Wahrscheinlich gehören in diese Ordnung nicht allein die Strongyloideen (Anguillula, Filaria, Ascaris), sondern auch die Gordiaceen, welche einen weiteren Grad der phyletischen Degene-

1) Auf diese Form-VerhäItnisse legen wir das grösste Gewicht, nicht allein, weil sie Nematoden und Chaetognathen als zwei nächst verwandte Würmergruppen nachweisen, sondern vielmehr besonders desshalb, weil sie uns einen Anknüpfungs - Punkt für die wichtigsten Descendenz-Fragen anderer Thierstämme darzubieten scheinen. Wenn die Wirbelthi e re, wie wir glauben, nicht aus einem eigenen Stamin sich entwickelt, sondern von den Würmern abgezweigt haben, so stehen sie offenbar den Nematelminthen am nächsten, und die Idee $M$ eis s ner's von einem verwandtschaftlichen Zusammenhang der Sagitten und Vortebraten, welche so viel verspottet wurde, hat doch vielleicht eine etwelche Begründung. - Wie uns der Querschnitt jedes Fisch-Schwanzes deutlich beweist, ist auch der Wirbelthier-Rumpf urs prïngli ch aus vier (nicht aus $z$ wi!) Antimeren zusammengesetzt (Vergl. Bd. I, S. 516, 51T), und zwar zeigen die niederen Vertebraten genau dieselbe Ausfubrung derinterradialen eutetrapleuren Grund- 
ration zeigen. Vielleicht jedoch sind die Gordiaceen nicht zu den Nematelminthen, sondern zu den Rhynchelminthen zu stellen, worauf möglicherweise der Hakenrüssel ihrer Larven hindeuten würde.

Zweiter Cladus der Würmer:

Annelida. Ringelwiirmer.

Dieser weniger mannichfaltig entwickelte Ast des Subphylum der Würmer zeigt uns diejenige Würmer-Form, welche durch die Homonomie zahlreicher Metameren besonders in die Augen springt, und bereits in den Cestoden-Ketten einen Ausdruck findet, zur höchsten Höhe entwickelt. Aller Wahrscheinlichkeit nach haben sich die Anneliden aus den Nemertinen oder aus gemeinsamer Wurzel mit diesen entwickelt, wiewohl andere Anzeichen auf eine nähere Verwandtschaft mit den Nematelminthen hindeuten. Man ptlegt neuerdings den Anneliden - Cladus gewöhnlich in fünf Ordnungen einzutheilen, nämlich 1. Gephyrea. 2. Hirudinea. 3. Onychophora. 4. Oligochaeta. 5. Chaetopoda. Von diesen haben wir die drei ersten bereits vorher an andere Stellen gewiesen, so dass bloss die beiden letzten als echte Anneliden übrig bleiben. Bei ihrer bedeutenden Verschiedenheit glauben wir denselben den Rang von Classen ertheilen zu müssen.

Erste Classe der Auneliden:

Drilomorpha, H. Kahlwï̈mer.

Wir vereinigen in dieser Classe die beiden Ordnungen der Oligochaeten und der von $\nabla$ ictor Carus zuerst unterschiedenen Haloscolecinen, ron denen die letzteren wahrscheinlich als Uebergangsstufe von den ersteren zu den Chactopoden von Wichtigkeit sind. Ob dieselben wirklich sich aus gemeinsamer Wurzel mit den Chaetopoden entwickelt haben, ist jedoch nicht ganz sicher, da sie in mancher Beziehung den Nematelminthen näher stehen.

Erste Ordnung der Drilomorphen.

Oligochaeta. Land-Kahlwïrmer.

(S ynonym : Lnumbricina. Scoleina. Terricolae.)

Von allen echten Anneliden stehen die Oligochaeten auf der tiefsten Stufe, und bieten uns vielleicht in den Naidinen noch wenig veränderte, alte Süsswasserformen, welche den Typus der gemeinsamen Anneliden-Vorfahren sehr conservativ festgehalten haben. Wahrscheinlich sind es diese unvollkommensten Anneliden, welche zunächst aus den Scoleciden hervorgegangen sind, und $z$ war vermuthlich aus der Nemertinen - oder doch gemeinschaftlich mit diesen aus der Rhabdocoelen-Gruppe. Von den Naidinen oder von den Tubificinen, oder von nahen Verwandten dieser im Süsswasser lebenden Oligochaeten haben sich wohl die Enchytraeinea und die Iumbricinen abgezweigt, welche sich an das Landleben gewöhnt haben.

form, wie die Nematoden. Auch bei den Fischen finden wir noch deutlich die viè longitudinalen IIuskelgxuppen der Nematodeu (,Seitenrumpfmuskeln"), welche rechts und links (in der Lateralebone) durch die beiden "Seitenlinien", oben und unten (in der Medianebene) durch die beiden „Medianlinien" geschieden werden. Vielleicht ist daher unsere Vermuthung richtig, dass die alten Ureltern der Wirbelthiere eben so einerseits durch progressive, wie die Nematoden andrerseits durch regressive Metamorphose aus den Vorfahren der nur wenig veränderten Chaetugnathen sich hervorgebildet haben. 
LXXXIV Systematische Einleitung in die Entwickelungsgeschichte.

\section{Zweite Ordnung der Drilomorphen: \\ Haloscolecina. See-Kahlwïl'mer.}

Diese Gruppe von Seewürmern umfasst die beiden Familien der Capitelliden oder Halelminthen (Capitella, Lumbriconais) und der Halonaiden (Dero, Polyophthalmus, Pleigophthalmus etc.). Sie bilden den unmittelbaren Uebergang von den Oligochaeten zu den Chaetopoden.

Zweite Classe der Anneliden:

Chaetopoda. Borstenwïirmer.

(S ynonym: Polychaeta. Branchiata. Annulata.)

Die Chaetopoden-Classe, wie wir sie hier begrenzen, umfasst die drei Ordnungen der Gymnocopen, Tubicolen und Vagantien. Von diesen hat sich. wahrscheinlich die letzte unmittelbar aus den Haloscolecinen entwickelt, während die beiden ersteren specielle Anpassungs-Formen von divergenten Zweigen der Vagantien darstellen.

Erste Ordnung der Chaetopoden:

Vagantia. Raubuürmer.

(Synonym: Dorsibranchia. Rapacia. Errantia.)

Diese äusserst formenreiche Ordnung bildet den eigentlichen Hauptstamm sowohl der Chaetopoden-Classe als auch des ganzen Anneliden-Cladus. Es gehört hierher nicht allein die bei weitem grösste Zahl aller Anneliden-Familien, sondern auch die höchsten und vollkommensten echten Würmer, unter denen namentlich die Aphroditen, Amphinomen, Nerciden etc. sich auszeichnen. Durch unmittelbare Uebergangs-Formen mit den Haloscolecinen verbunden, haben sich die Vagantien vermuthlich zunächst aus diesen entwickelt.

Zweite Ordnung der Chaetopoden:

Tubicolae. Röhrenwï̈mer.

(Synonym: Capitibranchia. Isimivora. Sedentia.)

Diese Ordnung umfasst diejenigen Würmer, welche die zahlreichsten fossilen Reste hinterlassen haben, nämlich harte, meist verkalkte Röhren, welche leicht sich erhalten konnten, und welche in allen Formationen, von den silurischen an, gefunden werden. Doch sagen dieselben bei ihrer indifferenten Form und als blosse Hautausscheidungen von sehr verschieden gebauten Thieren über deren Beschaffenheit gar nichts Näheres aus. Für die Phylogenie sind diese, wie alle anderen fossilen Würmer-Reste völlig werthlos. Es gehören zu den Tubicolen die Serpulaceen, von denen Serpula, Vermilia und Spirorbis, die Terebellaceen, von denen Terebella, und andere Familien, von denen verschiedene Gattungen fossile Röhren hinterlassen haben. Die Ordnung hat sich jedenfalls erst durch Anpassung an sitzende Lebensweise aus den Vagantien hervorgebildet.

Dritte Ordnung der Chaetopoden;

Gymnocopa. Ruderuïrmer.

Diese kleine, aber sehr eigenthümliche Gruppe, welche nur die Familie der frei schwimmenden Tomopteriden umfasst (Tomopteris), scheint uns nur 
einen divergenten, durch besondere Anpasssungs-Verhältnisse veränderten Seitenzweig der Vagantien-Ordnung darzustellen.

\section{Dritter Cladus der Würmer: \\ Rotatoria. Bäderthierchen.}

Dieser kleine Ast des Subphylum der Würmer umfasst nur die einzige Classe der liäderthierchen, welche aber durch ihre vielfachen und verwickelten Verwandtschafts - Beziehungen zu fast allen Hauptgruppen des Articulaten-Stammes von ganz besonderem Interesse ist, und daher auch den Systematikern von jeher die grössten Schwierigkeiten verursacht hat. Bald sind die Rotatorien zu den Infusorien, bald zu den Turbellarien, bald zu den Anneliden, bald zu den Crustaceen gestellt, und von den Einen eben so entschieden für echte Würmer, wie von den Andern für echte Arthropoden erklärt worden. In der That sind rerwandtschaftliche Beziehungen zu allen diesen Gruppen vorhanden, und der lebhafte Streit über ihre Stellung in dieser oder jener Gruppe zeigt deutlich, wie alle Systematik ohne das Licht der Descendenz-Theorie im Dunkeln tappt.

Nach unserer Ansicht ist die Classe der Räderthierchen ein schr alter Ueberrest von demjenigen Aste des Articulaten-Stammes, aus welchem sich zunächst die Crustaceen und somit weiterhin die Arthropoden ïberhaupt entwickelt haben. Einerseits sind die Rotatorien durch ihre tiefsten Formen so innig mit den Turbellarien (Rhabdocoelen) und selbst noch mit den Infusorien, andrerscits durch ihre höchsten Formen so nah mit den Crustaceen (Entomostraca) und dadurch mit dem Subphylum der Arthropoden verbunden, dass wir dieselben als eine Zwischenform zwischen den Scoleciden und den Arthropoden betrachten müssen, d. h. als uralte und sehr wenig veränderte directe Descendenten von jenen Würmern, aus denen sich die Arthropoden entwickelt haben. Die verschiedenen Formen, welche gegenwärtig noch aus der Rotatorien - Gruppe lebon und nur dürftige Zweiglein cines vormals gewiss sehr entwickelten Astes darstellen, lassen unter sich keine derartigen Unterschicde wahrnchmen, dass wir darauf hin einen Stammbaum der Classe selbst entwerfen könnten.

\section{Drittes Subphylum des Articulaten-Stammes: Arthropoda. Glicderfiusser.}

Der Unterstamm der Arthropoden wird zwar gewöhnlich dem der Würmer als völlig getrennt gegenübergestellt, und Beide werden als zwei selbstständige Phylen betrachtet. Indessen müssen wir die schon von Bär und Cuvier bewerkstelligte Vereinigung derselben in dem "Typus" oder Unterreich der Articulaten als völlig berechtigt reconstituiren, da die Arthropoden nur einen höher entwickelten und weiter differenzirten Zweig des Würmerstammes darstellen. Abgesehen ron den allgemeinen morphogenetischen Gründen, durch welche diese Ansicht fest gestuitzt wird, sind selbst die anatomischen Homologieen zwischen Beiden so zahlreiche, dass eine systematische Trennung sehr schwierig ist, und dass insbesondere die beiden Claden der Rotatorien und der Anneliden von den einen Zoologen mit eben so viel Bestimmtheit zu den Arthropoden, wie von den Anderen zu den echten Würmern im engeren Sinne, den Scoleciden gezogen werden. Welche von diesen beiden Claden, ob die Anneliden oder die Rotatorien, unmittelbar den genealogischen 


\section{Systematische Einleitung in die Entwickelungsgeschichte.}

Uebergang von den Scoleciden zu den Arthropoden herstellen, könnte zweifelhaft erscheinen. Indessen glauben wir, dass bei weitem mehr Argumente zu Gunsten der Rotatorien sprechen, während wir die Anneliden vielmehr für einen den Arthropoden parallel aufsteigenden Zweig des Würmerstammes halten, der sich schon früh von den Rotatorien getrennt hat.

Das Subphylum der Arthropoden wird gegenwärtig allgemein in die vier Classen der Crustaceen, Arachniden, Myriapoden und Insecten eingetheilt. Indessen ist es offenbar, dass die drei letzteren Classen unter sich viel inniger zusammenhängen und viel geringere Differenzen darbieten, als die verschiedenen Legionen und selbst die verschiedenen Ordnungen der Crustaceen. Diese könnten mit demselben oder noch grösserem Rechte als selbstständige Classen betrachtet werden. Wir vereinigen daher jene drei (durch Tracheen Luft athmenden) Arthropoden-Classen nach dem Vorgange von Bronn in dem Cladus der Trache a ten und stellen diesem als zweiten Cladus die (durch Kiemen Wasser athmenden) Crustaceen als Cariden gegenüber. Offenbar haben sich die Tracheaten erst aus den Cariden, diese dagegen unmittelbar aus den Würmern, und zwar am wahrscheinlichsten aus den Rotatorien entwickelt. Die Paläontologie liefert uns leider hierüber nur geringe Andeutungen, viel wichtigere die Ontogenie. Die phyletische Entwickelung der Hauptabtheilungen der Arthropoden fällt grösstentheils in die archolithische Zeit, aus welcher uns nur die wenigen cambrischen und die silurischen Reste berichten. Zudem sind die Körper der meisten Tracheaten und auch die der zarteren Crustaceen, nur wenig der Fossilisation fähig.

\section{Erster Cladus der Arthropoden: \\ Carides. Krelse (Kiemenathmende Artliropoden).}

Dieser Zweig umfasst nur die formenreiche Classe der Crustaceen, deren einzelne Hauptabtheilungen (Subclassen, Legionen, Ordnungen) man recht gut als selbsständige Classen aufführen könnte, wenn nicht so viele verbindende Zwischenglieder zwischen denselben existirten. Die Paläontologie liefert uns über die Phylogenie der Cariden weit umfassendere Aufschlüsse als über die der Tracheaten, jedoch wesentlich nur über das successive Auftreten einzelner Legionen. Am wichtigsten erscheint in dieser Beziehung das ganz uiberwiegende Vorherrschen der Trilobiten in der Primärzeit, der Macruren (und vielleicht auch der Poecilopoden?) in der Secundärzeit, während für die Tertiärzeit die Brachyuren bezeichnend sind.

\section{Einzige Classe des Cariden-Cladus: \\ Crustacen. Kruster.}

Diese Classe ist nebst den Radiolarien (vergl. S. XXIX) die einzige unter den wirbellosen Thieren, welche bisher eine genealogische Analyse im Sinne der Descendenz - Theorie gefunden hat. Fritz Müller hat sich dieser eben so schwierigen als interessanten $\Lambda$ ufgabe mit so viel Geist und mit so tiefem Verständniss unterzogen, dass wir hier nichts besseres thun, als auf seine ausgezeichnete Schrift „F $\mathrm{F}$ r $\mathrm{D}$ a rw in“ verweisen können (Vergl. unten S. 185). Allerdings sind unsere Kenntnisse dieser äusserst differenzirten und auf das Mannichfaltigste durch Anpassung veränderten Classe immer noch so unvollkommen, dass Fritz $\mathrm{M}$ üll er es noch nicht wagte, „die einzelnen Fäden, welche die Jugendformen der verschiedenen Kruster liefern, zu einem Gesammtbilde der Urgeschichte dieser Classe zu verweben." Wenn wir trotz 
unserer viel geringeren Kenntniss derselben dennoch diesen Versuch hier wagen, so geschieht es nur, um einen festen und angreifbaren Boden zur Discussion dieser Fragen vorzubereiten. Als die gemeinsame Stammform aller Crustaceen ist $z$ weifelsohne der Niuplius zu betrachten, welchen die vergleichende Ontogenie der Cariden mit der überraschendsten Sicherheit als solchen nachweist.

Erste Subclasse der Crustaceen:

Archicarida, H. Urliebse.

Diese Subclasse enthält die uns unbekannten selbstständigen, persistenten Nauplius - Formen, welche den Uebergang von don Rotatorien zu den übrigen Krustern herstcllten. Zweifelsohne hat die Nauplius - Form in der alteren archolithischen Zeit, lange vor der Silur-Zeit, einen sehr formenreichen Cariden-Zweig gebildet, dessen Repräsentanten uns jedoch wegen ihrer sehr geringen Grösse und Consistenz nicht erhalten bleiben konnten. Wahrscheinlich schon in der laurentischen, vielleicht schon in der antelaurentischen Zeit hat sich der Nuuplius aus den Rotatorien, oder mit diesen zusammen aus niederen Scoleciden entwickelt. Als divergente Zweige der gemeinsamen Nauplius-Form sind alle übrigen Subclassen der Crustaceen - Classe zu betrachten. Einerseits ging aus dem Nauplius die Zö̈a hervor, welche der Stammvater aller Malacostraca und wahrscheinlich auch der Tracheaten wurde. Andrerseits entwickelten sich aus der Nauplius - Gruppe, ohne Zwischentritt der Zö̈a-Form, alle übrigen Cariden-Legionen, welche frïher als Entom. ostrac a zusammengefasst wurden.

\section{Zweite Subclasse der Crustaceen: \\ Pectostraca, H. Ha/threbse.}

In dieser Legion fassen wir die beiden merkwürdigen, und von den übrigen Krustern sich am meisten entfernenden Ordnungen der Cirripedien und Rhizocephalen zusammen, von denen uns die ersteren vorzüglich durch die classischen Untersuchungen von $\mathrm{Ch}$ arles $\mathrm{D}$ arwin, die letzteren durch diejenigen von Fritz Müller genauer bekannt geworden sind. Wie der letztere nachgewiesen hat, stimmen die Nanplius - Stadien beider Ordnungen so sehr unter sich überein und weichen durch wesentliche Charaktere so sehr von denen der anderen Crustaceen ab, dass wir Beide als divergente Aestchen eines einzigien, tief unten abgehenden $\mathrm{Z}_{w}$ eiges betrachten muissen. Beide sind durch Hermaphroditismus ausgezeichnet. Durch weit gehende phyletische Degeneration entstehen aus ihnen die seltsamsten Gestalten.

\section{Erste Legion der Pectostraken: \\ Rhizocephala. Wurzelkrebse.}

Diese höchst merkwürdige Krebs - Legion, welche die Gattungen Pellogaster, Sacculina und Lernoeodiscus umfasst, zeigt uns den äussersten Grad parasitischer Degeneration unter den Gliederthieren, indem. der ganze Körper zu einem einfachen, beiderlei Geschlechtsproducte erzeugenden Sacke reducirt wird. Ihre Ontogenie beweist, dass sie neben den Cirripedien als besonderer Zweig der Pectostraken-Gruppe zu betrachten sind. Fossile Reste konnten sie nicht hinterlassen. 
LXXXVIII Systematische Einleitung in die Entwickelungsgeschichte.

$$
\begin{aligned}
& \text { Zweite Legion der Pectostraken: } \\
& \text { Cirripedia. Rankenfüsser. }
\end{aligned}
$$

Diese ausgezeichnete Krebslegion besitzt harte Kalkschalen, welche der fossilen Erhaltung fähig sind. Sichere Reste von den Balaniden (Chthamalus) sind bereits in der Kreide, von den Lepadiden (Pollicipes) im Jura gefunden. Vielleicht aber ist auch der devonische Bostrichopus ein Cirriped. Wahrscheinlich haben sich die Cirripedien schon in der archolithischen Zeit von den andern Crustaceen abgezweigt.

\section{Dritte Subclasse der Crustaceen: \\ Ostracoda. Muscliellirebse.}

Diese sehr eigenthümliche Krebsgruppe, welche nur die eine Ordnung der Conchocariden, mit den Familien der Cypriden, Cytheriden und Cypridiniden umfasst, zeigt so höchst verwickelte Verwandtschafts-Beziehungen zu fast allen übrigen Subclassen der Crustaceen; dass ihr ein Platz an den verschiedensten Orten angewiesen worden ist. Bald haben die Ostracoden für nächste Verwandte der Cirripedien, bald der Branchiopoden, bald der Poecilopoden, bald der Isopoden gegolten. Hieraus und aus ihrer Ontogenie geht hervor, dass wir es mit einer sehr alten und seit der archolithischen Zeit sehr wenig veränderten Thiergruppe zu thun haben, welche sich gleich den Pectostraken schon sehr frühzeitig, und zwar wahrscheinlich aus gemeinsamer Wurzel mit diesen, aus der Archicariden-Gruppe entwickelt hat. Die nächste Verwandtschaft mit den Cirripedien wird insbesondere durch die zweiklappige Schale bewiesen, welche die jugendlichen Larven („CyprisStadien") der letzteren mit den Ostracoden theilen. Fossile Schalen von Ostracoden (Cypris, Cythere, Cypridina) finden sich massenhaft schon in den ältesten Formationen, vom Silur an, am reichlichsten in den tertiären Ablagerungen.

\section{Vierte Subclasse der Crustaceen: \\ Copepoda. Ruderkrebse.}

Diese Subclasse, welehe ihre phyletische Entwickelung aus den Archicariden noch heute in ihrer Ontogenie sehr deutlich erkennen lässt, umfasst die beiden Legionen der Eucopepoden und Siphonostomen, von denen fossile Reste nicht bekannt sind. Die letzteren sind lediglich durch Parasitismus rückgebildete Seitenzweige der ersteren.

Erste Legion der Copepoden:

Eucopepoda, H. Freilebende Copepoden.

Diese Legion, welche die Familien der Cyclopiden, Calaniden, Corycaeiden, Notodelphyiden und viele Andere umfasst, bildet den eigentlichen Stamm der Copepoden - Gruppe, welcher sich unmittelbar aus den Archicariden entwickeit hat.

Zweite Legion der Copepoden:

$$
\text { Siphonostoma. Parasitische Copepoden. }
$$

Diese Legion, welche früher als eine besondere Hauptabtheilung der Crustaceen aufgeführt wurde, besteht lediglich aus echten Copepoden, welche 
durch Anpassung an parasitische Tebensweise die ausgezeichnetsten regressiven Metamorphosen erlitten haben. Es gehören hierher die Ergasiliden, Caligiden, Chondracanthiden, Penelliden etc.

\section{Fünfte Subclasse der Crustaceen: \\ Branchiopoda. Blattrebse.}

Diese Subclasse steht der vorigen am nächsten, und hat sich wahrscheinlich aus der gleichen Archicariden-Form mit derselben hervorgebildet. Doch erreicht sie einen weit höheren Entwickelungsgrad als die Copepoden. Es gehören hierher die beiden lebenden Legionen der Cladoceren und der Phyllopoden, und wahrscheinlich auch die ausgestorbene Legion der Trilobiten, welche in der Primär-Zeit die Hauptmasse der Kruster bildete.

\section{Erste Legion der Branchiopoden: \\ Phyllopoda. Blalt/üisser.}

Diese Legion, welche den eigentlichen Stamm der BranchiopodenGruppe bildet, umfasst die Familien der Artemiden (Altemia, Branchipus), der Apusiden ( $A$ /pus) und der Estheriden (Estheria, Limnadia). Sie hat sich scheinbar seit ihrer Abzweigung von den $\Delta$ rchicariden in sehr gerader Linic entwickelt, und ist nur wenig durch Anpassung verändert worden. ApusFormen, welche von dem heutigen Apus sehr wenig abweichen; finden sich bereits in der Kohle and in der Trias.

\section{Zweite Legion der Branchiopoden : \\ Cladocera. Wasserflöhe.}

Diese Legion, welche die einzige Ordnung der Daphniden umfasst (Daphnia, Sida, Polyphemus etc.) betrachten wir als einen Seitenzweig der Phyllopoden, welcher aus diesen durch besondere Anpassungs - Verhältnisse entstanden ist. Fossile Reste sind nicht bekannt.

\section{Dritte Legion der Branchiopoden: Trilobita. Palaeaden.}

Wahrscheinlich unmittelbar aus den Phyllopoden hervorgegangen, bildete diese Legion in der primordialen und primären Zeit eine äusserst vielgestaltige und hoch entwickelte Gruppe, welche damals der Hauptrepräsentant nicht allein der Crustaceen, sondern der Gliederthiere überhaupt war. Schon im oberen cambrischen Systeme vorhanden, erreichten die Trilobiten in der jüngeren Silurzeit die Acme ihrer Entwickelung, wo sie ausserordentlich massenhaft entwickelt waren, nahmen dann im Devon schon stark ab, und starben in der Kohle aus. Vielleicht entwickelte sich aus ihnen die folgende Subclasse.

\section{Sechste Subclasse der Crustaceen: Poecilopoda. Schildkrebse.}

Diese sehr eigenthümliche Subclasse umfasst die beiden Legionen der Xiphosuren und der Gigantostraken, von denen nur noch die ersteren einen einzigen lebenden Repräscntanten zeigen. Wahrscheinlich bildete diese Subclasse in der primordialın, primären und sccundären Zeit einen vielgestalti- 
XC Systematische Einleitung in die Entwickelungsgeschichte.

gen Zweig von schr hoch entwickelten Crustaceen, welche erst später im Kampfe um das Dasein dem Andrange der stärker sich entwickelnden Malakostraken unterlagen. Weder ihre noch ganz unbekannte Ontogenie, noch ihre Paläontologie vermag uns gegenwärtig ïber ihre Phylogenie aufzuklären. Doch haben sie sich aller Wahrscheinlichkeit nach aus der vorigen Subclasse entwickelt, entweder aus den Trilobiten oder tiefer herab, aus älteren Branchiopoden. Die Gigantostraken sind vielleicht eine eigene Subclasse.

\section{Erste Legion der Poecilopoden: \\ Xiphosura. Pfeilschwänzer.}

Nur die einzige Sippe Limulus giebt uns heutzutage noch ein Bild von dieser abweichenden Krebsgruppe, welche besonders in der Secundär-Zeit reich. lich entwickelt gewesen zu sein scheint. Fossile Reste derselben finden sich bereits im Carbon (Bellinurus) und im Perm (Limulus), jedoch selten. Reichlicher werden sie erst in der Trias (Halycine) und im Jura, wo sie ihre Acme erreichen.

\section{Zweite Legion der Poecilopoden: \\ Gigantostraca, H. Riesenkrebse.}

In dieser Legion vereinigen wir eine Anzahl von sehr eigenthümlichen ausgestorbenen Crustaceen, welche sich den Xiphosuren zunächst anzuschliessen scheinen, nämlich die beiden Gruppen der P terygotiden (Pterygotus), welche im Silur und Devon, und der Eurypteriden (Eurypterus), welche im Devon und der Steinkohle vorkommen. Es finden sich unter ihnen kolossale Formen, welche gegen sieben Fuss Länge erreichten, und also alle anderen bekannten Arthropoden bei weitem an Grösse übertrafen. Früher wurden sie zum Theil fuir Fische gehalten. Wahrscheinlich haben sich dieselben, zugleich mit den Limuliden oder getrennt von diesen, aus den Branchiopoden hervorgebildet. Vielleicht bilden sie mehrere verschiedene Legionen.

\section{Siebente Subclasse der Crustaceen: \\ Malacostraca. Panzerkrebse.}

Diese umfangreiche Subclasse umfasst den bei weitem grössten Theil aller jetzt lebenden Crustaceen, welche jedoch unter sich sämmtlich so nahe verwandt sind, dass wir dieser Subclasse keinen höheren Kang, als den sechs vorhergehenden einräumen können. Obgleich mit ihren ältesten Wurzeln bis in die Primärzeit hinabreichend, hat sie sich doch erst in der Jurazeit reichlicher entwickelt und ist erst in der Tertiärzeit zu ihrer vollen Blüthe und zur Herrschaft über die übrigen Crustaceen gelangt, so dass namentlich die Poecilopoden und Branchiopoden, welche in den älteren Zeiträumen herrschten, jetzt ganz gegen sie zuriucktreten. Von den beiden Legionen, in welche sich die Malacostraca theilen, den Podophthalmen und den Edriophthalmen, sind letztere die jüngeren, welche sich erst in der Jurazeit aus den ersteren entwickelt zu haben scheinen. Die Phylogenie dieser wichtigen Gruppe ișt durch Fritz $\mathrm{II}$ üller's glückliche und geistrolle Untersuchungen („Für Darwin") und insbesondere durch seine Entdeckung der Nauplius-Larven bei Eucariden, plötzlich so überraschend aufgcklärt worden, dass über die $A b-$ zweigung auch dieser Subclasse von den Archicariden kein Zweifel mehr bestehen kann. Auch die Stammform dieser Subclasse ist, wie bei allen vor- 
hergehenden, ein Nauplius, welcher bei seiner weiteren Metamorphose in den für dicse $\Lambda$ btheilung ganz charakteristischen Zoëa-Zustand übergeht, der sich noch wenig von den Phyllopoden entfernt. Diese Zoëa-Form ist höchst wichtig nicht allein als gemeinsame Stammform aller Malacostraken, sondern höchst wahrscheinlich auch der Tracheaten.

\section{Erste Legion der Malacostraca: Pod oph thalma. Stielaugen.}

Die Podophthalmen oder Thoracostraken umfassen den älteren und mächtigeren $\mathrm{Zweig}$ der Malacostraca, welcher sich in die rier Ordnungen der Zoëpoda, Schizopoda, Stomatopoda und Decapoda spaltet. Von diesen sind die beiden letzteren divergirende Zweige der Schizopoden, die ihrerseits aus den Zoëpoden hervorgegangen sind.

\section{Erste Ordnung der Podophthalmen: \\ Zoëpoda, H. Zoëa-Krebse.}

Diese Ordnung umfasst die uns unbekannten, ältesten, gemeinsamen Stammformen aller Malacostraken, welche schon in der Primordial-Zeit von den Archicariden sich müssen abgezweigt, uns aber keine fossilen Reste hinterlassen haben. Die merkwürdigen Zö̈a-Zustände, welche noch heute in der Ontogenese der meisten Podophthalmen eine so wichtige Rolle spielen, geben uns ein Bild von der Form dieser alten Malacostrara-Ahnen, welche, wie Fritz Müller trefflich gezeigt hat (l. c. S. 86), eine phyletische Entwickelungsstufe der Malacostraken darstellen, die durch eine ganze Reihe geologischer Formationcn als bleibende Form bestanden haben muss. Aus ihr haben sich höchstwahrscheinlich als zwei divergente Zweige die Schizopoden und die Protracheaten entwickelt, von denen jene die gemeinsame Stammform aller Malacostraken, diese aller Tracheaten wurden.

\section{Zweite Ordnung der Podophthalmen: \\ Schizopoda. Spaltfiisser.}

Die Schizopoden oder Caridioiden repräsentiren in den Genera $\mathbf{M y}$ sis, Euphausia etc. die ältesten jetzt noch lebenden Ahnen der Malakostraken, welche unmittelbar aus den Zoëpoden hervorgegangen sind. Als zwei divergirende $Z$ weige dieser Ordnung sind die Stomatopoden und Decapoden zu betrachten, von denen man bald diese bald jene Gruppe mit den Schizopoden vereinigt hat. Gewisse Eucariden (Peneus) und andere Macruren durchlaufen noch gegenwärtig während ihrer Ontogenese das Stadium der Mysis.

\section{Dritte Ordnung der Podophthalmen: \\ Stomatopoda. Maulfiisser.}

Diese Gruppe bildet den bei weitem schwächeren Zweig des Schizopoden-Astes, welcher nur die Familie der Squilliden oder Heuschreckenkrebse (Squilla, Gonodactylus, Erichthus etc.) umfasst. Er hat sich wahrscheinlich viel später als der Decapoden-Zweig, aus den Schizopoden hervorgebildet. Die, ältesten fossilen Reste desselben finden sich in Jura (Squilla). 
XCII Systematische Einleitung in die Entwickelungsgeschichte.

\author{
Vierte Ordnung der Podophthalmen. \\ Decapoda. Zehufiisser.
}

Diese äusserst formenreiche Gruppe, zu welcher die grössten und stärksten aller jetzt lebenden Krebse gehören, und welche seit der Tertiärzeit ebenso dominirt, wie in der Silurzeit die Trilobiten, wird allgemein in die drei Unterordnungen der Macruren, Anomuren und Brachyuren eingetheilt. Von diesen haben sich die Macruren als die ältesten unmittelbar aus den Schizopoden entwickelt, während die Brachyuren als die vollkommensten erst in der Kreidezeit ans den Anomuren, und durch diese aus den Macruren hervorgegangen sind. Die Unterordnung der Macrura beginnt mit der wichtigen Familie der Eucariden oder Caridinen (Garneelen), von denen einige Peneus-Arten nach der interessanten Entdeckung Fritz Müller's die Phylogenie der Decapoden noch ausgezeichnet in ihrer Ontogenie conservirt haben. Diese Peneus-Arten durchlaufen nach einander folgende vier Stadicn: I. Nauplius; II. Zö̈a; III. Mysis; IV. Peneus; und bestätigen so auf das Bestimmteste ihren vorher erläuterten Stammbaum. Bei den meisten anderen Decapoden ist das NaupliusStadium, und bei sehr Vielen auch das Zoëa-Stadium durch secundäro Abkürzung der Entwickelung verloren gegangen. Die Eucariden sind offenbar die reinsten Repräsentanten der alten gemeinsamen Starnmform aller Decapoden. Aus ihnen haben sich als 2 wei divergirende $\mathrm{Zweige}$ einerseits die übrigen, jüngeren und vollkommneren Macruren (die Familien der Scyllariden und Astaciden), andererseits die Unterordnung der Anomura entwickelt. Die letzteren sind theils besondere Anpassungs-Zustände der Macruren (Galathea, Pagurus), theils Uebergangs-Formen zu der Unterordnung der Brachyura oder Krabben, welche sich in der Kreidezeit aus ihnen entwickelt haben. Die Macruren, von denen die ältesten Reste (Gampsomyx) schon in der Steinkohle liegen, scheinen bereits im Jura dic Acme ihre Phylogenese erreicht zu haben, während die Brachyuren als die vollkommensten Decapoden noch gegenwärtig in Zunahme begriffen sind.

\title{
Zweite Legion der Malacostraca: Edriophthalma. Sitzaugen.
}

Die Edriophthalmen oder Arthrostraken, welche in mehrfacher Beziehung, obgleich verhältnissmässig unansehnlich, als die vollkommensten Crustaceen angesehen werden müssen, haben sich, wie es scheint, am spätesten von allen entwickolt, und zwar bilden sie wohl einen, von den Decapoden divergirenden Zeitenzweig der Schizopoden. Sic spalten sich in die beiden Ordnungen der Isopoden und Amphipoden, von denen die ersteren im Jura, die letzteren im Eocen ihrer ältestcu (übrigeils unbedeutenden) Reste hinterlassen haben.

\section{Erste Ordnung der Edriophthalmen:}

Amphipoda. Flohtrebse.

Diese Ordnung spaltet sich in die drei Unterordnungen der Saltatoria (Gammarus, Orchestia), der Ambulatoria (Hyperia, Phromima) und der Laemodipoda (Caprella, Cyamus) von denen die beiden letzte- 
ren wohl aus den ersteren als zwei divergirende Aeste durch Anpassung entstanden sind. Die Laemodipoden bilden meist eine besondere Ordnung.

\section{Zweite Ordnung der Edriophthalmen : \\ Isopoda. Asselkrebse.}

In mehrfacher Beziehung verdient diese Ordnung, welche neben den Amphipoden, und aus gemeinsamer. Wurzel mit ihnen von den Schizopoden abgegangen zu sein scheint, an die Spitze der Crustaceen-Classe gestellt zu werden. Durch Anpassung an sehr verschiedene Lebensverhältnisse zerfälit die Ordnung in eine Anzahl von Unterordnungen und Familien, die theils, wie die schmarotzenden Bopyriden (Bopyrus, Entoniscus, Cryptoniscus) eine rückschreitende phyletische Limbildung höchsten Grades erleiden, theils, wie die landbewohnenden Onisciden, sich zur Luftathmung erheben und Analogieen (aber keine Homologieen!) mit den Tracheaten, insbesondere den Myriapoden erwerben.

\section{Zweiter Cladus der Arthropoden:}

\section{Tracheata. Kerfe (Trachecnathmende Arthropoden).}

Dieser Cladus der Arthropoden umfasst die drei Classen oder Subclassen der Arachniden, Myriapoden und der echten Insecten (im engeren Sinne), und in den letzteren zugleich die bei weitem artenreichste $\mathbf{A b}$ theilung des ganzen Thierreichs. Jedenfalls haben sich die Tracheaten aus den Crustaceen und höchst wahrscheinlich aus den Zoëpoden entwickelt, worauf bereits Fritz Müller hindeutete Unter sich sind die drei Tracheaten-Gruppen so nah verwandt, dass man sie füglich eher, als die verschiedenen Subclassen der Crustaceen, in einer einzigen Classe vereinigen könnte. Die gemeinsame, uns unbekannte Stammform der drei Classen, ein Zoëpode, welcher sich an das Landleben und an die Luftathmung gewöhnte, und so allmählich im Laufe langer Generationen die sehr charakteristische Tracheen-Athmung erwarb, muss in dem Zeitraum zwischen der Silur-Zeit und der Kohlenzeit (also entweder in der Antedevon-, in der Devon- oder in der Antecarbon-Zeit) sich entwickelt haben; denn in der Silur-Zeit gab es noch keine landbewohnenden Organismen, in der Steinkohle aber traten bereits die ersten entwickelten Tracheaten, und zwar sowohl Insecten als Arachniden auf. Wir wollen diese Stammformen als Protracheaten den drei übrigen Classen voranstellen.

\section{Erste Classe der Tracheaten: \\ Protracheata. Urkerfe.}

Von diesen zwischen Silurzeit und Kohlenzeit aus den Zoëpoden entwickelten Stammformen der Tracheaten sind uns zwar keine fossilen Reste bekannt. Indessen erlaubt uns die vergleichende Ontogenie der Malacostraken, Arachniden, Myriapoden und Insecten, mit ziemlicher Sicherheit auf die Form derselben bestimmte Schlüsse zu ziehen. Gleich mehreren Zoëpoden (die uns noch jetzt in Zoëa-Stadien conservirt sind), und zugleich den echten Insecten, $z$ wischen welchen sie mitten inne standen, müssen die Protracheaten, als deren Typus man das hypothetische Genus Zoëntomon hinstellen könnte, drei Paar Kiefern und drei Paar locomotorische Extremitäten besessen haben. Aus diesen sechsbeinigen Zoentomiden ba- 


\section{Systematische Einleitung in die Entwickelungsgeschichte.}

ben sich höchst wahrscheinlich als gerade aus laufender Hauptzweig die Insecten, als schwächerer Seitenzweig die Arachniden entwickelt Die $\mathrm{My}$ riapoden stellen nur ein unbedeutendes Seitenästchen der Insecten dar. $\mathrm{Ob}$ jetzt noch Protrocheaten leben, ist zweifelhaft. Vielleicht könnte man die Solifugen hierher stellen, vielleicht auch jene "Hlïgellosen Insecten“, bei denen der Flügelmangel ursprünglich, nicht durch Anpassung erworben ist (falls es unter den lebenden Lnsecten solche giebt!).

\section{Zweite Classe der Tracheaten:}

\section{Arachnila. Spinnen}

Die Spinnen besassen ursprünglich, gleich den echten Insecten, drei Beinpaare, an drei getrennten Brust-Metameren befestigt, wie es die heute noch lebenden Solifugen deutlich erkennen lassen. Erst später hat sich bei der Mehrzahl derselben das hintere Kieferpaar den drei echten Beinpaaren assimilirt, daher man den Arachniden allgemein (aber mit Unrecht) als Unterschied von den Insecten vier echte Fusspaare zuschreibt. Die Verwandtschaft der verschiedenen Spinnen-Ordnungen ist nach unserer Ansicht bisher gewöhnlich sehr unrichtig beurtheilt worden, indem man sich dabei fast immer nur oder doch rorwiegend auf die A nalogieen, und nicht auf die Homologieen derselben stützte. Hier, wie bei den Crustaceen, bringt plötzlich dic Descendenz-Theorie helles Licht in das dunkle Chaos der Gestalten - Masse. Abgesehen von den beiden Legionen der Arctisken und Pantopoden, welche wir am liebsten ganz aus der Arachniden-Classe entfernen möchten, zerfallen die übrigen, echten Arachniden nach unserem Dafiirhalten in zwei divergento Zweige, Arthrogasteres und Sphaerogasteres, welche beide von der den Protracheaten nächstverwandten Solifugen-Form ihren Ausgang genommen haben. Die Arctisken und Pantopoden, namentlich die ersteren, haben sich dagegen wahrscheinlich schon viel früher von dem Arthropoden-Stamme abgezweigt. wir bilden daher aus ihnen die Subclasse der Pseudarachnen und stellen diesen die echten Spinnen als Autarachnen gegenuber.

Erste Subclasse der Arachniden:

Pseudarachnae, H. Scheiuspinnen.

Die Stellung dieser Gruppe unter den Arachniden betrachten wir als eine provisorische. Sie wird aber so lange beibehalten werden müssen, als nicht die Stelle ihrer Abzweigung rom Articulaten-Stamme entdeckt ist. Die beiden hierher gehörigen Legionen, Arctisken und Pantopoden, zeigen unter sich keine nähere Verwandtschaft.

\section{Erste Legion der Pseudarachnen: \\ Arctisca. (Tardigrada). Bürthierchen.}

Diese Legion umfasst nur die einzige Ordnung und Familie der Arctisken oder Tardigraden, die wir als einen uralten $\mathrm{Zweig}$ des GliederthierStammes betrachten, der wahrscheinlich viel älteren Ursprungs als die Arachnuden-Classe ist. Die Vierzahl der Beinpaare scheint uns nicht auf Homologie, sondern auf Analogie mit den Arachniden zu beruhen. Wir vermuthen, dass dieselben nähor den Würmern als den übrigen Glieder-Thieren stehen uıd viellcicht den Rotatorien, vielleicht den Scoleciden, mehr als den echten 
Arthropoden rerwandt sind. Stammen sie wirklich von den Protracheaten ab, so würden sie vielleicht als eigenthümlich angepasste, sehr alte Sphae.rogastern anzusehen sein und wohl den Milben am nächsten stehen.

Zweite Legion der Pseudarachnen:

Pantopoda. (Pycnogonida). Asselspinnen.

Diese Legion umfasst nur die einzige Ordnung und Familie $\operatorname{der} \mathbf{P}_{\mathbf{y}} \mathbf{c}-$ nogoniden, eine gleich der vorigen sehr eigenthümliche ArticulatenGruppe, welche jedoch viel nähere Verwandtschafts-Beziehungen $z u$ den übrigen Arthropoden zeigt. Viellcicht kann dieselbe als ein Zweig der Sphaerogastres betrachtet werden, der durch die einfache Anpassung an das Küstenleben seltsam modificirt worden ist. Vielleicht sind aber die Pantopoden auch sehr aberrante Crustaceen.

\section{Zweite Subclasse der Arachniden: \\ Autarachnae, H. Echie Spinnen.}

Hierher gehören alle Arachniden mit Ausnahme der Arctisken und Pantopoden. Alle Spinnen dieser Abtheilung sind zweifelsohne blutsverwandte Glieder eines einzigen Astes, welcher sich neben dem der vereinigten Insecten und Myriapoden von der Protracheaten-Classe abgezweigt hat. Diejenige Form, welche letztern am nächsten steht, sind die Solifugen, ron denen aus sich wahrscheinlich sowohl die Arthrogastres als Sphaerogastres, die beiden natürlichen Hauptgruppen der Autarachnen, als zwei divergente Zweige entwickelt haben. Zur Unterscheidung der verschiedenen Gruppen hat man bisher bei den Autarachnen, wie bei den Arachniden überhaupt, vorzugsweise die Differenzirung der Respirations-Organe benutzt. Offenbar ist diese hier aber nur von ganz untergeordnetem morphologischen Werthe, da sie bei nächstverwandten Arachniden durch verschiedene Anpassungs - Verhältnisse sehr rorschieden abgeändert ist. Die fossilen Reste der. Autarachnen (von den Pseudarachnen kennt man keine) sind im Ganzen sehr spärlich. Boch finden sich einzelne sehr deutliche Abdrücke von Arthrogastren (Scorpio, Chelifer) bereits in der Steinkohle, wogegen die Sphaerogastres erst im Jura auftreten (Palpipes). Dies stimmt überein mit unserer Vermuthung, dass die Sphaerogastres erst einen späteren Seitenzweig der Solifugen repräsentiren.

Erste Legion der Autarachnen:

Arthrogastres. Streckspinnen (Skorpione).

Diese Legion umfasst die Reihe der langgestreckten sogenannten "Arachnida crustaceiformia“, welche man auch kurzweg nach ihrem am höchsten entwickelten Zweige die Skorpione nennen könnte. Sie beginnt mit den Solifugen, welche durch die Phryniden mit den echten Skorpionen, und mit deren degenerirtem Seitenast, den Pseudoscorpionen verbunden sind.

Erste Ordnung der Arthrogastres:

Solifugae. Skorpionspinnen.

Die höchst interessante Ordnung der Solifugen wird gegenwärtig nur durch die einzige Familie der Solpugiden (Solpuga, Guleolles etc.) vertre- 


\section{Systematische Einleitung in die Entwickelungsgesehichte.}

ten. Wir erblicken in diesen Autarachnen die von allen lebenden Arachniden am wenigsten veränderten directen Nachlommen derjenigen Protracheaten, welche zwischen Silurzeit und Kohlenzeit von dem Hauptaste der Protracheaten sich abzweigten, um später die gemeinsamen Stammformen aller Autarachnen zu worden. Obgleich durch Anpassung sehr hoch entwickelt und zu den rollkommensten Arachniden gehörig, haben dennoch andererseits die Solifugen den ursprünglichen Protracheaten-Typus, der alle Arachniden, Myriapoden und lnsecten als nächste Blutsverwandte verbindet, in so ausgezeichneter Weise conservirt, dass sie als unschätzbare Zeugen dieser innigen Stammverwandtschaft an den Anfang der Autarachnen gestellt werden müssen. Wenn alle übrigen Arthrogastren ausgestorben wären, und bloss dic „eigentlichen" Spinnen (Araneae) existirten, würde man die Solifugen mit mehr Recht den Insecten, als den letzteren anfügen. Von den uralten Stammvätern der Autarachnen, die den Solifugen am nächsten standen, haben sich wahrscheinlich als drei divergente Zweige erstens die zu den Skorpionen hinüberführenden Phryniden, zweitens die Phalangiten und drittens die Araneen abgezweigt ${ }^{1}$ ).

Zweite Ordnung der Arthrogastres:

Tarantulae. (Phrynida). Taranteln.

Auch bei dieser Ordnung, welche die einzige Familie der Phryniden (Phrynus, Thelyphonus) umfasst, sind noch, wie bei den Solifugen, die drei echten Beinpaare völlig von dem hinteren Kiefertasterpaar (dem sogenannten ersten Beinpaar) verschieden, obgleich bereits Kopf und Brust rerschmolzen sind. Die Phryniden sind offenbar die nnmittelbare Uebergangsstufe von den Solifugen zu den echten Scorpionen.

\section{Dritte Ordnung der Arthrogastres:}

\section{Scorpioda. Skorpione.}

Diese Ordnung, welche die einzige Familie der echten Skorpione oder der Skorpioniden (Scorpio, Buthus) umfasst, hat sich höchst wahrscheinlich aus den Phryniden, und zunächst aus dem T'helyphonus äbnlichen Formen entwickelt, und zwar schon vor der Kohlenzeit, denn in der Steinkohle findet sich bereits ein echter Skorpion (Cyclophlhalmus).

\section{Vierte Ordnung der Arthrogastres:}

Pseudoscorpioda. Afterstiorpione.

Diese kleine Ordnung, welche nur die Familie der Obisiden (Obisium, Chelifer) umfasst, betrachten wir als einen verkümmerten Seitenzweig der vorigen Ordnung, welcher sich zu dieser ähnlich, wie die Milben zu den A raneen verhält. Uebergangsformen zwischen Scorpio und Chelifer finden sich schion in der Steinkohle (Microlabis).

1) Ganz wie bei den echten Insceten, ist auch bei den Solifugen der Rumpf noch aus drei völlig getrennten Stücken zusammengesetzt, Kopf, Thorax und Abdomen. I. Der Kopf trägt 1. das Augenpaar, 2. das Antennenpaar (Kieferfühler) 3. zwei Kiefertasterpaare (zwei Unterkieferpaare). II. Die drei Metameren der Brust tragen die drei echten Beinpaare. III. Der anhangslose Hinterleib ist aus zehn Metameren zusammengesetzt. Bei allen übrigen echten Spinnen sind nicht allein die drei Metameren des Thorax unter sich, soridern anch mit dem Kopfe zusammen zum Cephalothorax verschmolzen. Auch bei den Pantopoden sind jene vier Metameren noch von einander getrennt. 


\section{Fïnfte Ordnung der Arthrogastres: \\ Opiliones. Afterspinnell.}

Die Ordnung der Phalangier, welche aus der einzigen Familie der Opilioniden oder Phalangiden besteht (Phalangium, Opilio), steht durch ihre eigenthümlichen Verwandtschafts-Beziehungen so isolirt, dass sie keiner der übrigen Autarachnen-Ordnungen unmittelbar angeschlossen werden kann; bald wird sie mit den Arthrogastres, bald mit den Sphaerogastres vereinigt. In der That steht sie $z$ wischen Beiden in der Mitte. Uns scheint sie ein sehr alter, selbstständiger Ausläufer des Solifugen-Stammes zu sein, welcher sich nicht in andere Ordnungen fortsetzt. Sie ist die einzige Arachniden-Ordnung, welche mit den Solifugen die verästelten Tracheenbüschel theilt.

Zweite Legion der Autarachnen:

Sphaerogastres, H. Rundspinnen.

Diese Legion umf:ısst die Hauptmasse der Arachniden, nämlich die sogenannten "echten Spinnen" im engeren Sinne oder die Webespinnen (Araneae), und die Milben (Acara). Die Acaren sind nach unserer Ansicht Nichts weiter als ein rückgebildeter Seitenzweig der Araneen, welche letzteren sich als selbstständiger $A$ st aus den Solifugen entwickelt haben. Diese Entwickelung ist vorzüglich erfolgt durch Concentration des articulirten Rumpfs, durch Verschmelzung der Mletameren, und die dadurch bedingte Centralisation der Organsysteme, welche die Sphaerogastren vor allen andern Tracheaten auszeichnet, und ihnen unter diesen eine ähnliche Stellung giebt, wie den Brachyuren unter den Crustaceen.

\section{Erste Ordnung der Sphaerogastres:}

\section{Araneae. Webespinnen.}

Diese formenreiche Gattung umfasst die typischen oder „eigentlichen Spinnen" im engsten Sinne, welche sich aus den Solifugen, unabhängig ron den divergenten Aesten der Scorpione und Opilionen, entwickelt haben. Die den Solifugen noch am nächsten stehenden scheinen die Salticus zu sein. Den eigentlichen Stamm der Ordnung bildet die Unterordnung der $Z_{w}$ eilungen-Spinnen (Dipneumones), welche in die beiden Sectionen der nichtwebenden Vagabundae (Salticus, Lycosa) und der webenden Sedentariae (Tegenaria, Argyronela) zerfällt. Ueber letztere hat sich die zweite Unterordnung der Vierlungen-Spinnen (Tetrapnenmones) als ein höchst entwickelter Ast erhoben (Cleniza, Mygale). Fossile Reste der Araneen treten zuerst im Jura auf (Palpipes).

\section{Zweite Ordnung der Sphaerogastres: \\ Acara. Milben.}

Diese ebenfalls sehr formenreiche Ordnung, welche gewöhnlich mit Unrecht an den Anfang der Arachniden-Classe gestellt wird, halten wir nicht für den Ausgangspunkt, sondern für einen einseitig verkümmerten Seitenzweig der Classe, welcher durch besondere einfache Anpassungs - Verhältnisse aus den Araneen (oder vielleicht auch aus den Opilionen?) hervorgegangen ist. Der grösste Theil der hierher gehörigen, meist sehr kleinen und verküm- 
XCVIII Systematische Einleitung in die Entwickelungsgeschichte.

merten Spinnen ist durch das Schmarotzerleben sehr stark degenerirt, am stärksten die wurmförmigen Linguatuliden (Acanthotheca) und Si m o niden (Demodex). Dagegen sind die nicht schmarotzenden Oribatiden (Oribules) weniger entartet, ebenso die Hydrachniden (Limnnchares), Bdelliden (Bdella) ete. ${ }^{1}$ ).

\section{Dritte Classe der Tracheaten: \\ Illyriapoda. Tausend/üsser.}

Diese kleine Tracheaten-Gruppe erscheint in entwickeltem Zustande so sehr von den ïbrigen Articulaten verschieden, dass man sie weder den echten Insecten, noch den Arachniden (und am wenigsten den Crustaceen!) einreihen kann, obwohl man alle drei Versuche gemacht hat. Wie jedoch die vergleichende Anatomie und namentlich die Ontogenie beweist, sind die Mrriapoden den Insecten nächstverwandt, und besassen ursprünglich, gleich allen Tracheaten, drei Beinpare. Die Vielzahl der Beinpare ist hier (ebenso wie bei den Arachniden die Vierzahl) erst als secundär erworben zu betrachten. Die jungen aus dem Ei entschlüpfenden $\mathbf{M y}$ riapoden besitzen nur drei Beinpaare, wie sie ihre alten Voreltern zeitlebens behielten. Die Myriapoden haben sich wohl viel später, als die Arachniden, von dem in die Insecten-Classe sich fortsetzenden Hauptstamme der Tracheaten abgezweigt, jedenfalls ror der Jura-Zeit, da sie sich im Jura bereits fossil finden (Geophilus). Die kleine Classe enthält nur $z w e i$ Ordnungen; Chilopoda oder Syngnatha (Geophilus, Scolopendra) und Diplopoda oder Chilognatha (Julus, Polydesmus), ron denen wahrscheinlich die ersteren dem ursprünglichen Iyriapoden-Stammvater näher stehen, als die mehr vcrïnderte letztere Gruppe.

Vierte Classe der Tracheaten:

Insectn. Insecten.

Die Classe der echten oder sechsbeinigen Insecten als die formenreichste aller Thiergruppen hat in vieler Beziehung für die organische Morphologie eine besondere Bedeutung, besonders auch deshalb, weil nirgends so wie hier die unwissensehaftlichste und gedankeuloseste Formenspielerei als ,morphologische Wissenschuft" cultivirt und verherrlicht worden ist. Ihr grösstes reales Interesse für die wirklich wissenschaftliche Morphologie liegt darin, dass sie uns zeigt, wie innerhalb des engsten anatomischen Spielraums und ohne tiefure wesentliche Organisations-Modificationen die grösste Mannichfaltigkeit der Formen realisirt werden kann. In der That sind alle Insecten, trotz ihrer zahllosen Gattungen und Arten, so innig verwandt, und durch so wenig wesentliche und tiefer greifende Organisations-Differenzen getrennt, dass sie sich in sehr wenige Hauptabtheilungen (Ordnungen) zusammenfassen lassen, und dass selbst diese qualitativ weniger divergiren, als viele andere „Ordnungen" des Thierreichs.

Was den Ursprung der Insecten-Classe betrifft, so haben wir bereits bemerkt, dass dieselben die wenig veränderte Fortsetzung der aus den Zoëpoden entsprungenen Protracheaten darstellez. Das erete Protracheat, wel-

1) Wenn man die Milben an den Anfang der Arachniden stellt, so ist dies eben so falsch, wie wenn man die Cestoden an den Anfang der Würmer, die Siphonostomen an den Anfang der Crustaceen stellt. Die niedrige Organisation dieser Gruppen ist erst durch Anpassung erworben, nicht ursprünglich! 
ches zwei entwickelte Flügelpaare besass, können wir als den gemeinsamen Stammvater aller uns bekannten jetzt lebenden und fossilen Insecten betrachten, da dic flïgellosen Formen zweifelsohne sämmtlich von geflïgelten Voreltern (ebenso wie die zweiflügeligen von einflügeligen) abstammen und crst durch Anpassung und secundäre Degeneration ihre Flügel eingebüsst haben. Die Entwickelung jenes Stammraters fällt in den Zeitraum zwischen Silurzeit und Kohlenzeit, wahrscheinlich in die antedevonische oder die devonische Zeit. In der Steinkohle (vielleicht schon im Devon!) treten zum ersten Mlale unzweifelhafte Insecten auf, und zwar ausschlicsslich kauende Insecten (Orthoptera, Neuropiera, Coleoplera). Erst viel später (im Jura) erscheinen die vollkommensten Kauenden (Kymenoptera) und die echtén saugenden Insecten (Hemip/era, Diplera), am spätesten (erst tertiär) die Schmetterlinge (Lepidopleru). Offenbar haben sich also die Sugentien erst später aus den ursprïnglich allein vorhandenen Masticantien herrorgebildet ${ }^{1}$ ).

Erste Subclasse der Insecten:

\section{Masticantia. Kan-Insecten.}

Diese Gruppe steht den übrigen 'Tracheaten und namentlich den Solpugiden, viel näher, als die erst später von ibr abgezweigte Gruppe der Sugentien. Sie allein ist in der Primäzzeit rorhanden gewesen. Die allerältesten Insecten waren höchstwahrscheinlich entweder Orthopteren oder Neuropteren, oder Mischformen zwischen diesen beiden Ordnungen, welche wir in der Ordnung der Tocoptera oder Stamm-Insecten rereinigen, da wir dieselben in keiner Weise scharf zu trennen vermögen.

\section{Erste Ordnung der Insecten: \\ Tocoptera, H. Stamm-Insecten.}

Diese Ordnung gründen wir für die vereinigten Ordnungen der Orthoptera und Neuroptera, wclche durch die Pseudoneuroptera so unmittelbar verbunden sind, dass wir (bei der bereits bemerkten phylogenetischen Werthlosigkeit der Insecten - Metamorphose) dieselben in keiner Weise scharf zu

1) Sowohl diese paläontologische Urkunde, als viele andere Gründe berveisen, dass bei den Insecten der Lmstand, ob die Entwickelung mit oder ohne Metamor phose verläuft, nur ein s ecundäres Interesse besitzt, und für die morphologische Erkenntniss ihrer Vernandtschafts-Verlältnisse nur mit der grössten Vorsicht und Kritik verwerthet werden kann. Bei den Crustaceen, bei den Anneliden, bei deñ Mollusken, bei den Echnodermen ist dex Fall keineswégs selten, dass von näclistverwandten Arten (die oft selbst einern Gen us angehöı en!) die einen mit der ausgezeichnetsten Metamorphose, die andern dagegen ganz direct, ohne alle Metamorphose sich entwickeln! Dies rührt daher, dass die Metamorphose bald durch das Gesetz der abgelsürzten Vererbung "usammengezogen, bald durch Anpassung weiter"ausgedehnt, bald selhst neu erworben wird. Wie Fritz Müller (1. c. S. 80) sehr richtig bemerkt, ist wahrscheinlich auch die vollkommene Metamorphose vieler, wenn nicht aller Iusecten als eine solche durch neue Anpassungen während der Ontogenese erworbene (nicht ron dem ursprünglichen Stammvater der Insecten e rerb te!) anzusehen, wobei jedoch immer $\mathbf{R}$ ü $\mathrm{c} k$ schläge in die Metamorphosen früherer Voreltern mit in Spiel sein mögen.. Jedenfalls müssen wir die Eintheilung der Insecten in Ametabola und Metabola völlig verwerfen. Offenbar ist fïr diese falsche Trennung das Wort .,vollk ommene Metumorphose verhänguissvoll geworden! Nach aller sonstigen Aualogie 'müssten gerade die unvollkommensteu Iusecten die vollkommenste Metamorphose haben (wie die Eucariden unter Malacostraca), während die vollkommensten Insecten gar k ei nc Metamorphose mehr besitzen müssten (wie die Edriophthalmen unter den Malacostraca!). In der That ist es aber gerade umgekehrt! 
trennen im Stande sind. Sowohl die Orthopteren als die Neuropteren umfassen eine Anzahl von ziemlich verschiedenartigen, niedrig stehenden und offenbar sehr alten Insectenformen, von denen mehrere darauf Anspruch machen könnten, als die nächsten Verwandten der uralten Stammform aller Insecten zu gelten. Nebst den aus ihnen entwickelten Coleopteren sind die Tocopteren die einzigen.Insecten, die sich schon in der Steinkohle finden.

\section{Erste Unterordnung der Tocoptera: \\ P seud oneuroptera. Urnetzflïgler.}

Diese Unterordnung ist wahrscheinlich von allen jetzt lebenden InsectenGruppen die älteste und umfasst vermuthlich diejenigen Stamminsecten, aus denen sich demnächst erst Orthopteren und Neuropteren als zwei divergente Zweige entwickelt haben. Es gehören hierher die vier Sectionen der A mphibiotica (Ephemerida, Libellulida, Perlida), der Corrodentia (Ter. mitida, Embida, Psocida), der Thysanoptera (Physopoda, Thripila) und der Thysanura (Lepismida, Podurida). Von diesen sind wahrscheinlich die A mphibiotica diejenigen, welche von allen belsannten Insecten der ältesten gemeinsamen Stammform am nächsten stehen. Aus den Tracheen Kiemen, welche die Larven dieser Thiere besitzen, sind vielleicht die In se c ten-Flügel entstanden. Fossile Reste derselben finden sich bereits in der Steinkohle (Termes).

\section{Zweite Unterordnung der 'Tocoptera: \\ Neuroptera. 'Netzflighler.}

Diese Ordnung hat sich wahrscheinlich erst aus der vorigen, mit der sie nächstrcrwandt ist, entwickelt. Vielleicht ist jedoch das parentale Verhältniss auch umgekehrt. Sie umfasst drei Sectionen: I. Planipennia (Punorpida, Sialida, Hemerobida), welche den eigentlichen Stamm der Gruppe bilden; II. Tri choptera (Phrygunida) und III. Strepsiptera (Rhipiptera), welche beide erst von den ersteren als zwei besondere Aeste sich abgezweigt haben. Die in der Steinkohle gefundene Dictyophlebiu stellt eine verbindende Zwischenform zwischen den Sialiden (Neuropteren) und Libelluliden (Pseudoneuropteren) her.

\section{Dritte Unterordnung der Tocoptera: Orthoptera. Grudfligiler.}

Diese Unterordnung hat sich wahrscheinlich gleich der vorigen von den Pseudoneuropteren abgezweigt, mit welchen dieselbe gewöhnlich vereinigt wird. Jedenfalls ist auch dieser Zweig einer der ältesten und am wenigsten veränderten. Es gehören hierher die beiden Sectionen der Ulonata (Blattiden und Heuschrecken) und der Labidura (Forficuliden), von denen die letztere wahrscheinlich einen kleinen, durch specielle Anpassung abgeänderten Seitenzeig der ersteren darstellt. Fossile Reste von Blattiden, Acridiern und Locustiden finden sich bereits in der Steinkohle.

\section{Zweite Ordnung der Insecten: Coleoptera. Käfer.}

Die Käfer-Ordnung ist wohl von allen Gruppen der Organismen diejenige, bei welcher die unendliche Mannichfaltigkeit im Einzelnen und Kleinen 
das grösste Nissverhältniss zu der typischen Einförmigkeit im Grossen und Ganzen zeigt. Daher erscheint auch eine genealogische Anordnung ihrer zahlreichen Familien, und selbst eine Gruppirung derselben in wenige grössere Sectionen noch ganz unmöglich. Zweifclsohne haben sich die Käfer aus den Tocopteren, und zwar wahrscheinlich aus einem $Z$ weige der Orthopteren entwickelt. Sie sind die einzigen Insecten, welche ausser den Tocopteren bereits in der Steinkohle vorkommen (einige Curculioniden).

\section{Dritte Ordnung der Insecten: \\ Hymenoptera. Haufflügler.}

Gleich den Käfern erscheint auch die Ordnung der Hymenopteren als eine so einheitliche und in sich abgeschlossene Gruppe, dass keine Verbindungsglieder mit andern Insecten - Ordnungen bekannt sind. Gleich den Käfern sind auch die Hymenopteren jedenfalls aus den Tocopteren entstanden, und $z$ war wahrscheinlich aus einem Zweige der Neuropteren oder der Pseudoneuropteren. Von allen kauenden Insecten haben sie sich am spätesten entwickelt. Die ersten fossilen Reste derselben gehören dem Jura an.

\section{Zweite Subclasse der Insecten: Sugentia. Sang-Insecten.}

Die Insecten mit saugenden Mundtheilen oder die Sugentien, welche die drei Ordnungen der Hemiptera, Diptera und Iepidoptera umfassen, haben sich erst spät, aus der Subclasse der Masticantien entwickelt und zwar höchstwahrscheinlich aus den Tocopteren. Der nähere Ort ihres Ursprungs aus diesen wird sehr schwierig zu ermitteln sein, da alle drei Ordnungen in sich abgeschlossene Gruppen obne Uebergangs-Formen (gleich den Hymenopteren und Käfern) darstellen, und da uns weder die Ontogenie noch die Paläontologie über ihre Genetlogie belehren. Wahrscheinlich sind Hemiptera und Lepidoptera als zwei divergente Zweige aus den Tocoptereu, vermuthlich aus den Pseudoneuropteren oder aus den Neuropteren entstanden, wogegen die Dipteren sich aus den Hemipteren entwickelt haben werden. Die ältesten bekannten Reste gehören dem Jura an.

\section{Vierte Ordnung der Insecten: Homiptera. Schnabellierfe.}

Diese Ordnung ist höchst wahrscheinlich unter den Insecten mit sangenden Muudtheilen die älteste, welche sich vielleicht schon in der Primärzeit von den Tocopteren abgezweigt hat. Wenigstens scheint darauf der kürzlich ron Dohrn beschriebene Engereon aus dem Perm zu deuten, welcher eine Mischung von Charakteren der Neuropteren und Hemipteren darstellt und auf eine Uebergangsform von erstern zu letztern als auf ihren gemeinsamen Stammvater hindeutet. Von den beiden grossen Unterordnungen, in welche die Ordnung zerfällt, den Homoptera (Blattläusen und Cicaden) und den Heteroptera (Wanzen), sind die ersten wahrscheinlich die älteren. Von Beiden finden sich bereits Reste im Jura vor. Die Läuse oder Pediculiden, welche man als eine dritte Unterordnung betrachten kann, sind Hemipteren, welcke durch Anpassung an Parasitismus in ähnlicher Weise rückgebildet sind, wie die Flöhe unter den Dipteren. 
Fünfte Ordnung der Insecten:

Diptera. Fliegen.

Diese höchst umfangreiche Insecten-Ordnung hat sich wahrscheinlich aus den Hemipteren (vielleicht jeroch auch aus gemeinsamer Wurzel mit diesen oder direct aus den l'ocopteren) entwickelt. Von den beiden grossen Unterordnungen, in welche die Ordnung zerfällt, den Nemocera (Jücken) und den Brachycera (Fliegen) sind die crsteren sehr wahrscheinlich dic älteren, aus denen sich die letzteren erst spätcr entwickelt haben. Von Beiden finden sich die ältesten Reste im Jura. Als zwei weitere Unterordnungen kann man die Aphaniptera (Flöhe) und die Pupipara (Lausfliegen) betrachten, welche wahrscheinlich aus den Brachyeera (vielleicht aber auch aus einer älteren Gruppe der Dipteren) durch specielle AnpassungsVerhältnisse entstanden sind.

\section{Sechste Ordnung der Insecten: \\ Lepidoptera. Schmellerlinge.}

Diese Ordnung, welche in mehrfacher Beziehung als die vollkommenste der saugenden Insecten betrachtet werden kann, und den vorigen gegenüber eine ähnliche Stellung einnimmt, wie die Hymenopteren gegenüber den anderen Masticantien, scheint sich am spätesten von allen Insecten - Ordnungen entwickelt zu haben. Sichere fossile Reste derselben sind erst aus der Tertiärzeit bekannt. Ihre Abstammung erscheint sehr schwierig zu ermitteln, da auch diese Ordnung, gleich den vier vorhorgehenden, in der Gegenwart sehr ahgeschlossen erscheint und da alle verbindenden $\mathrm{Zwischenformen} \mathrm{und}$ Uebergangsglieder zu anderen Ordnungen ausgestorben zu sein scheinen. Aller Wahrscheinlichkeit nach haben sich die sichunetterlinge aus den Tocopteren (vielleicht aus gemeinsamer Wurzel mit den Hymenopteren oder aus diesen selbst?) entwickelt.

\section{Vierter Stamm des Thierreichs: \\ Mollusca. Weichthiere.}

Die Thiergruppe der Mollusken oder Weichthiere wird seit Bär und Cuvier von den meisten Zoologen als eine einheitliche und selbstständige Hauptabtheilung des Thicrreichs angeschen, welche der der Wirbelthicre, der Articulaten etc. äquivalent ist, mithin cinen selbstständigen Stamm, ein eigenes Phylon des Thierreichs darstellt. Frst neuerdings hat man diesen Stamm in zwei Hauptgruppen gespalten, welche von hervorragenden Zoologen, wie namentlich von $\mathrm{H} u x \mathrm{ley}$, als zwei besondere "Typen oder Unterruiche“ des Thiorreichs angesehen werden und demnach zwei besonderen "Phylen" entsprechen würden: die cine dieser Hauptgruppen umfisst die Molluscoiden oder falschen Mollusken, die drei Classen der Bryoz'oen, 'Tunicaten und Spirobranchien; die andere umfasst die Mollusken im engeren Sinne, oder die echten Mollusken, die vior Classen der $\mathrm{R} u$ dis ten (viclluicht Molluscoiden?), der lilatobranchien, Cochliden (Cephalophoren) und Cephalopoden. Nach unserer Ansicht ist es das Wahrscheinlichste, dass diese beiden Hauptgruppen nicht besondere Phylen, sondern nur Suhphylen eines und desselben Mollusken-Stummes sind. Die Moll uscoiden verhalten sich zu don echten 3 ollusken ähnlich, wie die Wür- 
mer (Vermes), zu den Glicderfüssern (Arthropoden); d. h. die ersteren enthalten die niederen und unvollkommueren phyletischen Entwickelungs - Stuf'n, aus welchen die letztern als höhere und rollkommnere, stärker differenzirte Formen sich erst später herrorgebildet haben. Wir glauben die Organisations-lnterschiede zwischen den beiden stammverwandten Hauptgruppen hinreichend herrorzuheben, indem wir diesclben als besondere Subphylen über einander stellen. Die Molluscoiden in dem Umfinge, in welchem wir dieselben hicr begrenzen (die drei Classen der Bryozoen, Tunicaten und Spirobranchien) bezeichnen wir als $\mathrm{H}$ imategen (Nantelthiere oder Sackthiere in weiteren Sinne). Die höheren oder eigentlichen Mollusken, welche sich unter Anderem durch den Besitz einer Herz-Vorkammer und dreier HauptGanglien-Paare von jenen unterscheiden, stellen wir ihncn als Otocardier (Mollusken mit Harzvorkammer) gegenüber.

Die Paläontolorie der Mollusken ist in vieler Beziehung äusserst merkwürdig und lehrreich, insbesondere für dic Erkenntniss des Ieeichtsinns und des Jlangels an kritischem Urtheil, mit dem bisher gewöhnlich das paläontologische Material verwerthet worden ist. Kein einziger organischer Stamm hat eine solche ausserordentliche Mlasse ron fossilen Resten in allen Schichten der Erdrinde, von den silurischen an, hinterlassen, als das Phjlum der Mollusken, sowohl was die Anzahl der Arten, als die ungcheuren Mengen der Individuen betrifft. Und dennoch haben diese Massen von petrificirten Mollusken-Resten fiur ihre Phjlogenie nur ein ganz untergeordnetes Interesse. Deutlicher als irgendwo tritt hier die weite Kluft $\%$ 'Tage zwischen dem Werthe, welchen die empirische Palä on tologie für die wissenschaftliche Phylogenie, und demjenigen, welchen sie für die praktische Geologie besitzt. Für die letztere sind die fossilen Mollusken-Reste ron der allergrössten Wichtigkcit, und spielen als „Leitmuscheln“, als „Denkmünzen der Schöpfung", welche die einzclnen Formationen und Systeme charakterisiren, die bedeutendste Rolle. Für die Phjlogenie dagegen sind die fossilen Mollusken - Reste fast ron geringerem Interesse, als diejenigen irgend einer anderen Hauptabtheilung der Organismen, die überhaupt zahlreiche Reste hinterlassen hat. Im Hinblick auf die ausserordentliche Menge und Mannichfaltigkeit ihrer fossilen Formen besitzt die Paläontologie der Mollusken fürdie Geologiedas grösste, für die Phylogenie das geringste Interesse.

Dieser auffallende Umstand erklärt sich unserer Ansicht nach einfach daraus, dass die eigentliche Entwickelungs-Zeit des Mollusken-Stammes als Ganzen, seine Epacme, schon in die ältere archolithische Zeit fallt, welche vor der Silur-Zcit verfloss. In den silurischen Schichten, den ältesten von allen petrefactenreichen Formationen, finden wir bereits das fertige und reife Resultat des ungeheucr langen Entwickelungs-lProcesses, welchen die Mollusken bereits vor der silurischen Zeit müssen durchgemacht haben. Wir finden daselbst nicht nur die vicderen, sondern auch bereits die vollkommenste Mollusken - Classe, die der Cephalopoden, in der reichlichsten Entwickelung ror. Viele Nollusken-Gruppen befinden sich in der Silur-Zeit offenbar bereits in der Acme, viele selbst schon in der Paracme. Diese silurischen Mollusken führen uns abernioht, wiegewöhnlich angenommen wird, die crsten Anfänge, sondern vielmehr ein sehr spätes Entwickelungs-Stadium dieses Stammes vor A ugen. Offenbar haben dic Mollusken, (und gleicherweise vermuthlich auch die Coelenteraten) in der archolithischen Zeit eine ebenso hervorragends 


\section{Systematische Einleitung in die Entwickelungsgeschichte.}

und herrschende Stellung behauptet, wie die Arthropoden und Vertebraten ron Beginn der Secundär.Zuit an. Die Blüthe der letzteren bezeichnet ebenso die secundäre und tertiäre, wie die Blüthe der ersteren die primordiale und primäre Zeit.

Diese Ansicht erscheint um so zutreffender, je mehr uns auch die verglcichende Anatomie und Ontogenie lehrt, dass der Mollusken-Stamm als Ganzes eine sehr tirfe, und unter den drei höheren (dipleuren) Thicrstämmen jedenfulls die tiefste Stufe einnimmt. Besonders ist für denselben der fast gänzliche Mangel der Metameren-Bildung sehr bezeichnend. Während die Arthropoden und Vertebraten durch allgemeine und sehr reichliche Metameren-Entwick lung stets als Bionten den Rang von Pers on en, oder von Form-Individuen fünfter Ordnung einnehmen, bleiben die meisten Mollusken (und grade die höheren, die Otocardier, allgemein!) als Bionten auf der vierten Stufe der morphologischen Individualität, auf der des einzelnen M eta meres stehen. Die Skeletbildung ist hier im Ganzen unvollkommener, als in irgend einem anderen Thierstamme, da sie sich meistens auf die Ausscheidung sehr einfach gebauter Kalkschalen beschränkt. Die Organisation des Central-Nervensystems, des Muskel-Systems etc. ist ebenfalls wcit unvollkommner, als bei den Vertebraten und Arthropoden, und selbst als bei den Echinodermen.

$\mathrm{Da}$ die meisten äusseren Mollusken-Schalen (und nur diese sind gewöhnlich erhalten) an und für sich sehr wenige Beziehungen zu den tieferen Organisations - Verhältissen der Thiere haben, so sind dieselben nur mit grosser Vorsicht zu Schlüssen auf letztere zu verwerthen. Sthr weit entfernte Mollusken haben oft höchst ähnliche Schalen, und von zwei sehr nah verwandten Mollusken-Gattungen (z. B. Helix und Aliv/l) besitzt oft die eine eine sehr ausgebildete, die andere gar keine Schale. Die zahlreichen nackten, aller Schalen entbehrenden Mollusken konnten gar keine fossilen Spuren hinterlassen. Und doch ist zu vermuthen, dass grade in der frühern Zeit die nackten Mollusken im Verhältniss noch weit massenhafter werden entwickelt gewesen sein, als die beschalten. Nach der gewöhnlichen Logik der Zoologen und Botaniker könnte man allerdings behaupten, dass keine nackten Mollusken vor der Je1ztzeit existirten, weil wir keine fossilen Spuren von ihnen finden, und dass dieselben alle erst im Anfang der "Jetztzeit" (nach Abschluss der "Vorz(ii"“!) "geschaffen" worden seien!

Da der Mollusken-Stamm in der Silurzeit bereits einen so hohen Entwickelungs-Grad erreicht hatte, dass (ausser den Rudisten) alle Classen desselben, (und selbst die meisten Hauptgruppen der einzelnen Classen) neben einauder existirten, so dürfen wir uns nicht wundern, dass uns die Paläontologie über deren successive Entwickelung so wenig Aufschlüsse liefert, und dass namentlich auch verbindende Zwischenformen zwischen den einzelnen Hauptgruppen hier im Ganzen seltener als sonst sind. Diese, sowie die alten gemeinsamen Stammeltern aller Mollusken, waren längst vor der Silur-Zeit schon ausgestorben. Auch die Ontogenie der Mollusken liefert uns aus diesem Grunde über ihre Phylogenie nur verhältnissmässig wenig Aufschlüsse; auch sie bezeugt vorzugsweise (namentlich in der Embryologie der Cephalopoden!) das ausserordentlich hohe Alter des Stammes. Unter diesen Umständen müssen wir die Phylogenie der Mollusken mehr aus ihrer vergleichenden Anatomie, als aus ihrer Ontogenie und Paläontologie construiren.

In kurzen Zügen síellt sich die Phylogenie der Mfollusken - Classen nach unserer jetzigen Auffassung folgendermaassen dar: Am tiefsten von allen be- 
kannten (!) Mollusken stehen die Bryozoen, welche wir demnach als Ausgangspunkt betrachten müssen. Aus diesen entwickelten sich als divergente Zweige einerseits dic Tunicaten (welche sich nicht weiter in andere Classen fortsetzten), andrerseits die Spirobranchien, aus denen wahrscheinlich die Rudisten und die Elatobranchien entsprangen. Unter den letzteren führen dje Inclusen (Pholadaceen) unmittelbar zu den Scaphopoden (Dentaliden) und durch diese zu den Pteropoden hinüber. So hat sich wahrscheinlich die höchst stehende Gruppe der mit Kopf und Zahn-Apparat versehenen Mollusken (Odontophora) aus den niedern, kopflosen und zahnlosen Mollusken (Elatobranchien und Himategen) hervorgebil'det. Die beiden Classen der Odontophoren, (Cochliden und Cephalopoden) betrachten wir als zwei divergente Aeste der Pteropoden-Gruppe (Vergl. Taf. VI).

Entweder hat sich der Mollusken-Stamm als ganz selbstständiges Phylum aus einer eigenen autogonen Moneren-Form entwickelt, oder er hängt an seiner Wurzel mit anderen thierischen Stämmen zusammen. Im letzteren Falle hat er sich aller Wahrscheinlichkeit nach von den Würmern, und zwar von den Turbellarien abgezweigt (S. unten S. 413). Falls Himategen und Otocardier zwei getrennte Phylen reprüsentiren sollten (was wir nicht glauben!), so würden vielleicht die ersteren durch die Bryozoen, die letateren durch die Lipobranchien (Rhodope!) mit den Würmern (Turbellarien) zusammeuhängen.

\section{Erstes Subphylum der Mollusken: \\ Himatega, H. Niedere Molluslien (ohne Herzohr).}

Als Himategen vereinigen wir die drei nicderen und unvollkommneren Classen des Jolluskenstammes: Bryozoen, Tunicaten und Spirobranchien, welche durch unvollkommneres Centralnervensystem und Circulationssystem, und speciell durch Mangel der Herzvorkammer, sich wesentlich von dem zweiten Subphylun, den Otocardicrn unterscheiden. Bald werden alle drei Classen, bald nur dic Bryozoen und Tunicaten, als Molluscoiden zusammengefasst. Vielleicht gehört als eine vierte Classe noch die der Rudisten hierher, welche zwischen den Spirobranchien und Elatobranchien mitten inne steht. Lie Wurzel der Himategen, wie der Mollusken überhaupt, bilden die Bryozoen, von deuen Tunicaten und Spirobranchien als zwei divergente Aeste ausgehen.

\section{Erste Classe der Himategen:}

Bryozoa. Mloosthiere.

Fon allen Mollusken stehen die Bryozoen hinsichtlich ihrer GesammtOrganisation am tiefsten, wie schon der Mangel des Herzens und besonderer Siunes-Organe, sowie überhaupt der niedere Differenzirungsgrad sämmtlicher Organsysteme beweist. Zugleich stehen dieselben von allen Mollusken den Würmern am nächsten, so dass sie selbst von vielen Zoologen gar nicht als Mollusken, sondern vielmehr als echte Würmer angesehen werden. Doch ist sowohl die Stelle des Articulaten-Stammbaun:s, ron welchem sich die Bryozeen eventuell abgezweigt haben könnten,' gauz unbekannt, als auch ihr unmittelbarer Zusammenhang mit den übrigen Mollusken -Classen sehr zweifelhaft. Am nächsten scheinen sie den Brachiopoden za stehen, deren Larven gewissen Bryozoen sehr ähnlich sind. Innerhalb der ganzen formenreichen Classe erscheint die gesammte innere Organisation so einförmig, dass 
wir daraus auf eine schon vor sehr langer Zeit (in früherer Primordial-Zeit) stattgefundene Abtrennung der Bryozoen von den übrigen Mollusken schliessen können. Die fossilen Reste von Bryozoen sind zwar schon ron den ältesten Formationen an sehr zahlreich, sagen indess über die Phylogenie derselben nur sehr wenig aus, da nur die härteren, mit festeren und stark verkalkten Gehäusen versehenen Bryozoen der Fossilisation fähig sind. Von den sieben Ordnungen, in welche die Classe zerfält wird, haben fünf Ordnungen gar keine, und nur zwei Ordnungen (Cyclostomen und Chilostomen) sehr zahlreiche fossile Reste hinterlassen. Ein sicherer Stammbaum ist daher nicht zu entwerfen. Von den beiden Subclassen, auf welche sich diese sieben Ordnungen vertheilen, Gymnolacma und I'/u/luc/olarmm, sind die ersteren offenbar die älteren, ans denen sich die letzteren erst später entwickelt haben.

\title{
Erste Subclasse der Bryozoen: \\ Gymnolaema. Moostlieve oline Kragen.
}

Diese Subclasse, welche an Umfang bei weitem die andere übertrifft, erscheint in jeder Beziehung als die unvollkommnere und niedriger organisirte von Beiden. Sie zerfällt in fïnf Ordnungen: 1. Cyclos to mata iCentrificginra), 2. Ctenostomata, 3. Chilostomata (Radicellulu el Incrus/u/a, s. Celluliner'), 4. Paludicellea, 5. Urnatellea. Von diesen haben die beiden letzteren, sowie die Ctenostomen, gar keine fossilen Reste hinterlassen. Von den beiden Unterordnungen der Chilostomen haben die Radicellaten fast gar keine, nur die Incrustaten zahlreiche Petrefacten geliefert; nur die einzige Ordnung der Cyclostomen scheint ziemlich vollständig conservirt zu sein. Alle Bryozoen-Reste, von der cambrischen Ot/hmmiu an bis zum Jura, gehören der Ordnung der Cyclostomen oder Centrifugineen an. Erst im Jura erschcinen die ersten vereinzelten Spuren von Chilostomen oder Cellulincen, welche in der Kreide bereits eine sehr starke Entwickelung zeigen, und gleich allen anderen bekannten Ordnungen noch jetzt am Lebeu sind.

\section{Zweite Subclasse der Bryozoen: \\ Phylactolaema. Moosthieve mit Kragen.}

Diese Subclasse, die höhere und vollkommnere von Beiden, hat sich offenbar erst aus der vorigen entwickelt. Sie umfasst die beiden Ordungen der Pedicellinea (Iedicellimila) und der Lophopodia (I'lumalellida et Cris(alellida). Von Beiden sind fossile Reste nicht bekannt.

\section{Zweite Classe der Himategen:}

Tunicata. Mantellhiere.

\author{
(Synonym: Ascidiae. Tethya. Gymnacephala. Perigymna. Xylimatia.)
}

Die Tunicaten oder Mantelthiere stimmen sämmtlich durch ihicc GesammtOrganisation und durch besondere Figenthümlichkeiten dersclben so sehr unter einander überein, dass sie von allen anderen Mollusken-Classen scharf getreunt erscheinen, und eine sogenannte ,gute oder natürliche“ Classe bilden. Dies heisst mit anderen Worten nichts weiter, als dass wir ihre rerwandtschaftliche Verkettung mit den anderen Mollusken, und namentlich ihre Vorfahren, nicht kennen. Alles deutet darauf hin, dass die Tunicaten schon sehr frühzeitig von der geneinsanen Mollusken-Wurzel sich abgezweigt und als selbstständige isolirte Gruppe entwickelt haben. Um so mehr ist es zu 
bedauern, dass grade diese, in mehrfacher Beziehung sehr ausgezeichnete Gruppe, eine von den wenigen Thierclassen ist, welche gar ke ine fossilon Reste hinterlassen haben. Wir sind daher bezüglich ihrer Abstammung lediglich auf die Zeugnisse der vergleichenden Anatomie und Ontogenie angewiesen. Diese lehren uns nahe Verwandtschafts-Beziehungen der Tunicaten sowohl zu den Bryozoen, als zu den Brachiopoden und Lamellibranchien. Doch sind diese Beziehungen so allgemeiner Nalur, dass wir keine speciellen phylogenetischen Schlüsse darauf gründen können. Wie es scheint, haben sich die Tunicaten von dem gemeinsamen Himategen-Stamme schon sehr tief unten abgezweigt, früher als die Brachiopoden. Die Bryozoen, wie wir sie jetzt kennen, lassen sich kaum als die unmittelbaren Voffahren der Tunicaten, wohl aber als $\mathrm{Abk}$ bömmlinge derselben Wurzel betrachten. Auch innerhalb der Tunicaten-Classe ist der Stammbaum schwer herzustellen, da alle gegenwärtig lebenden Tunicaten ( - und bloss aus diesen kennen wir die Classe! -) wohl nur spärliche Reste einer vormals sehr reich entwickelten Thiergruppe sind. Der uralten gemeinsamen Stammform aller Tunicaten scheint von den gegenwärtig lebenden die Ordnung der Appendicularien am nächsten zu stehen, von welcher als zwei divergente Hauptäste einerseits die schwimmenden, andrerseits dic festsitzenden Tunicaten ausgehen. Diese beiden Subclassen, Nerlasrilliae und Chllmmasrillia", scheinen zwei unabhängig von einander entwickelte Hauptzweige der Classe darzustellen.

Erste Subclasse der Tunicaten:

Nectascidiac. Schrimmende Mantellhiere.

Diese Subclasse umfasst rier verschiedene Ordnungen, nämlich: I. Copelata (Linzige Familie: Appendicularida. Genus: Appendiculurin). II. Thaliada (Einzige Familie: Salpida. Genera: Salpa. Salpella). IIL. Cy clom y aria (Einzige Familie: Doli olida. Genus: Duliolum). IV. Luciae (Einzige Familie: Pyrosomatida. Genus: l'yrosoma). Wir sind gegenwärtig noch ausser Siande, die genealogischen Beziehungen dieser vier Ordnungen zu einander näher zu erörtern. Wahrscheinlich sind die drei letzten Ordnungen vercinzelte Reste von divergenten $Z$ weigen eines fast ganz untergegangenen und früher vermuthlich reich entwickelten NectascidienAstes. Viel älter ist wahrscheinlich die kleine Ordnung der Copelaten, welche das einzige Genus Appouliculariu umfasst. Sie scheint unter allen bekannten Tunicaten der ursprünglichen gemeinsamen Stammform derselben am nächsten zu stehen. Insbesondere zeigt sie mit den jüngsten Larren der Chthonascidien grosse Uebereinstimmung. Sie ist daher wahrscheinlich als ein wenig veränderter gradliniger Descendent der uralten Tunicaten - Wurzel zu betrachten, von welcher einerseits die Chthonascidien, andrerseits die übrigen Nectascidien, als zwei divergirende Aeste, ausgegangen sind.

Zweite Subclasse der Tunicaten:

Chthonascidiae. Festsilzende Minlelthiere.

Diese Subclasse umfasst zwei verschiedene Ordnungen: I. Monascidiae, H. mit den beiden Familien: 1. Pelonaeida.(Genus: Pelommen);

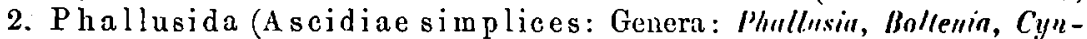
thic etc.). II. Synascidiae, H. mit den beiden Familien: 1. Clavelinida (Ascidiae sociales: Genera: Cherelina, Perophora etc.). 2. Botryllida (Ascidiae compositae: Genera: Bofryllus, Leptoclinum, Amaru- 


\section{Systematische Einleitung in die Entwickelungsgeschichte.}

cium etc.). Von diesen beiden Ordnungen sind zunächst jedenfalls die einzeln lebenden (Monascidiae) aus den Copelaten entstanden, mit welchen die jugendlichen Larven der Phallusiden noch sehr grosse Aehnlichkeit zeigen. Pelonaea scheint ein rückgebildeter Seitenzweig (also eine cataplastische, keine anaplastische!) Entwickelungsstufe der Monascidien-Ordnung zu sein. Die Ordnung der zu Colonieen verbundenen Synascidien ist wohl erst später aus den Monascidien entstanden, und zwar scheiven Claveliniden und Botrylliden aus mehreren, von einander ziemlich unabhängigen Seitenzweigen $\mathrm{zu}$ bestehen.

\section{Dritte Classe der Himategen: \\ Spiroloranchia. Spiralkiemer.}

(Synonym: Brachiopoda. Brachionopoda. Spirobrachia. Spiracephala. Brachiobranchia.)

Die eigenthümliche Mollusken - Classe der Spirobranchien oder Brachiopoden ist uns noch gegenwärtig so wenig bekannt, dass ihre systematische Stellung, und also auch ihre genealogischen Beziehungen zu den ibrigen Mollusken nur sehr unsicher zu bezeichnen sind. Nachdem man sie früher allgemein als echte Bivalven mit den Lamellibranchien vereinigt hatte, halen die neueren Untersuchungen immer sicherer herausgestellt, dass sie von diesen Mollusken sehr verschieden, viel niedriger organisirt, und dagegen den Bryozoen wahrscheinlich viel näher verwandt sind. Insbesondere ist die von Fritz M üller beobachtete Brachiopoden-Larve, welche den Bryozoen sehr ähnlich erscheint, in dieser Beziehung von grosser Bedeutung geworden. Dass die Aehnlichkeit der Spirobranchien mit den Lamellibranchien nur von sehr untergeordneter Bedeutung ist, geht schon daraus hervor, dass die beiden Schalenklappen bei den letzteren rechte und linke, bei den ersteren dorsale und ventrale sind. Die Elatobranchien erscheinen mithin lateral, die Spirobranchien dagegen dorsoventral comprimirt. Jedoch wird dadurch die Möglichkeit eines tiefer an der Wurzel stattfindenden genealogischen $\mathrm{Zu}$ sammenhangs der beiden Classen immerhin nicht vollständig ausgeschlossen. Vielmehr erscheinen die Spirobranchien auch jetzt immer noch als das wichtigste Bindeglied zwischen den Himategen und Otocardiern, und zunächst zwischen den Bryozoen und Lamellibranchien.

Die Spirobranchien haben ihre zweiklappige Schale in solchen Massen fossil in den rerschiedensten Formationen hinterlassen, dass sie für die Geologie und die ihr dienstbare Petrefacten-Kunde zu den wichtigsten Thierclassen gehören. Dagegen ist ihre Bedeutung für die Phylogenie der Mollusken trotzdem nur sehr gering. Es geht daraus bloss hervor, dass die Spirobranchien eine der ältesten 'Thierclassen bilden, welche bereits in der SilurZeit, also schon am Ende der Primordial-Zeit, die Acme ihrer phyletischen Entwickelung erreicht hatte, und von da an bis zur Jetztzuit stetig abnimmt. Von den beiden Subclassen, in welche sie zerfällt, war die niedere und unvollkommnere, die der Ecardines ("leuropygin, in juer frühesten Zeit verhältnissmässig stärker entwickelt und nahm rascher ab, als die höhere

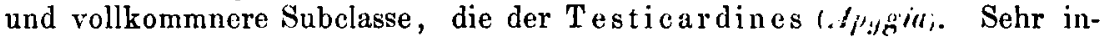
teressant sind die Spirobranchien dadurch, dass mehrere ihrer Genera (soweit aus der Schale allein zu urtheilen ist!) sich fast unverändert seit der Primordial-Zeit bis jetzt erhalten haben (gleichwie Asternranthion oder L'raster unter den Asteriden). Von den Pleuropygiern haben sich Ling"ula, Discina und Crania, von den Apygiern Rhynchonella, seit der Silur-Zeit bis jetzt durch alle Formationen fortgesetzt. 


\section{Erste Subclasse der Spirobranchien: \\ Ecardines (Pleuropygia). Angellose.}

Diese Subclasse, welche die drei Familien der Linguliden, Disciniden and Craniaden umfasst, erscheint durch unvollkommnere Ausbildung der Nervencentren, des Herzens und des Schliess-Apparats der Schale als niedere und unvollkommnere, trotzdem sie sich durch den Besitz eines Afters über die folgende erhebt. Sie nähert sich einerseits mehr den Bryozoen, andererseits mehr den Lamellibranchien, als die folgende Subclasse, und steht also wahrscheinlich der gemeinsamen Stammform der Spirobranchien und Lamellibranchien viel näher, als die folgende, welche wohl erst in späterer archolithischer Zeit aus ihr entstanden ist. Die Pleuropygier sind in den cambrischen und silurischen Schichten relativ weit zahlreicher als die Apygier vertreten, und nehmen in der Folgezeit weit rascher, als diese ab.

Zweite Subclasse der Spirobranchien:

\section{Testicardines. (Apygia.) Angelschalige.}

Diese Subclasse umfasst die beiden Ordnungen der Lineicardines (Familien der Calceoliden und Productiden) und der Denticardines (Familien der Chonetiden, Strophomeniden, Rhynchonelliden, Spiriferiden und Terebratuhden), von denen die letzte wahrscheinlich ebenso als eine höhere Entwickelungsstufe aus der ersteren, wie diese aus der vorigen Subclasse hervorgegangen ist. Die Lineicardines sind ausschliesslich auf die primordiale und primäre Zeit beschränkt, beginnen im Cambrischen, erreichen im Carbon ihre Acme und hören im Perm bereits auf. Die Denticardines kommen zwar auch schon in der cambrischen Formation vor und erreichen in der Silur-Zeit ihre Acme, gleich den Ecardines. Allein sie nohmen langsamer $a b$ und erhalten sich bis in die Jetztzeit stärker als die letzteren.

\section{Zweites Subphylum der Mollusken: Otocardia. Höhere Mollusken (mil Herzohr).}

Als Otocardier fassen wir hier die vier höheren Mollusken-Classen, die Rudisten, Elatobranchien (Lamellibranchien), Cochliden (Cephalophoren) und Cephalopoden zusammen, welche man auch wohl als ,eigentliche oder echte Mollusken" den Himategen oder Molluscoiden gegenüber zu stellen pflegt. Als eine vollkommuere und höhere OrganisationsStufe erscheinen die Otocardier (im Gegensatz zu den Himategen) insbesondere durch ihr Centralnervensystem, welches stets mindestens drei getrennte Ganglien-Paare besitzt (Ganglion cephalicum, G. pedale, G. parietosplanchnicum), und durch ihr Herz, welches stets aus Kammer und Vorkammer besteht. Im Uebrigen zeigen die vier Classen der Otocardier eben so wenig festere Beziehungen als die drei Classen der Himategen, und hier wie dort ist daher der Stammbaum schwer herzustellen. Zweifelsohne haben sich die Otocardier erst später aus den Himategen entwickelt, welche in einem sehr grossen Theile der Primordial-Zeit allein den Mollusken-Stamm repräsentirt haben mussen. Indessen ist offenbar die Divergenz aller Mollusken-Classen schon so frühzeitig vor der cam- 
CX Systematische Einleitung in die Entwickelungsgeschichte.

brischen und silurischen Zeit (wahrscheinlich in der laurentischen Zeit) erfolgt, dass wir in den silurisehen und selbst in den cambrischen Petrefacten des Mollusken - Ntammes bereits das fertige Resultat jener Divergenz vor uns sehen. Das Subphylum der (Otocardier zerfällt naturgemäss in zwei Claden oder Stammäste, von denen der eine (Anodontoda) die beiden Classen der Rudisten und Elatobranchien, der andere (Odontophora) die beiden Classen der Cochliden (Cephalophoren) und der Cephalopoden umfasst.

Erster Cladus der Otocardier:

\section{Anodontoda. Zalinlose Oocurdier.}

Von den vier Classen der Otocardier stehen die kopflosen und zahnlosen Anodontoden (Rudisten und Elatobranchien) im Ganzen viel niedriger und den Himategen, insbesondere den Spirobranchien viel näher, als die Odontophoren, welche wahrscheinlich erst viel später von ihnen sich abgezweigt haben. Unter den Spirobranchien zeigen die tiefsten und unvollkommensten Formen, insbesondere Lingula, die meisten Bezichungen zu den Anodontoden und stehen wohl den gemeinsamen Stammformen derselben am nächsten. Von den Rudisten ist es selbst noch zweifthaft, ob dieselben nicht wirklich echte Spirobranchien, und mithin Himategen sind.

\section{Erste Classe der Anodontoden:}

\section{Budista. Rudisten.}

Diese Mollusken-Classe erscheint hinsichtlich ihrer Structur und Entwickelung als eine der räthselhaftesten Thiergruppen. Plötzlich in dem oberen Neocom der Kreide auftretend, bleiben sie ausschlnesslich auf die Kreidezeit beschränkt. Aus den Schalen, welche wir allein kennen, lässt sich kein bestimmter Schluss auf dic Organisation des darin eingeschlossenen Thieres zichen, und es ist namentlich noch ganz unsicher, ob dasselbe nähere Verwandtschaft zu den Spirobranchien oder zu den Elatobranchien besitzt. Fast ebenso viele und bedeutende zoologische Autoritäten haben sich für die erstere als für die lutztere Classe ausgesprochen. Unter diesen Umständen erscheint es das Sicherste, die Rudisten als eine besondere Classe aufzufassen, welche einen ganz eigenthümlichen und nur kurze Zeit persistirenden Seitenzweig, entweder der Spirobranchien oder der Elatobranchien darstellt; unter letzteren stehen ihnen die Chamaceen am nächsten. Sollten sie sich direct aus den Spirobranchien entwickelt haben, so wurden sie wahrscheinlich nicht den Utocardiern, sondern den Himategen einzureihen sein. Unter sich zeigen alle lRudisten so viel Uebereinstinmung, dass man sie kaum in Ordnungen oder Familien eintheilen kann. Gewöhnlich werden jetzt drei Gruppen unterschieden: I. Hippuritida (Hippuriles); II. Caprinulida (laprinulu); III. Radiolitida (Radioli(es). Alle drei Gruppen finden sich ausschliesslich in der Kreide, vom Neocom bis zur Weisskreide hinauf.

Zweite Classe der Anodontoden:

Elatobranchia. Blattkiemer.

(Synonym: Lamellibranchua. Elatacephala. Pelecypoda. Cormopoda. Conchifera.)

Die Blattkiemer treten zwar, gleich den Spiralkiemern, auch schon im Sulur mit zahlreichen Art'n auf, zeigen indessen, in Gegensatz zu letz- 
teren, im Grossen und Ganzen eine beständige Zunahme bis zur Jetztzeit. Die drei Hauptabtheilungen derselben, Integripalliaten, Sinupalliaten und Inclusen, liefern sowohl in ihrem gegenseitigen Verhalten, als in dem ihrer einzelnen A btheilungen, ausgezeichnete Beweise für das Fortschritts-Gesetz, wie insbesondere Bronn nachgewiesen hat. Aller Wahrscheinlichkeit nach haben sich die Elatobranchien schon lange vor der Silurzeit von den Spirobranchien, und zwar wahrscheinlich von den Pleuropygiern abgezweigt.

Erste Subclasse der Elatobranchien:

\section{Integripalliata (Asip/onia). Gunzmanlelige Blatthiemer.}

Diese Abtheilung unfasst die zahlreichsten, darunter alle niedrigeren und unvollkommncren Lamellibranchien, ohne Mantelbucht, und meistens auch ohne entwickelte Siphonen: die neun Ordnungen der Ostreaceen, Aviculaceen, Aetheriaceen, Mytilaceen, Arcaceen, Lyriodontaceen, Najadeen, Lucinaceen und Cyprinaceen. Sie ist die älteste von den drei Subclassen, herrscht in der silurischen und palaeolitischen Zeit ganz überwiegend vor, erreicht ihre Acme in der Secundär-Zeit, und nimmt von der Eocen-Zcit an rasch bis zur Jetztzeit ab. Die Ostreaceen (insbesondere die Anomiaden) schliessen sich von Allen zunächst an die Spirobranchien an.

\section{Zweite Subclasse der Elatobranchien: \\ Sinupalliata (Siphoniotu). Buchtmantelige B/atliemer.}

Diese Abtheilung enthält die höheren und vollkommneren Blattkiemer, mit Nantelbucht und mit gut entwickelten Siphonen: die drei Ordnungen der Veneraceen, Myaccen und Solenaceen. Sie ist jünger, als die vorige, älter, als die folgende Subclasse. Sie hat sich erst später aus den Integripalliaten entwickelt. In der silurischen und palaeolitischen Zeit nur durch einzelne wenige Reprïsentanten vertreten, nimmt sie in der Secundär-Zeit allmählich zu und erreicht ihre stärkste Entwickelung in der Tertiär-Zeit und in der Gegenwart. Durch die Solenaceen schliesst sie sich unmittelbar an die Pholadaceen an.

Dritte Subclasse der Elatobranchien:

\section{Inclusa (Tubicolote). Lïhlreubewolmende Blattliemer.}

Diese Abtheilung umfasst nur die eine Ordnung der Pholadaceen, mit den drei Familien der Clavagelliden, Pholadiden und Terediniden. Von allen drei Subclassen der Lamellibranchien ist sie die vollkommenste, und demgemäss auch die jüngste. Sie fehlt in der Primärzeit ganz, tritt zum ersten Male in der Secundärzeit, jedoch noch spärlich auf, und nimmt erst in der Tertiärzeit mehr zu, bis zur Gegenwart. Durch Teredo schliesst sie sich unmittelbar an die Seaphopoden (Dentalium) und somit an die Otocardier an.

\section{Zweiter Cladus der Otocardier: \\ Odontophora. Bezalnte Otocardier.}

Dieser Cladus enthält die höchst entwickelten Weichthiere, die Cephalophoren oder Kopf-Mollusken (Cephalota) im weiteren Sinne, welche sich durch den Besitz eines Kopfes und insbesondere einer Bezahnung von allen vorhergehenden Mollusken unterscheiden. Es gehören hierher 


\section{Systematische Einleitung in die Entwickelungsgeschichte.}

die beiden Classen der Schnecken (Cochlides) und der Dintenfische (Cephalopora). Von diesen haben sich die letzteren jedenfalls aus tiefstehenden Gliedern der ersteren, sowie diese wahrscheinlich aus den höchsten Gliedern der Elatobranchien entwickelt. Doch ist auch hier, wic bei allen Mollusken, die specielle Genealogie zweifelhaft.

Erste Classe der Odontophoren:

Cochlides. Schnecken.

(S yuonym: Cephalophora. Gasteropoda. Cochli. Cochleae. Cochlaceae)'1).

Die äusserst vielgestaltige und umfangreiche Classe der Schnecken oder Cochliden bietet hinsichtlich ihrer Genealogie noch grössere Schwierigkeiten, als die übrigen Mollusken-Gruppen dar. Zwar zeigen ihre verschiedenen Abtheilungen mehrfache Berührungspunkte unter einander und mit anderen Gruppen; indessen lässt sich daraus keineswegs ein irgend sicherer Stammbaum herstellen. Die Scaphopoden (Denfulium) schliessen sich von allen zunächst an die Elatobranchien, als die nächstniedere Mollusken-Classe an. Dagegen sind gewisse Lipobranchien (Rhodope etc.) kaum von niederen Plattwürmern (Turbellarien) zu unterscheiden. Eine der äl. testen Gruppen unter den uns bekannten Cochliden scheinen die Pteropoden zu sein, welche wir nit den nächstverwandten Scaphopoden als Perocephala zusammenfassen. Von den Pteropoden scheinen als zwei divergente Hauptzweige einerseits die übrigen Cochliden, andererseits die Cephalopoden ausgegangen zu sein. Unter den übrigen Schnecken, welche wir wegen ihres höher differenzirten Kopfes als Delocephala den Perocephalen gegenüberstellen, treten als zwei Hauptgruppen (Legionen) die Lungenschnecken (Pueumocochli) den Kiemenschnecken (Branchiocochli) gegeniiber. Erstere haben sich erst spät aus den letzteren entwickelt.

\section{Erste Subclasse der Schnecken: \\ Perocephala, H. Stımncllöp/e.}

In. dieser Subclasse vereinigen wir die beiden naheverwandten Legionen der Scaphopoden und Pteropoden, von denen die ersteren den unmittelbaren Uebergang von den Elatobranchien zu den Cochlen, die letzteren dagegen den Ausgangspunkt sowohl für die Delocephalen als für die Cephalopoden bilden.

Erste Legion der Perocephalen:

Scaphopoda. Schaufelschnecken.

(Synonym: Solenoconchae. Prosopocephala. Cirrobranchia. Dentalida.)

Diese Legion wird nur durch die einzige Familie der Dentaliden, mit den beiden Sippen Denfalium und Siphonorlentaliun gebildet. Es sind die unvollkommensten aller Schnecken, welche den Filatobranchien (und speciell den Teredinen) am nächsteu stehen, so dass sie selbst von Vielen als eine besondere Classe der Blattkiemer betrachtet werden. In der That zeigen sie eine so vollständige Vermischung von Charalsteren der Elatobranchien (namentlich der Pholadaceen) einerseits, und der Cochliden (speciell der Pteropoden) andererseits, dass wir sie als gradlinige und wenig verän-

1) xoxìis, 'ò oder xóy.jcs, ó die Schnecke; Cochlea. 
derte Nachkommen der uralten Uebergangsform von den Elatobranchien zu den Cochliden betrachten dürfen. Ihre ältesten fossilen Reste, die man kennt, sind im Devon gefunden worden.

Zweite Legion der Perocephalen:

Pteropoda. (Coponautae). Fliggelschnecken.

Diese Legion scheint unter allen Cochlen, von den Scaphopoden abgesehen, die tiefste Stufe einzunehmen, und enthält in ihren gegenwärtigen Repräsentanten wahrscheinlich nur wenig veränderte Nachkommen von den uralten Stammschnecken, aus denen sich als zwei divergirende Zweige einerseits die Delocephalen, andererseits die Cephalopoden entwickelt haben. Wahrscheinlich haben sich dic Pteropoden entweder unmittelbar aus den Scaphopoden, oder doch aus gemeinsamer Wurzel mit diesen entwickelt. Die Paläontologie lässt uns auch hier wieder im Stich. Zwar werden allgemein eine Menge angeblicher Pteropoden-Schalen aus den silurischen und aus allen paläolithischen Formationen angeführt (während dieselben in allen mesolithischen Bildungen gänzlich fehlen sollen!). Indessen sind die Gründe, auf welche hin man jene Schalen gerade den Pteropoden zugeschrieben hat, nur schwacher Natur, und sie gehören vielleicht ganz anderen Organismen an. Von den beiden Ordnungen, in wclche man die Legion zerfällt hat, scheinen die Gymnosomata (Clioidea), welche wegen Mangels einer Schale überhaupt keine fossilen Reste hinterlassen konnten, die älteren, niederen und unvollkommneren $\mathrm{zu}$ sein, aus denen sich die beschalten 'I'hecosomata (Cymbulida, Hyalaeida, Limacinida) erst später entwickelt haben. Von diesen letzteren konnten die Cymbuliden, mit knorpelähnlicher, nicht verkalkter Schale, ebenfalls nicht conservirt werden. Es konnten also bloss Hyalaeiden und Limaciniden erhalten bleiben. Die zahlreichen silurischen und paläolithischen Schalen sind aber von diesen so sehr verschieden, dass man sie nicht mit Sicherheit denselben anschliessen kann.

Zweite Subclasse der Schnecken:

Delocephala, H. Kop/schnecken.

Diese Subclasse umfasst sämmtliche Schnecken, nach Ausschluss der Pteropoden und Scaphepoden, von denen sie sich durch den deutlich entwickelten Kopf und überhaupt einen höheren Grad der Differenzirung wesentlich unterscheiden. Vermuthlich sind alle Delocephalen erst später aus den Perocephalen hervorgegangen, welche anfangs allein die Cochliden-Classe vertraten. Wir theilen die Delocephalen in zwei Legionen: Branchiocochli (Kiemenschnecken) und Pneumocochli (Lungenschnecken) ron denen sich die letzteren ebenso aus den ersteren, wie diese aus den Pteropoden entwickelt haben.

Erste Legion der Delocephalen:

Branchiocochli, H. (Branchiogasteropoda). Kiemenschnecken.

Diese Legion enthält den bei weitem grössten Theil der ganzen Schnekken-Classe, nämlich die drei grossen Gruppen der Opisthobranchien, Prosobranchien und Heteropoden, von denen wir die beiden letzteren nebst den Chitoniden als Opisthocardier zusammenfassen. Diese haben sich jeHa acis l, Gencrelle Morphologie, II. 
CXIV Systematische Einleitung in die Entwickelungsgeschichte.

denfalls erst später aus den Opisthobranchien entwickelt, welche zunächst aus den Pteropoden herrorgegangen sind.

\section{Erste Sublegion der Kiemenschnecken: \\ Opisthobranchia. Hinterkiemer.}

Von allen Delocephalen enthält diese Gruppe die niedersten und unvollkommensten Formen, welche sich zunächst an die Pteropoden anschliessen, und wohl direct von diesen abstammen. Sie theilen mit ihnen die sehr einfache Zwitterbildung, die Opisthobranchien-Circulation und andere niedrige Organisations - Verhältnisse. Es gehören hierher drei Ordnungen: I. Lipobranchia, H. oder Fehlkiemer (Rhodopida, Pontolimacida, Phyllirrhoida, Elysida). II. Notobranchia oder Rü ckenkiemer (Cerabranehia, Cladobranchia, Pygobranchia). III. P leurobranchia oder Seitenkiemer (Dipleurobranchia, Monoplearobranchia). Von diesen drei Ordnungen haben sich wahrscheinlich die beiden letzteren als divergente Zweige aus der ersteren, vielleicht aber auch die Pleurobranchien aus den Notobranchien, wie diese aus den Iipobranchien entwickelt. Doch können die letzteren auch wohl eine, durch specielle Anpassungen rückgebildete Gruppe darstellen. Die auffallend nahe Verwandtschaft einiger Lipobranchien (Khodope) mit niederen Plattwürmern (Turbellarien) ist höchst merkwürdig, beruht indessen wahrscheinlich mehr auf Analogie (Anpassung an ähnliche Existenz-Bedingungen), als auf $\mathrm{H}$ omologie (wirklicher Blutsverwandtschaft). Die Paläontologie berichtet uns ïber die Entwiclselung der Prosobranchien, welche wir für die ältesten von allen Delocephalen halten, so gut wie Nichts, da die meisten Schnecken dieser Sublegion keine erhaltbaren Schalen besassen. Einzelne hierher gerechnete Schalen werden fast in allen Formationen, von der silurischen an, aufgefuhrt. Vermuthlich war diese Gruppe in der archolithischen und paläolithischen Zeit sehr reichlich entwickelt. $\Lambda$ ls $2 w 0 i$ divergente $\Lambda$ cste haben sich aus den Opisthobranchien wahrscheinlich einerseits die Opisthocardier und andererseits die Pneumocochlen hervorgebildet.

\section{Zweite Sublegion der Kiemenschnecken: \\ Opisthocardia, H. Hinlerherzen.}

Diese Abtheilung besteht aus der äusserst umfangreichen Ordnung der Prosobranchien und den beiden kleinen Ordnungen der Entomocochlen und der Heteropoden, welche in ihrer wesentlichen Organisation so nahe verwandt sind, dass wir sie nicht getrennt lassen können. Die Kielfüsser oder Heteropoden, welche sich in die beiden Familien der Pterotracheaceen und Atlantaceen spalten, scheinen uns nur einen einzelnen Seitenzweig der auf dem Boden kriechenden Prosobranchien darzustellen, welcher sich durch Anpassung an schwimmende pelagische Lebensweise eigenthümlich verändert hat. Unter den Vorderkiemern oder Prosobranchien bildet die Hauptmasse die äusserst formenreiche Unterordnung der Taenioglossa, an welche sich als divergente Zweige die kleineren Unterordnungen der Toroglossa, Rhachiglossa, Ptenoglossa und Rhipidoglossa (Aspidobranchia) anschliesen. Einen besondern Seitenzweig bildet die eigenthümliche Unterordnung der Cyclobranchia (Pafellida), welche von allen bekannten Schnecken sich am nächsten an die eigenthümliche Ordnung der Entomocochli (Chitnnida) anschliesst. 
Letztere ist vielleicht ein isolirter Ueberrest einer vormals reich entwickelten Schnecken-Gruppe, die möglicherweise sehr tief unten von dem gemeinsamen Opisthocardier - Stamme sich abgezweigt hat. Die harten Kalkschalen, welche die allermeisten Opisthocardier besitzen, sind in den Erdschichten von der silurischen Formation an zahlreich erhalten worden. Es ergiebt sich daraus eine stctige Zunahme dieser Sublegion von der silurischen bis zur Jetztzeit.

Zweite Legion der Delocephalen:

Pneum ocochli, H. (Pulmogasteropoda) Lungenschnecken.

Diese Legion, weit kleiner, als die vorhergehende, umfasst nur die einzige Ordnung der Pulmonaten oder Lungenschnecken, zu welcher der bei weitem grösste Theil aller landbewohnenden Schnecken gehört. Sie ist zusammengesetzt aus den Familien der Auriculiden, Iimnaeiden, Peroniaden, Veronicelliden, Janelliden, Limaciden, Testacelliden und $\mathrm{He}$ liciden. Diese Legion hat sich am spätesten von allen Schnecken - Gruppen entwickelt, wie sie denn auch in mehrfacher Beziehung als die höchste und vollendetste erscheint. Die ersten, jedoch vereinzelten Reste derselben finden sich in den untersten Kreideschichten (in der Wälderformation); alle hier befindlichen Pulmonaten sind Süsswasserbewohner (Planorbis, Lymnaeus, Physu etc.). Erst in der Anteocen-Zeit scheinen dieselben zum Landleben übergegangen zu sein. Schon in den Eocen-Schichten treffen wir zahlreiche landbewohnende Pulmonaten an, welche von nun an durch alle tertiären Schichten hindurch bis zur Jetztzeit zunehmen. Aller Wahrscheinlichkeit nach haben sich die Pneumocochlen nicht aus den gonochoristischen Prosobranchien, sondern aus den hermaphroditischen Opisthobranchien entwickelt.

\section{Zweite Classe der Odontophoren:}

Cephalopoda. Dintenfische.

.Die Classe der Cephalopoden, welche (in scheinbarem Widerspruch mit dem Fortschritts - Gesetz) bereits in dor Silurzeit als eine vielgestaltig entwickelte Gruppe auftritt, und von da an bis zur Jetztzeit allmählich abnimmt, obschon sie die vollkommenste aller Mollusken-Classen ist, beweist uns deutlich das hohe Alter des Mollusken-Stammes, welcher bereits in der archolithischen Zeit seine eigentliche Entwickelung, und schon gegen Ende dieser Zeit die Acme derselben erreicht hatte. Allem Anscheine nach haben sich die Cephalopoden (unabhängig von den Delocephalen) aus den Pteropoden entwickelt, welche ihnen von allen Mollusken am nächsten stehen. Von den beiden Subclassen, in welche die Classe zerfällt, Tetrabranchiaten und Dibranchiaten, scheinen die ersteren sehr lange Zeit hindurch, von der cambrischen bis zur Jura-Zeit, allein die ganze Classe vertreten $\mathrm{zu}$ haben, und erst in der Antejura-Zeit haben sich die letzteren aus ihnen entwickelt.

Erste Subclasse der Cephalopoden:

\section{Tetrabranchia (Tentaculifera). Vierkiemige Cephalopoden.}

Diese Subclasse enthält die niederen und unvollkommneren Cephalopoden, welche sich zunächst aus den Pteropoden in der archolithischen Zeit entwickelt haben. Sie zerfällt in die beiden Ordnungen der Nauti- 


\section{Systematische Einleitung in die Entwickelungsgeschichte.}

liden und Ammonitiden. Die Nautiliden als die ältesten von Allen beginnen bereits in cambrischen. System und nehmen vom silurischen System an allmählich ab, setzen sich jedoch mit einem Genus (Nautilus) durch alle Formationen bis zur Gegenwart fort. Die Ammonitiden haben sich wahrscheinlich erst aus den Nautiliden während der antesilurischen oder silurischen Zeit entwickelt, bleiben in der ganzen paläolithischen Zeit sehr spärlich und erreichen erst in der Jura-Zeit eine sehr starke, und in der Kreide-Zeit die stärkste Entwickelung, worauf sie in der AnteocenZeit völlig aussterben. Aus der ganzen Tertiär-Zeit sind keine fossilen Ammonitiden bekannt.

Zweite Subclasse der Cephalopoden:

\section{Dibranchia (Acetabulifera). Zweilicmige Ceplialopoden.}

Diese Subclasse enthält die höheren und vollkommneren Cephalopoden, welche sich aus den Tetrabranchien erst in der mesolithischen Zeit, wahrscheinlich erst in der Antejura-Zeit (vielleicht auch schon in der TriasZeit) entwickelt haben. Sie zerfällt in die beiden Ordnungen der Decabrachien und Octobrachien. Die Decabrachien (Belemnitiden, Spiruliden, Sepiaden und Teuthiden) haben die Subclasse während der Secundär-Zeit wohl allein vertreten, beginnen im Jura (vielleicht schon in der Trias?) und erreichen ebendaselbst (oder in der Kreide?) ihre Acme, worauf sie in der Teritär-Zeit abnehmen. Von den Octobrachien (Cirroteuthiden, Eledoniden, Philonexiden), welche meistens keine harten, der fossilen Erhaltung fähigen Theile besitzen, kennt man nur vereinzelte Reste (Argonanta) aus mittlern und neuern Tertiär-Schichten. Vielleicht haben sie sich als die vollkommensten Cephalopoden erst in der TertiärZeit aus den Decabrachien entwickelt.

\section{Fünfter Stamm des Thierreichs: Vertclorata. Wirbeltliere.}

Das Phylum der Wirbelthierc ist in sehr vielen Beziehungen der wichtigste und interessanteste Stamm, nicht allein im Thierreiche, sondern unter allen Organismen. $D_{a}$ der Mensch selbst, als der vollkommenste und höchste aller Organismen, Nichts weiter ist, als ein einzelnes, sehr junges Aestchen dieses Stammes, und da die Beweise, welche die vergleichende Anatomie und Ontogenie für die Wirbelthier-Natur des Menschen liefert, auch von denjenigen nie bestritten werden konnten, welche seine Abstammung von andern Vertebraten auf das Hartnäckigste leugneten, so musste das Phylum der Vertebraten schon aus diesem Grunde seit den ältesten Zeiten dic besondere Aufmerksamkeit auf sich ziehen, und wir kennen seine gesammte Anatomie, Ontogenie und Phylogenie besser, als diejenige irgend einer anderen Abtheilung der drei organischen Reiche.

Die Paläontologie liefert uns über die Phylogenie der Wirbelthierc äusserst zahlreiche und wichtige Aufschlüsse. Zwar sind die fossilen Reste der Wirbelthiere nicht entfernt so massenhaft erhalten als diejenigen der Mollusken und Echinodermen. Auch konnten sehr viele und namentlich niedere Wirbelthiere, wegen Mangels eines festen Skelets, oder (wie die Vögel) wegen dessen Zerbrechlichkeit keine oder nur wenige Spuren hinterlassen; und offenbar geben alle bekannten fossileu Wirbelthier-Reste zusammengenommen nur eine sehr schwache Vorstellung von dem Formen- 
reichthum des Stammes in der vormenschlichen Zeit Dennoch sind diese Reste als Fingerzeige von der grössten Bedeutung, und sehr oft schon hat ein einzelner Zahn, ein einzelner Knochen, eine einzelne Schuppe eines Wirbelthiers uns über Alter und Phylogenie einer ganzen Gruppe die wichtigsten Aufichlüsse gegeben. Diese ausserordentlich hohe Bedeutung der fossilen Vertebraten - Reste ist vorzüglich darin begründet, dass die erhaltenen Theile allermeistens Stiucke des inneren Skelets sind, eines morphologisch höchst wichtigen Organ-Sjstems, welches in den meisten Fällen besser als irgend ein anderes System des Körpers die VerwandtschaftsVerhältnisse und die systematische Stellung des Wirbelthiers erläutert. Nur die Echinodermen können sich in dieser Beziehung den Vertebraten vergleichen. Freilich sind auch die Schwicrigkeiten, welche sich der Erkenntniss der fossilen Vertebraten-Skelete entgegenstellen, sehr bedeutende, zumal nur selten ganze zusammenhängende Skelete, meistens nur einzelne abgetrennte Skelettheile erhalten sind.

Wenn nun schon die Paläontologie uns für die Bildung der genealogischen Hypothesen, durch welche allein wir die Phylogenie der Vertebraten construiren können, die wichtigsten empirischen Grundlagen liefert, so gilt dies doch in fast noch höherem Maasse von der vergleichenden Anatomie und Ontogenie der Wirbelthiere, und insbesondere von der letzteren. Nirgends so wie bei den Vertebraten, wird die ausserordentlich hohe Bedeutung völigklar, welche diedreifache genealogische Parallele, der causal-mechanische Parallelismus zwischen der phyletischen, biontischen und systematischen Entwickelungsreihe besitzt (vergl. unten S. 371). Es würde uns unmöglich sein, den äusserst wichtigen und interessanten Stammbaum der Wirbelthicre so, wie wir es auf den folgenden Seiten versuchen, zu construiren, wenn nicht die Paläontologie, die Embryologie und dic vergleichende Anatomie (dic anatomisch begrïndete Systematik) sich gegenseitig in der ausgezeichnetsten Weise erläuterten, und als drei parallele Entwickelungs-Stufenleitern ergänzten. Weder allein die Paläontologie, noch allein die Embryologie (Ontogenie), noch allein die rergleichende Anatomie (Systematik) der Wirbelthiere, vermag uns ihre Phy: logenie herzustellen, während dies durch die denkende Benutzung und vergleichende Synthese jener drei parallelen und durch den innigsten Causalnexus verbundenen Erscheinungsreihen in der überraschendsten und lehrreichsten Weise möglich wird. Da nua in der Regel die Paläontologen Nichts von Embryologie, und nur sehr Wenig von vergleichender Anatomie, die Embryologen und die vergleichenden Anatomen Nichts oder nur sehr Wenig von Paläontologie verstehen, so erklärt sich hieraus hinreichend, warum bisher noch so wenige Versuche gemacht sind, die offen da liegenden Fäden der Wirbelthier-Entwickelung zu dem Gewebe ihres Stammbaums zu verknüpfen, und warum die hierauf zielenden trefflichen Bemühungen von Gegenbaur und $\mathrm{Huxley}$ (s. unten S. 277. Anm.) bisher so isolirt dastehen. Keine andere Gruppe von Organismen zeigt so klar, wie diejenige der Vertebraten, dass nur die gründliche Kenntniss und die denkende Vergleichung ihrer paläontologischen (phylogenetischen), embryologischen (ontogenetischen) und systematischen (anatomischen) Entwickelung uns das volle Verständniss der Gruppen und ihrer Ent. stehung eröffnet. 
CXVII Systematische Einleitung in die Entwickelungsgeschichte.

Im vollen Gegensatze zu den Mollusken sind die Wirbelthiere eine verhältnissmässig erst spät entwickelte Thiergruppe. Von allen thierischen Stämmen ist das Phylum der Vertebraten, wie der höchste und vollkommenste, so auch der späteste und jüngste. Erst in der Tertiär-Zeit erreicht er seine volle Blüthe und befestigt die in der Secundär-Zeit errungene Herrschaft über alle übrigen Organismen. Die Entwickelung der grösseren und kleineren Gruppen liegt, im Grossen und Ganzen betrachtet, hier ausserordentlich klar vor Augen, und liefert sowohl im Ganzen, als im Einzelnen die glänzendsten Beweise für das Fortschritts-Gesetz. Aus der ganzen archolithischen Zeit kennen wir von den Vertebraten Nichts, als aus dem allerletzten Abschnitt derselben (aus der jüngsten Silur-Zeit) einige wenige Spuren von Fischen (Selachiern und Ganoiden). In der ganzen paläolithischen Zeit, rom Antederon bis zum Perm, kennen wir fast ausschliesslich Fische (Selachier und Ganoiden). Erst in der Kohle treten die ersten vereinzelten landbewohnenden Wirbelthiere, und zwar gepanzerte Amphibien (Ganocephalen) auf, und erst im Perm die ersten amniotischen Vertebraten, einige eidechsenähnliche Reptilien (Proterosuurus und Rhopalodon). In der Secundär-Periode ist der Stamm ganz vorwiegend durch die Reptilien vertreten, an deren Stelle in der Tertiär-Zeit die Säugethiere treten. Doch beginnt die Entwickelung der niederen Säugethiere aus den Amphibien, sowie die Entwickelung der Vögel aus den Reptilien, bereits zu Anfang oder gegen die Mitte der mesolithischen Zeit, woselbst auch die ersten Knochenfische (Teleostier) auftreten. Monodelphe Säugethiere sind mit Sicherheit erst aus der Tertiär-Zeit bekannt, gegen deren Ende wahrscheinlich bereits (oder vielleicht auch erst im Beginn der Quartär-Zeit) der wichtigste Schritt in der phyletischen Wirbelthier-Entwickelung geschah, die Umbildung des Affen zum Menschen.

Die Phylogenie der Wirbelthiere, wie sie uns so durch die Paläontologie in ihren Grundzügen skizzirt wird, erhält nun die werthvollsten Ergänzungen durch die Resultate der vergleichenden Anatomie und Embryologie. Hieraus lässt sich folgender Entwickelungsgang unseres Stammes entwerfen: Zuerst, in früherer archolithischer Zeit, war aller Wahrscheinlichlseit nach das Vertebraten-Phylum bloss durch Lep tocardier repräsentirt, von denen uns der einzige lekende Amphioxus noch Kunde giebt. Aus diesen entwickelten sich (innerhalb oder vor der Silur-Zeit) die echten $F$ ische (vielleicht zunächst aus den Monorrhinen oder Marsipobranchien, die aber vielleicht auch einen selbstständig auslaufenden Zweig der Leptocardier darstellen). Die ältesten echten Fische waren Selachier und zwar wahrscheinlich den $\mathrm{H}$ aifi s chen (Squalaceen) nächstverwandt. Aus diesen entsprangen fünf divergente Zweige, die drei Gruppen der Chimären, Rajaceen und Dipneusten (welche sich weiter nicht bedeutend differenzirten), und die beiden Gruppen der Ganoiden und Phractamphibien, von denen erstere den Teleostiern, letztere den übrigen Amphibien (Lissamphibien) den Ursprung gaben. Aus den Amphibien entstanden (wahrscheinlich in der Perm-Zeit) die ersten Amnioten, eidechsenartige Reptilien (Tocosaurier). Aus diesen ersten Reptilien entsprangen dann als vier divergirende Zweige die Hydrosaurier, Dinosaurier, Lepidosaurier und Rhamphosaurier, von denen die letzteren den Vögeln den Ursprung gaben. Die Säugethiere dagegen entwickelten sich wahrscheinlich unabhängig von den Reptilien, unmittelbar aus den Amphibien, oder hingen nur unten an der Wurzel mit den ältesten Reptilien zusammen. 
Der erste Ursprung der Wirbelthiere ist noch in tiefes Dunkel gehüllt, da ihre ältesten und unvollkommensten Repräsentanten, die Leptocardier, obwohl sehr niedrig organisirt, dennoch offenbar bereits das Resultat eines schr langen phyletischen Entwickelungs-Processes sind. Die Meisten werden vielleicht geneigt sein, eine besondere autogone MonerenForm als ersten Anfang das Vertebraten-Phylum anzunehmen und dieses mithin für völlig selbstständig anzusehen. Nach unserem Dafürhalten ist es wahrscheinlicher, dass die ältesten Wirbelthiere (noch tief unter dem Amphinxus stehend) aus Würmern, und zwar aus Nematelminthen sich entwickelt haben. In diesem Falle würden die Sagitten (Chaetognathen) und demnächst dic Nematoden, unsere nächsten Verwandten unter den wirbellosen Thieren sein (rergl. oben S. LXXXII und unten S. 414). Man könnte vielleicht auch die anatomischen „Verwandtschaftsbeziehungen", welche zwischen den Vertebraten einerseits und den Mollusken und Arthropoden andererseits bestehen, in genealogischem Sinne verwerthen wollen. Insbesondere könnte hierbei die Aehnlichkeit des Kiemenkorbes der Leptocardier und Tunicaten, die Aehnlichkeit des Rückenmarks der Vertebraten und des Bauchmarks der Arthropoden und andere derartige (namentlich histologische) Aehnlichkeiten in Frage kommen. Indessen halten wir diese doch nur für Analogieen, nicht für wahre Homologieen.

\section{Erstes Subphylum der Wirbelthiere: Leptocardia. Röhrenherzen.}

\section{Einzige Classe der cLeptocardier:}

Acrania. Schüdellose.

Der erste Unterstamm des Vertebraten-Phylum wird durch die einzige Classe der Schädellosen (Acrania) oder Gehirnlosen (Anencephala) gebildet, welche man wegen ihres cigenthümlichen CirculationsSystems gewöhnlich Röhrenherzen (Leptocardia) nennt. Der einzige bekannte Kepräsentant dieser merkwürdigen Hauptabtheilung des Wirbelthier-Stammes ist Amphioxus lanceolatus. Zwar wird dieses Thier gewöhnlich als ein Fisch angesehen, und sogar meistens als eine den ibrigen Fisch-Ordnungen gleichwerthige Ordnung; oft wird er selbst nur als eine eigene Familie mit den niederen Fischordnungen vereinigt. $\mathrm{Da}$ indess, wie bekannt, dieses Wirbelthier sich durch seine gesammte Organisation sehr viel weiter von allen übrigen Vertebraten entfernt als irgend ein anderes Glied dieses Stammes, da der Mangel des Schädels und des Gehirns, der Mangel eines compacten Herzens und, viele andere Charaktere ihn als eine ganz besondere Abtheilung auszeichnen, so nehmen wir keinen Anstand, denselben nicht allein als Vertreter einer besonderen Classe, sondern auch eines besonderen Unterstammes von allen übrigen Wirbelthieren zu trennen Wir erblicken in demselben den einzigen überlebenden Ausläufer einer Wirbelthier-Abtheilung, die wahrscheinlich in früheren Perioden der Erdgeschichte einen reich entwickelten und viel verzweigten Baum darstellte. Wegen Mangels fester Skelettheile konnten keine fossilen Reste derselben erhalten bleiben. Amphioxus ist also wahrscheinlich der letzte Mohikaner jener niederen Vertebraten-Abtheilung. welche sich zunächst von den Würmern abzweigte, und aus welcher erst später die vollkommneren Pachycardien sich entwickelten. 
CXX Systematische Einleitung in die Entwickelungsgeschichte.

\section{Zweites Subphylum der Wirbelthiere: Pachycardia, H. Centralherzen.}

(Synon ym: Craniota, Schädelthiere: Encephalota, Gehirnthiere.)

$\mathrm{Zu}$ dieser zweiten Hauptabtheilung des Wirbelthierstammes gehören alle bekannten Wirbelthiere, mit einziger Ausnahme des Amphioxus lanceolatus. Sie unterscheiden sich sehr wesentlich von diesem durch den Besitz eines Gehirns, eines Schädels, eincs compacten Herzens und durch viele andere Charaktere, welche sie hoch über denselben erheben. Offenbar haben sie sich erst später (jedoch schon innerhalb oder vor der Silurzeit) aus dem Unterstamme der Leptocardier entwickelt. Das Subphylum der Pachycardier zerfällt zunächst in zwei sehr ungleiche Stammäste, von denen der eine bloss die kleine Gruppe der Monorrhinen (Classe der Marsipobranchien), der andere sämmtliche übrigen Vertebraten (Amphirr hinen) umfasst.

\section{Erster Cladus der Pachycardier:}

\section{Monorrhina, H. Unpaarnasen.}

Als Monorrhinen sondern wir hier von den übrigen Pachycardiern die Classe der Cyclostomen oder Marsipobranchien ab, welche sich durch so wesentliche anatomische und ontogenetische Charaktere von den übrígen Wirbelthieren unterscheidet, dass wir sie nicht mit Recht als eine $\mathrm{Ab}$ theilung der echten Fische betrachten können. Während alle übrigen Pachycardier drei Bogengänge im Labyrinth des Gehörorgans besitzen, haben die Monorrhinen deren nur ein oder zwei. Während bei allen übrigen die Nase paarig, ist sie bei ihnen unpaar angelegt. Während alle übrigen ein sympathisches Nervensystem besitzen, ist dieses bei ihnen noch nicht entdeckt. Auch die Structur der Gewebe (insbesondere des NervenGewebes) ist bei ihnen so eigenthümlich, dass sie dadurch viel weiter von allen Pachycardiern sich entfernen, als irgend zwei verschiedene Gruppen der letzteren unter sich. Die Fische sind dem Menschen und den übrigen Säugethieren viel näher verwandt, als die Monorrhinen den Fischen. Daher glauben wir vollkommen im Recht zu sein, wenn wir die Marsipobranchien allen übrigen Pachycardiern als besonderen Cladus gegenüberstellen. Wir erblicken in ihnen die letzten überlebenden Repräsentanten eines früher vermuthlich mannichfaltig entwickelten Vertebraten-Astes, der unabhängig von den Amphirrhinen aus den Leptocardiern sich entwickelte.

Einzige Classe der Monorrhinen:

Marsipobranchia. Beutelkiemer.

(S ynon ym: Cyclostomi, Rundmäuler. Myzontes, Schleimfisehe.)

Die wenigen jetzt noch lebenden Glieder des Monorrhinen-Cladus, welche ẉir sämmtlich in der einen Classe der Marsipobranchien zusammenfassen, können uns wohl nur eine schwache Vorstellung von der FormenMannichfaltigkeit geben, welche aller Wahrscheinlichkeit nach diese Wirbelthier-Gruppe ebenso wie diejenige der Leptocardier, in den früheren Perioden der Erdgeschichte entwickelt hat. Wahrscheinlich schon in oder vor der silurischen Zeit haben sich die Marsipobranchien aus den Leptocardiern, divergent von den Amphirrhinen, hervorgebildet. Fossile Reste 
konnten sie aus Mangel an harten Skelettheilen nicht hinterlassen. Sie zerfallen in zwei Ordnungen: I. H y perotreta (Myxinoida), Myxine, Gastrobranchus, Bdellostoma, Beutelkiemer mit durchbohrtem Gaumen, mit einem einzigen Halbcirkel-Canal des Gehörorgans. II. Hyperoartia (Petromyzonida), Petromyzon (und seine Larve Ammocoetes), Beutelkiemer mit undurchbohrtem Gaumen, mit zwei Halbcirkelcanälen des Gehörorgans. Die Hyperoartien erscheinen in jeder Beziehung als eine jüngere, höher ausgebildete Gruppe, welche sich wahrscheinlich erst später aus den $\mathrm{Hy}$ perotreten entwickelt hat; doch sind letztere vielleioht auch durch Parasitismus rückgebildet.

Zweiter Cladus der Pachycardier:

Amphirrhina, H. Paarnasen.

Alle Amphirrhinen besitzen ein sympathisches Nervensystem, ein paariges Geruchsorgan, drei Bogengänge am Gehörorgan und niemals die beutelförmigen Kiemen der Monorrhinen. Diese Gruppe unterscheidet sich, wie schon erwähnt, durch die angeführten Charaktere so sehr von den Monorrhinen, dass wir sie als einen durchaus einheitlich organisirten Cladus oder Stammast sowohl den Monorrhinen als den Leptocardiern gegenüber stellen müssen. Offenbar sind alle hierher gehörigen Wirbelthiere Glieder eines einzigen Hauptastes, welcher sich schon sehr frühzeitig entweder ganz selbstständig aus den Leptocardiern hervorgebildet oder von den Monorrhinen abgezweigt hat. Diese Trennung muss in oder vor der Silurzeit erfolgt sein. Der Cladus der Amphirrhinen zerfällt in zwei Subcladen: Anamnien und Amnioten. Zu den ersteren gehören die drei Classen der Fische, Dipneusten und Amphibien, zu den letzteren die drei Classen der Reptilien, Vögel und Säugethiere. Die Amnioten als die vollkommneren Amphirrhinen haben sich erst spät (wahrscheinlich in der Anteperm-Zeit, oder in der Pern-Zeit) aus den Anamnien entwickelt, welche ihrerseits unmittelbar entweder von den Monorrhinen, oder direct von den Leptocardiern sich abgezweigt baben.

\section{Erster Subcladus der Amphirrhinen: \\ Anamnia, H. Amnionlose.}

Der Unterast der Anamnien umfasst die sogenannten niederen Wirbelthiere oder Anallantoidien, nach Ausschluss der Monorrhinen und der Leptocardier. Sie unterscheiden sich von den höheren Wirbelthieren wesentlich durch den Mangel des Amnion und den Besitz von wirklich athmenden Kiemen zu irgend einer Lebenszeit. Meistens ist auch die Allantois bei ihren Embryonen nicht entwickelt. Die Schädelbasis der Embryonen ist nicht geknickt. Fs besteht dieser Subcladus aus den beiden Classen der echten Fische und Amphibien, und aus der Beide verbindenden Classe der Dipneusten. Von diesen sind zunächst die Fische aus den Monorrhinen oder aus den Leptocardiern entstanden.

Erste Classe der Anamnien.

Pisces. Fische.

Die Classe der echten Fische beschränken wir auf die drei.Subclassen der Selachier, Ganoiden und Teleostier, indem wir einerseits dio 
CXXII Systematische Einleitung in die Entwickelungsgeschichte.

Leptocardier und Monorrhinen, andererseits die Dipneusten aus ihr ausschliessen. In dem so begrenzten Umfange erscheint die Fischclasse als eine einheitliche Gruppe, deren sämmtliche Mitglieder in einer grossen Anzahl von wichtigen und eigenthümlichen Charakteren völlig übereinstimmen. Die Fischclasse ist die älteste ron allen Anamnien und zugleich von allen Amphirrhinen. Fossile Reste derselben sind bereits im Silur vorhanden. Erst später haben sich aus ihr die beiden Classen der Dipneusten und Amphibien und noch viel später aus den letzteren die Amnioten entwickelt. Von den drei Subclassen der echten Fische ist ohne Zweifel die der Selachier die älteste, aus welcher erst später die Ganoiden, und aus diesen noch später die Teleostier sich entwickelt haben.

\section{Erste Subclasse der Fische: \\ Selachii. Urfische.}

(S ynonym : Elasmobranchii. Chondropterygii. Placoida. Playiostomi sensu ampliori.)

Den Ausgangspunkt aller echten Fische und somit zugleich aller Amphirrhinen, bildet die höchst interessante und wichtige Subclasse der Selachier, zu .welcher die silurischen Ahnen aller Amphirrhinen und also auch des Menschen gehörten. Die gegenwärtig lebenden und uns allein genauer bekannten Selachier erscheinen als sehr wenig typisch veränderte, obgleich in ihrer Art, in ihrem Typus sehr hoch entwickelte, directe Nachkommen der niedrig organisirten archolithischen Urfische, aus welchen sich alle anderen Fische einerseits, alle Amphibien und somit auch alle Amnioten andererseits hervorgebildet haben. Leider liefert uns die Paläontologie über die nähere Beschaffenheit dieser unserer alten Urahnen keine befriedigenden Aufschlüsse. Da das Skelet der Selachier grösstentheils nicht der Erhaltung im fossilen Zustande fähig ist, so sind uns von denselben fast bloss die härteren Zähne und Flossenstacheln (Ichthyodorulithen) erhalten. Nur insofern sind diesclben von Interesse, als sie in grosser Zahl fast in allen Formationen, vom Silur an, vorkommen, und also die Existenz der Selachier-Gruppe schon in der Silurzeit beweisen. Uebrigens liesse sich diese auch ohne jene Reste schon aus den silurischen Ganoiden erschliessen, da diese als Descendenten der Selachier erst auf die letzteren gefolgt sein könuen. Die Selachier haben sich entweder unmittelbar aus den Leptocardiern, oder mittelbar aus einem gemeinsamen Ast mit den Monorrhinen entwickelt, sich jedoch schon sehr frühzeitig (wohl lange vor der Silurzeit) ron diesen abgezweigt. Die Subclasse spaltet sich in zwei divergente Aeste, die Plagiostomen und Holocephalen.

\section{Erste Legion der Selachier: \\ Plagiostomi. Quermüuler.}

Diese Legion bildet aller Wahrscheinlichkeit nach die Hauptstammgruppe der Fische, aus welcher sich einerseits die Holocephalen, andererseits die Ganoiden, und wahrscheinlich als zwei besondere Aeste die Dipneusten und die Amphibien entwickelt haben. Sie wird zusammengesetzt aus den beiden Ordnungen der Haifische (Squalaceen) und Bochen (Rajaceen). Nicht so sicher, als die Abstammung der Ganoiden, Dipneusten und Amphibien ron den Plagiostomen, erscheint diejenige der Holocephalen, welche sich vielleicht auch unabhängig von den eigentlichen Plagiostomen aus gemeinsamen Stammformen mit ihnen entwickelt haben. 


\section{Erste Ordnung der Plagiostomen: \\ Squalacei (Squali). Haifische.}

Wie die Plagiostomen unter den Selachiern, so bilden die Squalaceen unter den Plagiostomen den eigentlichen Kern der Gruppe, welcher den alten Urstamm in gerader Linie fortsetzt. Von allen jetzt lebenden Amphirrhinen sind die Haifische aller Wahrscheinlichkeit nach diejenigen, welche den silurischen Ahnen des Menschen und der Amphirrhinen überhaupt am nächsten stehen, und uns diesen Typus unserer gemeinsamen Stammeltern aus der archolithischen Zeit am reinsten erhalten zeigen. Da die fossilen Reste der Haifische sich auf ihre Zähne und Flossenstacheln beschränken, so sind dieselben von eben so geringer specieller, als von grosser genereller Bedeutung. Die ältesten finden sich im obern Silur.

\section{Zweite Ordnung der Plagiostomen: \\ Rajacei (Rajae), Rochen.}

Die Rochen betrachten wir als einen eigenthümlich angepassten Seitenzweig der Haifische, welcher sich wohl erst in der Mitte der paläolithischen Zeit von diesen abgezweigt hat und aus welchem keine weiteren VertebratenGruppen entsprungen sind. Die ältesten Reste derselben finden sich in der Steinkohle. Es gehören hierher die Familien der Squatinorajiden (Squatinoraja), Trygoniden (Trygon), Myliobatiden (Ifyliobaies) etc.

\section{Zweite Legion der Selachier: \\ Holocephali. Seekatzen.}

Diese Legion umfasst nur die einzige Ordnung der Chimaeraceen und die einzige Familie der Chimaeriden, welche wahrscheinlich gleich den Rochen einen sehr eigenthümlich durch Anpassung entwickelten Seitenzweig der Selachier darstellt, der- sich nicht in andere Thiergruppen fortgesetzt hat. Jedoch haben sich die Chimacren offenbar viel weiter als die Rochen von den Haifischen entfernt, falls nicht überhaupt der ganze Holocephalen-Ast etwa noch früher, als der eigentliche Plagiostomen-Ast von den unbekannten Zwischenformen zwischen den Selachiern und Leptocardiern sich abgezweigt hat. Als fossile Reste der Holocephalen haben sich bloss ihre eigenthümlichen Zahnplatten erhalten, welche sich zuerst in der Trias, besonders zahlreich im Jura finden. Die gegenwärtig allein noch lebenden beiden Genera Chimaera und Calorrhynchus sind die letzten Ausläufer dieser vormals reich entwickelten Gruppe.

\section{Zweite Subclasse der Fische: \\ Ganoides. Schmelzfische.}

Die merkwürdige Subclasse der Ganoiden oder der schmelzschuppigen Fische bildet den unmittelbaren Uebergang von den Selachiern zu den Teleostiern. Von den drei Jegionen, welche wir in derselben unterscheiden, schliessen sich die Tabuliferen, als die ältesten, unmittelbar an die Selachier an und haben sich wohl direct aus diesen entwickelt, während die beiden andern Jegionen, Rhombiferen und Cycliferen, wahrscheinlich als zwei divergente Aeste aus den Tabuliferen entsprungen sind. Aus den Cycliferen haben sich die Teleostier entwickelt. 
CXXIV Systematische Einleitung in die Entrickelungsgeschichte.

Erste Legion der Ganoiden:

Tabuliferi, H. (Placoganoides). Panzer-Ganoiden.

Diese Legion wird durch die beiden sehr eigenthümlichen Fisch - Ordnungen der Pamphracten und Sturionen gebildet, von denen die letzteren nur aus der secundären und tertiären Zeit bekannt und noch in der Gegenwart durch einzelne Repräsentanten vertreten sind, während die ersteren auf die primordiale und primäre Zeit beschränkt waren. Wahrscheinlich sind die Sturionen die unmittelbare Fortsetzung eines einzelnen Zweiges der Pamphracten, welche sich ihrerseits unmittelbar aus den Selachiern entwickelt haben. Beide Ordnungen stimmen überein in der eigenthümlichen Täfelung des Körpers mit grossen Knochenplatten, und in der fehlenden oder höchst mangelhaften Verknöcherung der Wirbelsäule und des inneren Skelets überhaupt. Die meisten Tabuliferen besitzen keine Zähne.

Erste Ordnung der Tabuliferen:

Pamphracti, H. Schildkröten - Fische.

Als Pamphracten fassen wir die beiden ausgezeichneten Familien der Cephalaspiden und Placodermen zusammen, welche ausschliesslich in der primordialen und primären Zeit lebten, und unter denen sich die ältesten bekannten Fische nächst den Selachiern befinden. Bei den Cephalaspiden ist der Kopf von einer einzigen grossen halbmondförmigen Knochenplatte bedeckt, bei den Placodermen dagegen, wie der übrige Körper, mit mehrern grossen Knochenplatten getäfelt. Die Cephalaspiden (Cephalaspis, Pleraspis, Menaspis) finden sich im oberen Silur, im Devon und im Perm (Menaspis). Es gehört hierher der älteste aller bekannten Ganoiden (Preraspis ludensis, aus den unteren Ludlow - Schichten im oberen Silur). Die Placodermen (Asterolepis, Plerichthys, Coccosteus, Cheliophorus) sind bisher nur im devonischen System, und einzeln auch in der Steinkohle gefunden worden. Es finden sich unter ihnen kolossale Formen von $20-30$ Fuss Länge. Aus den Cephalaspiden haben sich wahrscheinlich die Sturionen, aus den Placodermen als zwei divergente Aeste einerseits die Rhombiferen; andrerseits die Cycliferen entwickelt.

\section{Zweite Ordnung der Tabuliferen: \\ Sturiones. Stör-Fische.}

Die Ordnung der Störe scheint die unmittelbare Fortsetzung der Pamphracten in der secundären und tertiären Zeit bis zur Gegenwart zu bilden. Von den beiden Familien, welche die Ordnung enthält, finden sich die echten Störe oder Accipenseriden (Accipenser) fossil schon in den untersten Jura-Schichten (Chondrosteus im Lias). Die nackten Löffelstöre oder Spatulariden (Spaluluria) konnten keine fossilen Reste hinterlassen.

\section{Zweite Legion der Ganoiden:}

\section{Rhombiferi. (Rhombogauoides) Eckschuppen-Ganoiden.}

Diese Legion bildet die Hauptmasse und den eigentlichen Kern der Ganoiden-Gruppe, so dass man sie auch oft als Ganoiden im engeren Sinne bezeichnet. Zu ihr gehört der bei weitem grösste Theil aller Fische, welche vom Beginn der devonischen bis zum Ende der Jura-Zeit lebten. Sie sind 
demnach die vorzüglichsten Repräsentanten der Fische während der ganzen primären und der ersten Hälfte der secundären 'Leit, und zugleich die charakteristischen Vertebraten der Primärzeit übcrhaupt. Vom Jura an nehmen sie rasch ab, und sind in der Gegenwart nur noch durch wenige spärliche Ausläufer vertreten (Polypterus, Lepidosteus). Wahrscheinlich haben sich die Rhombiferen im Beginn der Primär - Zeit entweder aus den ältesten Cycliferen, oder im Zusammenhang mit diesen aus den Tabuliferen, oder aber (unabhängig von den Cycliferen) unmittelbar aus den Tabuliferen entwickelt. Der Stanmbaum der formenreichen Rhombiferen-Gruppe ist jedoch schwer zu ermitteln, und die verschicdenen Versuche, die zahlreichen Genera und Familien der Rhombiferen in wenige grössere Gruppen zu ordnen, haben zu keinem befriedigenden Resultate gefuhrt. Wir unterscheiden drei verschiedene Ordnungen: Efulcri, Fulcrati und Semaeopteri.

Erste Ordnung der Rhombiferen :

Efulcri, H. Sehindellose Eckschuppen-Fische.

Diese Ordnung umfasst die drei ausgestorbenen Familien der Acan thodiden (ausschliesslich paläolithisch: Acunthodes, Diplacanthus), der Dipteriden (ausschliesslich deronisch: Dipterus, Diplopterus) und der P ycnod on tiden (vón der Steinkohle bis in die Tertiärzeit: Pycnodus, Sphaerodus). Durch den Nangel der Fulcren oder Flossenschindeln, welche die Fulcraten auf der Rückenfirst der Schwanzflosse und oft auch der übrigen Flossen tragen, erscheinen die Efulcren, letzteren gegenüber, als eine einheitlich charakterisirte Gruppe.

\section{Źweite Ordnung der Rhombiferen: \\ Fulcrati, H. Schindelflossige Eckschuppen-Fische.}

Alle Fische dieser Ordnung tragen Flossenschindeln (Fulcra) auf der Rückenfirst der Schwanzflosse, und oft auch der übrigen Flossen. Es gehören hierher die beiden umfangreichen Familien der Monostichen (Palaeoniscus, Dapedius) mit einer Schindelreihe, und der Distischen (Lepidotus, Lepidosteus) mit zwei Schindelreihen. Von Andern werden beide Familien als Lepidosteiden zusammengefasst, und in die beiden Gruppen der kegelzähnigen Sauroiden und der hechelzähnigen Lepidoiden vertheilt. Sie sind in allen paläolithischen und mesolithischen Formationen, rom Devon bis zum Jura zahlreich, jetzt nur noch durch Lepidosteus vertreten.

Dritte Ordnung der Rhombiferen:

Semaeopteri, H. Fahnenflossige Eckschuppen-Fische.

Diese sehr ausgezeichnete Rhombiferen-Ordnung wird nur durch die eine Familie der Poly pteride $n$ gebildet, . mit dem einzigen jetzt lebenden Genus Polypterus, welches sich durch mancherlei Eigenthïmlichkeiten von allen anderen Rhombiferen unterscheidet. Fossile Reste der Semaeopteren sind nicht bekannt.

Dritte Legion der Ganoiden:

\section{Cycliferi. (Cycloganoides) Rundschuppen-Ganoiden.}

Die Ganoiden mit runden Schuppen sind vorzïglich wichtig und interes. sant als die verbindenden Zwischenformen zwischen den übrigen Ganoiden 
CXXVI Systematische Einleitung in die Entwickelungsgeschichte.

und den Teleostiern. Wahrscheinlich haben sie sich unabhängig von den Rhombiferen im Beginne der Primär-Zeit (in der Antedevon-Zeit) aus den Tabuliferen entwickelt, denen namentlich dic Holoptychiden noch sehr nahe stehen. Diese führen durch die Coelacanthiden (mit denen wir sie als Coeloscolopen vereinigen) zu den Pycnoscolopen hinüber, welche sich durch die Leptolepiden (Thrissopiden) unmittelbar in die Teleostier fortsetzen.

\section{Erste Ordnung der Cycliferen: \\ Coeloscolopes, H. Hohlgrüthen.}

Als Coeloscolopen, d. h. Cycliferen mit hoblen Gräthen, fassen wir die beiden nächstverwandten Familien der Holoptychiden und Coelacanthiden zusammen, welche nicht allein durch die hohlen Knochen und Gräthen, sondern auch durch viele andere Charaktere nächstverwandt sind. Die Holoptychiden (Holoptychius, Hhizodhs, Aclinolepis) bilden den Ausgangspunkt der Cycliferen-Legion, und hängen unmittelbar mit den Pamphracten zusammen, von denen wahrscheinlich die Placodermen ihre Voreltern sind. Sie finden sich ansschliesslich im Devon und der Kohle. Von den Holoptychiden haben sich schon frihzeitig (in der Deronzeit) die Coelacan thi den abgezweigt (Coelacanthus, Glyptolepis, Macropoma), welche in der Steinkohle ihre Acme erreichen, sich aber mit einzelnen Repräsentanten bis in die Kreide hinein fortsetzen.

\section{Zweite Ordnung der Cycliferen: \\ Pycnoscolopes, H. Dichtgräthen.}

Als Pycnoscolopen, d. h. Cycliferen mit dichten (nicht hohlen) Gräthen, vereinigen wir hier diejenigen rundschuppigen Ganoiden, welche den Uebergang von den Coeloscolopen zu den Teleostiern (Thrissopiden) vंermitteln. Es sind dies die drei Familien der Coccolepiden (Coccolepis, im Jura), der Megaluriden (Megalur'ss, Oligopleurus, im Jura) und der Amiaden (die Amia der Jetztzeit). Sie sind den Thrissopiden nächstverwandt.

Dritte Subclasse der Fische:

Teleostei. Knochenfische.

Wie die Ganoiden im primären und secundären, so sind die Teleostier im tertiären und quartären Zeitalter die vorzüglichen Repräsentanten der Fisch-Classe. Erst in der Mitte der Secundär-Periode, in der Jura-Zeit treten sie zum ersten Male auf, und in Uebereinstimmung mit dieser wichtigen paläontologischen Thatsache beweist ihre gesammte Anatomie und Ontogenie, dass sie sich unmittelbar aus den Ganoiden entwickelt haben. Die directen Verbindungs - Glieder sind einerseits die Pyenoscolopen, andrerseits die Thrissopiden, welche von den einen Zoologen noch als Ganoiden, von den anderen als Teleostier betrachtet werden. Sie schliessen sich unmittelbar an die Physostomen (Clupeiden) an, welche wir als gemeinsamen Ausgangspunkt der ganzeu Teleostier-Subclasse zu betrachten haben.

Die Subclasse der Teleostier wird nach den vorzïglichen Untersuchun-

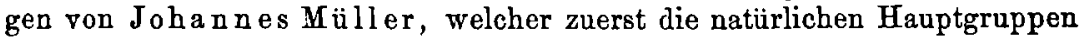
der Fische erkannte, und die künstlichen Fisch - Systeme von Cuvier und Agassiz durch ein natürliches, auf die Blutsverwandtschaft begriindetes ersetzte, in die sechs Ordnungen der Lophobranchien, Plectognathen, Physo- 
stomen, Pharyngognathen, Anacanthinen und Acanthopteren eingetheilt. Indessen sind diese sechs Ordnungen keineswegs gleichwerthig. Vielmehr glauben wir, dass die Physostomen einerseits den fünf übrigen Ordnungen andrerseits gegenüber zu stellen sind. Wur fassen die letzteren als $\mathbf{P h y}$ so clisten (Fische mit geschlossener Schwimmblase) zusammen. Es fehlt ihnen ein sehr wichtiger embryonaler Charakter, welchen die Physostomen mit den Ganoiden theilen, nämlich der Luftgang, welcher die Schwimmblase mit dem Schlunde verbindet. Auch durch andere Eigenthümlichkeiten beweisen die Physostomen, dass sie älter sind, als die Physoclisten, welche sich erst aus ihnen entwickelt haben.

Frste Legion der Teleostier:

Physostomi. Aeltere Finochenfische (mil Luftgang der Schuimmblase).

Diese Legion enthält die ältesten Teleostier, welche sich unmittelbar aus den cycliferen Ganoiden entwlckelt haben. Die Stammformen dieser Legion, und somit aller Teleostier, enthält die Familie der Thrissopiden (oder der Leptolepiden im engeren Sinne), welche die Genera Thrissops, Leptolepis, Thursis umfasst. Es sind dies härıngsartige Fische aus dem Jura, welche bereits in dessen untersten Schichten, im Lias, beginnen, aber in der Kreide schon wieder aufhören. Einerseits schliessen sich die Thrissopiden ebenso eng an die Cycliferen (Pycnoscolopen), wie andrerseits an die $\mathrm{Phy}$ sostomen (Clupeiden) an, und werden desshalb bald mit diesen, bald mit jenen vereinigt. Die Physostomen sind die einzigen Teleostier während der ganzen Jura-Zeit. Sie zerfallen in zwei Ordnungen, Thrissogenen und Enchelygenen, von denen die letzteren nur cinen divergenten Seitenzweig der ersteren darstellen.

Erste Ordnung der Physostomen:

Thrissogenes, H. (Physostomi abdominales.) Buuchflossige Physostomen.

Diese Ordnung umfasst die Hauptmasse der Physostomen und den eigentlichen Kern dieser Legion: die Familien der Thrissopiden, Clupeiden, Salmoniden, Scopeliden, Cyprinoiden, Characinen, Siluroiden etc. Die allermeisten dieser Fische besitzen wohl entwickelte Bauchflossen. Die Thrissogenen sind die Stammgruppe aller Teleostier, aus welcher sich als zwei divergente Zweige einerseits die Enchelygenen, andrerseits die Physoclisten entwickelt haben. Während der Jura - Zeit ist diese Ordnung nur durch die Familie der Thrissopiden, die älteste aller T'eleostier, vertreten, welche den Clupeiden am nächsten steht und den grössten Theil der Leptolepiden enthält (Thrissops, Leptolepis, Tharsis). In der Kreide finden sich bereits echte Clupeiden und daneben noch Scopeliden und Salmoniden. Die meisten andern Familien der Thrissogenen, namentlich auch die Cyprinoiden und Siluroiden, erscheinen erst in der Tertiär-Zeit.

\section{Zweite Ordnung der Physostomen:}

\section{Enchelygenes, H. (Physostomi apodes.) Bauchflossenlose Physostomen.}

Wie die Thrissogenen („Härirgskinder") die unmittelbaren Nachkommen der Thrissopiden und Häringe, so sind die Enchelygenen (,Aalkınder") die unmittelbaren Epigonen der Ur-Aale, welche sich aus den ersteren erst später entwickelt haben. Die Enchelygenen oder Aale umfassen die drei Fami- 
CXXVIII Systematische Einleitung in die Entwickelungsgeschichte.

lien der Muraeniden, Gymnotiden und Symbranchiden. Fossile Reste kennt man bloss von den Muraeniden, und zwar nur aus der Tertiär-Zeit. Die Enchelygenen stellen einen isolirten Seitenzweig der Thrissogenen dar, welcher sich nicht weiter entwickelt hat.

\section{Zweite Legion der Teleostier:}

Physoclisti, H. Jüngere Kinochenfische (ohne Luftgang der Schuimmblase).

Diese Legion hat sich, wie bemerkt, erst später aus den Physostomen, und zwar aus den Thrissogenen, entwiekelt; wie es scheint, erst während der Kreidezeit, da die ältesten sicheren fossilen Reste von Physoclisten dem Grünsande angehören. Die Iegion besitzt nicht mehr den embryonalen Charakter, welchen die Physostomen noch mit den Ganoiden theilen, den Luftgang, der die Schwimmblase mit dem Schlund verbindet Den Hauptstamm der Physoclisten bildet die Ordnung der Stichobranchien, während die beiden anderen Ordnungen, Plectognathen und Lophobranchien, nur als eigenthümlich angepasste Seitenzweige der ersteren erscheinen.

\section{Erste Ordnung der Physoclisten: \\ Stichobranchii, H. Reihentiemer.}

In dieser Ordnung, welche unmittelbar aus den Physostomen hervorgegangen ist, fassen wir drei Unterordnungen J o han nes Müller's zusammen, die Acanthopteri, Anacanthini und Pharyngognathi. Den Hauptstamm der Ordnung, wie der ganzen Physoclisten-Legion, bildet die sehr umfangreiche Unterordnung der A can tho pteren, zu welchen die Percoiden, Cataphracten, Sparoiden, Sciaenoiden, Scomberoiden, Blennioiden und zahlreiche andere Familien gehören. Unter allen Fischgruppen ist diese die bei weitem formenreichste; jedoch entwickelt sie ihre ausserordentliche Mannichfaltigkeit innerhalb eines sehr cngen anatomischon Breitengrades, durch oberflächliche Anpassung an verschiedene Existenzbedingungen. Die ältesten Reste derselben finden sich in der Kreide, vorzüglich im Grïnsande, und gehören meistens Percoiden, Cataphracten, Scomberoiden und Sphyraeniden an. Sehr zahlreich erscheinen die meisten Familien der Acanthopteren im Tertiärgebirge. Die Unterordnung der Pharyngognathen umfasst theils Stachelflosser, welche den Acanthopteren näher stehen (Labroiden, Pomacentriden, Holconoten, Chromiden), theils Weichfiosser sehr eigenthümlicher Art (Scomberesoces). Die meisten fossilen Reste dersclberf gehören der Tertiär-Zeit, nur einzelne der Kreide an. Von der dritten Unterordnung der Stichobranchien, den Anacanthinen, kennt man nur sehr wenige fossile Reste, und zwar núr aus der Tertiärzeit (Pleuronectiden und Gadoiden).

\section{Zweite Ordnung der Physoclisten: Plectognathi. Heftkiefer.}

Diese eigenthümliche Ordnung, welche früher wegen ihrer Hautbedeckung mit den Panzer-Ganoiden vereinigt wurde, scheint nur ein eigenthïmlich angepasster Seiten-Zweig der Stichobranchien zu sein. Fon den beiden hierher gehörigen Familien, Sclerodermen und Gymnodonten, kennt man fossile Reste aus der Tertiär-Zeit, von ersteren auch einzeln aus der Kreide-Zeit. 


\section{Dritte Ordnung der Physoclisten: \\ Lophobranchii. Bïschelkiemer.}

Auch diese Ordnung halten wir, gleich der vorigen, bloss für einen eigenthümlich entwickelten Seitenzweig der Stichobranchien. Es gehören hierher die Familien der Syngnathiden, Pegasiden und Solenostomiden. Alle fossilen Reste derselben gehören der Tertiär-Zeit an.

\section{Zweite Classe der Anamnien:}

\section{Dipueusti. Molchfische.}

(Synonym: Dipnoi. Lepidota. Protopteri. Pneumoichthyes. Sirenoida.)

Die Classe der Dipneusten ist in den letzten Jahrzehnten zu hervorragender Berühmtheit gelangt durch die ausgezeichnete Mittelstellung, welche sie zwischen den echten Fischen und den Amphibien einnimmt. In der That vereinigt dieselbe so vollständig viele charakteristische Eigenthümlichkeiten der Fische und der Amphibien, dass ausgezeichnete und kritische Forscher für die Stellung der Dipneusten sowohl unter jenen als unter diesen gewichtige Gründe anführen konnten. Will man die Dipneusten durchaus einer von jenen beiden Classen einreihen, so erscheint es immerhin passender, sie den Fischen, als den Amphibien zuzurechnen. Will man aber diese beiden Classen durch eine scharfe Definition trennen, so erscheint es umgekehrt bequemer, die Dipneusten wegen ihrer doppelten Herzvorkammer und ihrer wahren (der Schwimmblase homologen) Lungen den Amphibien beizugesellen.

Wie alle systematischen Fragen, so kann auch diese viel behandelte Streitfrage nur durch die Descendenz-Theorie klar und endgïltig entschieden werden. Diese lehrt uns, dass die Dipneusten sich aus den Fischen ebenso wie die Amphibien entwickelt haben, und zwar wahrscheinlich unabhängig von diesen letzteren. Man könnte geneigt sein, in den jetzt lebenden Dipneusten die geradlinigen und wenig veränderten Nachkommen jener uralten Anamnien zu sehen, welche in der Primärzeit, während der Entwickelung der Amphibien aus den Fischen, den Uebergang zwischen beiden Classen vermittelten. Indessen ist es wohl wahrscheinlicher, dass die lebenden Dipneusten die Nachkommen solcher aus den Fischen entwickelten Anamnien sind, welche nicht weiter zu Amphibien sich fortgebildet haben, gewissermassen also fehlgeschlagene Versuche der Fische, sich zum Landleben und zur Luftathmung zu erheben. Unter diesen Umständen erscheint es uns am passendsten, die Dipneusten als eine besondere Classe zu betrachten.

Die jetzt lebenden Dipneusten bilden nur die einzige Ordnung und Familie der Protopteriden, mit den beiden Genera Protopterus und Lepidosiren. Aller Wahrscheinlichkeit nach sind dieselben nur die vereinzelten letzten Ausläufer einer vormals reich entwickelten Dipneusten-Classe, welche aber wegen Mangels harter Skelettheile keine fossilen Reste hinterlassen konnten. Was ihre unmittelbaren Voreltern unter den Fischen betrifft, so sind diese wohl in den Selachiern, und nicht in den Ganoiden zu suchen, mit denen man die Dipneusten neuerdings hat vereinigen wollen. Die Dipneusten, Ganoiden und Amphibien sind wahrscheinlich drei Geschwister - Gruppen, welche von dem gemeiusamen parentalen Selachier-Stamm an verschiedenen Stellen sich abgelöst haben. Man kann dieselben daher nicht in eine einzige Reihe ordnen, wie es mehrfach versucht worden ist. 
CXXX Systematische Einleitung in die Entwickelungsgeschichte.

\section{Dritte Classe der Anamnien : Amphibia. Lurche.}

Die höchst wichtige Classe der Amphibien ist uns, gleich der vorhergehenden, hinsichtlich ihrer Phylogenie leider nur höchst unvollständig bekannt, viel unvollständiger als die der Fisøhe. Alles, was uns die Paläontologie von den Amphibien der früheren Erdperioden erhalten hat, zusammengenommen mit allen jetzt lebenden Amphibien, ist aller Wahrscheiulichkeit nach nur ein verschwindend geringer Rest von der reich und mannichfaltig entwickelten Amphibien - Classe, welche in der secundären und insbesondere in der primären Zeit die Erdrinde belebt hat. Als nach Abluuf der Silurzeit zum ersten Male das Leben auf dem Festlande begann, und in der langen antedevonischen Zeit von verschiedenen Gruppen der wasserbewohnenden Pflanzen und Thiere Versuche gemacht wurden, sich dem Landleben anzupassen, haben sich wahrscheinlich aus den Fischen mehrere solcher Landansiedler gleichzeitig und unabhängig von einander entwickelt. Als eine solche, nicht weiter zu hoher Differenzirung gelangte Gruppe haben wir bereits vorher die Dipneusten bezeichnet. Wine $z$ weite solche Gruppe von Luftathmern bildet die Classe der Amphibien, die übrigens wahrscheinlich aus mehreren Classen zusammengesetzt ist, deren jede sich unabhängig von den andern aus den Fischen entwickelt hat. Insbesondere dürften die beiden Subclassen, welche wir hier unterscheiden, Phractamphibien und Lissamphibien, zwei selbstständige Classen darstellen. Beide haben sich wohl getrennt von einander aus den Selachiern entwickelt. Die ältesten bekannten Amphibien-Reste sind in der Steinkohle gefunden worden.

\section{Erste Subclasse dèr Amphibien: Phractamphibia, H. Punzerlurcle.}

Diese Subclasse umfasst die merkwürdige Ordnung der Labyrinthodonten und die neuerdings davon abgelöste Ordnung der Ganocephalen, welche den Fischen noch näher steht, und aus welcher sich wahrscheinlich die erstere erst entwickelt hat.

\section{Erste Ordnung der Phractamphibien: \\ Ganocephala. Schmelzköpfe.}

Diese Ordnung ist bis jetzt nur durch drei Genera vom Amphibien bekannt, welche sämmtlich der Steinkohlenzeit eigenthümlich sind: Archegosaurus, Dendrerpeton und Raniceps. Von allen Amphibien stehen diese den Fischen am nächsten, und sind wahrscheinlich direct aus den Selachiern oder sehr tief unten aus dem Ganoiden-Stamm (aus den Pamphracten?) hervorgegangen.

\section{Zweite Ordnung der Phractamphibien: \\ Labyrinthodonta. Wickelzähner.}

Diese bisher meist mit der vorigen vereinigte Ordnung hat sich erst später aus derselben entwickelt und ist bereits bedeutend höher differenzirt. Namentlich besitzt sie schon zwei entwickelte Condyli occipitales, welche den vorigen noch fehlten. In der Primärzeit ist sie bloss durch den carbonischen Baphetes und durch den permischen Zygosaurus vertreten. Ihre eigentliche 
Acme, eine hohe und reiche Entwickelung, erreicht sie in der Trias, mit welcher sie auch erlischt (Mastodonsaurus, Tremalosaurus, Capilosaurnes. etc.). Die Labyrinthodonten scheinen keine Nachkommen hinterlassen zu haben.

Dritte Ordnung der Phractamphibien:

Peromela. Blindwiihlen.

(Synonym: Apoda. Oymnophiona. Ophiomorpha. Caecziae.)

Diese kleine Ordnung, welche nur die einzige Familie der Caeciliden (Cnecilia, Siphonops etc.) umfasst, ist in fossilem Zustand nicht bekannt. Sie ist wahrscheinlich der letzte überlebende Rest einer vormals reich entwickelten Amphibien-Gruppe, welcher nicht bloss wegen seines Schuppenkleides, sondern auch durch andere Charaktere den Ganocephalen und auch den Fischen viel näher steht, als die Gymnamphibien. Sie hat sich wahrscheinlich von dem Ganocephalen - Aste abgezweigt.

\section{Zweite Subclasse der Amphibien: \\ Lissamphibia, H. Nachlluvele.}

Diese Subclasse unterscheidet sich von der vorigen nicht allein äusserlich sehr auffallend durch die vollkommen glatte und nackte Haut, ohne alle Verknöcherungen, sondern auch durch innere anatomische Eigenthümlichkeiten, so dass Beide sich wohl schon sehr frühzeitig als divergente Aeste von dem gemeinsamen Amphibien-Stamme getrennt haben, falls sie überhaupt in einem solchen vereinigt waren. Die fossilen Reste dieser Gruppe sind nur äusserst spärlich erhalten und von sehr geringer Bedeutung. Theils ihre Lebensweise, rorzugsweise aber die zarte und oft nur theilweis knöcherne Beschaffenheit ihres Skelets entzog sie der Petrification. Man kennt bloss tertiäre Reste und diese nur sehr dürftig. Aller Wahrscheinlichkeit nach waren aber die Lissamphibien in der ganzen Secundär-Zeit vorhanden und haben sich wohl bereits in dem älteren Abschnitt der Primär-Zeit aus den Selachiern, vielleicht aus gemeinsamer Wurzel mit den Phractamphibien, vielleicht auch aus einem Ausläufer der letztern entwickelt. Die noch lebenden Lissamphibien legen uns in ihrer systematischen ebenso wie in ihrer ontogenetischen Entwickelungsreihe den paläontologischen Entwickelungsgang der Subclasse sehr deutlich vor Augen.

\section{Erste Ordnung der Lissamphibien:}

Sozobranchia (Perennibranchiala). Kiemenlurche.

Diese Ordnung umfasst diejenigen nackten Amphibien, welche auf der niedersten Entwickelungsstufe stehen bleibeu, indem sie zeitlebens ihre äusseren Kiemen beibehalten. (Gen era: Siren, Proteus, Menobranchus etc.) Fossile Reste derselben sind nicht bekannt.

\section{Zweite Ordnung der Jissamphibien: \\ Sozura (Caulata). Schwanzlurche.}

Diese Ordnung geht in ihrer Entwickelung einen Schritt weiter, als die vorige, indem sie die Kiemen verliert, den Schwanz aber noch behält. Es gehören hierher die beiden Familien der Derotremen (Menopoma, Cryptobranchus), welche noch die Kiemenspalten an der Halsseite behalten, und 
CXXXII Systematische Einleitung in die Entwickelungsgeschichte.

der Lipotremen (Triton, Salamandra), welche auch diese Kiemenspalten verlieren. Von Beiden sind tertiäre Reste vorhanden, unter denen besonders der Andrias Schenchzeri als „Homo diluvii testis" berühmt geworden ist. Aus dieser Ordnung haben sich wahrscheinlich die Anuren sowohl, als auch die Reptilien (Tocosaurier) und die Mammalien entwickelt.

\section{Dritte Ordnung der Lissamphibien: \\ Anura (Ecaudata). Froschlurche.}

Diese Ordnung erreicht den höchsten Grad der Entwickelung unter den Amphibien. Sie verliert nicht nur Kiemen und Kiemenspalten, sondern auch den Schwanz. Es gehören hierher die drei Familien der Zungenlosen (Aglossa) der Kröten (Bufonida) und der Frösche (Ranida), von denen bloss die letzteren zahlreiche (jedoch unbedeutende) Reste in der Tertiär - Zeit hinterlassen haben.

\section{Zweiter Subcladus der Amphirrhinen:}

Amniota, H. Amnionthiere.

Wir haben oben die Amphirrhinen, d. h. die Wirbelthiere, welche nach Ausschluss der Leptocardier und Monorrhinen übrig bleiben, in zwei Hauptgruppen gespalten, welche sehr wesentlich verschieden sind, in Anamnien und Amnioten. Zu den A namnien gehören die drei Classen der Fische, Dipneusten und Amphibien; zu den Amnioten gehören die drei Classen der Reptilien, Vögel und Sängethiere. Die Amnioten unterscheiden sich von den Anamnien hauptsächlich durch den Besitz des embryonalen Amnion, sowie dadurch, dass sie zu keiner Zeit ihres Lebens durch Kiemen athmen. Ferner ist die Schädelbasis ihrer Embryonen stets stark geknickt, während die der Anamnien grade gestreckt ist. Endlich entwickeln ihre Embryonen sämmtlich eine Allantois, wesshalb man sie auch Allantoidia genannt hat. Doch kann man die Anamnien nicht Anallantoidien nennen, da auch von diesen Viele bereits eine deutliche, wenn auch kleine Allantois besitzen. Die gesammte Anatomie, Ontogenie und Phylogenie der Amphirrhinen beweist übereinstimmend, dass dieser Cladus ursprünglich (bis zur Permzeit) allein aus den Anamnien bestand, und dass erst später die Amnioten sich aus diesen entwickelten. Jedenfalls sind die Amnioten unmittelbar aus den Amphibien entstanden; und zwar haben sich als zwei divergente $Z$ weige, unabhängig von einander, einerseits die Monocondylien (Reptilien und Vögel), andrerseits die Amphicondylien (Säugethiere) entwickelt.

\section{Erste Serie der Amnioten:}

Monocondjlia, H. Amniolen mil einfachem Occipital-Condylus.

Als Monocondylien fassen wir hier die beiden Classen der Reptilien und Vögel zusammen, welche unter sich viel näher, als mit den Säugethieren verwandt sind. Die grosse Kluft, welche diese von jenen trennt, hat neuerdings besonders $H \mathbf{u} \times$ le y hervorgehoben, welcher die Monocondylien von den Mammalien unter dem bereits mehrfach verbrauchten und vieldeutigen Namen der Sa u roiden abtrennte. Dieselben sind vorzüglich charakterisirt durch einen einfachen Condylus occipitalis, durch die verwickelte Zusammensetzung des Onterkiefers, und seine Articulation an einem besonderen Quadratbein, durch rothe Blnt-Zellen (kernführende Plastiden), dureh 
partielle Dotterfurchung, durch Mangel des Parasphenoid, der Milchdrüsen etc. Von den beiden Classen der Monocondylien haben sich die Vögel ebenso als ein höherer Seitenzweig aus den Reptilien, wie diese aus den Amphibien (und zwar wahrscheinlich aus den Sozuren) entwickelt.

\section{Erste Classe der Monocondylien: \\ Reptilia. Saurier.}

Diese äusserst vielgestaltige und interessante Wirbelthierclasse beherrscht das mesolithische Zeitalter in ähnlicher Präponderanz, wie die Fische das paläolithische, die Säugethiere das cänolithische. Den verschiedenartigsten Existenz-Bedingungen passten sie sich in der mannichfaltigsten Weise an und entwickelten dadurch eine bewunderungswürdige Formen-Divergenz, welche ihre Genealogie ausserordentlich erschwert. Dazu kommt, dass alle fossilen Reste der Reptilien zusammengenommen, obwohl äusserst werthvolle „Denkmünzen der Schöpfung“, dennoch nur ein blasses Schattenbild von dem wunderbaren Reiche landbewohnender Reptilien darstellen, welches in der Secundärzeit existirte. Die Verwandtschafts - Verhältnisse der verschiedenen Hauptgruppen der Reptilien unter einander sind so äusserst verwickelte, dass es sehr schwer ist, ihron Stammbaum zu entwerfen. Wir betrachten daher auch die nachfolgende Genealogie nur als einen ganz provisorischen Versuch. A)s Ausgangsgruppe der Classe, welche unmittelbar aus den Amphibien (und wahrscheinlich aus den Sozuren) entstand, betrachten wir die I. Subclasse, die der Tocosaurier, welche ausser den triassischen Thecodonten die ältesten aller Reptilien, die permischen Dichthacanthen enthält. Sie sind nebst den Rophalodonten die einzigen Saurier der Primärzeit. Alle anderen Reptilien gebören der Secundär-Zeit an. Von Jenen aus haben sich wahrscheinlich als divergente $\mathrm{Zweige}$ folgende vier Subclassen entwickelt: II. die $\mathrm{H}$ ydrosaurier (Halisaurier und Crocodilier); III. die Dinosaurier; IV. die Lepidosaurier (Lacertilier und Ophidier) und endlich V. die Rhamphosaurier, mit der'Stamm-Ordnung der Anomodonten, aus der wahrscheinlich als drei divergente $\mathrm{Zweige}$ sich die Pterosaurier, Chelonier und Vögel entwickelten.

\section{Erste Subclasse der Reptilien: Tocosauria, H. Stamm-Reptilien.}

In dieser Subclasse, welche den Ausgangspunkt aller übrigen Reptilien bildet, fassen wir die beiden Ordnungen der Dichthacanthen und Thecodonten zusammen, welche unter sich nächstrerwandt und wahrscheinlich grad. linige Nachkommen der unbekannten Reptilien sind, aus welchen sich alle übrigen Subclassen als divergente $\mathrm{Z}_{w}$ eige entwickelten.

\section{Erste Ordnung der Tocosaurier: \\ Dichthacantha, H. Gabeldorner.}

Diese Ordnung umfasst die einzige Familie der Proterosauriden, mit dem einzigen Genus Proterosaurus, welches in vielfacher Beziehung von ausserordentlichem Interesse ist. Abgeschen von dem im russischen Perm gefundenen Rhopalodon, welcher vielleicht den Uebergang von den Dichthacanthen zu den Anomodonten bildet, sind die Proterosauren die einzigen, bis jetzt bekannten Reptilien, welcheman mit voller 


\section{Systematische Einleitung in die Entwickelungsgeschichte.}

Sicherheit als paläolithische betrachten kann; alle anderen Saurier, welche man bisher der Primärzeit zuschrieb, haben sich neuerdings als viel jünger, als secundär (meistens als triassisch) herausgestellt. Zugleich sind es die einzigen Reptilien, welche gabelspaltige Dornfortsätze der Wirbelsäule besitzen, (wesshalb wir sie Dichthacanthen nennen). Auch ausserdem, obwohl den Lacertilien anscheinend sehr ähnlich, sind sie mehrfach ron den übrigen Reptilien unterschieden. Wahrscheinlich haben wir in diesen ältesten bekannten Repräsentanten der Reptilien-Classe ganz eigenthümliche Mischformen vor uns, welche den unbekannten, aus den A Inphibien (Sozuren) entstandenen Stamm - Vätern aller Reptilien am nächsten stehen. Die Dichthacanthen sind zufällig zugleich diejenigen fossilen Reptilien, welche von allen zuerst (schon 1710!) wissenschaftlich untersucht und beschrieben worden sind (durch den Berliner Arzt Spener). Bisher sind sie ausschliesslich im Thüringer Perm, und zwar im Kupferschiefer von Eisenach, gefunden worden. Die älteste und bekannteste Art ist Prolerosaurus Speneri, eine andere P. macronyx.

\section{Zweite Ordnung der Tocosaurier: \\ Thecodonta. Fachzähner.}

Diese Ordnung, welche der vorigen von allen Reptilien am nächsten verwandt ist, und vielleicht von ihr direct abstammt, gehört wahrscheinlich zu der gemeinsamen Stammgruppe, aus welcher sich alle oder doch viele der übrigen Reptilien als divergente Aeste entwickelt haben. Alle bis jetzt sicherbekannten Thecodontengehörender Trias, und zwar meistens dem Keuper an. Bisher galten dieselben fast allgemein für paläolithisch, da man die Schichten, in denen sie sich finden, (insbesondere das Bristol-Conglomerat) irrthümlich für permisch hielt. Es gehören hierher mit Sicherheit die vier Genera: Paläosnurus (platyadon, cylinulrodon), Thecodonlosaurus (mmliquens), Belodon (Plieningert) und Clalyodon (Lloydii). Ausserdem gehören höchst wahrscheinlich auch die beiden Genera Bathygnalhus (borenlis) und Telerpeton (elginense) hierher. Letzteres (auch als Leptopleuron lucerfinum beschrieben) galt lange Zeit für das älteste nicht allein aller Reptilien, sondern sogar aller landbewohnenden Wirbelthiere, da man die triassischen Schichten, in denen es sich fand, irrthümlich für devonisch hielt.

\section{Zweite Subclasse der Reptilien: \\ Hydrosauria. Wasserdrochen.}

In dieser Subclasse vereinigen wir nach dem Vorgange von Carl Vogt die buiden Ordnungen der Halisauricr und der Crocodilier, von denen sich vielleicht die letzteren aus den ersteren entwickelt haben. Doch ist es auch sehr wohl möglich, dass diese beiden Ordnungen an schr verschiedenen Stellen, unabhängig von einander, von dem leptilienstamme sich abgezweigt haben.

\section{Erste Ordnung der Hydrosaurier:}

\section{Halisauria. Seedrachen.}

\section{(Synonym: Enaliosauria. Nexipoda. Hydropterygia).}

Diese ausgezeichnote Reptilien - Ordnung ist ausschliesslich auf die Secundär-Periode beschränkt, welche sie von Anfang bis zu Ende durchlebt hat. Ihre vielfachen Aehnlichkeiten mit den Fischen und insbesondere mit 
den Ganoiden haben zu der Annahme geführt, dass sie diesen näher als den übrigen Reptilien verwandt seien, und man hat selbst neuerdings versucht, die Ganoiden, Ganocephalen, I labyrinthodonten, Ichthyosaurier und Sauropterygier (Nothosaurier und Plesiosaurier) als fortlaufende Glieder einer einzigen Entwickclungsreihe darzustellen. Indessen ist es viel wahrschejnlicher, dass diese Aehnlichkeiten nur Anpassungs-Aehnlichkeiten sind, und dass die Halisaurier sich zu den übrigen Reptilien verhalten, wie die Cetaceen zu den Säugethieren. Wahrscheinlich sind sie aus den Tocosauriern in der Antetrias-Zeit entstanden. Wir zerfällen die Ordnung der Halisaurier in drei Unterordnungen: I. Simos a u ria oder Urdrachen (Simosaurus, Nolhosmurus, Iracosaurus) ausschliesslich in der Trias, die ältesten Vertretèr der Halisaurier, und ihre einzigen Repräsentanten in der Trias, haben sich vermuthlich aus den Thecodonten entwickelt. II. Die Plesiosauria oder Schlangendrachen (Plesiosaurus) in allen Schichten des Jura und der Kreide, haben sich wohl in der Antejurazeit aus den Simosauriern entwickelt, und gehen durch Spomdylosaurus und Pliosuurus unmittelbar in die Ichthyosauren über. III. Die I ch thy o sa uria oder Fischdrachen (Ichthyosaurus), ebenfalls nur im Jura und (selten) in der Kreide, haben sich demnach ebenso aus den Plesiosauren, wie diese aus den Ichthyosauren entwickelt.

\section{Zweite Ordnung der Hydrosaurier: \\ Crocodilia (Loricala). Crocodile.}

Die Stellung der Crocodile ist ziemlich unsicher, da sie gleichzeitig zu mehreren Reptilien-Subclassen mehrfache Beziehungen besitzen. Es ist möglich, dass dieselben an ihrer Wurzel mit mehreren andern Subclassen unmittelbar zusammenhängen. Vielleicht haben sie sich auch als selbstständiger Ast direct aus den Tocosauriern hervorgebildet. Am wahrscheinlichsten ist es jedoch, dass sie sich von den Halisauriern abgezweigt haben, unter denen insbesondere Pliosaurus sich den Crocodilen sehr nähert. Jedenfalls muss diese Abzweigung schon vor der Jurn-Zeit erfolgt sein, da die Crocodile im Lias bereits entwickelt auftreten. Die Ordnung zerfält in drei Unterordnungen, von denen die der A mphicoelen oder Teleosaurier die älteste ist (Mystriosaurus, Gnathosamrus, Teleosaurus etc.). Diese Unterordnung ist durch biconcave, denen der Halisaurier gleiche Wirbel ausgezeichnet. Sie bleibt auf den Jura beschränkt. Aus ihr haben sich als zwei divergente A este einerseits die Opisthocoelen, andrerseits die Prosthocoelen entwickelt; bei erstern ist die Chorda dorsalis bloss am vorderen (oralen), bei letzteren bloss am hinteren (aboralen) Ende der Wirbelkörper durch Knochen ersetzt worden. Die Opisthocoelen oder Steneosaurier (Cetiosumrus, Sleneosa"rus) bleiben auf Jura und Kreide beschränkt, während die Prosthocoelen oder Alligatoren, zu welchen alle jetzt lebenden Crocodile gchören (Gavinlis, Alligalor, Crocodilus) erst in der Kreide auftreten, und vorzüglich in der Tertiärzeit entwickelt sind.

Dritte Subclasse der Reptilien:

Dinosauria (Paclypoda). Lindüirmer.

Eine der merkwürdigsten Reptilien-Gruppen ist die der Dinosaurier oder Pachypoden, welche während der Secundär-Zeit die gewaltigsten und colossalsten Landbewohner erzeugte. Sie finden ihresgleichen an Umfang und Schwerfälligkeit nur in den pachydermen Säugethieren der tertiären und 
CXXXVI Systematische Einleitung in die Entwickelungsgeschichte.

quartären Zeit, und vertraten diese damals in ähnlicher Weise auf dem Iande, wie die Halisnurier im Meere das Aequivalent der carniroren Cetaceen waren. Die Dinosaurier zeigen unter allen Reptilien am meisten anatomische Beziehungen zu den Säugethieren, ähnlich wie die Pterosaurier zu den Vögeln. Doch sind diese Achnlichkeiten nur Analogieen, keine Homologieen. Wahrscheinlich haben sich die Dinosaurier unmittelbar aus der Stammgruppe der Tocosaurier, (vielleicht auch in Zusammenhang mit den Crocodilen, wahrscheinlicher aber in Zusammenhang mit den Lacertilien, insbesondere den Leguanen) entwickelt. Unter den Tocosauriern zeigt Belodon zu ihnen die nächsten Beziehungen, und Pluleosuurus aus dem Keuper scheint bereits zu ihnen zu gebören. Ihre eigentliche Entwickelung erreichten sie jedoch gegen Ende der Jura - und im Beginn der Kreide-Zeit (Wealden). Wir zerfällen die Dinosaurier in zwei Ordnungen, fleischfressende und fllanzenfressende Lindwürmer.

Erste Ordnung der Dinosaurier:

Harpagosauria, H. Carnivore Lindwïrmer.

Die fleischfressenden Dinosaurier bilden den eigentlichen Stamm der Subclasse. Sie beginnen wahrscheinlich schon in der Trias (mit Plateosaurus aus dem Keuper). Hierher gehören Mlegalosaurus $(30-40$ Fuss lang) aus dem Jura, und Hylaeosaurus und Pelorosaurus aus dem Wealden (letzterer wohl 40-80 Fuss lang). Leider sind ihre Reste, wie die der meisten mesolithischen landbewohnenden Vertebraten, sehr selten und unvollständig.

Zweite Ordnung der Dinosaurier:

Therosauria, H. Herbivore Lindwïrmer.

Die pflanzenfressenden Dinosaurier sind bis jetzt bloss durch den colossalen Iguanodon Mamlelli belsannt, den grössten Pflanzenfresser der Secundär-Zeit, viel grösser und stärker als ein Elephant. Er ist bisher ausschliesslich in den unteren Formationen des Kreide-Systems, ,im Wealden und Neocom gefunden worden, und stellt wahrscheinlich einen Seitenzweig der Harpagosaurier dar.

Vierte Subclasse der Reptilien:

Lepidosauria, H. Schuppen-Sauvier.

Diese Subclasse umfasst die beiden nächstverwandten Ordnungen der Lacertilien und Ophidier, von denen die letzteren bloss einen eigenthïmlich entwickelten Seitenzweig der ersteren darstellen. Die Lacertilien stehen unter allen Reptilien den Tocosauriern, als dem Stamm der ganzen Classe, am nächsten, und bilden gewissermaassen deren gradlinige Fortsetzung bis zur Gegenwart.

\section{Erste Ordnung der Lepidosaurier: \\ Lacertilia. Eidechsen.}

Unter allen Reptilien scheinen die gewöhnlichen Eidechsen die conservatirste Gruppe darzustellen, welche die ursprüngliche Form der gemeinsamen Stammgruppe, der Tocosaurier, am reinsten erhalten hat. Die jetzt lebenden Lacertilien spielen daher unter den Reptilien eine ähnliche 
Rolle, wie die Selachier der Gegenwart unter den Fischen, oder die Beutelthiere der Jutztzeit unter den Süugethieren. Die fossilen Reste dieser Ordnung sind sehr spärlich. Die ältesten bekannten Reste stammen aus den obersten Schichten des Jura und den untersten der Kreide, zahlreichere aus der Tertiärzeit. Unter den Lacertilien der. Kreide zeichnen sich die Nosasaurier (Mosusaurus, Grosaumus etc.), welche den Monitoren nächst. verwandt sind, durch riesige Grösse aus. Von den beiden Unterordnungen der Lacertilien haben nur die echten Eidechsen oder Autosauria (Squamala) fossile Reste hinterlassen, nicht aber die Ringeleidechsen oder Gly ptodermata (Annulalu).

\section{Zweite Ordnung der Lepidosaurier: Ophidia. Schlungen.}

Die Gruppe der Schlangen ist Nichts weiter als ein eigenthümlich entwickelter Seitenast der Lacertilien, welcher sich wahrscheinlich erst im Beginn der Tertiär-Zeit (in der Anteocen-Zeit) ron den Lacertilien abgezweigt hat. Ihre fossilen Reste sind selten und spärlich, alle nur in tertiären Schichten, vom Eocen an, gefunden. Die Schlangen-Ordnung ist die einzige Reptilien-Ordnung, welche auf die Tertiärzeit und die Gegenwart beschränlst erscheint.

Fünfte Subclasse der Reptilien: Rhamphosauria, H. Schnabelsanvier.

In dieser Subclasse vereinigen wir die drei Ordnungen der Anomodonten, Pterosaurier und Chelonier, welche unter sich mehr Verwandtschaft als zu den übrigen Reptilien zeigen, und deren jede durch eine Anzahl ron Charakteren bereits zu den Vögeln hinüber neigt. Indessen sind wegen der Nangelhaftigkeit ihrer fossilen Reste ihre Beziehungen doch noch zu werig bekannt, als dass wir mit roller Sicherheit ihr genealogisches Verhältniss zu einander und zu den Vögeln feststellen könnten. Wahrscheinlich haben sich die Anomodonten, als die ältesten Rhamphosaurier, von den Tocosauriern abgezweigt, und haben ihrerseits als drei divergente $\mathrm{Zweige}$ die Pterosaurier, die Chelonier und die Vögel entwickelt. Vielleicht sind aber auch Pterosaurier und Anomodonten zwei divergente $Z$ weige eines alten (aus den Tocosauriern entstandenen) Rhamphosauricr-Stammes, und aus den Anomodonten haben sich als zwei divergente Aeste einerseits die Chelonier, andererseits die Vögel entwickelt.

\section{Erste Ordnung der Rhamphosaurier: \\ Anomodonta. Schnabcl-Eidechsen.}

Diese Ordnung kennen wir bisher pur aus verhältnissmässig wenigen, aber sehr interessanten fossilen Resten, welche derselben eine ausserordentliche Wichtigkeit beilegen. Sie besteht aus den drei Pamilien oder Unterordnungen der Rhopalodonten, Dicynodonten und Cryptodonten. Die Familie der $\mathrm{K}$ hopalod ontia, die älteste, wird durch die im russischen Perm gefundene Sippe Rhopulodon (mit 2 Arten) gebildet, nächst dem Proferosaurus die einzigen bis jetzt mit Sicherheit bekannten Reptilien der Primärzeit. Sie scheinen den Uebergang von den Tocosauriern zu den Dicynodonten zu vermitteln. Die Familie der Dicynodontia wird durch die 
CXXXVIII Systematische Einleitung in die Entwickelungsgeschichte.

beiden südafrikanischen Genera Dicynodon (mit 4 Arten) und Plychognathus (mit 3 Arten) gebildet, welche der Trias angehören (nicht dem Perm, wie man früher glaubte). Sie nähern sich durch die ausgezeichnete Bildung ihres Schädels und Schnabels noch mehr, als die Rhopalodonten, den Schildkröten und Vögeln und sind wahrscheinlich nächste Verwandte von deren gemeinsamen Stammeltern. Die dritte Familie endlich, die der Cryptodontia, wird durch die beiden triassischen Genera Udenodon (U. Bainii aus Südafrica) und Rhynchosmerus (R. arliceps aus England) gebildet. Diese vermitteln den unmittelbaren Uebergang zu den Cheloniern und Vögeln. Während die Rhopalodonten in ihren Schnabel ausser mehreren kleinen angewachsenen Zähnen ein paar grosse Hauzähne, die Dicynodonten bloss diese beiden letzteren tragen, sind bei den Cryptodonten alle Zähne aus dem Schnabel verschwunden.

\section{Zweite Ordnung der Rhamphosaurier: \\ Pterosauria. Flug-Eidechsen.}

Diese Ordnung umfasst die ältesten fliegenden Wirbelthiere; von denen man mit Sicherheit weiss. Sie beginnen mit Rhamphorhynchus macronyx in den ältesten Schichten des Jura, und sind durch zahlreiche Arten von P/erodacty/us im mittleren und oberen Jura und der Kreide vertreten, bis zur Weisskreide hinauf, in der sich kolossale Formen finden. Man hat die Pterosaurier vielfach für unmittelbare Uebergangsformen von den Reptilien zu den Vögeln gehalten. Indessen ist cs viel wahrscheinlicher, dass sich die Pterosaurier tiefer unten, als die Vögel, ron den Anomodonten, oder selbst unmittelbar ron den Tocosauriern abgezweigt haben. Keinenfalls haben sie sich unmittelbar in die Vögel fortgesetzt. Die Pterosaurier baben keine Nachkommen hinterlassen.

\section{Dritte Ordnung der Rhamphosaurier: \\ Chelonia. Schildkröten.}

Diese Ordnung nähert sich von allen jetzt lebenden Reptilien-Ordnungen am meisten den Vögeln, und zeigt namentlich auch zu diesen nähere Verwandtschaft als die Pterosaurier. Am wahrscheinlichsten dürfte dje Vermuthung sein, dass Chelonier und Vögel als divergente, an ihrer Wurzel vielleicht noch zusammenhängende Zweige sich aus den Anomodonten entwickelt haben. Diese Divergenz hat jedenfalls for der Jurazeit, wahrscheinlich schon im Beginn der Secundïr-Periode stattgefunden. Fussspuren, sowohl von Schildkröten als ron Yögeln, werden bereits im Sandstein der Trias angegeben; doch siud diese sehr unsicher. Die ältesten sicheren Reste von Cheloniern gehören dem Jura an, und $\mathbf{z w a r}$ finden sich hier bereits Reste von drei rerschiedenen Familien, den Thalassiten oder Seeschildkröten (Chelme), den Potamiten oder Fluesschildkröten (Trinmyr) und den Eloditen oder Sumpfschildkröten (Emys). Dagegen erscheint die vierte und vollkommenste Fanilie, die der Chersi te $\mathbf{n}$ oder Landschildkröten (Tes/udı) erst in der Tertiär-Zeit; unter diesen letzteren ist die riesige Colossochelys allus aus dem Subhimalaja hervorzuheben. Bei den ältesten Schildkröten ist der Knochenpanzer noch sehr wenig entwickelt, unvollkommen virknöchert oder aus zahlreicheren Stücken zusammenge'setzt, wie bei den Embryonen der höheren Chelonier. 
Zweite Classe der Monocondylien:

Ares. Vögel.

Im Gegensatze zu den Reptilien licfert uns die Paläontologie über die Entwickelung der Vögel nur sehr geringfügige Aufschlüssc. Dagegen können wir aus ihrer vergleichenden Anatomie und Embryologie mit voller Sicherheit schliessen, dass die Vögel unmittelbar aus den Reptilien entstanden sind, und dass sie nur einen eigenthümlich angepassten Seitenzweig dieser Classe darstellen. Wie schon bemerkt, haben sich die Vögel höchstwahrscheinlich aus den Anomodonten, als ein von den Cheloniern divergirender Zweig dieser Subclasse, entwickelt; und zwar wohl im Beginn oder gegen die Mitte der mesolithischen Zeit. A us der Trias-Zeit kennt man zahlreiche Fussspuren (besonders im nordamerikanischen Sandstein von Connecticut), welche riesigen Vögeln zugeschrieben werden. Doch können dieselben eben so gut auch Sauriern angehört haben. Die Reptilien, welche die Voreltern der Vögel waren, können sehr wohl bereits ihre charakteristische Fussbildung besessen haben. Der älteste wirkliche Vogelrest ist die berihmte Archacopleryx lithographica aus dem Jura. In der Kreide folgen einzelne Reste von Stelz - und Schwimm-Vögeln. Alle Paedotrophen-Reste gohören der Tertiär-Zeit an. Die Bestimmung der fossilen Vogelreste im Einzelnen ist sehr schwierig, da dieselben meist nur sehr schlecht und höchst unvollständig erhalten sind, und da überdies fast alle systematischen Differenzen sich auf die Bildung des Schnabels und der Füsse beschränken. Die Vögel-Classe ist in ähnlicher Weise, wie die der Insecten, nur sehr einförmig, innerhalb eines sehr engen Spielraumes entwickelt; sie verhalten sich $\mathrm{zu}$ den viel gestaltenreicheren Reptilien ähnlich, wie die Insecten zu den Crustaceen. Was die historische Reihenfolge der einzelnen Hauptgruppen der Vögel betrifft, so haben sich aus den Anomodonten zunïchst die Sauriuren, aus diesen erst die Ornithuren entwickelt, und zwar Autophagen; aus diesen sind erst ị der Tertiär-Zeit die typischen Vögel, die Nesthocker (Insessores) entstanden.

Erste Subclasse der Vögel:

\section{Sauriurae, H. Ficdersclixïnzige Vögel.}

Die Subclasse dor Sauriuren stellen wir für dicjenigen Vögel auf, welche den unmittelbaren Uebergang von den Reptilien zu den echten Vögeln vermityeln, und welche im Beginn und in der Mitte der Secundär-Zeit vermuthlich in grosser Mannichfaltigkeit vorhanden waren. Bis jetzt ist uns diese Subclasse nur durch die sehr wichtige Aichaedplery $x$ lilhographica (macrura) aus dem Jura des lithographischen Schiefers von Solenhofen bekannt. In der ausgezcichneten Bildung ihres Schwanzes, welcher ganz von dem aller übrigen Vögel abweicht, besitzt dieselbe einen Charakter, welchen die letztercn nur als Embrsonen noch einige Zuit hindurch zcigen, und welcher lediglich die Abstamming der Vögel von den Reptilien bestätigt. Die älteste Ahnenreihe der Vögel zu Ende der prinären und im Beginn der secundären $Z$ it war wahrscheinlich folgende: 1. Tocosuuria, 2. Anomodonta (I. Rhopalodon, II. Ni(ynodon, III. Cryptodon), 3. Sauriurae (Archacoptery $\mathrm{x}$ ), 4. Ornithurae (Saurophilli). 
CXL Systematische Einleitung in die Entwickelungsgeschichte.

\author{
Zweite Subclasse der Vögel: \\ Ornithurae, H. Füchcrschwünzige Vögel.
}

Diese Subclasse umfasst die echten Vögel, welche bereits die charakteristische Schwanzbildung aller jetzt lebenden Vögel, und gar nicht (oder nur als Embryonen) den verlängerten Eidechsen-Schwanz der Sauriuren besitzen. Jedenfalls sind die Ornithuren erst später aus den Sauriuren, wie diese früher aus den Anomodonten entstanden. Von den beiden Legionen, in welche die Ornithuren gewöhnlich zerfällt werden, sind die Paedotrophen erst später (wahrscheinlich in der Tertiär-Zeit) aus den Autophagen entstanden.

\title{
Erste Legion der Ornithuren: \\ A u to phagae. (Nidifugae) Nes/flïchler.
}

Diese Legion umfasst diejenigen Ornithuren, welche sehend das Ei verlassen und sich sogleich selbst ernähren. Es gehören hierher folgende Ordnungen: 1. Natatores (Palmipedes), 2. Grallatores, 3. Rasores (Gallinaceae, nach Ausschluss der Penelopiden) 4. Ineptae (Didus) 5. Saurophalli (Penelopida, und dreizehige Strausse: Rhea, Dromaeus, Casuarius), 6. Apterygia (Apleryx, Pulapteryx, Dinornis), 7. Struthocameli (S/ruthio) $\left.{ }^{1}\right)$.

Was die Genealogie dieser Ordnungen betrifft, so ist dieselbe zur Zeit noch sehr dunkel, und lediglich aus ihrer vergleichenden Anatomie muthmaasslich $z u$ erschliessen. Die wahrscheinliche Ausgangsgruppe der Autophagen, welche sich unmittelbar aus den Sauriuren entwickelt hat, scheinen die Saurophallen zu bilden, von welchen sich vielleicht als

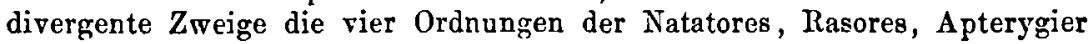
und Struthocamelen abgezweigt haben. Den Uebergang zwischen den Saurophallen und den Natatores vermitteln die (noch mit dem gleichen Penis versehenen) Anatiden (Lamellirostres); zwischen den Saurophallen und Rasores stehen die Penelopiden; die Apterygier sind unter den Saurophallen dem Casuarius, die Struthocamelen dagegon der Rhea am nächsten verwandt. Die Grallatores haben sich wahrscheinlich aus den Rasores (vielleicht auch aus den Aptersgiern?) entwickelt. Auch die Inepten sind vermuthlich ebenso wie die Columben, und vielleicht mit diesen im Zusamnrenhange aus den Rasores entstanden. Die äusserst dïrftigen fossilen Reste der Autophagen klären uns leider über ihre Phylogenie nicht auf; die ältesten sind in der Kreide gefunden worden, und gehören einem Natator

1) Wir sehen uns hier gezwungen, die Ordnung der Cursores oder Laufvögel, eine der künstlichsten Gruppen des Thierreichs, in Ordnungen aufzulösen, da diese unter sich in höherem Grade verschieden sind, als die übrigen anerkannten Ordnungen der Vögelclasse. Die Penelopiden (Penelope, Crax, Urax), welche allgemein zu den Rasores gestellt werden, sind den dreizehigen Straussen (Rhea, Dromacus, Casuarius) viel näher als den Hühnern verwandt, und verdienen schon allein wegen ihrer merkwürdigen PenisBildung (abgesehen von anderen anatomischen Verwandtschafts-Documenten) mit ihnen als „S a urophalli" vereinigt zu werden. Dagegen ist der zweizehige Strauss (Struthio camelus), durch den ganz ejgenthïmlichen Bau seines Penis und seines Beckens, sowie durch andere merkwürdige Charaktere so ausgezeichuet, dass er eher: den Rang einer besondern Ordnung verdient, als z. B. die verschiedenen Ordnungen der Paedotrophen. Auch die Apterygier und die Inepten sind so ausgezeichnet, dass sie weder mit den Strothocamelen, noch mit den Saurophallen vereinigt bleiben lönnen. 
(Cimoliornis diomeders), und einem Grallator (Srolopax) an. Vielleicht rühren auch die Ornithichnithen der Trias von Autophagen her.

Zweite Legion der Ornithuren:

Paed otrophae. (Insessores) Nesthocker.

Diese Legion umfasst diejenigen Ornithuren, welche blind das Ei verlassen und von ihren Eltern gefuittert werden. Alle fossilen Reste von Paedotrophen gehören der Tertiär-Zeit an. Es gehören hierher folgende fiunf Ordnungen: 1. Peristerae (Columbae), 2. Clamatores, 3. Oscines, 4. Scansores, 5. Raptatores. Unter diesen scheinen die Tauben (Peristerae) in ähnlicher Weise den Ausgangspunkt der Paedotrophen-Gruppe zu bilden, wie die Saurophallen denjenigen der Autophagen. Wahrscheinlich sind die Peristeren direct aus den Rasores entstanden, mit denen sie durch die Pterocliden unmittelbar zusammenhängen. Aus den Peristeren (vielleicht aber auch direct aus den Rasores) sind als zwei divergente $Z_{w}$ eige vernuthlich die Clamatores und Scansores entstanden, von denen wahrscheinlich die ersteren den Oscines, die letzteren den Raptatores den Ursprung gegeben haben. Vielleicht sind aber auch die Raptatores aus den Clamatores, oder direct aus den Columben entwickelt. Da zwischen allen verschiedenen Vögel-Ordnungen Uebergangs-Bildungen vorkommen, und da uns ihre spärlichen und ganz unbedeutenden fossilen Reste gar Nichts über ihre Phylogenie berichten, so ist jede Specialisation des ornithologischen Stammbaums zur Zeit noch sehr schwierig.

\section{Zweite Serie der Amnioten:}

Dicondylia, H. Amniolen mit doppellem Occipital-Condylus.

Die Gruppe der Dicondylien umfasst bloss die eine Classe der Säugethiere (Mammalia), welche von den Monocondylien, den beiden Classen der Vögel und Reptilien, viel weiter entfernt sind, als die beiden letzteren unter sich. Die Dicondylien unterscheiden sich von den Monocondylien wesentlich nicht allein durch" den doppelten Condylus occipitalis, sondern auch durch die viel einfachere Zusammensetzung des Unterkiefers, den Mangel eines besonderen Quadratbeins, durch den Besitz eines Parasphenoid, durch rothe Blut-Cytoden (kernlose Plastiden), durch totale Dotterfurchung, durch die ganz eigenthümlichen Milchdrüsen, und durch zahlreiche andere wichtige Charaktere. Aller Wahrscheinlichkeit nach haben sich die Dicondylien unmittelbar aus den Amphibien, oder aus dem unbekannten paläozoischen Amnioten-Stamme (vielleicht im Zusammenhang mit der Tocosaurier-Gruppe) entwickelt (vergl. Taf. VII).

\section{Einzige Classe der Dicondylien: \\ Mammalia. Säugethiere.}

Die Classe der Sängethiere zerfällt in drei Subclassen von sehr ungleichem Umfange, die Ornithodelphia, welche bloss die beiden Genera Ornithorhynchus und Erhidna, die Didelphia, welche die Beutelthiere oder Marsupialia, und die Monodelphia, welche die ganze Masse der übrigen Säugethiere (P/acentalia) umfassen. Die beiden Subclassen der Ornithodelphien und Didelphien werden häufig in einer Subclasse als Implacenlalia zusammengefasst, und den Placentalien gegenüber gestellt. Diese Zweitheilung der 


\section{Systematische Einleitung in die Entwickelungsgeschichte.}

Säugethierclasse ist aber in sofern nicht richtig, als die Differenzen zwischen den Ornithodelphien und Didelphien, wenn auch anderer Art, doch nicht minder wichtig sind, als diejenigen zwischen den Didelphien und Monodelphien. Richtiger würde es sein, die Ornithodelphien als A m a s ta ( $\ddot{\alpha} \mu \alpha \sigma \tau \alpha$, Brustwarzenlose) den vereinigten Didelphien und Monodelphien als Masto-

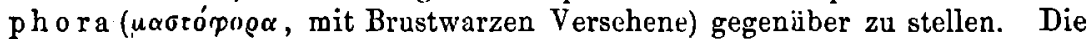
Amasten oder Ornithodelphien stehen offenbar den unbekannten Stammformen der Säugethicre, welche aus den Amphibien entstanden, viel näher, als die Mastophoren, welche sicher viel späteren Ursprungs sind. Leider lässt uns die Paläontologie bei dieser sehr wichtigen Frage wieder im Stich, da grade aus der langen Secundär - Periode, während welcher die Entwickelung der Säugethier-Classe aus den Amphibien oder aus den niedersten Amnioten, wenn nicht ausschliesslich, doch rorwiegend stattfand, nur sehr wenige und unbedeutende Säugethier - Reste erhalten sind. Diese gehören alle Didelphien an. Von den Ornithodelphien berichtet uns die Paläontologie leider gar Nichts. Verhältnissmässig zahlreich und wichtig sind die fossilen Reste der Monodelphicn, welche ausschliesslich der Tertiär - und Quartär-Zeit angehören. Wahrscheinlich haben sich also die Monodelphien erst im Beginn der Tertiär-Zeit (in der langen Anteocen-Zeit) aus den Didelphien entwickelt; wogegen diese vermuthlich schon im Beginn der Secundär-Zeit (in der Antetrias-oder Trias - Zeit) aus Ornithodelphien entstanden sein werden. (Vergl. Tuf. VII und VIII.)

Erste Subclasse der Säugethiere:

$$
\text { Ornithodelphia (Amasla). Brustlose. }
$$

Aus dieser Subclasse kennen wir bloss die eine Ordnung der M o n otremata oder Kloakenthiere, welche gegenwärtig nur noch durch zwei australische Genera: Ornithorhynchus und Erhidna vertreten ist. Diese höchst eigenthümlichen Mammalien, welche offenbar nur die letzten überlebenden Reste einer vormals reich entwickelten Säugethier-Gruppe sind, verhalten sich zu den übrigen Mammalien ähnlich, wie Amphioxus zu dem ganzen Wirbelthier-Stamme, oder wie Hydra zu dem Coelenteraten-Stamme. Leider sind gar keine fossilen Reste von den nächsten Verwandten und Vorfahren derselben erhalten worden. Sie stehen in vielen Beziehungen den Monocondylien näher, als alle anderen Mammalien, und sind daher als uralte, höchst conservative Formen zu betrachten, wclche von allen bekannten Gliedern der Classe den im Beginn der Secundär - Zeit lebenden Uebergangs-Formen der Amphibien in die Säugethiere am nächsten stehen.

\section{Zweite Subclasse der Säugethiere: \\ Didelphia (Marsupialiu). Beutelthiere.}

Auch diese Subclasse der Säugethiere ist gleich der vorhergehenden im Aussterben begriffen, und nur verhältnissmässig unbedeutende Reste derselben haben in Australien (einige wenige auch auf den Sunda-Inseln und in Amerika) im Kampfe um das Dasein sich zu erhalten rermocht. Wahrscheinlich hat dieselbe in der ganzen Secundär - Zeit mit den Monotremen zusammen die Säugethier - Classe allein repräsentirt und damals eine ähnliche Formen-Mannichfaltigkeit durch Anpassung an verschiedene Lebens - Verhältnisse entwickelt, wie in der Tertiär-Zeit und in der Gegenwart die Monodelphien. Die fossilen Reste der Didelphien sind äusserst spärlich und dürf- 
tig, und nur insofern von hohem Interesse, als sie erstens die weite geographische Verbreitung der Subclasse in der Secundär-Zeit, und zweitens ihr hohes Alter beweisen. Die ältesten Reste finden sich im Keuper der Trias in Deutschland und England. (Mlicrolestes antiquns.) Ausserdem sind neuerdings im $J$ u r a von England zahlreiche Reste von fossilen Marsupialien gefunden worden: Thyluco/herium (Amplitherium), Phascololherium, Amphilestes, Slereognalhus, sämmtlich im Bath oder unteren Oolith (in den Schiefern von Stonesfield); ferner Spulacolherium, Plugiaulux, Triconodon, im Portland oder oberen Oolith (in den jüngsten Purbeck-Schichten). Die meisten Reste sind Unterkiefer und gehören carnivoren und insectivoren, einige jedoch (Stereognuthus) auch herbiroren Marsupialien an.

Die Beutelthiere werden gewöhnlich als eine einzige Ordnung betrachtet: doch sind die einzelnen Familien durch ihre Anpassung an die verschiedenartigste Lebensweise im Gebiss und übrigen Köperbau nicht weniger differenzirt, als die verschiedenen Ordnungen der Monodelphien, und es ist daher richtiger, sie als diesen äquivalente Ordnungen zu betrachten, zumal sie in vielen Beziehungen auffallende Parallelen zu diesen darbieten. Dieser Paralleiismus wird durch die nachfolgende Uebersicht anschaulich; von den hier aufgeführten acht Didelphien-Ordnungen kann man die vier ersten als Legion der fleis chfressenden Marsupialien (Zonphaga), die vier letzten als Legion der pflanzenfressenden Marsupialien (Botanophaga) zusammenfassen.

Parallele der didelphen und monodelphen Säugethier-Ordnungen.

\begin{tabular}{|c|c|c|c|}
\hline $\begin{array}{l}\text { Ordnungen der } \\
\text { Didelphien: }\end{array}$ & $\begin{array}{c}\text { Typus -der } \\
\text { Didelphien - Ordnung : }\end{array}$ & $\begin{array}{l}\text { Ordnangen der } \\
\text { Monodelphien : }\end{array}$ & $\begin{array}{c}\text { Typus der } \\
\text { Monodelphien- } \\
\text { Ordnung: }\end{array}$ \\
\hline 1. Creophaga & Thylacinus, Dasyzrzes & 1. Carnivora & Canis \\
\hline 2. Cantharophaga & Perameles, Myrmecobius & 2. Insectivora & Einaceus \\
\hline 3. Edentula & Tarsipes & 3. Edentata & Dasypus \\
\hline 4. Pedimana & Didelphys, Chironectes & 4. Prosimiae & Lemur \\
\hline 5. Carpophaga & Petaurus, Phalangista & 5. Simiae & Hapale \\
\hline 6. Rhizophaga & Phascolomys & 6. Rodentia & Castor \\
\hline 7. Barypoda & Diprotodon, Nototherium & 7. Pycnoderma & Hippopotamus \\
\hline 8. Macropoda. & Halmaturus, Hypsiprymuus & 8. Ruminantia & Cervus \\
\hline
\end{tabular}

Dieser schon vielfach und mit Recht hervorgehobene Parallelismus ist besonders desshalb von hohem Interesse, weil er zeigt, bis zu welchem Grade die Anpassung an gleiche Existenz-Bedingungen und gleiche Jebensweise (insbesondere auch gleiche Nahrung) im Stande ist, entsprechend gleiche Form-Umbildungen (besonders auch in der Bildung des Gebisses) zu bewirken. Denn offenbar sind alle diese Aehnlichkeiten nur Analogieen, nicht Homologieen. Die einzelnen Monodelphien-Ordnungen sind nicht durch Transformation (etwa durch Erwerbung einer Placenta) aus den entsprechenden Didelphien-Ordnungen entstanden, sondern vielmehr das DifferenzirungsProduct eines einzigen Placentalien-Zweiges, welcher wahrscheinlich nur aus einer einzigen Didelphien - Form entstanden ist (Vergl. Taf. VIII).

Was die Genealogie der Marsupialien betrifft, so sind leider ihre'fossilen Reste viel $\mathrm{zu}$ dürftig und unvollständig, um sie paläontologisch begründen zu können. So weit sich aus ihrer vergleichenden Anatomie schliessen lässt, 
CXLIV Systematische Einleitung in die Entwickelungsgeschichte.

bildet den Ausgangs - Punkt (ebenso wie unter den Deciduaten die Prosimien) die Ordnung der Pedimanen, welche unter allen Didelphien den Monodelphien, und zwar den Prosimien am nächsten zu stehen scheinen. Aus diesen sind als zwei divergente $\mathrm{Zweige}$ einerseits die Cantharophagen ( $\mathrm{Z}_{0} 0$ phagen!), andrerseits die Carpophagen (Botan ophagen!) hervorgegangen. Aus den Cantharophagen haben sich wahrscheinlich die Edentula und Creophaga, aus den Carpophagen dagegen die Rhizophaga, Macropoda und Barypoda entwickelt.

Dritte Subclasse der Säugethiere:

\section{Monodelphia (Placentalia). Placentalthiere.}

Aus der Thatsache, dass alle fossilen Säugethier-Reste der SecundärZeit Didelphien angehören, lässt sich der Schluss ziehen, dass die Monodelphien erst im Beginn der Tertiär-Zeit aus den ersteren entstanden sind. Doch ist dieser Schluss keineswegs sicher, da wir aus dem ungeheuer langen Zeitraum zwischen Ablagerung der obersten Jura-Schichten (Purbeck) und der untersten Tertiär-Schichten gar keine Säugethier-Reste besitzen. Es ist sehr leicht möglich, dass die Umbildung der Marsupialien zu Placentalien bereits während der Kreide-Zeit oder noch früher (in Antecreta - oder Jura-Zeit) stattgefunden hat. Jedeufalls wäre die Anteocen-Zeit die jüngste mögliche Zeit dieses Umbildungs-Processes, da wir das Resultat desselben schon in den ältesten Eocen-Schichten vollendet vor uns sehen.

Wir zertällen die Subclasse der Monodelphien in zwei Legionen, welche wahrscheinlich schon sehr frühzeitig sich von einander getrenut haben, und als zwei divergente Hauptäste der ältesten Placentalien-Gruppe zu betrachten sind, welche unnittelbar aus den Didelphien entsprang. Diese beiden Legionen, wesentlich durch die Structur (weniger durch die äussere Form!) der Placenta verschieden, sind die Indeciduen und die Deciduaten. Die specielle Ableitung ihtes Ursprungs und ihrer gegenseitigen Beziehungen ist noch äusserst duukel. Wahrscheinlich sind die Deciduaten erst später aus den Indecidu e n entstanden. Vielleicht aber sind beide di-

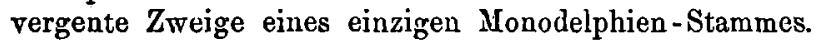

Erste Legion der Monodelphien:

Indecidua. Placentulthiere ohne Decidua.

Diese Legion umfasst diejenigen monodelphien Säugethiere, deren Uterus keine Decidua bildet. Es wird dieselbe aus $z$ wei sehr divergenten Gruppen gebildet, einerseits den Edentaten, andrerseits den Pycnodermen, welche jedoch trotz anscheinend sehr grosser Verschiedenheit vielfache Verwandtschafts-Beziehnngen zeigen und offenbar zwei Aeste eines einzigen Indeciduen-Zweiges sind.

Erste Sublegion der Indeciduen:

Edentata (Bruta). Zahnlose.

Diese Sublegion enthält die einzige Ordnung der E dentata oder Zahnlosen, welche unter allen bekannten Placentalien die tiefste Stufe einzunehmen und sehr alten Ursprungs zu sein scheint. Wahrscheinlich sind die jetzt lebenden Edentaten, ebenso wie die Marsupialien der Jetztzeit, nur die letzten kümmerlichen Reste einer vormals reich entwickelten Thieroruppe. Noch in der Diluvial-Zeit besass dieselbe einen hohen Grad der Entfaltung, wie 
die colossalen Skelete der Macrotherien, Glyptodonten und Gravigraden beweisen. Die Phylogenie der Edentaten ist sehr schwierig zu errathen, da uns offenbar sehr viele alte Stammformen und $Z$ wischenglieder fehlen. Wahrscheinlich haben sich von den Pycnodermen zunächst die Vermilinguien abgezweigt, aus denen vielleicht die Gravigraden entstanden sind. Da diese letzteren offenbar die Charaktere der Cingulaten und Bradypoden gemischt enthalten', sind sie wahrscheinlich die gemeinsamen Stammformen dieser beiden Gruppen.

\section{Zweite Sublegion der Indeciduen: Pycnoderma., H. Derbhäuter.}

Als Pycnodermen vereinigen wir hier die beiden Ordnungen der Cetaceen und der Ungulaten, welche nicht allein durch die Beschaffenheit ihrer Placenta und ihrer Haut, sondern auch durch viele andere Charaktere als nächstverwandte Glieder eines einzigen Astes sich erweisen. Lediglich die Anpassung an den Aufenthalt im Wasser hat die Cetaceen in ähnlicher Weise von den Ungulaten entfernt, wie die Pinnipedien von den Carnivoren.

\section{Erste Ordnung der Pycnodermen: Ungulata. Hufthiere.}

Die Ordnung der Ungulaten ist von allen Thiergruppen eine der interessantesten und lehrreichsten, vorzüglich auch desshalb, weil sie in der ausgezeichnetsten Weise die Unentbehrlichkeit der paläontologischen Entwickelungsgeschichte für das Verständniss der natürlichen Verwandtschaften nachweist. Wir zerfällen diese sehr natürliche Ordnung, welche eine trotz alles Formenreichthums durchaus einheitlich organisirte Gruppe darstellt, (gleichwie unter den Deciduaten die Nagethiere) in zwei Unterordnungen, Artiodactylen und Perissodactylen.

Soweit sich die Genealogie der Ungulaten gegenwärtig übersehen lässt, scheint die Familie der Lophiodonten den Ausgangspunkt der. ganzen Ordnung zu bilden. Zu ihnen gehören die ältesten aller bekannten Ungulaten-Reste, welche sich schon im untersten Eocen (London-Thonj finden (Coryphodon). Ausserdem nehmen sie eine so zweifelhafte Mittelstellung zwischen Artiodactylen (Suilliden) und Perissodactylen (T'apiriden) ein, dass sie bald mit den ersteren, bald mit den letzteren vereinigt werden. Wahrscheinlich sind sie demnach die Stammväter der Ordnung, von denen die beiden Unterordnungen als zwei divergente Aeste ausgegangen sind.

Aus den Anoplotheriden, den Stammeltern des ArtiodactylenZweiges, haben sich als zwei divergente Aeste die Anthracotheriden und $\mathrm{Xiphodonten} \mathrm{entwickelt,} \mathrm{jene} \mathrm{zu} \mathrm{den} \mathrm{Setigera} \mathrm{und} \mathrm{Obesa,} \mathrm{diese} \mathrm{zu} \mathrm{den}$ Ruminantia hinüberführend. Die ältesten Stammformen der Ruminantien sind die Dremotheriden, Mittelformen zwischen Moschiferen und Cervinen, aus denen diese beiden als divergente Aeste entstanden sind. Die Giraffen sind wohl bloss ein Zweig des Cervinen - Astes. Die Cavicornien haben sich wohl ebenfalls aus den Cervinen entwickelt, und zwar zunächst die Antilopiden, aus diesen die Aegoplasten (Caprinen). Aus letztern sind wahrscheinlich die Probatoden (Ovina) und aus diesen die Tauroden (Bovina) entstanden.

Aus den Palaeotheriden, den Stammeltern des PerissodactylenZweiges, haben sich wahrscheinlich als zwei divergente Aeste die $\mathrm{N}$ as i cornien und die Tapiriden entwickelt. Aus den Tapiriden sind als zwei

Ha ecke1, Generello Morphologio, II. 


\section{Systematische Einleitung in die Entwickelungsgeschichte.}

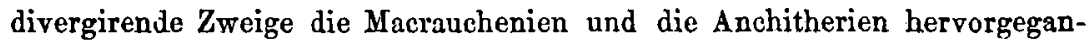
gen, jene zur Section der Camele (Tylo poda), diese zur Section der Pferde (Solidungula) hinüberführend. Ile Camele entfernen sich durch viele Charaktere (namentlich durch osteologische Eigenthümlichkeiten und durch die Placentarbildung) von den Ruminantien und nähern sich vielmehr den Pferden und den Tapiren, mit denen sie durch Macrauchenia verbunden sind.

\section{Zweite Ordnung der Pycnodermen: \\ Cetacea. Wale.}

Die Ordnung der Wale oder Walfische ist, wie bemerkt, den Ungula. ten nächst verwandt, und verhält sich zu diesen eben so wie die Pinnipedien zu den Carnivoren. Die Cetaceen sind Ungulaten, welche durch Anpassung an das Leben im Wasser sich Fischen analog umgebildet haben Bei der innigen anatomischen uud systematischen Verwandtschaft der beiden Ordnungen kann der U'sprung der Cetaceen aus den Ungulaten kaum zweifelhaft sein. Wir theilen die Ordnung der Cetaceen in drei Unterordnungen: I. P h ycoceta (Siremia) oder pflanzenfressende Cetaceen (Halicore, Manatus, Rhylina). II. A u toceta (Balaenia) oder fleischfressende Cetaceen (Delphinus, Hyperoodom, Monodon, Physeter, Balaena). III. Z eugl oc et a (Zeuglodontia) oder Hydrarchen (Zeuglodon s. Hydrarchos). Von diesen drei Cnterordnungen sind wahrseheinlich zunächst die Sirenien aus den Ungulaten hervorgegangen und zwar aus den Artiodactylen, unter denen die $\mathrm{O}$ besen (Hippopolamus) ihnen am nächsten stehen. Die A u toceten und $\mathrm{Zeuglo-}$ ceten sind wahrscheinlich zwei divergente Aeste der Phycoceten.

\section{Zweite Legion der Monodelphien: \\ Deciduata. Ptacentalthiere mil Decidua.}

Diese Legion umfasst alle Monodelphien, nach Ausschluss der Edentaten und Pycnodermen, welcho sich durch Mlangel der Decidua-Bildung wesentlich von den Deciduaten unterscheiden. Wir zerfällen diese Legion in zwei Sublegionen, welche durch die Form der Placenta versehieden sind: I. Zon op lacentalia, mit ringförmiger Placenta, und II. Dis coplacentalia, mit scheibenförmiger Placenta.

\section{Erste Sublegion der Deciduaten: \\ Zonoplacentalia. Deciduaten mit gürtelförmıger Placenta.}

In dreser Sublegion fassen wir die beiden Ordnungen der Chelophoren und Carnarien zusammen, von denen jene die 4 Unterordnungen der Hyraciden, Toxodonten, Dinotherien und Elephanten, diese die beiden Unterordnungen der Landraubthiere (Carnivora) und der Seeraubthiere (Pinnipedia) enthält. So verschieden auch diese Zonoplacentalien durch Anpassung an verschiedenartige Nahrung und Lebensweise differenzirt sein mögen, so stimmen sie doch alle wesentlich überein durch einen sehr wichtigen anatomischen Charakter, welcher ihre nahe Blutsverwandtschaft beweist, nämlich die ringförmige Placenta. Offenbar ist diese ein gemeinsame $\mathbf{E r b}$ s tü ok von einer gemeinschaftlichen unbekannten Stammform, und verbindet die beiden Ordnungen der Zonoplacentalien in ähnlicher Weise, wie die scheibenförmige Placenta die Discoplacentalien. Leider sind uns die fossilen Reste dieser Gruppe nur höchst unvollständig bekannt, und ihre Phylogenie daher zur Zeit noch sehr unklar. Wahrscheinlich war die gemeinsame Stamm- 
form der Zonoplacentalien ebenso wie diejenige der Discoplacentalien, ein omnivores Deciduat, von dem als zwei divergente $Z$ weige die beiden Ordnungen der pflanzenfressenden Chelophoren und der fleischfressenden Carnarien ausgingen. Unter den Discoplacentalien entsprechen den letzteren die Insectivoren, den ersteren die Rodentien.

\section{Erste Ordnung der Zonoplacentalien: \\ Cholophora, H. Hufträger.}

Diese Ordnung, welche den Rodentien unter den Discoplacentalien correspondirt, ist uns nur höchst unvollkommen durch einige wenige lebende Formen und sehr unvollständige fossile Fragmente bekannt, so dass ihre Genealogie sich nur sehr unsicher errathen lässt. Gewöhnlich werden die Chelophoren als Pachydermen (also als ein Theil der Ungulaten betrachtet), von denen sie aber nicht allein durch den Besitz einer Decidua und durch die gürtelförmige Placenta, sondern auch durch zahlreiche und sehr wichtige osteologische Charaktere wesentlich verschieden sind. Die auffallenden äusseren Aehnlichkeiten der Chelophoren und Ungulaten sind nur Analogieen, nicht Homologieen. Viel näher als den Ungulaten, sind die Chelophoren den Rodentien verwandt. Wir zerfällen die Chelophoren in vier Unterordnungen, die übrigens trotz aller gemeinsamen Charaktere so sehr divergiren, dass wir ihnen lieber den Rang von Ordnungen zugestehen möchten: I. Lamnungia: Familie der Hyraciden (Hyrax). II. Toxodonta: Familie der Toxodontiden (Toxodon). III. Gonyognatha: Familie der Dinotheriden (Dinotherium). IV. Proboscidea (Mastodon, Elephas). Die näheren Beziehungen der vier Unterordnungen zu einander sind wegen des Mangels ihrer verbindenden $\mathrm{Z}$ wischenformen schwer zu bestimmen. Doch zeigen einerseits die Lamnungien und Toxodonten, andrerseits die Gonyognathen und Proboscideen mehr Aehnlichkeit; vielleicht sind aber auch Toxodonten und Dinotherien nahe verwandt gewesen. Falls die letzteren Wasserthiere ' waren, verhielten sie sich zu den Elephanten ähnlich, wie die Cetaceen zu den Ungulaten.

\section{Zweite Ordnung der Zonoplacentalien: \\ Carnaria, H. Raubthiere.}

Diese Ordnung entspricht ebenso den Insectivoren unter den Discoplacentalien, wie die vorige den Rodentien. Doch ist sie uns weit vollständiger, als die vorhergehende, durch zahlreiche lebende und fossile Repräsentanten bekannt. Die Carnarien zerfallen in zwei nahverwandte Unterordnungen: I. Oarni vora oder Landraubthiere, und II. Pinnipedia oder Seeraubthiere. Die letzteren sind erst später aus den ersteren darch Anpassung an das Leben im Wasser entstanden, and verhalten sich zu diesen ebenso, wie die Cetaceen zu den Ungulaten. Den Ausgangspunkt, und den elterlichen Stamm der ganzen Gruppe bildet die ausgestorbene Familie der A rctocyoniden oder Bärenhunde, welche durch Sohlengang und plumpe Körperform mehr mit den Bären, durch die Bildung des Gebisses dagegen mehr mit den Hunden (und theilweis auch mit den Viverren) übereinstimmten. Es gehören hierher die ältesten aller bekannten fossilen Carnarien, Arctocyon und Palaenmyctis aus dem unteren Eocen (Londonthon). Aus dieser Familie haben sich zunächst als reine Sohlengänger (Plantigrada) die Bären (Ursina) entwickelt, welche in der älteren Tertiär-Zeit überwiegend die Carnivoren repräsentiren. Aus ihnen haben sich weiterhin die Halbsoh- 
CXLVIII Systematische Einleitung in die Entwickelungsgeschichte.

lengänger (Semi p lan tig rada) hervorgebildet, die Familien der Viverrinen und Mustelinen, von denen namentlich die ersteren bereits mehrfache Uebergänge zu den echten Zehengängern (Digitigrada) enthalten, den Familien der Hunde (Canina) und Hyänen (H yaenida). Aus den letzteren sind schliesslich die Katzen (Felina) als der höchst entwickelte Carnivoren-Zweig hervorgegangen. Die Hunde haben sich vielleicht auch unabhängig von den Viverren und Katzen direct aus den Bären oder aus den Arctocyoniden entwickelt. Die zweite Unterordnung, die der Seeraubthiere oder Pinni pedien hat sich wahrscheinlich aus den M ustelid en entwickelt, unter denen noch jetzt die Lutra und Enhydris unmittelbare Uebergangsformen darstellen.

\section{Zweite Sublegion der Deciduaten: \\ Discoplacentalia. Deciduaten mit scheibenförmiger Placenta.}

Diese Legion erscheint weit formenreicher und entwickelungsfähiger, als die der Zonoplacentalien; doch können wir auch hier die beiden divergenten Gruppen der Pflanzenfresser und Fleischfresser unterscheiden, von denen die ersteren (den Chelophoren entsprechend) hier vorziiglich durch die Rodentien, die letzteren (den Carnivoren correspondirend) durch die Insectivoren vertreten werden. Einen eigenthümlichen Seitenzweig bilden die Fledermäuse (Chiroptera). Zwischen jenen betden divergenten Gruppen hat sich jedoch bei den Discoplacentalien der gemeinsame omnivore Ahnenstamm, durch die Prosimien noch jetzt repräsentirt, nicht allein erhalten, sondern in der Ordnung der echten Affen, zu welcher auch der Mensch gehört, zur höchsten Organisations-Höhe emporgehoben. Dass diese fünf Ordnungen (Prosimiae, Rodentia, Insectivora, Chiroptera, und Simiae) nächst verwandt sind, wird nicht allein durch ihre scheibenförmige Placenta, sondern auch durch viele andere anatomische Eigenthümlichkeiten, sowie durch zahlreiche noch vorhandene Zwischenformen zwischen den einzelnen Ordnungen bewiesen. Da der Mensch selbst ein Glied dieser Legion ist, so erscheinen grade hier diese Uebergangsformen von der höchsten Bedeutung.

\section{Erste Ordnung der Discoplacentalien : Prosimiar (Hemipitheci). Halbaffen.}

Die sehr merkwürdige und wichtige Ordnung der Halbaffen, von deren früherem Formenreichthum uns leider nur noch sehr wenige lebende Repräsentanten eine dürftige Vorstellung geben, und deren fossile Reste uns noch unbekannt sind, betrachten wir als die gradlinige Fortsetzung des uralten Discoplacentalien-Stammes, aus welchem sich die übrigen Ordnungen dieser Snblegion als divergente Aeste entwickelt haben. Wir glauben, dass diese Ansicht durch ihre zahlreichen und verwickelten Verwandtschafts - Beziehungen und durch die einzelnen, aber sehr wichtigen Uebergangs - Formen zu anderen Gruppen lediglich bestätigt wird. Es führen die Lep todoctyla, (Chiromys) von den Prosimien unmittelbar zu den Rodentien hinüber, die Macrotarsi (Tarsius, Otolicnus) zu den Insectivoren, die P tenopleura (Galeopithects) zu den Chiropteren, die Brachytarsi (Lemur, Slenops) zu den Simien. Sehr wichtig erscheint es uns ferner in dieser Beziehung, dass die niederen Prosimien unter allen bekannten Monodelphien in vielen Beziehungen den Didelphien am nächten stehen, insbesondere den P edimanen (Didelphys). Alle diese Beziehungen sprechen dafür, dass die Prosimien (ähnlich wie die Selachier unter den Fischen, die Sozuren unter den Amphibien, die Lacertilien unter den Reptilien, die Saurophallen unter den Vögeln) 
ein sehr alter idealer Typus sind (s. unten S. 222), von welchem viele verschiedene praktische Typen als divergente Aeste ausgegangen sind.

\section{Zweite Ordnung der Discoplacentalien: \\ Rodentia (Glires). Nager.}

Diese formenreiche, aber trotz aller Anpassungs - Divergenzen sehr einheitlich organisirte Ordnung bildet den rein herbivoren. $Z$ weig der Discoplacentalien, und entspricht als solcher den Chelophoren unter den Zonoplacentalien, zu denen sie noch vielfache Beziehungen besitzen (insbesondere die Subungulaten und Fyraciden). Die Ordnung der Nagethiere zerfällt in vier Unterordnungen. Von diesen hat sich zunächst wahrscheinlich diejenige der Eichhornartigen oder Scıuromorpha aus den Prosimien entwickelt, mit denen sie durch Chiromys noch jetzt unmittelbar verbunden ist. Hiermit stimmt auch die Paläontologie der Rodentien trefflich überein. Alle fossilen Nagethier-Reste der Eocen-Zeit gehören ausschliesslich Sciuriden oder Uebergangsformen derselben zu den anderen Ordnungen an. Aus den Sciuriden haben sich wahrscheinlich als zwei divergente Aeste die beiden Ordnungen der Mäuseartigen oder $\mathbf{M}$ yomorpha und der Stachelschweinartigen oder Hystrichomorpha entwickelt, jene durch eocene Myoxiden, diese durch eocene Psammoryctiden unmittelbar mit den Sciuriden zusammenhängend. Die vierte Unterordnung endlich, die der Hasenartigen oder Lago morph a (Leporiden) ist hinsichtlich ihres Ursprungs durch keine fossilen Documente aufgeklärt, hat sich aber wahrscheinlich aus Hystrichomorphen entwickelt.

\section{Dritte Ordnung der Discoplacentalien : Insectivora. Insectenfresser.}

Wie die Rodentien den rein herbivoren, so repräsentiren die Insectivoren den rein carnivoren 7 weig des Discoplacentalien-Stammes. Sie sind den Nagern viel näher als den Carnivoren verwandt, mit denen sie früher als "Ferae" vereinigt wurden Ausser der scheibenförmigen Placenta stimmen sie mit den Rodentien namentlich durch den Besitz grosser Samenblasen überein, welche den zonoplacentalien Carnivoren stets fehlen. Durch ähnliche Anpassung haben sich die einzelnen Gruppen der Insectivoren und Rodentien in auffallendem Parallelismus entwickelt. Es entsprechen die kletternden Scandentia (Cladobatida) den Sciuromorphen, die Soricida den Mäusen, die Talpida den Wühlmäusen unter den Myomorphen; die Igel (A cu lea ta) correspondiren den Hystrichomorphen. Die älteste Ausgangsgrappe der Ordnung scheinen die Scandentien zu bilden, welche den Macrotarsen unter den Prosimien am nächsten verwandt sind.

\section{Vierte Ordnung der Discoplacentalien: Chiroptera (Volitantia). Fledermüuse.}

Die Ordnung der fliegenden Chiropteren ist ein Zweig des Discoplacentalien-Astes, welcher in ähnlicher Weise durch specielle Anpassung an das Leben in der Luft abgeändert worden ist, wie die Gruppe der schwimmenden Pinnipedien unter den Zonoplacentalien durch Anpassung an das Leben im Wasser. Wahrscheinlich haben sich die Chiropteren unmittelbar aus den Prosimien entwickelt, unter denen die Galeopitheken noch jetzt den Uebergang zu vermitteln scheinen. Von den beiden Unterordnungen der Chiropteren- 


\section{Systematische Einleitung in die Entwickelungsgeschichte.}

Ordnung, den P terocy nen (Frugivoren) und den Nycteriden (Insectivoren) haben sich wahrscheinlich die letzteren erst später aus den ersteren, diese dagegen unmittelbar aus den Prosimien entwickelt.

\section{Fünfte Ordnung der Discoplacentalien: Simiae (Pitheci). Affen.}

Die Ordnung der echten Affen oder Simien, die letzte und oberste des Thierreichs, ist die höchste und vollkommenste Ordnung nicht allein unter den Discoplacentalien, sondern unter allen Säugethieren, da auch der Mensch aus derselben nicht ausgeschlossen werden kann. Die Affen haben sich jedenfalls unmittelbar aus den Halbaffen entwickelt, mit denen sie gewöhnlich als Primates vereinigt werden. Die Ordnung zerfällt in drei Unterordnungen: I. Arctopitheci oder Krallenaffen: Familie der Hapaliden (Hapale); II. Platyrrhinae oder Plattnasen (Amerikanische Affen): Familien der A ph yocerken (Pilhecia, Callithrix) und Labidocerken (Mycetes, Lagothrix); III. Catarrhina oder Schmalnasen (echte Affen der alten Welt): Section der Menocerken: Familie der Anasken (Semnopithecus) und der Ascopareen (Cynocephalus, Inuus); und Section der Lipocerken: Familien der Tylogluten (Hylobates), der Lipotylen (Salyrus, Engeco, Gorlla, Dryopilhecus), und der Erecten (Homo) ${ }^{1}$ ).

1) Die systematischen Benennungen der drei grossen lebenden (Lipotylen) dürften am passendsten in der Weise geordnet werden, dass man jeden derselben als Repräsentanten eines besonderen Genus ansieht, da die Differenzen zwischen denselben vollkommen zu einer generischen Trennung hinreichen Gewöhnlich werden Gorilla und Chimpanze als zwei Arten des Genus Troglodytes aufgeführt. Dieser Gattungs-Name ist zuerst von G Éffroy $S$. Hilaire 1812 für den Chimpanze eingeführt wordén. Allein bereits 6 Jahre früher (1806) hatte Vieillot denselben generischen Namen für das Vogel-Genus aufgestellt, zu welchem unser kleinster europäischer Vogel, der Zaunkönig, Troylodytes parvulus gehört, unl diese Benennung ist allgemein augenommen. Es muss daher der Genus-Name Troglodytes, wenn man Gorilla und Chimpanze unter demselben vereinigen will, durch eine neue Bezeichnung ersetzt werden, für welche der alte Name Pongo sich am besten eignen dürfte. Es wäre dann der Gorilla als Pongo gorilla, der Chimpanze als Pongo troglodytes zu bezeichnen. Will man dagegen, was uns passender erscheint, beide Affen als besondere Gattungen trennen, so ist für den Gorilla der bereits in Gebrauch gekommene Name Gorilla engena oder Gorilla gina beizubehaiten. Der Chimpanze dürfte als generischen Namen am passendsten die Bezeichnung beibehalten, welche er in seiner Heimath bei den Negern führt: Engeco; und dio Art würde nach den Regeln der systematischen Nomenclatur Engeco troglodytes zu nennen sein. Der Orang führt gewöhnlich entweder den Namen Simia satyrus oder Pithecus satyrus; da jedoch sowohl der Ausdruck Simia als auch Fithecus sehr häufig zur Bezeichnung der ganzen Ordnung der echten Affen, im Gegensatz zu den Halbaffen (Prosintiae, Hemipitheci) ge* braucht wird, so erscheint es passend, seinen bisher gebräuchlichen Species-Namen zur Bezeichnung des Genus zu erheben, als welcher er bereits 1641 von Tulpi us zur Bezeichnung eines Anthrupoiden, ,von den Indiern Orang-Outang genannt", verwendet wurde. Falls der Simia morio $O \mathrm{wen}^{\prime} \mathrm{s}$, wie es scheint, eine gute Art ist, so würde man beide Orang-Arten als Satyrus orang und Satyrus morio tremnen können. Die Synonymie der Authropoiden wäre demnach folgende:

1) Gorilla engena (Gorzlla gina, Simia gorilla, Troglodytes gorilla, Pongo gorilla).

2) Engeco troglodytes (Simia troglodytes, Pithecus troglodytes, Troglodytes niger, Troglodytes leucoprymnus, Pongo troglodytes).

3) Satyrus or ang (Simia satyrus, Pethecus satyrus).

4) S atyrus morio (Srmza morio, Puthecus morra). 


\section{Anhang zor systematischen Finleitung in die Entwickelungsgeschichte.}

\section{Der Stammbaum des Menschen.}

Bei der ausserordentlich hohęn Bedeutung, welche die Systematik der Wirbelthiere und insbesondere der Affen für die "Frage aller Fragen“, für die Frage „, $v 0 n$ der Stellung des Menschen in der Natur" besitzt, orscheint es gerechtfertigt, hier auf das Syetem der Affen, mit welchem wir unsere vorhergehende genealogische Uebersicht des natürlichen Systems der Organismen abgeschlossen haben, noch einen näheren Blick zu werfeu, und die systematische Stellung des Menschen in demselben zu erlïutern. Wie wir unten im siebenten Buche zeigen werden, findet die Descendenz-Theorie ebenso auf den Menschen, wie auf jeden anderen Organismus, ihre volle und unbedingte Anwendung. Kein objectiver und vorurtheilsfreier Naturforscher kann bestreiten, dass der Mensch ein Wirbelthier, und zwar ein Säugethier, gleich allen anderen ist, und dass er demgemäss; wenn überhaupt die DescendenżTheorie wahr ist, sich aus einem und demselben Stamme mit den ersteren entwickelt haben muss. Die Theorie, dass der Mensch von niederen Wirbelthieren, und zwar zunächst von unter ihm stehenden Säugethieren abstammt, ist eine vollkommen gesicherte und nothwendige Deduction, welche wir aus dem umfassenden Inductions - Gesetz der Descendenz - Theorie ableitẹn. Da wir dieses Vërhältniss unten im XXVII. Capitel noch näher erörtern werden, wollen wir uns hier nicht länger bei der allgemeinen Begründung dieser hochwichtigen Fragè aufhalten. Vielmehr soll hier lediglich die specielle Stellung des Menschen im System der Säugethiere vom rein zoologischen Standpunkte aus erörtert werden.

Glïcklicherweise ist die Stellung des Menschen im System der Sängethiere so deutlich und fest ausgeprägt, es sind seine Verwandtschafts-Beziehungen zu den verschiedenen übrigen Gruppen der Säugethiere so klar und bestimmt durch seine noch lebenden nächsten Verwandten offenbart, dass der Stammbaum des Menschen mit viel grösserer Sicherheit und Leichtigkeit, als die Genealogie sehr vieler anderer Thiere sich in seinen allgemeinen Grundzügen feststellen lässt. Die anatomische Verwandtschaft des Menschen zu den Affen springt so sehr in die Augen, dass sie von allen Menschen, wenn auch nur als ",körperliche Aehnlichkeit", unbestritten anerkannt wird, und dass bereits der Gründer der formalen Systematik, Lin né, den Menschen mit den echten Affen und den Halbaffen in einer und derselben Ordnung der Primates vereinigte. Zwar haben verschiedene Schriftsteller den 
CLII Anhang zur systematischen Einleitung in die Entwickelungsgeschichte.

Versuch gemacht, dem Menschen dadurch eine eximirte Stellung zu wahren, dass sie ihn zum Repräsentanten einer besonderen Subclasse der Säugethiere (Archencephala) oder gar eincr besonderen Wirbelthierclasse (Anthropi) erhoben, und Einige sind sogar so weit gegangen, neben dem Pflanzenreich und dem Thierreich noch ein besonderes Nenschenreich zu errichten. Indessen springt die Verkehrtheit aller dieser Versuche so sehr in die Augen, dass wir uns nicht mit deren Widerlegung aufzuhalten brauchen. Jeder objective Zoologe muss zugebcn, dass in dem vorstehenden System der Säugethiere, welches auf den wichtigsten Vererbungs - Beziehungen der natürlichen Bluts - Verwandtschaft fusst, Her Mensch ein Glied aus der Sublegion der Discoplacentalien ist. Gleich allen Affen, Fledermäusen, Insectenfressern, Nagethieren und Halbaffen gehört der Mensch in die Subclasse der Monodelphien oder der placentalen Säugethiere, in die Legion der Deciduaten, in die Sublegion der Discoplacentalien.

Weniger einfuch ist die Beantwortung der Frage, welche Stellung der Mensch innerhalb der Discoplacentalien - Gruppe einzunehmen hat. Fast allgemein wird noch heute die Sublegion der Discoplacentalien in folgende funf Ordnungen eingetheilt: 1. Rodentia (Nagethiere). 2. Insectivora (Insectenfresser). 3. Chiroptera (Fledermäuse). 4. Quadrumana (Vierhänder). 5. Bim an a (7weihänder). Die Ordnung der Bimana umfasst allein den Menschen, während die Ordnung der Quadrumana die echten Affen (Simiae) und die Halbaffen (Prosimiae) enthält. Huxley hat das Verdienst, in seinen vortrefflichen „Zeugnissen für die Stellung des Menschen in der Natur" zuerst nachgewiesen zu haben, dass diese Eintheilung eine völlig unberechtigte, die Trennung der Primaten - Ordnung Linn é's in Bimana und Quadrumana eine durchaus künstliche ist, und dass der Fuss aller Affen und Halbaffen keine Hand, sondern ebenso ein echter Fuss, wie der Fuss des Menschen ist. Der Fuss unterscheidet sich von der Hand durch die charakteristische Anordnung der Fusswurzelknochen, die von der der Handwurzelknochen wesentlich verschicden ist, und durch den Besitz dreier besonderer charakteristischer Mluskeln, welche der Hand fehlen (Musculi peronaeus longus, flexor brevis, exiensor brevis). Diese Differenz von Hand und Fuss findet sich bei allen Primaten ebenso wie beim Menschen. Alle Primaten, alle echten Affen und Halbaffen, sind also in der That nicht Qundrumana, sondern Bimana, sie besitzen alle zwei Hände und zwei Füsse: Die Unterschiede aber, welche sich in der speciellen Differenzirung der Extremitäten bei den verschiedenen Primaten vorfinden, sind geringer zwischen dem Menschen und den nächstverwandten lipocerken Affen (Gorilla insbesondere), als $z w i s c h e n$ diesen und den niederen Affen.

Ébenso wie mit den Extremitäten, welche man für den wichtigsten Differential-Charakter der Thiere hielt, verhält es sich mit allen anderen Charakteren. Dẹr Bau des Schädels, des Gehirns und jedes anderen Körpertheils zeigt grössere Differenzen zwischen den niederen und den höchsten $\Delta \mathrm{ffen}$, als zwischen diesen und dem Menschen. Huxley hat diese wichtige, fundamentale Thatsache (l. c.) so ausfihrlich und unnmstösslich festgestellt, dass wir hier lcdiglich auf seine oben erwähnte Abhandlung zu verweisen brauchen, in welcher er auf Grund der sorgfältigsten anatomischen Untersuchungen zu dem höchst wichtigen Schlusse gelangt: „W ir mögen daher ein System von Organen vornehmen, welches wir wollen, die Vergleichung ihrer Modificationen in der Affenreihe führt uns $z u$ einem und demselben Resultate: 
dass die automischen Verschiedenheiten, welcheden ilenschen rom Gorilla und Chimpanze scheiden, nicht sogross sind, als die, welche den Gorilia ron den nledrigeren Affen trennen."

Die Ordnung der Bimana ist also definitiv aufgelöst. Der Mensch kann innerhalb des zoologischen Systems nicht Anspruch darauf machen, Repräsentant einer besonderen Säugethier-Ordnung zu sein. Höchstens können wir ihn das Recht zugestehen, innerhalb der Primaten-Gruppe oder innerhalb der echten Affen-Ordnung eine besondere Familie zu bilden. Wir sagen: Höchstens! denn in der That sind die ron Huxley so vortrefflich erläuterten „Beziehungen des Menschen zu den nächstniederen Thieren" noch innigere und nähere, als es nach seinem System scheinen könnte. Wir glauben, dass $\mathrm{Huxley}$ 's System der Primaten in dieser Beziehung nicht scharf genug die bedeutenden quantitativen und qualitativen Differenzen der verschiedenen Primaten-Gruppen hervorhebt, und dass das verwickelte Verhältniss der Coordination und Subordination dieser Gruppen noch eine schärfere Definition erfordert. $\mathrm{Huxley}$ zerfällt die Ordnung der Primates in folgende ,sieben Familien von ungefähr gleichem systematischen Werthe": 1. Anthropini (Homo), 2. Catarrhini (Cynucephalus, Gorilla etc.), 3. Platyrrhini (Callithrix, Mycetes etc.), 4. Arctopithe i (Hapale), 5. Lemurini (Slenops, Tarsius etc.), 6. Chiromyini (Chiromys), 7. Galeopithecini (Galeopilhecus). Die ununterbrochene Stufenleiter von höchst vollkommenen zu höchst unvollkommenen Discoplacentalien, welche diese Kette der Primaten - Familien darbietet, begleitet $\mathrm{Huxley}$ mit folgender treffender Bemerkung: „Es bietet wohl kaum eine Säugethier-Ordnung eine so ausserordentliche Reihe von Abstufungen dar, wie diese; sie führt uns uninerklich von der Krove und Spitze der thierischen Schöpfung zu Geschöpfen herab, von denen scheinbar nur ein Schritt zu den niedrigsten, kleinsten und wenigst intelligenten Formen der placentalen Sängethiere ist. Es ist, als ob die Natur die Anmaassung des Menschen selbst vorausgesehen hätte, als wenn sie mit altrömischer Strenge dafür gesorgt hätte, dass sein Verstand durch seine eignen Triumphe die Sclaven in den Vordergrund stellt, den Froberer daran mahnend, dass er nur Staub ist." So gewiss gerade diese ununterbrochene Stufenfolge von den niedrigsten nagethierartigen Discoplacentalien bis zu den höchsten, bis zum Menschen hinauf, von der höchsten Bedeutung ist, so wird doch das wahre genealogische Verhältniss der verschiedenen Gruppen zu einander nicht einfach durch das Bild einer Stufenleiter, sondern rielmehr durch dasjenige einer Astgruppe ausgedrückt, wie dies in der rechten oberen Ecke des Stammbaums auf Taf. VIII angedeutet ist. Zur näheren Erläuterung unseres schon vorher aufgestellten Affen-Systems mögen daher noch folgende Bemerkungen dienen.

Díe A uflösung der Primaten-Ordnung in die beiden Ordnungen der echten Affen (Simiae) und der Halbaffen (Prosimiae) scheint uns deshalb geboten, weil die Ordnung der Halbaffen nach unserer Anschauung die Stammgruppe der Discoplacentalien bildet, welche zu allen übrigen Ordnungen dieser Sublegion in parentalem Verhältnisse steht, und selbst noch gegenwärtig durch vermittelnde Zwischenstuf:n unmittelbar mit ihnen verbunden ist. Wir betrachten also die Prosimien als gradlinige und sehr wenig veränderte Nachkommen des DiscoplacentalienStammes, aus welchem die vier Ordnungen der Rodentien, Insectivoren, 
CLIV Anhang zur systematischen Einleitung in die Entwickelungsgeschichte.

Chiropterien und Simien als dirergente Seitenlinien hervorgingen. Die Rodentien sind noch heute unmittelbar durch die Leptodactyla (Chiromys), die Insectivora durch die Macrotarsi (Tarsius, Otolicnus), die Chiroptera durch die Ptenopleura (Galeopithecus), die Simiae endlich durch die Brachytarsi (Slenops, Lemur) mit der parentalen Stammgruppe der Prosimiae oder Hemipitheci auf das innigste vereinigt. Dabei erinnern wir nochmals ausdrücklich daran, dass von allen Monodelphien die Prosimien den Didelphien, und zwar deren Stammgruppe, den Pedimanen (Didelphys) am nächsten stehen, und uns die Abkunft der ersteren von den letzteren zu verrathen scheinen.

Das System der echten Affen (Simiae s. Pitheci), welche demnach von den Halbaffen zu trennen sind und mit Einschluss des Menschen eine besondere Ordnung für sich bilden, scheint sich nach folgenden Gesichtspunkten ordnen zu lassen. Zunächst kann man als zwei selbstständige. Aeste eines uralten Simien-Stammes, welche sich unabhängig von einander auf ihrem eigenen, scharf abgegränzten geographischen Gebiete entwickelt haben, die Affen der alten Welt (Heopitheci) und die Affen der neuen Welt (Hesperopitheci) trennen. Die ersteren bilden die Unterordnung der Schmalnasen oder Catarrhinae, die letztoren die Unterordnung der Plattnasen oder Platyr rhinae. Die kleine Familie der $\mathrm{Ha}$ paliden (Hapale, Midas), welche wir als eine dritte Unterordnung (A rctopitheci) aufgefiuhrt haben, und welche ebenfalls auf die neue Welt beschränkt sind, hat sich entweder unten von der Wurzel der Platyrrhinen abgezweigt, oder schon früher von dem gemeinsamen uralten SimienStamme, vielleicht auch direct von den Prosimien. Wenn wir von dieser -kleinen, tiefstehenden Affengruppe absehen, welcho für den menschlichen Stammbaum weiter kein Interesse haben, so bleiben uns nur die beiden Unterordnungen der echten Affen der alten und neuen Welt, Catarrhinen und Platyrrhinen ubrig, welche in ihrer unabhängigen und doch parallelen Entwickelung ein ungewöhnliches Interesse darbieten. Man kann nicht einfach die Platyrrhinen als niedere und unvollkommnere, die Catarrhinen als höhere und vollkommnere Affen bezeichnen, denn beide Gruppen haben sich unabhängig von einander, als zwei divergente, coordinirte $Z$ weige, zu ihrer typisohen Vollkommenheit selbstständig entwickelt; und unter den Platyrrhinen in Amerika haben sich die am meisten veredelten Affen (Callilhrix, Cebus) durch fortschreitende Vervollkommnung des Schädels und Gehirns und dèm entsprechend ihres Geistes, ebenso über die niederen Plattnasen erhoben, wie die Menschen über die Affen der alten Welt.

Der Mensch ist ohne $Z$ weifel aus den Catarrhinen der alten Welt entstanden und er kann von dieser Cnterordnung der echten Affen im Systeme nicht getrennt werden. Wir können nicht Anthropinen, Catarrhinen nnd Platyrrhinen als drei coordinirte Familien betrachten. Der Mensch hat dieselbe charaliteristische Nase wie alle Catarrhinen, eine schmale Nasenscheidewand, und nach unten gerichtete Nasenlöcher, während alle Platyrrhinen eine breite Nasenscheidewand besitzen, so dass die Nasenlöcher nicht nach unten, sondern nach der Seite geöffnet sind. Der Mensch hat ferner vollkommen dasselbe Gebiss, wie alle Catarrhinen, nämlich in jeder Kieferhälfte zwei Schneidezâhne, einen Eckzahn, zwei Lückenzähne (falsche Backzähne) und drei Mahlzähne (echte Backzähne), zusammen also 32 Zähne. Alle Platyrrhinen 
haben dagegen 36 Zähne, nämlich in jeder Kieferhälfte einen Lückenzahn mehr ${ }^{2}$ ).

Wir können also keinen zoologischen Charakter entdecken, durch welchen wir den Menschen als besondere Unterordnung ron den Catarrhinen zu trennen vormöchten. Sehen wir nun weiter zu, wio sich der Mensch za den verschiedenen untergeordneten Gruppen der Catarrhinen verhält. Man kann in dieser Unterordnung zunächst als zwei divergente Gruppen die beiden Sectionen der geschwänzten (Menocerca) und der schwanzlosen Catarrhinen (Lipocerca) unterscheiden. Belsanntlich wird von den meisten Menschen ein ausserordentlicher Werth gerade auf den Besitz eines Schwanzes, als auf das wesentlichste differentielle Merkmal der echten Affen gelegt, und die Entdeckung "geschwänzter Menschen" galt lange als das erste Postulat für den Nachweis wirklicher Verwandtschaft von Menschen und Affen. Und doch ist die ganze Section der Lipocerken oder Anthropoiden ebenso ungeschwänzt, wie der Mensch selbst, oder vielmehr, sie besitzen, ebenso wie der Mensch selbst, unter der Haut versteckt die rudimentäre Schwanzwirbelsäule (Vertebrae coccjgeae), welche als dysteleologisches Erbstück von ihren gemeinsamen Voreltern von sehr hoher morphologischer Bedeutung ist. Wenn wir also Menocerke und Lipocerke unter den Catarrhinen unterscheiden wollen, so unterliegt es keinem Zweifel, dass der Mensch zur Section der Lipocerken gerechnet werden muss. Dabei ist noch besonders hervorzuheben, dass die Differenzen, welcheden Menschen rom rollkommensten Lipocerken, dem Gorilla trennen, immer noch geringer sind, als diejenigen, welche den letzteren vonden unvollkommneren Menocerkon, z, B. dem C5nocephalus, trennen.

Man könnte endlich noch einen Schritt weiter gehen und die Lipocerken in Tylogluten und Lipotylen trennen. Die Tylogluten, durch das Genus Hylobales repräsentirt, haben noch dieselben Gesässschwielen (Tyla glutaea), welche sämmtliche Anasken und Ascopareen besitzen. Die Lipotylen oder die eigentlichen Anthropoiden haben nicht bloss den Schwanz, sondern auch die Gesässschwielen verloren. Das Gesäss ist hier behaart, während es beim Yenschen nackt ist: anch durch eine Anzahl anderer Charaktere nähern sich die Hylohates mehr den Menocerken, als den Lipotylen, und man kann daher ganz wohl die Tylogluten als eine Uebergangsform von jenen zu diesen auffassen. Als eine dritte Familie der Lipocerken kann man dann den Tylogluten und den Lipotylen die Menschen-Gruppo als Gymnoglita oder Erecta odert Hunanä gegenüber stellen.

$\mathrm{Zu}$ den Ijipotylen gehören die berühmten menschenähnlichen Affen oder die Anthropoiden im engeren Sinne, diè drei Genera Salyrus, Engeco und Gorilla, sowie höchst wahrscheinlich auch der neuerdings entdeckte fossile Dryopithecus, welcher eine sehr wichtige Zwischenform zwischen dem Gorilla und dem Menschen herstellt. $Z$ war kennt man von

1) Nicht mit Recht legt man noch immer allgemein grosses Gewicht auf die vollkommen geschlossene $Z$ ahnreihe des Mensclien. welche ausserdem nur noch die Anoplotherien, die alten Stammväter der Ungulaten oder Hufthiero, mit dem Menschen theilen sollen. Und doch sind Menschen mit einer grossen Zaknilicke, verursacht durch das Herüberragen der übermässig entwickelten Eckzähue aus der einen in die andere Kieferhälfte, keineswegs selten Gewiss die meisten Schädelsammlungen werden menschliche Schädel besitzen, bei denen diese starken Eckzähne (oft ganz wie Stosszähne oder „Hauer"), ebenso oder noch stärker, als bei andern Catarrhinen, vorragen. 
CLVI Anhang zur systematischen Einleitung in die Entwickelungsgeschichte.

diesem Dryopithecus Fontani bis jetzt fast bloss Unterkiefer und Zähne, welche 1856 in einer miocenen Süsswasser-Ablagerung am Fusse der $\mathrm{Py}_{\mathrm{y}}$ renäen gefunden wurden. Indessen beweisen dieselben zur Genüge die miocene oder mitteltertiäre Existenz eines riesigen europäischen Anthropoiden, welcher den Gorilla an Grösse übertraf, und dem Menschen wahrscheinlich noch bedeutend näher stand, als alle jetzt noch lebenden Authropoiden. Wenigstens ist die Form des Unterkiefers selbst noch menschenähnlicher, als selbst diejenige des Chimpanze ${ }^{1}$ ).

Was nun die Blutsverwandtschaft des Menschen zu diesen Anthropoiden betrifft, so darf jedenfalls keines der drei noch lebenden Genera (wie überhaupt keine der lebenden Affen-Formen) als ein unmittelbarer Vorfahr des Menschen angesehen werden; dagegen ist es wohl möglich, dass der fossile Dryopilhecus zu diesen Vorfahren zählt. Eben so sicher erscheint uns aber auf der andern Seite der Schluss, dass alle bekannten Lipocerken, Hylobates, Gorilla, Engeco und Satyrus und der Mensch selbst, von einem und demselbèn alten, uns unbekannten lipocerken Catarrhinen, als gemeinsamem Stammvater, abstammen.

Die Frage, ob man dem Menschen die Ehre gönnen soll, eine besondere Familie : Erecla, Humana oder Anthropina, neben den Anthropoiden und Tylogluten, oder eipe besondere Section neben den Lipocerken zu repräsentiren, oder ob mán ihn mit den Anthropoiden zusammen in der Familie der Lipotylen vereinigt lassen soll, ist im Ganzen nur von sehr untergeordnetem Werthe. Denn die Discoplacental-Natur des Menschen, die Thatsache, dass er in den Anthropoiden seine nächsten Blutsverwandten besitzt, wird dadurch in keiner Weise verwischt, dass wir eine besondere Familie für ihn stiften, ebenso wenig als durch die verunglückten Versuche, den Menschen als Repräsentanten einer besonderen Ordnung, einer besondern Classe oder gar eines besondern Reiches hinzustellen. V.on rein zoologisch-systematischem Standpunkte aus würde es schwer halten, irgend ein anatomisches Merkmal aufzutinden, welches in so scharfer und präciser Form die Humanen gegenüber den Anthropoiden charakterisirt, und dieselben von den Lipocerken so scharf trenzt, wie der Besitz des Schwanzes die Menocerken trennt. Am ersten könnte noch der aufrechte Gang des Menschien angefïhrt werden, den aber auch bereits mehrere Hylohates-Arten und der Gorilla zeitweis annehmen. Auch die Bildung der Extremitäten und des Gebisses erlaubt uns nicht, eine scharfe Diagnose aufzustellen, welche den Mensohen ebenso streng von den Lipocerken, wie diese von den Menocerken scheidet. Jedenfalls bleiben die Menschen im zoologischen System ein Bestandtheil der Unterordnung Catarrhinạe, und entfernen sich inzerhalb derselben treniger von den übrigen Lipocerken, als diese von den Menocerken. 


\section{System der Sängethiere.}

(Erläuterung der Tafel VIII.)

Classis: Ma m malia.

Erste Subclasse der Säugethiere:

Ornithodelphia (s. Amasta). Brustlose.

I. Ordo: Monotremata. Kloakentliere.

1. Familia: Ornithorhynchida (Omithorhynchus)

2. Familia: Echidnida (Echidna).

Zweite Subclasse der Säugethiere:

Didelphia (s. Marsupialia). Beutelthiere.

Erste Legion der Didelphien:

B otanophaga, H. Pflanzenfressende Beutelthiere.

I. Ordo: Carpophaga. Frü̈clitefressende Beutelthieve.

1. Familia: $\mathbf{P h a}$ langistida (Phalangista, Petaums)

2. Familia: Phascolarctida (Phascolarctos).

II. Ordo: Rhizophaga. Wurzelfressende Beutelthiere.

1. Familia: Phascolomyida s. Glirina (Phascolonys).

III. Ordo: Barypoda, H. Hufbeutelthiere.

1. Familia: Stereognathida (Stereognathus, Pliolophus).

2. Familia: Nototherida (Nototherium, Diprotodon).

IV. Ordo: Macropoda. Kïngurulis.

1. Familia: II almaturida (Halmaturus, Macoopus, Hypsiprymnus).

Zweite Legion der Didelphien:

Zoophaga, H. Fleisehfressende Beutelthiere.

I. Ordo: Pedimana. Affentïssige Beutclthiere.

1. Familia: Didelphyida (Didelphys)

2. Familia: Chironectida (Chironectes).

II. Ordo: Cantharophaga, H. Insecten/vessende Beutelthiere.

1. Familia: Phascolotherida (Phascolotherium, Thylacotherium, Microlestes)

2. Familia: Myrmecobida (Myrmecobius, Plagiaulax)

3. Familia: Peramelida s. Syndactylina (Perameles, Choerupus).

III. Ordo: Edentula. Zahnarme Beutelthiere.

1. Familia: Tarsipedina (Tarsipes).

IV. Ordo: Creophaga, H. Lanbbeutelliere.

1. Familia: Dasyurida (Dasyurus, Thylacinus). 


\section{Dritte Subclasse der Säugethiere: Monodelphia (s. Placentalia). Placentalthiere.}

Erste Legion der Monodelphien:

Indecidua. Placentalthiere ohne Decidua.

Erste Sublegion der Indeciduen:

Edentata (Brula). Zahnlose.

I. Ordo: Edentata (Bruta). Zahnlose.

1. Familia: Vermilinguia (Mymecophaga, Manis, Macrotherium)

2. Familia: Cingulata (Dasypus, Chlamyphorus, Glyptodon)

3. Familia: Gravigrada (Megatherium, Mylodon, Megalonyx)

4. Familia: Bradypoda (Bradypus, Choloepus).

Zweite Sublegion der Indeciduen:

Pycnoderma, H. Derbhüuter.

I. Orḍo: Ungulata. Hufthiere.

I. Subordo: Artiodactyla. Paarzehige $\left.{ }^{1}\right)$.

1. Sectio: Choeromor pha, H. Schweineformige.

1. Familia: Lophiodonta (Lophiodon, Coryphodon, Pachynolophus)

2 Familia: Anoplotherida (Anoplotherium, Chalicotherium, Eurytherium)

3 Familia: Anthracotherida (Anthracotherum, Choeropotamus)

4. Familia: Setiger a s. Suillida (Sus, Dicotyles, Palaeochoemus)

5. Familia: Obesa s. Hippopotamida (Hippopotamus)

6 Familia: Xiphodonta (Xiphodon, Dichodon, Dachobune)

2. Sectio: Ruminantia. Wiederkäuer.

I. Subsectio: Elaphia, H. Hirschformige.

1. Familia: Dremotherida (Pö̈brotherium, Dremotherium, Dorcatherium)

2. Familia: Moschifera (Amphatragulus, Tragulus, Moschus)

3. Familia: Cervina (Orotherium, Palaeomeryx, Cervus)

4. Familia: Giraffae s. Dovexa (Suatherium, Camelopardalis)

II Subsectio: Cavicornia.

5. Familia: Antilopida s. Gazellae (Antilope, Capella)

6. Familia: A egomorpha s. Caprina (Capra, Ibex)

7. Familia: Probatoda s. Ovina (Tragelophus, Ovis)

8. Familia: Tauroda s. Bovina (Ovibos, Bos)

\section{Subordo: Perissodactyla. Unpaarzehige.}

1. Sectio: Tapiromorpha, H. Tapirförmige.

1. Familia: Palaeotherida (Propalaeothervim, Palaeotherium)

2. Familia: Tapirida s. Nasuta (Tapizus)

3 Familia: Nasicornia s. Rhinocerida (Acerotherium, Rhinoceros)

2. Șectio: Tylópoda. Schwielenfiusser.

4. Familia: Camelida (Macrauchenia, Auchenia, Camelus)

3. Sectio: Solidungula. Einhufer.

5. Familia: Equuina (Anchitherium, Hipparion, Equus).

1) Noch immer werden fast allgemein die Ungulaten in die drei Ordnungen der $\mathrm{Pa}_{\mathbf{a}}$ chydermata, Ruminantia und Solidungula gespalten, obgleich längst die zahlreichen fossilen Uqgulaten bekannt sind, welche diese Eintheilung als eine durchaus künstliche und unnatürlichè nachweisen. Die ganz verwerfliche Gruppe der Pachydermen enthält theils Artiodactylen (Choeromorpha), theils Perissodactylen (Tapisomorpha), von denen erstere mit den Ruminantien, letztere mit den Solidungulen enger und niher, als beide unter sich verwandt sind. Ausserdem werden zu den Pachydermen auch noch die Proboseideen (Elephas) und Lamnungien (Hyrax) gerechnet, welche echte Deciduaten sind. 
II. Ordo: Cetacea. Walthiere.

I. Subordo: Phycoceta, H. (Sirenia). Pflanzenfressende Wale.

1. Familia: Manatida (Manatus, Halicore, Halianassa)

2. Familia: Rhytinida (Rhytine).

II. Subordo: Autoceta, H. (Balaenia). Fleischfressende Wale.

1. Familia: Delphinida Delphinus, Phocaena, Arionius, Stereodelphis)

2. Familia: Hyperoodonta (Hyperoodon, Ziphius, Dioplodon)

3. Familia: Monodonta (Monodon)

4. Familia: Physeterida Physeter)

5. Familia: Bala nida (Balaena, Balaenoptera).

III. Subordo: Zeugloceta, H. (Zeuglodonta). Drachenuale.

1. Familia: Zeuglodontida (Zeuglodon s. Hydrarchos).

Zweite Legion der Monodelphien:

Deciduata, Placentalthiere mit Decidua.

Erste Sublegion der Deciduaten:

Zonoplaceutalia. Deciduaten mit gürtelförmiger Placenta.

I. Ordo: Chelophora, H. Hufträiger.

I. Subordo: Lamnungia. Klippdachse.

1. Familia : H yracida (Hyrax).

II. Subordo: Toxodonta. Pfeilzähner.

1. Familia: Toxod onta (Toxodon, Nesodon).

III. Subordo: Gonyognatha, H. Winkelkiefer.

1. Familia: Dinotherida (Dinotherium).

IV. Subordo: Proboscidea. Elephanten.

1. Ermilia: Elephantida (Mrnstodm, Elephas),

II. Ordo: Carnaria, H. Raubthiere.

I. Subordo: Carnivora. Lundraubthiere

1. Familia : Arctocy onida (Arctocyon, Palaeonyctis).

2. Familia: Amphicyonida (Amphicyon, Hyaenodon)

3. Familia: Ursina (Tylodon, Ursus, Procyon, Nasua)

4. Familia: Viver rina (Viverra, Doricictis)

5. Familia: Mustelina (Mustela, Gulo, Lutra, Thalassictrs)

6. Familia : Can in a (Palaeocyon, Cymodon, Canis)

7. Familia: H y a nida (Hyaena)

8. Familia: Felina (Pseudailurus, Machaerodus, Felis).

II. Subordo: Pinnipedia. Seeraubthiere.

1 Familia: Phocida (Phoca, Cystophora, Otaria)

2. Familia: Trichecida (Thehecus).

Zweite Sublegion der Deciduaten:

Discoplacentalia. Deciduaten mit scheibenformiger Placen/a.

I. Ordo: Prosimiae (Hemipitheci). Halbaffen.

1. Familia: Leptodactyla (Chiromys)

2. Familia: Ptenopleura (Qaleopithecus)

3. Familia: Macrotarsi (Tarsius, Otolienus)

4. Familia: Brachytarsi (Lemur, Stenops). 


\section{Ordo: Rodentia (Glives). Nagethiere.}

I. Subordo: Sciuromorpha. Eichhorntöpfige Nagethiere.

1. Familia: Sciurina (Sciurus, Tamias, Fteromys)

2. Familia: Arctomyida (Arctomys, Spermophilus, Plesiarctomys).

II. Subordo: Myomorpha. Mäuseköpfige Nugethiere.

1. Familia : Myoxida (Myoxus)

2. Familia: Sciurospalacida (Ascomys, Thomomys)

3. Familia: Murina (Mus, Cricetus, Hypudaens)

4. Familia: Georrhychida (Spalax, Georrhychus, Bathyergus)

5. Familia: Castorida (Castor)

6. Familia: Jaculina (Jaculus, Dipus, Pedetes).

III. Subordo: Hystrichomorpha. Slachelschweinköpfige Nagethiere.

1. Familia: Hystricida (Hystrix, Synetheres)

2. Familia: Ps ammoryetida (Psammoryctes, Myopotamus, Adelomys)

3. Familia: Lagostomida (Lagostomus, Eriomys, Lagidium)

4. Familia: Dasyproctida s. Subungulata (Dasyprocta, Cavia, Hydrochoerus).

IV. Subordo: Lagomorpha. Husenköpfige Nagelliere.

1. Familia: Leporina s. Duplicidentata (Lagomys, Lepus).

III. Ordo: Insectivora. Insectenfiesser.

I. Subordo: Menotyphla, H. Insectenfresser mit Blinddarm.

1. Familia: Cladobatida s. Scandentia (Cladobates, Tupaja)

2. Familia: Macroscelidia s. Salientia (Macroscelides, Rhynchocyon).

II. Subordo: Lipotyphla, H. Inseclenfresser ohne Blinddarm.

1. Familia: Soricida (Sorex, Crossopus, Crocidura)

2. Familia: Talpida (Talpa, Condylura, Chrysochloris)

3. Familia: Erinaceidea (Erinaccus, Gymnura)

4. Familia: Centetida (Centetes, Solenodon).

IV. Ordo: Chiroptera. (Volitantia) Fleder'mäuse.

I. Subordo: Pterocynes. (Frugivora) Friichtefressende Fledermäuse.

1. Familia: Pteropodida (Pteropus, Macroglossus)

2. Familia: H y podermida (Hypoderma).

II. Subordo: Nycterides. (Insectivora) Inseclenfressende Fledermäuse.

1. Familia: Gymnorrhina (Vespertilio, Dysopes, Noctilio)

2. Familia: Histiorrbina (Rhinolophus, Megaderma, Phyllostoma).

V. Ordo: Simiae. (Pitheci) Affen.

I. Subordo: Arctopitheci. Krallenaffen.

1. Familia: Hapalida (Hapale, Midas).

II. Subordo: Platyrrhinae. Platmasige Affen.

1. Familia: Aphyocerca, H. (Nyctipithecus, Pithecia, Callithrix)

2. Familia: Labidocerca, H. (Mycetes, Lagothrix, Ateles).

III. Subordo: Catarrhinae. Schmalnasige Affen.

1. Sectio: Menocerca, H. Geschwänzte Catarrhinen.

1. Familia: Anasca, H. (Colobus, Semnopithecus)

2. Familia: Ascoparea, H. (Cynocephalus, Inutus, Cercopithecus).

2. Sectio: Lipocerca, H. Schwanzlose Catarrhinen.

1. Familia: Tylogluta, H. (Hylobates)

2. Familia: Lipotyla, H. (Satyrus, Engeco, Gorilla, Dryopithecus)

3. Familia: Erecta s. Humana (Pithecanthropus, Homo). 